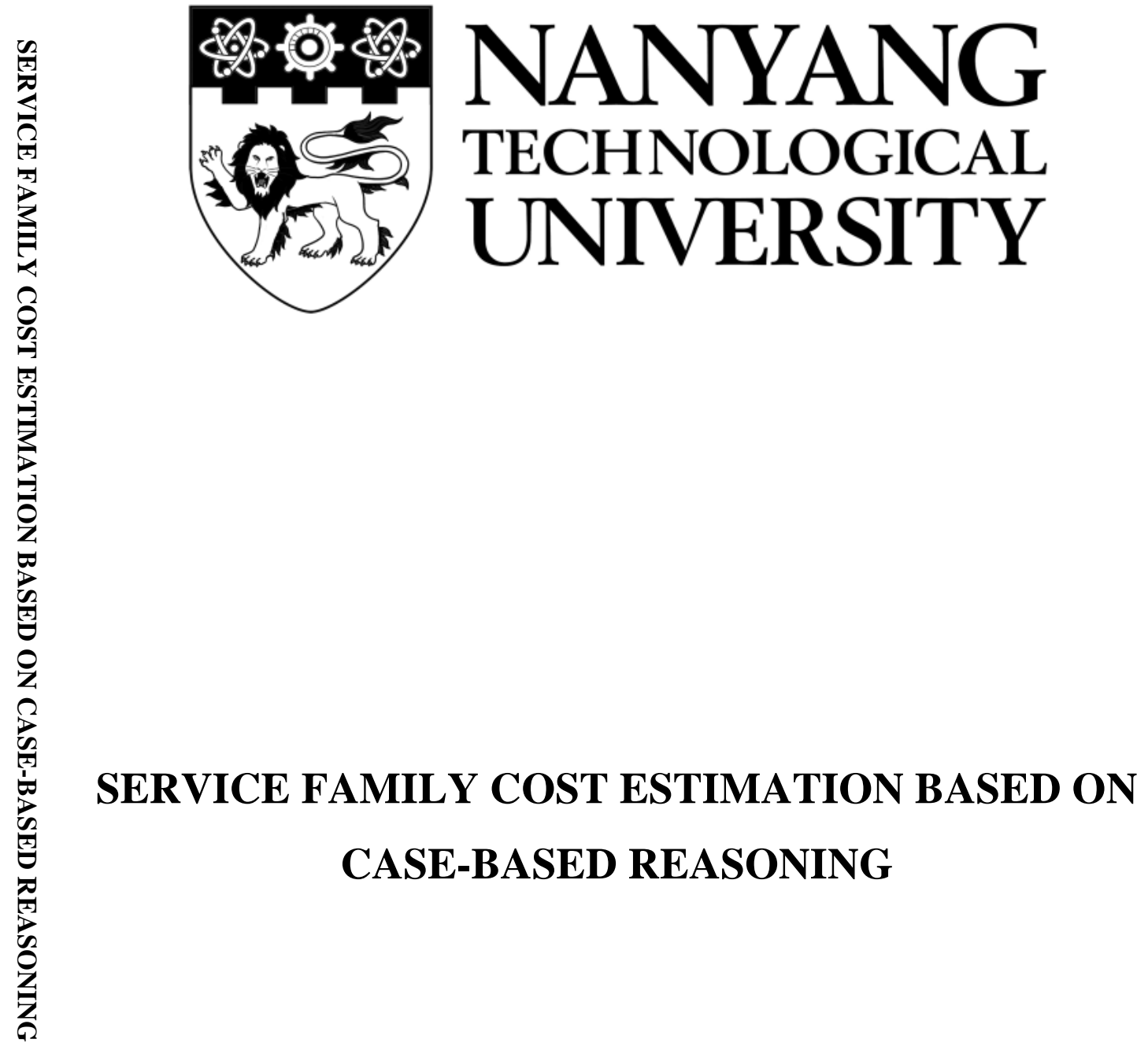

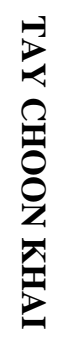

TAY CHOON KHAI

$\stackrel{N}{\mathcal{G}}$

SCHOOL OF MECHANICAL AND AEROSPACE

ENGINEERING 


\section{SERVICE FAMILY COST ESTIMATION BASED ON CASE-BASED REASONING}

2-13

\section{TAY CHOON KHAI}

School of Mechanical and Aerospace Engineering

A thesis submitted to the Nanyang Technological University in partial fulfilment of the requirement for the degree of

Doctor of Philosophy 


\section{Acknowledgements}

First of all, I would like to take this opportunity to express my deepest gratitude and appreciation to my supervisor, Assistant Processor Chen Song Lin for his invaluable guidance, careful supervision and good advices this thesis as well as my $\mathrm{PhD}$ study in the past three years. He is a caring supervisor and always concerns my progress on the thesis and always spends his valuable weekend rest time to discuss the thesis with me. At the same time, he also provides important suggestions and comments that are useful in my research works. Besides, I would also like to thank him for his patience and encouragements that carried me on through the ups and downs that I am facing during my PhD study. More importantly, he has shown his generosity in teaching me the skills and techniques to analyse and solving research problems. These skills have become my important assets that guide me through the thesis and future research works. I feel that, it is my honour to be able to work with him.

Apart from that, I would also like to thank and express my appreciation to Head of Division (Systems and Engineering Management), Associate Professor Leong Kah Fai who have given me encouragement to continue my $\mathrm{PhD}$ study. 
Abstract

Acknowledgement

List of Figures

List of Tables

Chapter 1: Introduction

1.1 Background 1

1.2 Research Motivation 2

1.3 Research Objectives $\quad 4$

1.4 Research Methodology 4

$\begin{array}{ll}1.5 \text { Report Organisation } & 6\end{array}$

Chapter 2: Literature Review

2.1 Service Family Design 7

2.2 Product Family Costing 13

$\begin{array}{ll}2.3 \text { Service Costing } & 18\end{array}$

2.4 Research Gap $\quad 42$

Chapter 3: Conceptual Framework of Service Family Cost Estimation

3.1 Activity-Based Service Cost Estimation 48

3.2 Activity Cost Estimation Based on Cased-Based Reasoning 55

3.3 Service Family Modularisation 63

3.4 Overview of Proposed Cost Estimation Methodology 67

Chapter 4: Service Family Representation and Formation

4.1 Selection of Services and Formation of a Service Family 69

$\begin{array}{ll}4.2 \text { Formation of a Service Family } & 69\end{array}$

$\begin{array}{ll}4.3 \text { Identification of Service Activities } & 73\end{array}$

4.4 Classification of Service Activities 76

4.5 Chapter Summary

Chapter 5: Service Family Modularisation

5.1 Creating a Modular Service Family 78

5.2 Mapping of Service Activities to Service Modules 83

$\begin{array}{lr}5.3 \text { Chapter Summary } & 89\end{array}$ 
Chapter 6: Service Family Cost estimation and Analysis

6.1 Stage One Cost Estimation: Service Activity Cost Estimation 91

6.2 Stage Two Cost Estimation: Service Cost Estimation 107

$\begin{array}{ll}\text { 6.3 Chapter Summary } & 107\end{array}$

\section{Chapter 7: A Case Study of Aircraft Maintenance Cost Estimation}

$\begin{array}{ll}7.1 \text { Introduction of Case Study } & 109\end{array}$

7.2 Formation of Long Range Aircraft Maintenance Service Family 113

7.3 Modularisation of $S F_{\text {Long_Range }} 116$

7.4 Activity Cost Estimation of Long Range Aircraft Maintenance Service Family 124

7.5 Service Cost Estimation of Long Range Aircraft Maintenance Service Family 136

7.6 Effectiveness of Proposed Cost Estimation Methodology 138

Chapter 8: Summary and Future Research Work

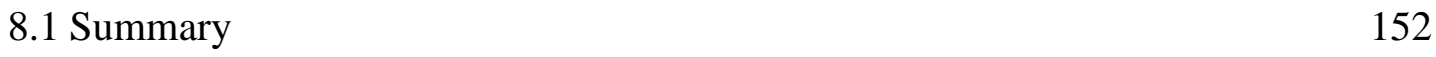

8.2 Limitations and Future Research Work 154

$\begin{array}{ll}\text { Reference } & 157\end{array}$ 


\section{Abstract}

In recent years, companies and organisations are competing to offer high varieties of customised services to increase revenues and customers' satisfaction. One of the effective ways to create service variations is to adopt product family design theories and methodologies. Consequently, novel service design concepts such as service family and service platform have been developed. However, research work related to service family costing is found to be scarce. Furthermore, existing service cost estimation methodologies are not feasible for estimating the costs of a service family. This research bridges these gaps by proposing a novel service family cost estimation methodology based on activity-based costing ( $\mathrm{ABC}$ ), case-based reasoning (CBR) and product modularity. The cost estimation and analysis of a service family is carried out via a three steps cost estimation framework. In step one, a service family is defined by a set of selected services. Then, activities related to these services are identified by activity diagram. A service family is regarded as a complex service delivery system. Increasing numbers of service activities and variations will complicate the process of cost estimation and analysis. To minimise the impacts, a modularisation mechanism based on product modularity is proposed to decompose a set of service family into a set of service modules.

In last step, a two-stage cost estimation mechanism which is based on $\mathrm{ABC}$ and $\mathrm{CBR}$ is used to estimate service family costs. The objective of $A B C$ is to setup cost linkages between cost elements of a service family so that accurate cost allocations can be carried out. Despite the advantages, implementation of $\mathrm{ABC}$ is time consuming and expensive. Furthermore, accuracy of $\mathrm{ABC}$ is questionable when erroneous cost allocation bases are used. Therefore, $C B R$ is integrated to the $A B C$ framework to overcome these shortcomings. Based on past experiences obtained from past services, activity cost is estimated without the need of cost driver measurements and time consuming data collections. Besides, service reference cluster (SRC) concept is introduced to enhance the accuracy of cost estimation. Instead of relying on single past experience, a SRC which consists of a set of similar past experiences are used to 
provide more rational and unbiased cost estimations. In stage two cost estimation, estimated service activities costs are allocated to relevant services.

The applicability of proposed cost estimation methodology is demonstrated with a case study to estimate the costs for a fleet of long range aircraft. The result of the case study shows that, proposed cost estimation methodology is feasible to estimate the costs for a service family. It is also proves that CBR can be applied in estimating service activity costs. 


\section{List of Figures}

Figure 3.1 Interactions between resources, service activities and services.

Figure 3.2 Working principles of Activity Based Costing (ABC)

Figure 3.3 Activity cost estimation mechanism of CBR under ABC framework

Figure 3.4 Overview of proposed service family cost estimation methodology

Figure 4.1 Examples of activity diagram syntaxes and nodes

Figure 4.2 Activity diagram for lower and upper igniter plugs replacement of GE90 engine

Figure 5.1 Function-structure diagram for a service family

Figure 5.2 Physical decomposition of an OCBC Bank branch

Figure 5.3 Functional decomposition of banking services

Figure 5.4 Function-structure mapping of branch banking service

Figure 6.1 Overview of two-stage cost estimation mechanism

Figure 7.1 Structural components of commercial airliners (Niu, 1999)

Figure 7.2a Characteristics of $D S A_{32,772 E R}$

Figure 7.2b Characteristics of $m_{\text {Wing }}$

Figure 7.3 Statistical summary of SRC-601 cost data

Figure 7.4 Comparisons of unit maintenance costs (estimated vs actual average)

Figure 7.5a A380 unit cost (Estimated Vs Actual)

Figure 7.5b 747 unit cost (Estimated Vs Actual)

Figure 7.5c 777-200ER unit cost (Estimated Vs Actual)

Figure 7.5d 777-300ER unit cost (Estimated Vs Actual)

Figure 7.6 Unit maintenance cost (Estimated Vs Activity-Based Costing)

Figure 7.7 Simple regression analysis graph (actual Vs predicted costs)

Figure 7.8 Unit maintenance cost comparison (Estimated Vs CER)

Figure 7.9 Comparisons of annual total labour hours before and after standardisation 


\section{List of Tables}

Table 3.1 General characteristics of cost modelling techniques

Table 4.1 Service Commonality Rating Table

Table 4.2 Cardiovascular treatments provided by Parkway Pantai Limited in Singapore

Table 5.1 Personal and business banking services of OCBC Bank at branch

Table 5.2 Example of activity-module relation matrix template

Table 5.3 Examples of Activity-Module Relation Matrix

Table 6.1 (a) Assisted cataract surgery (b) Non-assisted cataract surgery

Table 6.2 Examples of power control unit repair costs of an international airline

Table 6.3 Examples of medical treatments of a service activity case-base

Table 6.4 Jaccard coefficients of past medical treatments in Ophtalmology department of a hospital.

Table 6.5 Examples of Indexes for Indexing of Query

Table 6.6 Indexes assigned to query NA001

Table 7.1 General characteristics of B777-200ER, B777-300ER, B747-400 and A380

Table 7.2 Classification of identified service activities

Table 7.3 Major physical and functional elements of A380, 747-400, 777-200ER and 777-300ER

Table 7.4 Examples of relation scores for $S F_{\text {Long_Range }}$

Table 7.5 Example of indexed past service activity

Table 7.6 Samples of past cases organised in a flat organisation

Table 7.7 Examples of features in a feature library

Table 7.8 Examples of Jaccard similarity coefficients

Table 7.9 An Example of indexed a query case $Q\left(D S A_{45,773 E R}\right)$

Table 7.10 Euclidean distances between query $Q\left(D S A_{45,773 E R}\right)$ and past service activities

Table 7.11 List of service activities contain in SRC-601

Table 7.12 Examples of direct service activities costs obtained by CBR

Table 7.13 Examples of indirect service activities costs of the maintenance service family $S F_{\text {Long_Range }}$

Table 7.14 Service costs for long range aircraft maintenance service family ( $S F_{\text {Long_Range }}$ )

Table 7.15 Annual resources consumed by the long range aircraft 


\section{Chapter 1: Introduction}

In this chapter, background knowledge leading to this research is provided. From the discussion of background and research motivation, the research problem is identified as developing effective cost estimation methodology for estimating the costs of a service family. Based on that, the research objective and scope are defined. Subsequently, the organisation of the report is outlined.

\subsection{Background}

According to the definition given by American Management association in 1960s, a service is defined as activities, benefits or satisfactions, which are offered for sale, or are provided in connection with the sales of goods (Cook et al, 1999). Besides, Jiao et al (2003) define a service as a class of activities, works or acts that are performed for others. These activities represent a set of processes, operations, objects, and/or features that are needed during the process of service delivery.

In recent years, innovative companies are starting to pay attention to customised services by actively generating a large variety of services that can satisfy the needs of different market segments (Giovanni et al, 2001). Apart from that, many companies and organisations offer customised services on top of customised products to increase revenues and customers' satisfaction (Moon et al, 2011). For example, in aviation industry, leading commercial aircraft manufacturers such as Boeing and airbus are starting to extend their coverage in the field of aircraft maintenance services. Leveraging their strength in aircraft design and manufacturing, customised aircraft maintenance services such as Airbus's tailored support programme (TSP) and Boeing's GoldCare engineering supports are offered to airlines around the world.

In supply chain management, companies such as DB Schenker and Ballore are providing customised supply chain solutions which can be oriented towards unique and specific supply chain requirements of different market segments. In order to deliver such services, special types of storage facilities, inventory management systems and customised processes have been developed. Apart from that, in building management sector, Otis Elevator Company and Kone Corporation provide integrated 
building management services, which are covering the entire service lifecycle of a building management system such as escalator system, elevator system and etc.

From the perspective of market, service industries are important parts of the economy for many countries around the world. According to the Service Annual Survey carried out by Census Bureau (U.S. Department of Commerce, 2010), an estimated total service revenues of US $\$ 11,020$ billion have been generated by service industries. In European Union, an estimated 72.9\% of GDP (Gross Domestic Product) is generated by service industries (U.S Central Intelligence Agency, 2014). Besides, economic research carried out on the service sectors of 12 Asian countries show that an average of 5.85\% of real GDP has been achieved from year 2000 to 2010 (Asia Development Bank, 2012). Based on this research, optimistic forecasts on the growth of service sectors in Asia have been concluded by the researchers.

In such a context, service sectors such as healthcare, maintenance and repair, telecommunication, banking and finance, utility services, tourism and so on are expected to contribute significantly to the service industries. Taking the example of repair and maintenance sector, US\$300 billion are spent annually on plant maintenance and operations by U.S industries and about $80 \%$ of the funds are spent on chronic failures of systems, machinery and human resources (Dhilon, 2002). Besides, based on the estimation carried out by Mobley (2004), annual spending on maintenance in the USA is increasing over the years. In 1981, the expenditures on maintenance were US\$600 billion. However, this number has increased to US\$800 billion in 1991. In specific industries, maintenance costs can be varied from 15\% to $60 \%$ of total production costs.

\subsection{Research Motivation}

In order to meet the growing demands and sustain competitiveness in service industries, ability to design and develop a large numbers of customised services within a short period of time is important. One of the most efficient ways is to adopt and apply product family design theories and methodologies in designing and developing new services (Peter \& Saidin, 2000; Meyer \& DeTore, 2001; Jiao et al, 2003). Based on 
these theories and methodologies, novel concept such as service family and service platform have been developed by researchers (Moon et al, 2011).

Apart from developing robust service family design methodologies, examining costing aspects of a service family, particularly in different stages of service lifecycle is equally important. This is simply due to cost is one of the most influential factors that decides the end products and services (Huang et al, 2012). Therefore, service providers are required to manage and control service delivery costs while maintaining reasonable level of service quality, so that they can compete in today's highly competitive market place. Furthermore, companies that are able to produce effective cost estimations during conceptual design stage tend to have better profitability and control during production stage (Hoult et al, 1996).

Under such circumstances, accurate and reliable cost information is crucial for management team in making business decisions, developing long term strategies and managing resources. However, recent research works that are related to service family are only focused on developing methodologies to design a family of services and costing aspects of a service family have been neglected.

Besides, reported cost estimation methodologies in the literature contain limitations and unable to estimate the costs of a service family. In general, these cost estimation methodologies are highly customised and developed based on the requirements of specific services. Therefore, adaptation of these methodologies for service family cost estimation is not feasible. For instance, substance abuse cost analysis programme (SASCAP) (Zarkin et al, 2004; Zarkin et al, 2008) Treatment Cost analysis Tool (TCAT) (Flynn et al, 2008) are developed specifically to estimate service costs of drug treatment programmes. Moreover, these methodologies are mainly focused on estimating total costs of a service without providing an in-depth understanding of how the service resources are consumed. As a result, comprehensiveness of cost analysis is questionable.

The objective of a service family is to facilitate service mass customisation by promoting customer values and providing a variety of cost-effective services for 
different market segments (Moon et al, 2009). It is defined by a set of services that shared certain commonalities and each service contains unique features to create service variations. Therefore, a service family is considered as a complex service delivery system that tends to induce complicated costing relationships between the cost elements of a service family. This has resulted challenges and complexities in estimating and analysing service family costs.

\subsection{Research Objectives}

This research aims to develop a novel service family estimation methodology by applying activity-based costing (ABC), case-based reasoning (CBR) and product modularity concepts. This cost estimation methodology will be able to address the following challenges:

a. Generate accurate and reliable cost estimation for a family of services that can be developed from different service platforms.

b. Explain causal relationships between fundamental cost elements of a service family by creating cost linkages between these cost elements.

c. Improve the accuracy and consistency of activity cost estimation by using the solution generated from a set of past service experiences.

d. Facilitate the process of cost estimation and analysis through modularisation of a service family into a simpler structure.

\subsection{Research Methodology}

Service activities are basic building blocks of a service. Concurrently, they are the factors that resulted in consumptions of different resources during the process of service delivery. The cost to deliver a service is equal total resources consumed by the service activities. However, under the structure of a service family, complex interrelationships between service resources, service activities and individual service members can lead to inaccuracy in estimating the cost for a service family. As a result, unreliable and inconsistent cost estimations are generated.

The key factor to overcome this problem depends on the ability to trace and explain the causal relationships between cost elements of services. In such a context, activity- 
based costing ( $\mathrm{ABC}$ ) is considered the most suitable cost estimation methodology. It is able to model the resource consumptions of activities and subsequently linked back to individual services (Cooper \& Kaplan, 1988). In this research, ABC is applied to model the consumptions of service resources for a service family. By creating cost linkages between cost elements, accurate cost assignments can be carried out and a detailed cost visualisation can be produced to explain the flow of resources to individual service activities and services.

Despite the feasibility in performing service family cost estimation, ABC possesses several disadvantages that affect the implementation and accuracy of this methodology. First, implementation of $\mathrm{ABC}$ is expensive and time consuming. The key operation of $\mathrm{ABC}$ is to estimate service activity costs by using appropriate cost drivers. However, identification and measurement of these cost drivers require substantial management support and financial resources. Furthermore, in order to ensure the cost drivers are up-to-date, regular updates are required and this will increase the burdens in obtaining and analysing financial data. More importantly, increasing complexity of cost analysis may lead to inappropriate identifications of cost drivers. Consequently, when erroneous cost drivers are used, inaccurate cost information is generated. Under this circumstance, accuracy of ABC becomes a major concern.

This research attempts to overcome the shortcomings of ABC by integrating casebased reasoning (CBR) to the $\mathrm{ABC}$ framework. In this case, instead of using cost drivers to measure activity costs, CBR estimates activity costs by using past experiences that are stored in a case-base. As a result, the needs of expensive and time consuming cost driver identifications and measurements can be minimised. Apart from that, regular updates of costing information can be reduced. This is because CBR can learns by acquiring experiences from each problem solving and these experiences can be retained in a case-base for future problem solving. More importantly, CBR is able to perform problem solving with minimal human intervention. Therefore, the likelihood of using erroneous cost drivers during the process of cost estimation can be reduced and resulted in improvement of cost estimation accuracy. 
When service variations of a service family increase, formation of complex service delivery structure will complicates the process of cost estimation and analysis. In order to facilitate the process of cost estimation and analysis, a simplified service family structure is required. This research will presents a service family modularisation mechanism based on product modularity concepts. In specific, product concept analysis proposed by Kamrani \& Salhieh (2002) will applied primarily in decomposing a service family into a modular structure. Besides, an activity mapping mechanism will be developed to map the service activities to relevant service modules.

\subsection{Report Organisation}

This report is organised in several chapters. Chapter 2 provides the literature reviews on product family design, service design, product family costing and service costing. By end of this chapter research gaps are identified. Following that, chapter 3 explains the working principles of proposed cost estimation methodology which is based on activity-based costing (ABC), case-based reasoning (CBR) and product modularity. Subsequently, detailed architecture of proposed cost estimation methodology will be presented in chapter 4, 5 and 6. Chapter 4 illustrates how a service family is formed from a set of services. Besides, the mechanism to identify service activities of individual services are presented. In chapter 5, detailed procedures to decompose a service family into a set of service modules are discussed. Meanwhile, chapter 6 presents a two-stage service family cost estimation mechanism that is based on ABC and CBR. In chapter 7, a case study to estimate maintenance cost for a family of long range aircraft will be carried out. Lastly, a summary of current and future research work will be provided to report on the status of current research and future research works to break through the current ones. 


\section{Chapter 2: Literature Review}

The emergence of global market has fundamentally changed business competitions by creating a highly dynamic market that further compresses product development time and expansion of product variations (Sanderson \& Uzumeri, 1997). Traditional homogenous market has been swinging towards more individualistic requirements that can only be satisfied with high variety of innovative products. As a result, massive investments are made by companies in product family practices to produce sufficient product variations across diverse markets (Meyer \& Utterback, 1993; Sundgren, 1999). In recent years, there has been growing interests in both industry application and academic on topics related to design and development of a service family based on product family design theories and methodologies (Jiao et al, 2003; Moon et al, 2009). This is mainly contributed by the growing demands of customised services that providing customers with various options and choices for individual customers' needs. This chapter reviews the literature related to service family design, product family costing and service costing. At the end of this chapter, research gaps related to service family costing are identified.

\subsection{Service Family Design}

A product family facilitates product customisation by providing a range of products for different market segments in a cost-effective way (Simpson et al, 2004). It is defined by a set of related products based on a common product platform and concurrently, possess specific features or functionalities to meet particular requirements. From marketing and sales perspective, the functional structure of a product family represents the product line or product portfolio of a company. Hence, it is characterised by different functional features for different customer groups (Agard \& Kusiak, 2004). Under the context of engineering, a product family is characterised by factors such as design parameters, components and assembly structures since different product technologies and associated manufacturability are embodied to the products (De Lit et al, 2003; Simpson, 2004). 
In recent years, product family design theories and methodologies have been applied in developing new services. This trend has been driven by increasing demands of customised services to fulfil the individual needs of customers. For instance, Meyer \& DeTore (2001) develop service platform concepts based on methods and processes for developing product platforms for physical products. Product platform design principles such as implementation of common subsystems and interfaces, modular or non-monolithic platform development, extension beyond technology for markets and business model, core capabilities renewal and organisational platform have been applied for designing new service platforms. The service platform concepts have been applied in a case study to renew and redesign services for an international insurer. By implementing these concepts, this insurer is able to identify unfulfilled needs and growth opportunities for developing new solutions for its customers. Besides, creation of service platforms assists the insurer to organise its organisation more effectively to develop and deploy capabilities for its new services.

The key advantage of platform based service design is that it is a more effective methodology to operationalise service innovations. It make services more profitable by creating a common bases of human resources, processes and technologies needed for specific service deliveries. However, implementation of this methodology will requires substantial financial resources and efforts as it requires certain degree of organisational and operational transformation of an organisation. Even though this research has presented a novel service design methodology for creating a family of services, however, it does not provide a systematic framework to create a service platform. For example, a detailed mechanism to identify commonalities and interfaces of services is not included. More importantly, this methodology does not have an effective method to assess the economic aspects of a service platform. This feature is vital for ensuring profitability of a service family is optimised by controlling and distributing sufficient resources to the services.

Jiao et al (2003) suggest that, instead of perceiving a service delivery system as traditional operation system, it should be considered as a broad-sense product. This is because both services and products render certain types of benefits to its customers. In 
such a context, service delivery systems and manufacturing goods possess no difference from a customer perspective. By approaching services as physical products, design theories and methodologies for products and manufacturing systems are generally applicable to the design of service delivery systems. Besides that, fundamental issues concerning the design of a service delivery system are discussed. These fundamental issues include defining customer benefits, developing service process and developing physical components. Defining customer benefits is the process to identify benefits that are intended to convey to the customers during service design phase. Meanwhile, service processes are developed based on the aspects of customer processes and employee processes. Lastly, the physical components of a service delivery system are defined by human resources and inputs that associate with service process activities.

The key contribution of this research is that it approach a service delivery system from the perspective of a physical product. This assumption enables service designers to design new services systematically by simply adopting appropriate product design theories and methodologies. However, the suitability and limitations of these design theories and methodologies in are not assessed. Even though the fundamental issues for designing a service delivery system have been discussed in this research, but it does not provide explicit examples for its validity. More importantly, this research does not provide the implications related to service design costs.

In the field of information technology services, Peter \& Saidin (2000) examine the applications of modularity concepts for achieving mass customisation of services. Based on their research, each service offering that contains a scope of works or a scope of services can be sub-grouped into logical sub-offerings. And, these sub-offerings can be offered independently to customers. Apart from that, the study also found that specific service offerings can function as bus modules to host different sub-offerings or service work tasks. In the case study that involves IBM Malaysia service unit, modularity concepts have been implemented partially throughout the organisation for modularising the scope of works and processes. This case study shows that, the implementation of service modularisation is able to reduce the time that is required to 
go through the business case process to respond to each customer request while standard offerings are continually developed. However, this approach comes with few shortcomings. First, the choices of service offerings might not fulfil the needs of customers. Besides, as the number of service offerings are growing, too many options may be overwhelming to the customers.

This research has provided a good investigation on the feasibility of applying modularity concepts for achieving service mass customisation in the field of information technology services. The results of the study clearly show that, modularity concepts are applicable to modularise services. In fact, it is relatively easy to implement and can be used to provide immediate benefits such as providing more flexibility to service offerings and reducing the needs of service redesign to the organisation. Despite that, some of the challenges to implement service modularity especially the impacts on financial aspects of service modularity are not discussed.

Modular architecture is one of the most important design concepts to achieve mass customisation. The application of modular architecture enables service providers to react according to the changing market conditions or customer needs based on different combinations of existing modular components. It simplifies system complexity by breaking service components into smaller units that interchangeable and easier to manage. It also transforms the basic of service delivery process by creating a dynamic robust network of modules. But, design and development of a modular service family is highly knowledge intensive. To overcome such problems, Ramesh et al (2002) apply a knowledge management system based on a traceability network framework to facilitate the design and development of customised information products and e-services.

The knowledge management system captures deliberations that lead to the identification of commonality and variability requirements which can be used to facilitate decision making process. Besides, a tracing mechanism provides the primitives to represent the agents, inputs and outputs of the service delivery system as well as the linkages among them to aid the identification of common and variable requirements. The captured information is then retained and managed by REMAP 
(Representation and Maintenance Process Knowledge). The knowledge management system is able to capture the rationales behind platform-oriented and architectural decisions that assist the users to identify the requirements which are common to the customers, thereby facilitating the addition of features to the product or service platform so that future customisation costs can be reduced. However, the implementation of a knowledge management system requires high overheads to acquire information.

In designing and developing a service family, Moon et al (2009) extend modulebased product family design concepts by introducing a methodology to develop service ontology by integrating object-oriented concepts and ontologies. The function of a service ontology is to capture and reuse design knowledge of a service family by defining elements that can be used to characterise the knowledge elements which necessary for managing variability in the service family. This methodology consists of three phases. In phase one, selection and analysis of a service family design are carried out by using product and service development processes, object-oriented concepts and function-process matrix. Following that, unified modelling language (UML) and graph models are used to identify service modules and components of a service family. Lastly, a service ontology is defined to represent the relationships between the functional modules and process modules. The applicability of this methodology is demonstrated in a case study for developing a family of banking services.

Apart from the applications of module-based product family design principles, this research has presented a novel methodology to enhance service design process. For instance, the creation of a service ontology enables service designers to identify all related components in a module in service family design. Furthermore, this methodology is capable providing a visual representation to its users for modelling and designing services. The key disadvantage of this methodology is that, it requires to identify suitable design attributes to achieve optimal results. Although this research has presented a robust methodology to design and develop a service family, but it does 
not include a cost estimation model to assess the cost effectiveness of a service family design.

In subsequent research, Moon et al (2011) develop a methodology to design customised families of services by incorporating a game theory to simulate situations involving dynamic market environments. In this methodology, a service family is first decomposed into strategic and operational level modules. Subsequently, objectoriented concepts are applied to identify service attributes that are required to define service functions and processes. To identify the relationships between service functions and processes, function-process matrix is employed. Once the initial structure of a service family is decided, module-based service strategies are determined by configuring functional services into unique, common and variant modules. The combinations of these modules are vital for controlling service production of a service family. Module selection is considered as a strategic modulesharing problem in a collaboration situation. Therefore, it is necessary to simulate the sharing situations of service modules due to uncertainties in dynamic market environments. In last stage of the methodology, a coalitional game theory model is employed to resolve module selection problem. Based on this model, variant modules that provide optimal benefits will be selected.

This research has presented a novel service family design methodology by combining module-based product family design concepts and object-oriented concepts to develop a family of services. Apart from creating a visual representation of a service family, the incorporation of a coalitional game model in this research enables service designers to simulate potential module sharing and determine which service modules are capable of providing optimal benefits to the service platform. Despite the robustness as shown above, an effective search algorithm is required to generate a set of feasible strategies. In this case, sophisticated computational and mathematical modelling are required and this will affects the applicability and practicability. Moreover, this methodology is unable to perform in-depth cost analysis for a service family design as there is lack of a comprehensive cost estimation and analysis methodology. Consequently, user can only assess minimally on the cost effectiveness 
of a service family design without an understanding on how the service costs are distributed to respective service components.

\subsection{Product Family Costing}

As reported in previous section, novel service family design methodologies have been developed by incorporating product family design principles and theories. Despite their capabilities in designing and developing a family of customised services, costing issues of a service family such as service delivery costs and how service resources are consumed by individual services are not discussed in these research. Unlike single service delivery system, a service family is considered a highly complex service delivery system that consists of multiple services. Based on the assumption made by Jiao et al (2003) that services can be regarded as a type of products that resemble as similar content to physical goods, this section reviews the literature related to product family costing.

In designing and developing a product family, product designer is required to determine the correct components or design variables to be shared among the products to maintain economies of scale without trading off the quality of each product in the family. Park \& Simpson (2005) propose a three-stage production cost estimation framework to support product family design based on activity-based costing (ABC). In allocation stage, production activities that transform raw material into finished products are identified. Besides, resources that are corresponding to these activities are identified with activity table, resource table and production flow. To facilitate the cost allocation for production, a product family structure is represented by a hierarchical classification of products that form a product family. Next, in estimation stage, product family costs which can be categorised into linked costs and allocated costs are estimated based on product family structure data and resource data. Subsequently, these costs are assigned back to the product family structure. Total production costs of a service family design are estimated by collecting all costs occurring within the product family hierarchy. Lastly, in the analysis stage, potential components or design variables to be used for a product family design are investigated with resource sharing methods through activity analysis. 
This cost estimation framework enables service designers to investigate the production system and product structure of a service family design. By connecting these two components in a structured way, production costs of a service family can be generated by ABC. Through the analysis of activities, resources to be shared, selected, reduced and eliminated can be identified. This is very important for product manufacturer to control product costs while providing quality products to consumers with reasonable price. Despite the advantages, practicability of this framework is questionable as prior information such as design data, production activities and resources data are required. But, it is common that these information are not available to designers and engineers during design stage.

The main contribution of this framework is that, it is able to breakdown a product family design into a logical structure and subsequently coupled with production information and design data to estimate product family costs. By incorporating ABC in this framework, it gives a clear overview to product designers to assess the cost effectiveness of product family design and provides a detailed analysis on the resources consumed by individual activities. Moreover, applicability and practicability of this framework may be limited as it does not have robust mechanism to manage highly complex product family and production system such as manufacturing of aircraft, ship building and so on.

In subsequent research, Park \& Simpson (2008) develop a cost estimation framework based on activity-based costing (ABC) to design cost-effective product families and product platforms. The production activities of a product family are identified and classified into direct production activities (DPA), indirect production activities (IDA) and non-production activities. Based on the working principles of $\mathrm{ABC}$, costs are allocated to these categories of activities in the forms of direct material, direct labour and activity costs. In order to understand the implications of a product family design, cost modularisation concept is introduced. Under this concept, parts or sub-assemblies and cost modules for cost estimation are subsequently developed. These cost modules enables product designers to evaluate design alternatives by investigating the economic impacts of these design alternative to activity costs and 
their cost drivers in the cost modules. In the final stage, activity costs are restructured to make the costs more relevant to product family design decisions. In this case, cost restructuring can be carried out by sharing components, subsystems or production processes and by adding new resources and redesigning existing ones.

The incorporation of activity-based costing (ABC) in this framework provides a robust cost analysis to its users by showing how resources are consumed by different classes of production activities corresponding to a product family design. As product life-cycle is becoming shorter, accurate and quick decision making on product family design is vital for product manufacturers to produce a wide range of customised products to meet customers' expectations and fast changing market conditions. Besides that, through the introduction of cost modularisation, product family design is facilitated as product designers are able to evaluate and revise cost modules that are affected by design decisions. This is to ensure economies of scale of a product family is optimised and concurrently, certain features and performance of the products can be preserved. The key disadvantage of this cost estimation framework is that it requires prior inputs of design information and data to determine relevant production activities and corresponding production resources. However, design information and data usually are not available to the product designers.

This research has fundamentally improved previous research works by introducing cost modularisation. By grouping parts or sub-assemblies of similar functions into part modules and mapping them to relevant activity costs, product cost estimation and analysis is facilitated. The main problem of this feature is that it does not have a robust modularisation mechanism to group parts or sub-assemblies based on their similarities or interdependencies that will lead to inaccurate formations of part modules. Furthermore, the tendency of inaccurate cost estimation of products may be high as there is no appropriate mapping mechanism to accurately link the parts or subassemblies to production activity costs.

Platform-based product family design and development is one of the effective ways to achieve product mass customisation as it is able to bring economies of scale to manufacturers who are offering a wide range of customised products to customers. 
Li et al (2010) develop an adjusted activity-based costing (ABC) methodology to examine the economic benefits of a platform-based design strategy and allocating overhead costs to individual products of a product family. This methodology measures product family costs in two ways. For indirect costs of both platform and non-platform components of a product family, cost estimation is performed via costing-by-analogy. By using existing products as references, costs are calculated based on the adjustments made on design variables or other product specifications. Meanwhile, indirect costs which are shared by multiple products are estimated by implementing ABC. In order to compensate the differences in the rates due to production volume, learning effects are used for estimating indirect costs and the learning factors are obtained by employing a matrix-based learning curve.

The key advantage of this methodology is that, it considers learning effects as part of the factors to perform cost estimations for achieving economies of scale and cost allocations for a platform-based product family design. With this approach, the ABC model is able to facilitate platform-based product development by determining how to allocate and reduce production costs by sharing parts, components or features. As the cost estimation of this methodology is carried out with assumptions that the products will be produced with a cost structure similar to a current production system, significant estimation errors will be resulted when new product features and production technologies are introduced. Apart from that, this methodology uses different methods to measure direct and indirect costs of a product family, this approach will results in the disconnections direct and indirect costs of a product family and the comprehensiveness on the cause and effect between these costs may be affected.

By making the assumption that the cost parameters are similar for the products in a product family, Wei \& Qin (2012) propose a rapid product cost estimation framework based on a modular product family model. Under this framework, a modular product family is created by decomposing the product family into a set of generic modules. Each of these modules is described with a set of attribute variables. To carry out cost estimation, customer's requirements are translated into a set of 
quantitative attribute variables and a distance-based search algorithm is used to retrieve product modules which are nearest to the requirements. The costs of the customised products can be calculated quickly by accumulating the costs of selected modules in each level of the modular product family.

This methodology has provided a robust cost estimation solution by providing instantaneous cost analysis to its users without the needs of producing intensive product family design information and specifications. This has greatly reduced the time that is required to design customised products and business responses to customers. Since the product family is decomposed into a dynamic network of product modules, different combinations of customised products can be produced to optimise economies of scale for manufacturers. Despite the advantages, this methodology is unable to reveal detailed cost analysis on how the resources are consumed by production activities and non-production activities as only modular costs are calculated. Furthermore, in order to maintain the sensitivity of the cost estimation framework, regular updates are required to support wider range of customised products. More importantly, massive changes may be needed if new manufacturing technologies and new product families of different product platforms are introduced.

Johnson \& Kirchain (2011) use a generative cost model to quantify development efforts and lead-time based on product and project characteristics. The cost estimation model developed in this research is used to project development costs for a product family which include labour, equipment, software and overhead by using direct engineering effort along with indirect costs. In principle, it provides quantitative information on the engineering effort, cost and lead-time implications of component and subassembly characteristics of a product family. To ensure accuracy in estimating product development costs, advanced engineering data, prototyping data, process development data and general product development are gathered and used characterise the products. Based on this methodology, case studies concerning two instrument panel (IP) beam families and an automotive body-in-white (BIW) are examined.

This research has presented a robust cost estimation model. Implementing this cost estimation methodology enable product designers to examine development costs for a 
family of products in detailed and provide accurate implications of these costs to the economies of scale of the products. The results estimated by this cost estimation methodology provides significant influence on the use of product platforms and related platform strategies. It is also able to help manufacturers to reduce product costs by eliminating unnecessary fixed investments. However, this methodology is developed specifically based on the operation of an automotive manufacturing firm. Therefore, modifications for other applications are difficult and complex. Besides, implementation of this methodology requires experts who are familiar with product development processes and basic statistical methods.

\subsection{Service Costing}

Over the years, there has been growing interest on topics concerning the costing aspects of a service. In this section, literatures related to cost estimation methodologies and techniques to estimate and analyse the costs of a service are reviewed.

\subsubsection{Healthcare Services Cost Estimation Methodologies}

Healthcare services are important parts of service industries. In the United State of America, a total of US\$2,490 billion have been spent on healthcare services (U.S. Department of commerce, 2010). Besides, in United Kingdom, healthcare expenditures have increased from $£ 55$ billion in year 1997 to $£ 142.8$ billion in year 2011 (U.K. Office for National Statistics, 2013). Realising the importance of healthcare service costs, there has been growing literature on related topics in developing robust healthcare service cost estimation methodologies.

Accurate cost estimates are important for policy makers to decide whether drug abuse services are cost-effective. Zarkin et al (2004) develop service cost analysis programme (SASCAP) to estimate the costs of specific drug treatment services. The main function of this methodology is to estimate resources consumed by specific services of a programme and how these resources are distributed across treatment services. There are two main components in SASCAP. A cost survey is included to collect data on programme costs and revenues, whereas a labour allocation survey is used to collect data related to staff time allocated across various treatment services. 
Based on the data of the surveys, information on total costs expended by a clinic and labour allocations across various services are used to estimate the average unit cost for specific methadone treatment services. In later research, SASCAP is applied to estimate treatment costs for 25 methadone treatment clinics across the U.S (Zarkin et al 2008). In this study, three different data collections methods which include key formants, staff surveys and staff diaries have been used.

SASCAP possess several advantages for its users. First, large scale collection data can be avoided. Instead of gathering staff time allocation information from each of the staff, these information are gathered through key informants. Hence, less burdens are created for the programmes for data collections. Furthermore, on top of direct labour, indirect labour and non-labour resources consumed by the patients are considered during cost estimation. This advancement improves the practicability and quality of cost estimates. However, this methodology also contains limitations. In this case, accuracy of cost estimates is not optimised because information on non-labour resources consumed by the service providers are not captured and included in the cost estimations. More importantly, self-reported information on service costs and director assessments on staff time allocations may be biased and can lead to inaccurate cost estimations.

Flynn et al (2008) use a Microsoft® Excel-based workbook known as treatment cost analysis tool (TCAT) to allocate, analyse and estimate outpatient treatment costs in the U.S. TCAT is designed and developed to serve several purposes. First, it is used as self-administered cost analysis tool for programme financial staff to capture the data for research studies and establish a data set for economic analyses. In this case, TCAT is able to collect, analyse and report outpatient substance abuse treatment cases and cost data which include allocations of overhead (indirect) costs related to an administrative agency. Based on collected data, TCAT is able to use as a management tool to estimate service provision costs, compare outpatient programmes costs and carry out operation planning and forecasting based patient volume and staffing patterns. The key features of this methodology include consistency checking, 
programmed calculations and reporting functions in tabular and graphics formats in a single and automated workbook package.

The distinctive advantage of TCAT is that it is able to provide a comprehensive cost analysis tool for treatment program directors and financial staff. Apart from collecting data directly from various sources, automated mathematical functions and graphical financial analysis embedded in the same workbook can be used to generate a comprehensive analysis without the need of complex cost estimation models. To carry an extensive research study or cost analysis, sufficient data collections are vital and collecting this information means extensive data entry and lengthy instrument to accommodate the data are required. Moreover, this methodology is developed based on the outpatient treatment programmes implemented in the selected locations in the U.S, it may be not suitable for other treatment centres which may be providing different kinds of services. This methodology has shown its simplicity in implementation and cost estimation. However, the major problem of this methodology is that it does not provide a detailed cost visualisation to its users on the flow of resources from different departments to the services.

Aging population and declining birth rate are part of the contributing factors of increasing health care expenditures. Ryu (2009) propose a methodology to calculate home care nursing services costs by applying cross-sectional descriptive study. In this study, activities that are associated with home care nursing services are identified. Based on these activities, associated direct costs and indirect costs of the services are calculated. The direct costs are expenditures that are related to the nurses who are directly providing the health services to the patients while indirect costs are expenditures that are used to support the deliveries of home nursing such as overhead costs and allocated costs from supportive departments. Once the total direct and indirect costs are determined, average service cost per home care visit is calculated by averaging total direct and indirect costs with total numbers of home visits.

The cost estimation methodology proposed in this research is providing a simple and yet effective way to estimate and analysis the costs for home care nursing services since it does not require complex mathematical functions or models. Furthermore, by 
analysing the caseload or workload of nurses, home care nursing managers are able to plan, monitor and evaluate the nursing activities. Besides, data obtained by this methodology are valuable management information that can be used for administrative, supervisory and direct service personnel purposes. Even though this methodology has shown simplicity in cost estimation, but implementation of this methodology requires robust and standardised data collections systems at individual nursing care centres. Furthermore, different types of nursing care services are provided by each nursing care centre and some of the service activities of these services may be similar. In such a context, similar resources may be consumed by these activities. However, the cost analysis obtained by this methodology unable to reflect the costing relationships between these service activities.

Economic evaluations are important references for decision makers to determine registration, reimbursement and pricing of hospital services. However, the decision process can be affected by large variations between economic variations and this is due to the differences in costing methodologies that have been used in obtaining economic variations. Tan et al (2009) apply top-down and bottom-up micro-costing to study the reliability of total cost estimates for hospital services. To perform the cost estimation, direct costs and indirect costs (overhead costs) that are associated with the patients from the point of admission to discharge from the hospital are identified. In bottom-up micro-costing, total cost of a service is valued by the identification of resources consumed by the patients and hospital specific unit costs. On the other hand, top-down micro-costing estimates the total cost of a service is estimated based on patient specific resources and national tariffs.

The bottom-up micro-costing is considered a robust and reliable methodology to estimate the costs of hospital services as this approach is able to identify and value all cost components at very detailed level. This enables the users to identify service costs per patient with valuable insights for the contributions of each cost component in the total costs. However, implementation of this costing methodology is very time consuming especially when hospital costing data are absent or insufficient. More importantly, inaccurate cost estimates may be produced for cases where patients are 
required long length of stay. The top-down micro-costing is a strong alternative to bottom-up micro-costing. However, poor cost estimation results using this approach may be produced when the cost components with a large impact on the total costs are obtained.

The micro-costing has proven to be a simple and practical technique to estimate the total costs of a service. It can provides a detailed cost analysis without the need of complex cost computation functions. But, one major setback of this methodology is that it does not reveal the relations between the service activities and services provided by a hospital. In this case, it would be interesting for cost analyst to understand whether these activities are common to some of the services and potentially, these activities that consume the same resources can be reduced or eliminated.

Implementation of cancer screening programmes required substantial financial resources. In order to carry out these programmes cost-effectively, economic assessments are required to produce detailed programme cost data for managing and controlling programmes costs. Subramanian et al (2009) develop a cost assessment tool (CAT) to collect cost and resource-use information from cancer screening programmes and activity-based costing (ABC) is used to assign all cost and resourceuse data to specific program activities. This costing tool is designed to perform cost estimations from a programmatic perspective where a direct correlation between programme activities and resources is established. To support the cost analysis generated by this tool, both in-kind labour and non-labour cost data are collected.

The results of the study indicate that this costing tool is user-friendly and able to collect high quality data without creating more burdens to the screening programmes. This is because the collection of costing data is relied on several key informants and the involvement for other staff of the programme is minimal. Therefore, the scale of the data collection is minimal and resources that are expended on data collection can be significantly reduced. Besides, this cost estimation tool allows programme management to identify key factors that are affecting the effectiveness of overall programme by obtaining detailed activity-specific cost analysis. Besides, the cost estimates can be used to identify input parameters for future cost modelling. 
Unlike other cost estimation methodologies, CAT is able to identify correlations between service activities and resources consumed by these activities. However, the distributions of these resources are only limited to specific activities. Due to this reason, comprehensiveness and accuracy of the cost analysis may be affected. For example, in the case study, programme management contains sub-activities such as programme administration, programme reporting and programme strategic planning. Instead of distributing the resources to these activities, they have been distributed to programme management during cost analysis. As a result, cost modelling of these activities is not visualised. To ensure high accuracy of cost analysis, a robust activity identification mechanism should be included.

O`Sullivan et al (2011) develop cost prediction equations based on administrative claims data and generalised linear models to estimate the costs of various cardiovascular events for patients with specific demographic and clinical characteristics over different time spans. The methodology use standard techniques of incidence based cost-of-illness estimation. These techniques require longitudinal estimation of costs due to a health event from a base year of onset until the disease is resolved or through remaining life span of the patient. Medical care services received by the patients are tracked along the way. To predict the costs, medical and pharmacy claims data are collected and analysed statistically. From these data, a set of predictive variables are identified. Based on these variables, cost prediction equations are estimated by using generalised linear models.

The key benefit of this methodology is that it is able to estimate the lifecycle costs for medical events tracing from acute phase to intermediate cares received during recovery and follow-up. This feature provides a complete information for medical care providers to understand the cost drivers at each phase and help them to reduce or eliminate unnecessary service costs. The cost prediction equations are estimated by using generalised linear equations. To estimate these equations, statistically significant predictor variables are required to be identified and this requires huge volumes of data to be collected and analysed. In this research, data related to the patients and clinical characteristics are tracked from one month to lifetime. To track and collect long term 
data, sophisticated data collection systems are required to collect, manage and analyse data, and this will increase the costs and practicability of this methodology. In term of cost analysis, the major problem of this methodology is that it cannot provide the relations between service activities that are associated with the medical care events especially, similar medical care events are provided to the patients.

Occupational safety and health (OSH) is one of the most important parts of business administration. Companies are required to implement OSH activities to fulfil legal, financial and moral requirements. Therefore, employers need to include welfare for their employees and ensure sufficient OSH activities are implemented for the employees. Costs that are expended on OSH activities can be considered as a form of investment by companies to improve employees' health and wellness. To help employers to decide on OSH policies, a thorough understanding on the cost breakdowns is important. Nagata et al (2014) develop a cost estimation methodology to estimate the costs for OSH activities from a corporate perspective based on activitybased costing $(\mathrm{ABC})$. In this methodology, a list of OSH activities are obtained by collecting these information from OSH staff members. Besides, cost accounting data associated with OSH are collected from finance department. By using ABC, OSH services costs are estimated and detailed analysis about the OSH costs are generated.

Apart from providing a detailed cost analysis, this methodology allows policy makers to compare outsource and insource costs of OSH services so that they can determine whether to outsource these OSH services to third party companies. Cost estimation is important for economic evaluation studies. The proposed cost estimation methodology is able to provide a detailed cost breakdown that allows comparison between economic evaluations. There are several limitations contained in this methodology. First, this methodology is unable to account the costs of depreciation for investments that are made for OSH activities. Thus, there are possibilities of OSH costs underestimation. Second, this methodology is designed and developed for large scale enterprises and it may be not suitable for small and medium companies to apply this methodology due to the changes that required for adaptations. 
Ability to predict medical costs for hepatitis patients is vital for hospital to provide high quality treatments and prevent resources wastage. Kuo et al (2015) employ a fuzzy neural network (FNN) to develop a cost estimation model to predict medical costs for hepatitis patients. The FNN model combines low-level learning and computational power of neural networks and high level human-like thinking and reasoning of fuzzy systems. Therefore, it has the learning ability of neural network and inference technology of fuzzy systems to solve characteristics behaviours. In this research, data related to medical resources that are consumed by the patients are collected from emergency departments. Based on these data, significant cost prediction variables are selected. By defining a set of fuzzy IF-THEN rules, the cost prediction variables are used to train the FNN system and predict medical costs.

The key advantage of this methodology is that it is able to use fuzzy inference rules to identify the causal relationships between medical costs and cost prediction variables. This feature enables hospital managers and doctors more easily understood the cost implications and assist them to explain the cost structure of hepatitis related medical costs. However, this methodology also possesses a major disadvantage where huge volumes of data are required for generating accurate cost estimates. As a result, additional hospital resources are expended for data collection. By adopting fuzzy inference rules, the proposed cost estimation model is able to explain the correlations between estimated costs and cost variables. But, it is not able to reveal how the medical resources are distributed across the service activities associated with specific services. Under these circumstances, detailed cost analysis is not available for hospital managers to identify services or service activities that can be eliminated or combined for optimisation of resource usage.

Laboratory diagnostic is a highly complicated and diversified business. But, due to rapid growth of medical expenses and global economy uncertainties, clinical laboratories are required to deliver high quality services with lower funding. In this case, cost minimisation is the simplest approach to manage and control laboratory costs. Su et al (2016) present a cost evaluation methodology based on activity-based costing $(\mathrm{ABC})$ to evaluate the costs and incomes of a clinical laboratory. To calculate 
cost per laboratory test, monthly average direct costs are grouped under respective test sections of the department. Besides, departmental shared costs related to the test services such as public expenses and administrative shared costs are allocated to respective sections according to the hospital cost drivers. Lastly, total costs of each section are allocated to respective laboratory tests. By using a simple regression equation, profit and loss is predicted and department's breakeven point, fixed and contribution margin ratio are evaluated.

In this research, the application of ABC enables its users to obtain detailed cost breakdowns of laboratory services. Apart from closely simulating actual costs expended by the services, laboratory managers are able to visualise the flow of resources to activities which directly and indirectly associated with the services. This feature allows them to identify cost driving factors for generating potential cost reduction measures. Despite that, producing a detailed cost analysis requires large scale data collections. Certainly, this will increase the burdens ti implement this methodology as data collections are costly and time consuming. The comprehensiveness of a cost analysis based on ABC depends on the cost allocations to activities. However, the proposed methodology is lack of systematic mechanism to simulate the activities of a service. For example, in the case study of this research, information technology department is assumed to be one of the non-profit activities for cost allocation. However, in actual operating environment, an information technology department delivers various services to its customers. In such a context, the proposed methodology is not fully simulating the costs of the department and actual cost driving factors are not identifiable.

A comprehensive understanding of resources usage is vital in optimising pharmaceutical services. Therefore, there is a need to measure services costs based on realistic cost data instead of assumptions and self-reported data. Gregório et al (2015) develop a cost estimation model based on time driven activity-based costing (TDABC) to estimate service costs. Unlike traditional ABC concepts, TDABC measures service costs with only two parameters: 1 . Unit cost of supplying capacity and 2. The time required to perform transactions and activities. To initiate cost estimation, information 
related to work activities are required to be collected and this can be accomplished by using work sampling and time and motion (T\&M) study. Work sampling requires an inference to be made for calculating the percentage of overall work time spent on an activity, whereas T\&M technique records actual time spent on each activity by an observer. To perform these observational studies, a list of activities is manually created by participating pharmacies. By assuming each activity as a cost centre, direct costs and support resources are allocated. Besides, relations between activities and corresponding resources are revealed.

The distinctive advantage of this methodology is that it is able to provide a highly transparent cost analysis as compared to other conventional cost accounting methods. It allows managers to identify and optimise the activities that consume the most time. Besides, implementation of TDABC is relatively easier as compared to traditional ABC since only two cost measurement parameters are required in TDABC. But, this methodology also contains several shortcomings. To implement this methodology, time \& motion (T\&M) study is required to be carried out so that time that is needed to complete each activity is recorded. However, this type of study is time consuming and requires extensive resources such as time observer and robust data recording system. To increase sample size for better accuracy, larger numbers of pharmacies and repeated time observations are required As a result, heavy burdens are created for implementing this methodology. Furthermore, data collected by T\&M and work sampling are prone to errors as workers may change their working attitude when subjected to observations and this can lead to inaccuracy of cost estimates.

The proposed methodology has been proven to be an effective method to estimate the costs for pharmaceutical services and it may be applicable to other type of services. However, accuracy and consistency of estimated service costs are major concerns of this methodology. This is because the data are collected within a short period of time and not statistically analysed. Hence, it may lead to inaccurate cost estimates. Furthermore, observed data can be varied from one observer to another observer that resulting the inconsistency of the data. Apart from that, this methodology does not have a systematic tool to assist researcher to identify service activities and 
associated indirect activities. As a result, incompleteness of cost allocations can be happened and affect the comprehensiveness of cost estimation. The researcher also assume that the participating pharmacies will have similar service activities. This is impractical and not realistic as different pharmacies might have different operating procedures and policies.

\subsubsection{Building, infrastructure and Construction Services}

The costs to install building services contribute significantly to the share of total construction costs of building projects. Therefore, the accuracy of building services costs plays a vital role in the process of estimating total building construction project costs. In order to overcome the ineffectiveness of single value deterministic cost estimation method in determining building services costs, risk management process (RMP) can be used to identify the risk factors that would affect the costs and allowances in cost estimations. Mok et al (1997) conduct a survey to identify current building services cost estimation practices and obtain an in-depth understanding the usage and application of RMP in preparing building services cost estimates. RMP is a risk identification framework that enables project teams to develop a complete understanding and awareness about the risk associated with a building construction project. When the risks are defined and quantified, appropriate risk mitigation plans and measures can be taken to minimise them. The RMP framework includes processes to identify alternative risks, risk assessments, risk uncertainties, resource selection and identification to cope with the risk factors.

The application of RMP provide some benefits to its users which include useful for solving complex decision problems, simplifying interpretation of cost estimates, permitting a thorough options analysis and providing a systematic and logical approach to decision-making. Despite these benefits, implementation of RMP requires high intensity of cost data or information to determine accurate risk factors. Besides, it is also very costly to adopt this methodology as it requires robust computing capabilities to analyse and process collected data and generate risk analysis. The RMP may be a useful methodology to manage the financial risks of a building construction project. However, it is only limited to functioning as a supplemental tool to assist cost 
estimator in making decisions in managing building contribution projects. Therefore, the applicability to other applications is questionable.

Edward et al (2000) propose a methodology to estimate plant maintenance service costs by using multiple regression analysis. To perform cost estimation, a set of quantitative and qualitative variables of the plant are required to be identified. In this case, quantitative variables are referred to machine specifications such as machine bucket capacity, machine weight and machine horsepower. These variables are linearly related to each other. Meanwhile, qualitative variables refer to organisational factors such as operator ability, company ownership and type of ground condition. These variables are input into the regression analysis by using dummy variables. Based on the machine history file data of 33 plant items, the total maintenance costs of a plant is estimated. From the analysis, it is found that, machine weight, type of industry and company attitude towards predictive maintenance are found to be best predictor variables.

The cost estimation methodology presented in this research is considered useful for upper management to compare financial performance of individual plant manager and plant maintenance cost based on benchmark standard. More importantly, this methodology can be used as effective cost estimation procedures in the event of absent of historical file data. However, this methodology also contains several problems. One of the major problems of this methodology is that, it is developed and customised to the requirements of specific cases within a fixed domain. As a result, it is only applicable to estimate total plant maintenance costs of similar predictor variables. Alterations of the model will require intensive data collections to redevelop the mathematical models. More importantly, the mathematical models of the methodology are defined based on a set of selected variables by the users. In such a context, other important factors which may be contributing significantly to the total plant maintenance cost may be neglected. Consequently, inaccurate and misleading cost estimates can be produced.

In a nuclear power plant, there are two types of maintenance interventions: planned and corrective. The maintenance costs incurred due to these maintenance 
events include labour cost, new part costs and emergency order of expensive items. Therefore, it is critical to make accurate predictions for these unexpected maintenance expenditures. Elmira et al (2006) develop a Bayesian Weibull lifetime distribution based cost estimation model to forecast monthly cost for a nuclear power plant. In this model, a Bayesian model is used to perform the modelling for the failure rate of the equipment. Besides, reliability growth modelling and analysis for the nuclear plant is generated by using Crow-Army Material Systems Analysis Activity (AMSAA) model. Based the data generated by this model, economic performance, component health trend and maintenance unavailability of the nuclear plant can be evaluated. By identifying the maintenance variables that are associated with the nuclear power plant, simple regression models are created to explain the variability of total repair cost and produce future maintenance cost forecasts.

The key contribution of this research is that it combines the principle of component analysis and factor regression modelling to explain the variability of maintenance cost that shows very good statistical characteristics. Besides, the methodology also good in evaluating benefits of maintenance strategies by using failure rate and failure events of components. Additionally, it can be used as lifecycle management of components. Despite the advantages, this cost estimation methodology also possesses several disadvantages. First, it requires massive collections of data to obtain accurate component failure and reliability analysis. In the case study, data from 1987 to 2004 to model the failure rate and maintenance events of components. Apart from that, the cost estimation model proposed in this research is only focused on total repair cost estimation based on selected variables defined by the users. As a result, discontinuities between estimated maintenance costs and components of the maintenance programmes produce gaps for users to have an in-depth understanding of the distributions of maintenance resources to these programmes. More importantly, this cost estimation methodology is developed by customising the requirements and conditions of selected nuclear power plants. Hence, it may be not suitable to be applied for other applications. 
Anani \& Madanat (2010) present a highway maintenance marginal cost estimation methodology by relaxing the assumption that only one type of maintenance rehabilitation and reconstruction (MR\&R) activities which is traditionally applied in perpetual overlay indirect approach. In this methodology, type C (activity which is triggered by cracking) and type R (activity which triggered by rutting) activities have been considered as part of the cost estimations. Type $\mathrm{C}$ activities are performed each time alligator cracking level reaches triggering. This type of activity improves cracking but neglects rutting. Meanwhile, type $\mathrm{R}$ activity improves both alligator cracking and rutting. The computations of highway maintenance costs are carried out by a mathematical model that take in variables such as unit cost, discount rate, annual traffic load and equivalent single axle load (ESAL).

The major difference of this methodology as compared to traditional approaches is that it includes two types of MR\&R activities to perform highway maintenance marginal cost estimation. The key benefit of this approach is that more realistic cost estimates can be generated. Besides, in order to accommodate different types of highway $M R \& R$ strategies, the proposed cost estimation methodology can be modified and extended for analysing different situations and maintenance conditions. Although this cost estimation methodology is capable of generating more accurate cost estimations and providing more flexibilities to its users, but neglects most of the maintenance activities and non-maintenance activities related to highway maintenance. Consequently, valuable cost information is neglected especially overhead costs that are related to non-maintenance activities such as engineering support, equipment, engineering administration and so on. The negligence of these costs will lead to inaccurate cost estimation.

The total costs of a construction project can be divided into direct costs that are related to the executions of works and indirect costs that accompany the delivery of construction project. Lesniak (2013) presents an artificial neural network (ANN) based cost estimation model to predict indirect cost index for construction projects. In order to build the model, an appropriate database that collects the data associated with the factors conditioning indirect costs of construction projects is required to be developed. 
Through data collections, factors which have significant impacts on the volume of construction works indirect costs are identified. These factors are used as input parameters for the artificial neural network model to compute indirect cost index.

The proposed model has improved the accuracy of cost estimation when compared to other exiting indicative methodologies. By using selected factors associated with indirect costs as input parameters to the model, individual characteristics of construction works executions can be taken into considerations. This cost estimation model possesses some shortcomings. One of the key issues of this cost estimation is that it is heavily relying on the amount of collected data to identify critical indirect cost factors. Besides, estimated indirect cost index does not show direct relationships with construction project activities where the users are unable to determine the cause and effect of the indirect costs corresponding to these activities.

In projects for constructions of new bridges, preliminary engineering (PE) cost estimates are usually and significantly underestimated. In order to address this problem, Hollar et al (2013) propose a cost estimation model by using multiple regression analysis to predict PE costs of new bridges. The key elements to develop this model includes database compilation, variable analysis and variable selection techniques for predictive modelling. In order to create the database, historical data such as project descriptive data, cost estimates and actual cost expenditures for bridge projects are collected. By grouping the data into different data functions, correlation and sensitivity of these data are statistically assessed so that independent variables related to the bridge projects can be identified. Lastly, independent variables which are statistically significant are selected and used in multiple regression analysis to predict PE costs for new bridges.

The application of this cost estimation model enables project managers to identify and assess key factors that are affecting the PE costs of bridge projects. By using these key factors, PE costs for future bridge projects can be projected. Another advantage of this cost estimation model is that its applicability can be extended to other similar projects. This is because variables that are populated from bridge inspection data are using standardised inspection and reporting guidelines. However, there are 
some shortcomings which may be affecting the performance of this model. First, record keeping procedures are not standardised through the organisations. As a result, inaccurate and incomplete records can be produced. Besides, reporting of direct costs for PE activities are varies. This could reduce the reliability of data that are used for predicting PE costs. The reported cost estimation model seems to address the fundamental problems to estimate the PE costs for new bridges, but it does not provide the relationships between significant factors and activities that are required to perform PE functions. In such a context, project managers will not able to measure resources that are needed for each phase of the project.

In early stages of planning and programing of road maintenance, rehabilitation and construction, accurate cost estimations are essential for obtaining the right conclusions of feasibility studies. In this case, overestimations and underestimations can lead to serious issues after the implementation phase of the work programs. Cirilovic et al (2014) present a methodology for developing cost estimation models to forecast road rehabilitation and reconstruction (RRR) costs under limited availability of information. To develop cost estimation models, identification of data sets and analysis of variables are required to be performed based on their significance in both engineering and statistical terms. Besides, a classification tree is used to validate the significance of selected prediction variables. Based on these variables, cost estimation models can be developed either by multiple regression analysis (MRA) or artificial neural network (ANN).

The application of this methodology possesses several advantages. First, the cost estimation models based on MRA and ANN are relatively easy to setup as these techniques are widely used and readily available. MRA is easy to interpret and able to identify statistically significant variables for cost analysis. It is also able provide the mathematical relations between the variables. ANN provides better practicability as it does not need to follow a specific statistical distribution and predefined relationships between input and output are not required in ANN. Although these cost estimation techniques are practical and simple to adopt but they require large input of data in order to identify appropriate variables for producing accurate cost estimation. 
However, data are difficult to obtain and substantial resources and efforts are required to collect large amount of data. Moreover, these cost estimation models can only provide limited cost analysis to the users as the estimated costs are not linked with the activities that consume various type of resources.

Engineering services are important parts of a building. They are influential factors in the operating costs of the building. Therefore, it is important to consider the cost impacts of engineering services during project planning and design stage to prevent cost overrun and achieve energy efficient building. Aibinu et al (2015) apply artificial neural network (ANN) to develop a learning model to predict and compare the costs of light wiring, power wiring and cable pathways during early stage of design. To develop the cost estimation model, output and input variables are first identified and only variables that are practically used during design stage will be considered. Based on data obtained from previous project estimates, the ANN model is trained with a set of input and output data to adjust the weights of the model so that it can provide the same outputs. Once the model is trained, a new set of data is used for predicting the accuracy of estimated costs. Lastly, performance and sensitivity of the model is evaluated and analysed.

The results of the research indicate that ANN is a more capable alternative for cost modelling. This is because ANN is able to generate distribution function relationships between engineering services costs and cost influencing variables of unknown distribution. The stochastic nature of ANN based cost estimation model shows more superiority than parametric modelling techniques. Apart from that, engineering services costs can be influenced by a large number of variables which are usually difficult to evaluate by using project documents especially during design stage where limited project information is available. Since the ANN model predicts engineering services costs based on past project estimates, this makes the proposed ANN model suitable to predict engineering costs at early design stage. In order to accurately predict the engineering services costs, huge volumes of data are required to train the model. However, it is difficult and costly to obtain data in large scale. 
In public construction project management, conceptual costs are used to establish construction budget, forecast probable actual costs and make decisions for investments. Hyari et al (2016) present an artificial neural network (ANN) model to estimate conceptual costs of engineering services for public construction projects. An ANN model consists of a set of neurons which are interconnected to form a network, it is commonly used to model complex relationships between inputs and outputs through adaptive learning from training examples. In this research, back-propagation network (BPN) which is one of the variants of ANN is used to estimate the engineering services costs due to its simplicity and good generalisation capability. The cost estimations of engineering services are carried out in three phases. Prior to cost analysis, historical bid data are collected, organised and formatted. Then, in network training phase, values of network parameters are determined. Finally, new cases is tested by using the model. The results generated by the model are compared with actual engineering services costs.

The model presented in this research has demonstrated its capability in estimating conceptual costs of engineering services. One of the advantages of this model is that it is able to map the underlying relationships between input costs factors and costs of engineering services. This feature enables users to identify cost driving factors of a public construction project. Apart from that, this model is extendable for other applications that are focused on specific types of construction projects such as bridges and schools. Thus, improving the practicability of proposed model. But, implementation of an ANN model is data intensive since the robustness and accuracy of the model depend on the volumes of data input into the system. The disadvantage of this is that, substantial resources and preparations are required to collect and analyse the data. Although an ANN model is relatively easy to develop, but usefulness and comprehensiveness of estimated costs are questionable. This is because results generated by an ANN model is unable to reveal the relations between activities associated with engineering services and corresponding resources that are consumed by these activities. As a result, a detailed cost analysis is not available for project managers to explain how the costs are consumed. 


\subsubsection{Transportation, Equipment, Logistics and other Services}

Instead of managing their own engine maintenance operations and repair facilities, airlines nowadays tend to outsource these maintenance functions by entering into long term maintenance contracts with maintenance service organisations. However, magnitude and uncertainties of long term aircraft maintenance contracts can expose airlines to significant risks. To mitigate and manage these risks, Bowman et al (2001) develop a simulation model based on discrete event simulation to examine costs over the life of a contract, so that a fair contract price can be established. In this model, the failure time of the engine is generated by a statistical failure model. Besides, a statistical cost model is used to determine repair costs of engines due to shop visit events. By using the data in aircraft portfolio database, engine portfolio database and data generated by failure time and repair cost models, long term maintenance costs of engines and associated performance measures such as total maintenance costs, labour costs, material costs, number of shop visits, part replacement costs and so on are simulated.

The cost simulation model proposed in this research is considered an effective cost analytic and decision support tool for airlines management teams as it is able to predict and expose financial risks associate with maintenance services that are on the basis of long term contracts with maintenance service organisations. Consequently, airlines are able to mitigate these financial risks by signing fair long term maintenance services contracts with maintenance service organisations. To produce accurate simulation, large input of data are needed. But, obtaining the data are difficult especially separate databases are required to be created to collect different sets of data.

Even though this model is capable of simulating the lifecycle costs of a long term maintenance service contract and providing major cost measures, but it is not able to produce a detailed cost analysis that simulates the distributions of resources to corresponding maintenance service activities. This feature is important for service subscribers to identify and eliminate activities that are financially significant to the overall cost structure of a maintenance programme so that a more cost effective contract can be established. For instance, an aircraft engine is made of multiple 
components or parts, instead of simulating the total replacement costs based on parts replacements history, it would be more valuable to understand the costs that are consumed by the parts replacement activities and associated non-part replacement activities such as logistics, warehousing, purchasing and so on. This information provide additional insight to decision makers in establishing a comprehensive maintenance contract.

To predict aircraft maintenance cost, Liang \& Zhou (2006) develop a cost estimation methodology by using project evaluating method and cost estimating relationships (CER). The project evaluating method is functioned to subdivide the aircraft maintenance costs into some basic expense units where final cost can be added from the bottom up. Apart from that, customer cost benefit model is applied to predict the maintenance costs. Meanwhile, CERs are mathematical expressions of varying degree of complexity, taking cost as function of one or more cost driving variables. Within the CER structure, a statistical database is used to setup the cost estimating model with regression method, time series method or grey theory system to analyse and evaluate various influential factors.

The application of project evaluating provide a relatively detailed and accurate expenses budgetary estimation on aircraft maintenance costs. Besides, it is also able to identify flow direction of the resources clearly. However, implementation of this method requires intensive human labour as it requires to carry out abundant miscellaneous calculations. On the other hand, cost estimation relationships (CER) method can be used in situations with limited data. With only a few discrete data, CERs are able to characterise an unknown system. Thus, this method is suitable to be applied by decision makers for making cost forecasting in competitive environments. In order to identify CERs, related cost driving variables are defined statistically from the data. To identify appropriate cost driving variables, a sound database with large input of data is required and this will needs substantial resources to collect useful data and well trained cost analyst to analyse these data.

Traffic initiated wears, fatigue initiated surface crack and rail breaks are common railway defects that are caused by high axle loads and traffic densities. These defects 
are significant contributors to railway maintenance costs. Reddy et al (2007) develop a railway maintenance cost estimation model for lubrication strategy and rail-grinding interval to reduce wear and rolling contact fatigue (RCF). For modelling cost of lubrication, costs of different lubrication strategies such as no lubrication, lubrication throughout the year and start/stop lubrication are modelled and compared. Apart from that, total cost of maintaining a segment rail which includes the costs for preventive rail grinding, loss of traffic due to rail grinding, rectification based on non-destructive testing and so on is calculated to develop effective maintenance strategies that combining both technology and safety methods for optimal rail grinding.

The maintenance cost estimation model presented in this research has provided a simple and effective approach for developing optimal lubrication and rail grinding strategies based on historical railway maintenance cost data. Despite its simplicity and capability in modelling railway maintenance costs, this model is unable to generate a comprehensive and detailed cost analysis for its users as it is emphasised on calculating total railway maintenance costs based on a set of variables without correlating these variables with corresponding railway maintenance activities. Consequently, detailed cost analysis that explains the costing relationships between them is not provided.

The estimation of repair and maintenance costs plays significant roles in assisting machinery managers to make decisions on whether to replace or substitute machines. Abbas et al (2011) study the potential of artificial neural network (ANN) technique as an alternative methodology to estimate machinery repair and maintenance costs. In this research, basic back propagation (BB) training algorithm and back propagation with declining learning rate factor algorithm (BDLRF) have been used to perform the cost estimation functions. Prior to cost analysis, historical machinery data such as monthly usage, monthly repairs costs, monthly maintenance costs, year of purchase and tractor models are required to be collected. Then, these data are separated into a training set and a test set. The training set is used to estimate model parameters while the test set is functioned to assess the generalisation ability of the model. Besides, pre- 
processing of these data into normalised data prior to any ANN training process is necessary step to produce meaningful prediction results.

In this research, both $\mathrm{BB}$ and BDLRF algorithm have been proven to be feasible and superior in predicting the repair and maintenance costs of machinery. Different from regression analysis, ANN does not assume a permanent form of dependency between output and input values. Due to this reason, it is considered a more practical choice to estimate repair and maintenance costs in a quick, inexpensive and accurate way. However, the user friendliness of this technique is questionable as it requires large input of training data to achieve high level of cost estimation accuracy. Besides, collected data are required to be processed and analysed so that desired results can be generated. More importantly, results generated by an ANN cost estimation model may be less useful and inaccurate since only a set of predefined cost parameters are used in the process of cost estimation. In such a context, other valuable cost information may be neglected and thus, lead to bias costing perceptions.

Marginal costs are important factors to determine pricing policy. Hakinov \& Muller (2014) present a marginal cost estimation methodology to define marginal cost functions for the airports and use these cost functions to predict marginal costs for different types of aircraft. In this methodology, econometric approach is adopted to estimate marginal cost functions based on data related to aeronautical activities of an airport. By using these cost functions, marginal costs are estimated for each type of aircraft. Apart from predicting marginal costs, the results obtained from the cost estimations can be used to measure " $k$ " coefficients of the Ramsey-pricing formula for simulating the market power of the airports. The simulation is important for analysing the cost efficiency of various airports.

The marginal cost estimation methodology presented in the research enables its users to benchmark the performance of various airports based on the cost efficiency and this allows them to study and compare the pros and cons of each airport. The benefit of this is that they are able to identify key areas for improvements and increase the competitiveness of the airports. However, the accuracy of estimated marginal costs is questionable since the data are limited to information obtained from the balance 
sheets of the airports. These cost information are lack of comprehensiveness to fully reflect the operations of an airport. Furthermore, the costs are not segregated according to aeronautical and non-aeronautical activities. Even though the proposed methodology has identified appropriate attributes to predict the marginal costs but the results of cost estimation do not reveal the cause and effect relationships with associated airport activities. In this case, airport managers are not able to fully understand the deficiencies imposed to the airport operations which directly and indirectly affecting the competitiveness of the airports.

Distribution cost is one of the most important considerations for logistics service providers in serving each new customer for pricing. Instead of analysing distribution costs through cost allocation on delivery routes, cost estimation is considered a better choice due to robust costing rules. However, distribution cost estimation is challenging because distribution is consists of complex collaborative mechanisms. Sun et al (2015) develop a distribution cost prediction model by combining a data selection approach and regression or artificial neural network techniques. In order to predict distribution cost, location-based and cooperation based attributes are identified based on the analysis of activities related to distribution costs. To optimise the reliability of cost prediction, properties of these attributes such as availability of new customers, significance of attributes and instability of time window based attributes are assessed. By using a set of selected attributes, cost prediction models which are based on a data selection approach and regression analysis or artificial neural network are constructed. Besides, an explicit continuous approximation model is employed for quick implementation and model explanation.

The distribution cost prediction model presented in this research has addressed the cost estimation problems of distribution services in collaborative logistics in a practical way. Instead of using static scenario to estimate distribution cost, this model is capable of modelling the distribution costs under dynamic scenarios where pricing of distribution services change accordingly with the locations of delivery and customers. Furthermore, a through cost analysis associated with selected cost attributes can be forecasted. Despite the robustness in estimating distribution costs, it 
is highly customised and applications to other areas might not be feasible. Furthermore, costing relationships between each cost attribute and associated distribution activities are not explain. In such a context, disconnections between these elements prevent the users from understand how the services resources are distributed to each service activity. Furthermore, it is quite complex and difficult to implement this methodology as it requires experts to analyse the data statistically and construct highly complex mathematical models.

Batarce (2016) develops a methodology to study industrial structure of urban bus transit without using cost data. The marginal cost function of urban bus transit is estimated under the assumption that bus transit firms compete on bus service frequencies and adjust bus transit frequencies to maximise their profits. In this methodology, a transit network assignment model is developed to generate data for the marginal cost function. It produces the demand functions for all the bus lines in the city. By assuming consistent microeconomic behaviours of bus transit firms, the marginal cost function estimation equations are derived. Lastly, the use of nonparametric approach for the cost function estimation enables the users to examine the complex relations between total output and operation environment variables to capture the heterogeneity of bus transit services in terms of cost and other indices such as functions of demand and fleet size.

The key advantage of this methodology is that it enables users to examine the economies of scale of bus transit firms under limited access of actual cost data. By simply using a data generation model and related non-costing data obtained from various sources, marginal cost functions of bus transit firms can be estimated. Despite its simplicity, this methodology is customised to bus transit firms that are established in a specific city. Applications to other bus transit firms might not appropriate and major changes to the model parameters and mathematical functions may be required. These shortcomings will reduce the applicability of this methodology. More importantly, this methodology is not able to generate a detailed cost analysis to its users in terms of resources consumptions and their relationships with operational activities that are needed to delivery bus transit services. 


\subsection{Research Gap}

Increasing demands of customised and more individualistic services and intense competitions have driven service providers to design and develop a family of services that can fulfil the needs of different market segments. One of the most effective solutions is to adopt product family design theories and methodologies. In section 2.1, literatures related to service family design have been reviewed and reported. These research works are purely focused on developing methodologies that can be used to design and develop a family of services. Based on product family design principles, novel service design concepts such as service platform design, service modularity and module-based service family design have been developed by researchers.

However, these researches have given minimal attention to the costing aspects of a service family. Cost is one of the determinants that decides final products and services. It is also an important objective for operations management of a company because resources will be spent on staff, facilities, technology, equipment, and so on. For example, a hospital will spend most of its operating resources on medical staff such as doctors, nurses and pharmacists who provide day to day healthcare services to the public. It is very important for a company to keep the costs as low as possible while meeting the requirements and expectations of customers. Therefore, there is a need to develop a robust cost estimation and analysis methodology to examine the economic impacts and effectiveness of a service family.

From the review of product family costing, majority of reported product family cost estimation methodologies adopt activity-based costing (ABC) to estimate and analyse the costs for a product family. The main advantage of this accounting technique is that it is able to reveal the costing relationships between production activities and corresponding resources that allow product designers to visualise detailed cost breakdowns of a product family and assist them to restructure, reduce and/or eliminate resources that are shared by the products. This feature is vital for product manufacturers to optimise economies of a product family. Besides, novel methods such as cost modularisation and learning curve functions are used to facilitate the process of cost estimations. Besides ABC, alternative solutions are developed by 
researchers. For instance, modular product family model is employed to provide flexible and instantaneous costs estimates to users without the need of intensive design information and specifications. Besides, a generative cost model is developed to estimate the costs of a product family based on product and project characteristics. This method enable product designers to eliminate unnecessary fixed investments of new products.

Despite the novelties and capabilities shown in estimating product family costs, the methodologies contain some limitations and unable to adopt directly for estimating the costs of a service family. One of the major problems of these methodologies is that they are highly customised and only workable for product families that are developed from similar product platforms and production systems. As a result, these methodologies are not able to compare and benchmark similar products that are produced by different product platforms or production systems. For example, management team of Airbus will be interested to compare the detailed production costs of A320 aircraft family production lines which are based in Toulouse (France), Hamburg (Germany) and Tianjin (China). High degree of flexibility and adaptability are key factors in estimating the costs for a service family. This is attributed to service organisations are typically have high level of interactions with customers and customers' satisfactory will directly impact the financial performance of the organisations. Therefore, a service organisation tends to develop and deliver a wide range of services to its customers and ability to compare and benchmark the costs of these services is the key factor to remain competitive in the market. For example, SingHealth Group is one of the largest healthcare service providers in Singapore. It provides over 40 medical specialties and services via three public hospitals and five specialist centres across Singapore. In order to optimise resources, a robust and flexible service family cost estimation methodology is desired.

Besides, the cost estimation functions of these methodologies are based on the assumptions that the product families are manufactured based on existing designs and production technologies. When there are new products, product features or production technologies are introduced to the product families, modifications and updates of these 
methodologies in terms of cost data, cost estimation parameters and computation functions are required. However, this will requires substantial financial resources and organisational efforts. More often, these modifications and updates are time consuming and complex. Unlike manufacturing of physical products, services are usually a set of activities, acts or works that are created and delivered based on the requirements of customers. To maintain customers' satisfactory, regular changes are usually required. For example, telecommunication companies such as Singapore Telecommunications Limited and StarHub Ltd are constantly revising their mobile phone service offerings for meeting customers' expectations and requirements. Thus, it is important to have a cost estimation methodology that is able to generate detailed cost predictions of the services without the need of regular changes and updates.

As mentioned earlier, reported product family cost estimation methodologies in section 2.2 are primarily based on activity-based costing (ABC). Despite its feasibility, these methodologies are lack of a robust and effective mechanism to identify the activities for a product family. Activities are core elements to perform cost estimation and analysis, incompleteness of activity identification especially supporting activities that consumed overhead costs will lead to inaccurate cost estimations. For example, production of an A320 aircraft involves complicated manufacturing processes and technological advanced production systems. Furthermore, high intensity of supporting activities such as logistics, warehousing, facilities, material procurements and administrative functions are needed. The availability of a mechanism to simulate these processes and associated supporting activities are key factor to ensure comprehensiveness and accuracy of cost estimations and this is particularly important for estimating the costs of a service family. A service is a package or bundle that is purchased by the customers. It contains three major elements, namely: physical goods, sensual benefits and psychological benefits. The physical goods are tangible aspects of a service whereas sensual and psychological benefits are intangible deliverables that are directly experienced by the customers. In order to accurately estimate the costs of the services, ability to simulate the processes and activities is critical. 
In section 2.3, a sizeable number of research works related to the developments of service cost estimation methodologies for various types of services have been reported. These methodologies mainly adopt analogical, parametric and analytical cost estimation techniques or methods to perform cost estimation functions. For instance, fuzzy neural network, multiple regression analysis and back propagation neural network are some of the analogical techniques that have been used in some of these methodologies. These techniques estimate services costs by using a set of statistically significant cost estimating variables that are derived from large volumes of historical data. Analogical techniques are relatively easy to setup and use. Besides, they are capable to deal with cases where limited data are available. However, these techniques are expensive to setup as time consuming and expensive data collections are necessary to optimise the accuracy of cost estimations.

Meanwhile, a parametric cost estimation technique utilises a parametric estimation model which is a mathematical representation of cost relationships between characteristics of a product or service and estimated costs. In the review, cost estimating relationships (CER), which is one type of parametric cost estimation techniques has been applied to estimate aircraft maintenance services costs. One of the key advantages of parametric cost estimation technique is that it is capable of producing highly accurate cost estimations within a short period of time. However, in order to achieve accurate cost estimations, comprehensiveness in identifying the cost drivers to forecast service costs and this can only be achieved with a sound database and robust statistical analyses.

For analytical type cost estimation approach, the working principle is to decompose a service into work breakdown elements or activities for estimating the costs by simulating the resources consumed by these activities. Activity-based costing (ABC), micro-costing, service cost analysis programme (SASCAP), treatment cost analysis tool (TCAT) are examples of cost estimation methodologies that are based on analytical cost estimation techniques. The benefit of applying analytical type cost estimation techniques is that detailed cost estimation and analysis can be produced for users to identify cost driving factors and optimise service costs to allowable limits. 
But, implementations of analytical type cost estimation techniques require high initial costs and experienced personnel to setup and control the cost estimation systems. Besides, the accuracy of these techniques depends on collected data. Hence, regular updates and collections of cost data are needed to accommodate the changes.

Beside specific characteristics possess by each type of cost estimation approach, reported service cost estimation methodologies are sharing some general limitations and not suitable to be applied for estimating the costs of a service family. First, these methodologies are highly customised to the requirements and specifications of specific services. Modifications and changes to these methodologies will be complex, time consuming and expensive. For example, cost assessment tool (CAT) are designed and developed specifically for assessing the costs of breast and cervical cancer screening programmes which are funded by National Breast and Cervical Cancer Early Detection Programme (NBCCEDP). Fundamentally, CAT is based on a large scale data collection system and activity-based costing (ABC) concepts. To apply CAT for other services, complex, time consuming and expensive modifications and changes to the cost estimation framework and data collection system are required. A service family consists of a set of services that shared common features and contain unique features for each service to create service variations. Therefore, a service family cost estimation methodology should be able to perform cost estimation functions for a wide range of services. Besides, it is also able to accommodate changes to a service family without the need of massive changes and modifications.

Accuracy of cost estimations is one of the most important criteria for a cost estimation methodology. To ensure high level of accuracy, reported methodologies require large input of relevant cost data to generate reliable cost estimates. For example, substance abuse analysis programme (SASCAP) is designed and developed solely for examining methadone treatment services costs that are provided by selected treatment clinics across the U.S.A. Implementation of this methodology will require the setup of large scale survey systems to collect data at different sites. Moreover, experts are required to analyse the data so that total costs of the services can be estimated. When this methodology is applied for other treatment services, a new set of databases are 
required. This will involves the redevelopment of the survey systems and the collected data are required to be re-evaluated by experts. Realistically, a service family will be changing from time to time to accommodate the needs of customers. Hence, increasing service variations will definitely quick and detailed cost analysis to make business decisions. Therefore, it is important for a potential service cost estimation methodology to produce quick and accurate results without constant updates of data. Ideally, existing databases can be used to predict the costs of new services or service features.

Apart from that, reported service cost estimation techniques which are based on analogical and parametric cost estimation techniques are capable of predicting accurately total costs of the services and providing the correlations between cost predicting variables and estimated services costs. But, they are unable to provide an in-depth understanding on how organisational resources are consumed by the services. As a result, users are not able to visualise the cost structures of a service and distributions of resources to service activities and associated supporting activities. Furthermore, analogical and parametric cost estimation techniques estimate the costs of a service based on a set of statistically significant cost predicting factors. The direct consequence of this is that less important cost driving factors may be neglected and lead to inaccurate cost estimations and incomprehensiveness of a cost analysis. For estimating the costs of a service family, ability to simulate the resource consumptions by services are highly important as a service family is a complex service delivery system that contains service activities that are shared by the services. Concurrently, each of the service consists of unique elements for creating service variations within the service family. Therefore, identifying and characterising the costing relationships between basic cost elements of a service family are key factors. 


\section{Chapter 3: Conceptual Framework of Service Family Cost Estimation}

In this chapter, conceptual framework of proposed service family cost estimation methodology to fill the research gaps is presented and discussed. This methodology is based on activity-based costing (ABC), case-based reasoning (CBR) and product modularity concepts.

\subsection{Activity-Based Service Cost Estimation}

\subsubsection{Measuring the Cost of a Service and Its Implications to Service Family Costing}

A service is defined as the acts or actions that are performed for a customer (Stevenson, 2014). It is considered as a package or bundle that groups the features that are purchased by the customers. Specifically, a service package consists of physical goods purchased by the customers, explicit services and implicit services. The physical goods are tangible aspects of a service. For example, in a fast food restaurant, hamburgers, and French fries consumed by the customers as well as the facilities such as dining table, chairs and air-conditioning provided by the restaurant are considered physical goods.

Explicit and implicit services are intangible benefits that are received by the customers during service delivery. For instance, quality of the hamburgers and French fries and food preparation time are examples of explicit services. On the other hand, implicit services are psychological benefits that received by the customer during service delivery. For example, a customer will feels delighted when there are sufficient parking lots provided by the fast food restaurant. Apart from that, a service package also includes the resources that are needed during service delivery such as labour, material and other functions of a service organisation.

The service package is represented by a set of service activities. In the 1960s, The American Management Association defines a service as activities, benefits or satisfaction which are offered for sale, or are provided in connection with the sale of 
goods (Cook et al, 1999).These activities consists of processes, operations, people, object and/or works that are required to satisfy the requirements of a service (Jiao et al, 2003; Moon et al, 2011). From costing perspectives, service activities are cost factors of a service (Horngren et al, 2012). This is simply due to organisational resources are consumed by service activities during the process of service delivery. The total costs of a service is equivalent to total accumulated resources consumed by these activities.

However, different from manufacturing of physical products which is typically based on standardised manufacturing processes, delivering of services is more complex as non-standardised processes according to customers' requirements are often needed and deliveries of physical components and intangible benefits purchased by the customers are expected. For example, a hair stylist in a beauty salon will needs to design and cut different hairstyles for different customers and various types of hairstyling tools and equipment are needed. Furthermore, the salon is also expected to provide an ambient and relaxing environment for customers such as comfortable chairs and good attitudes provided by the employees. Therefore, instead of focusing on obtaining accurate total service cost estimates, an in-depth understanding on how the resources are consumed by the services are vital for managers to determine strategic planning and control, capacity and competitive priorities.

Similarly, for service family costing, a highly visualise and comprehensive cost structure is critical for service operations managers to achieve effective operations strategies and make strategic decisions. A service family consists of a set of services that aims to facilitate service mass customisation by promoting customer values and providing services for different market segments cost-effectively (Moon et al, 2009). Apart from sharing commonalities between services, distinctive components or unique features are included in each service to define service variations within the service family. Variability of a service family plays significant roles in shaping the service operations, it is orientated based on the timing, needs and wants of customers which are less predictable. Hence, regular adjustments are needed from time to time to accommodate large number of variables and dynamic market requirements. 
Correspondingly, changes to the allocations of organisational resources to respective services are needed to optimise the economies of scale of a service family. Furthermore, a service family is a complex service delivery system which tends to induce complicated interrelationships between service activities and individual services that make the process of cost estimation and analysis more difficult (Figure 3.1).

The problems resulted from the characteristics of a service family create challenges for service organisations to trace and allocate costs to each service without distortion. Since each service consists of service activities, the key factor to overcome these problems is the ability to establish the causal relationships between service activities and consumed resources. The interconnections formed between resources, service activities and individual services will enable accurate cost allocations to be carried out. Besides, highly visualise and transparent cost analysis can be obtained for explaining the flow of organisational resources the service activities and services within a given service family.

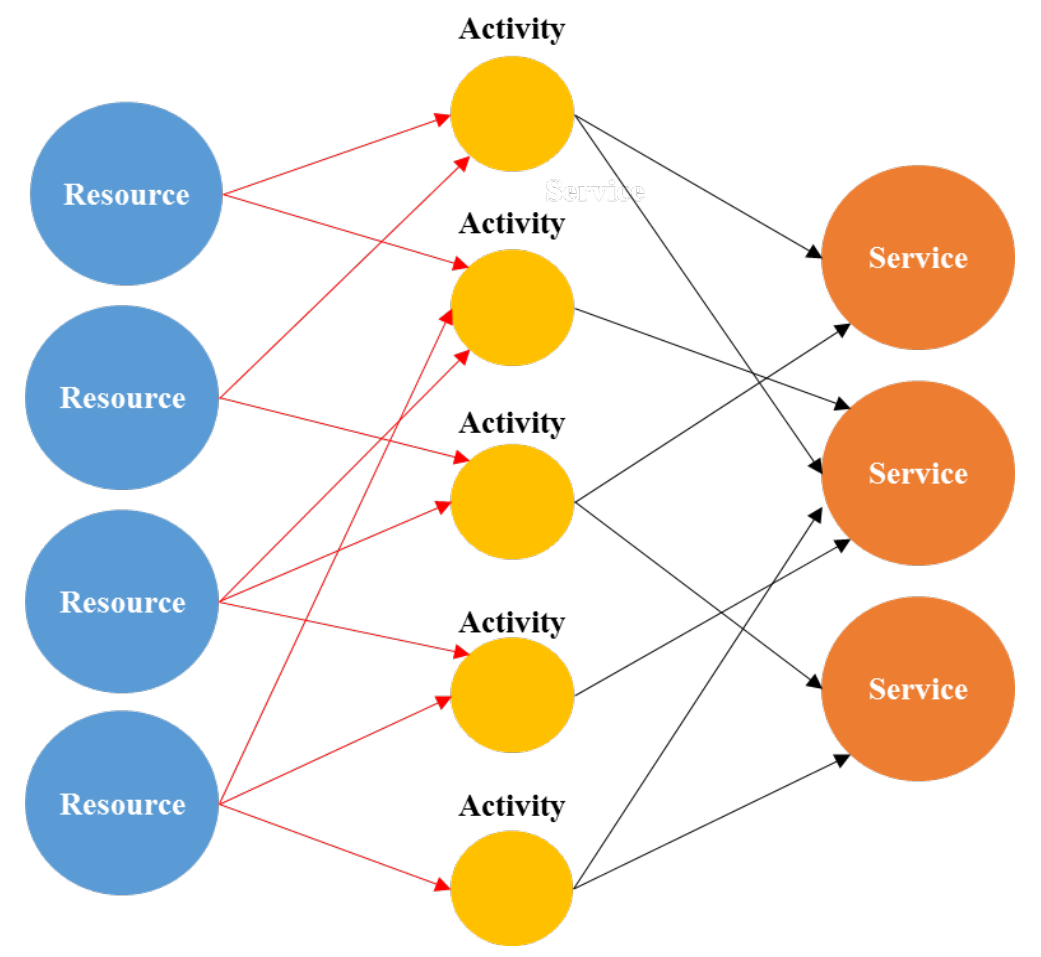

Figure 3.1 Interactions between resources, service activities and services. 


\subsubsection{Activity-Based Service Family Cost Estimation}

Based on the characteristics and costing requirements of a service family as described above, analytical type cost estimation techniques are more appropriate as compared to other cost estimate techniques (Table 3.1) and this research adopts activity-based costing (ABC) concepts to estimate the costs for a service family.

Table 3.1 General characteristics of cost modelling techniques

\begin{tabular}{|c|l|}
\hline $\begin{array}{c}\text { Cost Modelling } \\
\text { Technique }\end{array}$ & \multicolumn{1}{c|}{ General Characteristics } \\
\hline Intuitive & a. Cost estimates are generated based on past experiences. \\
\hline Analogical & $\begin{array}{l}\text { a. Cost predictions are carried out by analyse the degree of similarity } \\
\text { between new service and another service which the costs have been } \\
\text { estimated in past. } \\
\text { b. Based on experience or historical databases }\end{array}$ \\
\hline Parametric & $\begin{array}{l}\text { a. Utilise analytical functions of a set of parameters that characterise } \\
\text { the service without describing it completely. } \\
\text { b. Known as top down applications. }\end{array}$ \\
\hline Analytical & $\begin{array}{l}\text { a. Decompose a service into detailed work breakdowns for cost } \\
\text { estimation and analysis. } \\
\text { b. Known as bottom-up techniques based on cost data collected from } \\
\text { the smallest components and aggregated to total service level. }\end{array}$ \\
\hline
\end{tabular}

ABC is introduced by Cooper and Kaplan in 1980s as an alternative cost accounting techniques to overcome distorted cost information resulted by traditional costing systems which are mainly focused on estimations of direct labour and direct material for products and services (Cooper \& Kaplan, 1988). However, proliferations of products and services have diversified the expenses of companies. Apart from fixed overheads, support operations, marketing, distribution and other overheads have become important contributors to the cost structure of organisations. But, conventional costing systems are only able to trace direct materials and direct labour to the products and services, other overheads costs are allocated to specific departments, activities or some other cost objectives but not to the product or service itself (Ben-Arieh \& Qian, 
2003). As a result, these costing systems often lead to inaccurate and distorted product or service cost information.

In contrast, $\mathrm{ABC}$ seeks to understand the factors that create the demands for overheads and support resources (Kaplan \& Atkinsons, 1989). In this case, the costs of consumed resources are assigned to activities by using cost drivers. Subsequently, these activities are assigned based on the demands made by individual products or services. Instead of summing the overhead costs into a single cost factor, the working principles of $\mathrm{ABC}$ enable the segregations of expenses due to indirect and support activities. Besides that, $\mathrm{ABC}$ also reveals the relations between activities and the demands those activities make on the organisational resources, thus giving managers a clear picture of how products, services, brands, facilities, regions, distributions channels both generate revenues and consume resources (Cooper \& Kaplan, 1991). By generating a detailed cost analysis, managers are able to focus on improving or eliminating activities that will have bigger impacts on the bottom line.

Assign to Other cost Objects

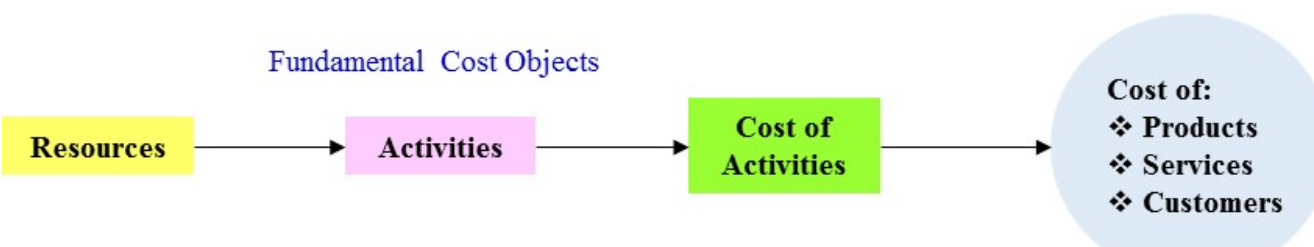

Figure 3.2 Working principles of Activity Based Costing (ABC)

Another important feature of $\mathrm{ABC}$ is that it is able to improve accuracy and relevance of products or services costing by providing timely cost information for decision making and allowing more detailed tracking of indirect costs to cost objectives (Ben-Arieh \& Qian, 2003). When the range of products or services are increasing, the ratio of overhead to total costs of products or services become larger and does not vary with the volumes and this problem often leads to cost distortions. $\mathrm{ABC}$ is able to minimise this problem by measuring overhead costs that are not proportional to the volumes, instead of measuring overhead costs in parallel to the 
volumes. This is particularly important to ensure accuracy of cost estimates especially under low volume environment.

In this research, $A B C$ is functioned as the basis to develop a two-stage cost estimation mechanism for estimating the costs of a service family and providing a robust cost analysis to the users. The fundamental of $\mathrm{ABC}$ is to measure activities costs. In order to obtain accurate cost estimates, comprehensiveness of service activities in representing a service family is critical and identification of different service activities within a service family is one of the key steps in achieving this objective. Therefore, in this study, a service family is viewed as a complex service delivery system which is decomposable into a set of service activities. And, each service activity is defined by a set of processes, operations, people, and/or features. However, unlike production activities which are usually based on standardised processes, a service activity is typically immaterial in nature and processes to deliver a service are typically based on the requirements of customers. As a result, it is difficult to describe precisely a service activity. To minimise this problem, an activity identification mechanism is introduced to systematically identify different class of service activities for a service family. Apart from identifying service activities that are directly involve in the service delivery, this mechanism is also functioned to identify support activities which are associated with the service activities. These support activities are important part of a service family and may be contributed significantly to the total costs of a service.

Once the service activities are identified, activities costs are estimated by relating and quantifying the resources that are consumed by the activities. Subsequently, service costs are measured by assigning the activities cost to individual services. The two-stage cost estimation mechanism proposed in this research allows a systematic way to model organisational resources that are consumed by a service family. In this case, structured and highly transparent distributions of resources to service activities and services create cost linkages that are able to explain the relations between the fundamental cost elements of a service family. Besides, they are able to assist cost analyst to understand how the resources are consumed so that cost driving factors of a service family can be identified. 


\subsubsection{Limitations of Activity-Based Costing (ABC)}

Despite the feasibility of $A B C$ in estimating the costs for a service family, it has several limitations that would hinder its implementation and effectiveness. One of the major limitations of $\mathrm{ABC}$ is that it is expensive to implement and maintain (Kinney \& Raiborn, 2009). In ABC costing, the cost of a service is estimated by accumulating activities costs that assigned to the service. To calculate activities costs, different cost allocations bases such as labour hours, material usage, inspection hours, repair hours, material orders and so on are required. These cost allocation bases are cost drivers that are used to quantify the amount of resources allocated to each service activity. Besides, they are regarded as the cost factors that have direct cause and effect relationships with consumed resources. However, identification of these cost drivers requires extensive cost measurements and calculations based on collected data especially when service variations of a service family increase. As a result, a service organisation is required to provide substantial management efforts and organisation's resources to operate an ABC system.

Apart from expensive cost measurements and calculations, it is also very costly to obtain accurate cost data for an ABC system (Weygandt et al, 2011). This is because, in order to optimise the cost accuracy of an ABC system, a robust data collection system is required to record and capture data that are not only available within the finance department but also other departments within the organisation such as logistics, sales and marketing, engineering, supply management and human resource. Data like number of inspections performed by the engineers, total purchase orders made by supply management department, total repair events of facilities and number of calls received by customer service department are typical examples for $A B C$ users to identify cost drivers and to estimate services costs. Besides, the collected data must be checked and entered in a database by the experts. Moreover, optimal and up-to-date cost estimation capabilities can only be achieved for a service family if regular updates are provided to the database Hundal, 1997; Qian \& Ben-Arieh, 2008). But, this will certainly increase the burdens to maintain an ABC system. 
Besides implementation problems, accuracy and reliability of $\mathrm{ABC}$ are major concerns for its users (Kaplan \& Anderson, 2007). As mentioned previously, cost drivers are key elements in $\mathrm{ABC}$ to allocate the costs to the activities and they have direct cause and effect relationships with consumed resources. However, as cost analysis become more detailed, more cost pools and cost allocation bases are needed to calculate activity costs. This will increase the likelihood of misidentifying cost drivers for different activity cost pools (Horngren et al, 2012). For example, managers and supervisors are likely to misallocate the time required for different activities if they to allocate the time over five activities rather than two activities. Consequently, when erroneous cost drivers are identified and applied, inaccurate cost estimates may be obtained and incorrect representations of relationships between activities and resources may be used. For instance, if the cost per load moved decrease, the management may interpret that this process has become more efficient in its operations. However, lower cost per load move may have resulted solely from moving many lighter loads over shorted distances.

\subsection{Activity Cost Estimation Based on Case-Based Reasoning (CBR)}

As previously discussed, the key operation of an ABC system is to estimate activities costs by using cost drivers that are identified based on collected data. The accuracy of cost estimates and representations between activities and consumed resources depends on the appropriateness of these cost drivers. In such a context, the solution to overcome the limitations of $\mathrm{ABC}$ is by integrating an activity cost estimation method or technique into the $\mathrm{ABC}$ framework to estimate activities costs with minimal human interventions and without the need of intensive and massive data collections. This research attempts to achieve these objectives by integrating case-based reasoning (CBR) into the ABC framework.

\subsubsection{A Brief Introduction of Case-Based Reasoning (CBR)}

CBR is an artificial intelligence methodology introduced in 1980s for developing knowledge-based problem solving systems based on past cases or experiences (Kolodner, 1992; Lopez, 2013). Unlike most problem solving methodologies in 
artificial intelligence (AI), CBR is memory based where it can reflects the human use of remembered problems and solutions as a starting point for new problem solving. From the perspective of psychology, CBR provides both a methodology for building systems and cognitive model of people, and it is consistent with the observations of psychologists in the natural problem solving. Hence, CBR is considered closer to actual human decision processes.

Instead of relying on general knowledge within a problem domain or associating generalised relationships between problem descriptors and conclusion, CBR is capable of utilising specific knowledge of previously experienced, concrete problem situations. In a more general term, CBR means reasoning using past experiences in solving a situation (Kolodner, 1993). A situation can be referred to suggesting new solutions to a problem, pointing out problems with a solution being computed, interpreting a new situation, making predictions or creating arguments to justify some conclusions. For instance, a doctor uses diagnosis and treatment of a previously treated patient for his current patient after getting a reminder that is caused by a similarity of important symptoms This example proves that reasoning by using past experiences is an effective and frequently applied way to solve problems by humans. This claim is also supported by results from cognitive psychological research which several studies have given empirical evidence for the dominating role of specific, previously experienced situations (Aamodt \& Plaza, 1994).

The CBR reasoner can be classified into problem solving type CBR and interpretive style CBR (Kolodner, 1992). A problem solving type CBR provides solutions to new problems that are derived from past experiences. This type of CBR is characterised by heavy use of adaptation processes to generate potential solutions and widely applied in problem solving tasks such as planning, diagnosis and design. For application of CBR in design field, problems are first defined under a set of restrictions. Then, a problem solver is required to provide a conclusive reasoning that solves the problems. In order to produce a set of appropriate solutions, reasonable specification of restrictions is needed. This is to ensure important restrictions are fulfilled whereas other less important restrictions are compromised. 
For application related to planning, steps and schedules are defined to achieve certain level of real world state and the state shall be designated with fixed terms. The objective is to make sure CBR functions within the expectations of real world applications. In solving diagnosis problems, the user is provided with a set of problems and asked to explain them. When a small number of potential explanations are available, diagnosis can be viewed as a classification problem. In contrast, when the explanations are not available, diagnosis is viewed as the problem of creating an explanation. The users use a series of past cases to suggest explanations for problems and to provide warning for explanations that have been found to be inappropriate.

Meanwhile, interpretive CBR refers to a process to evaluate situations or solutions based on past experiences. For example, a doctor may use past patient records to justify the conditions of a new patient. By inserting a new situation or solution into a CBR system, the output can be a classification of the situation, an argument supporting the classification or solution, and/or proofs that support the solution. This type of CBR is useful in classifying situations, evaluating solutions, argumentations, interpretations, plans and projections of effects for a decision or plan. In justification and adversarial reasoning, lawyers tend to use adversarial arguments to convince others about their positions on specific issues. In order to make a persuasive argument, a position must be specified and supported by hard facts and valid references.

Interpretation in the context of CBR refers to the process to decide whether a concept fits some open-ended or fuzzy-bordered classification. Many of the classifications are open-ended varieties. The projection in CBR is defined as the process to predict the effects of a decision plan. It is regarded as an important part of the evaluation element of any planning or decision making scheme. When information related to a situation is provided, a projection is merely a process of running known inferences forward from a solution to see where it leads. However, in real-world situations, up front information is not known and the impacts cannot be predicted with accuracy based on any simple set of inference rules. 


\subsubsection{Relevance of Case-Based Reasoning (CBR) in Estimating Service Activity Cost}

The CBR has several advantages as compared to other problem solving methodologies and these advantages make CBR a suitable method to be integrated into the ABC framework for estimating service activities costs of a service family. First, CBR is able to propose solutions to problems quickly, thus avoiding the time necessary to derive the solutions from scratch. It also helps the users to get a head start on solving problems without the need to redo time consuming computations and inferences.

In ABC costing, a significant number of steps and procedures are required to estimate service activities costs. This is mainly contributed by the needs of identifying cost drivers that are used to estimate service activities costs. By applying CBR, the requirements to calculate and measure cost drivers based on collected data can be minimised. This is because CBR estimates the cost of a service activity by referring to similar service activities that are stored in a case-base. Therefore, instead of performing time-consuming and tedious cost calculations, the users are only required to fully or partially adopt the solutions proposed by the CBR system. Thus, it is able to simplify the processes to estimate service activities and reduce the resources that are required to implement an $\mathrm{ABC}$ system.

CBR is considered as a problem solving methodology that is closer to human decision making (Ketler, 1993). When a service activity cost estimation problem is presented to the CBR system, the retrieval mechanism retrieves a set of similar past service activities by matching the features assigned to the problem. By selecting the best case, a solution with sufficient justifications to the problem can be generated and recommended to the user. Once the solution is accepted, it will be adapted and applied to solve the cost estimation problem. The CBR reasoning cycle requires minimal human interventions during the process of cost estimation as the user is only required to identify and assign appropriate features to the problem and to make decision on the solution that is proposed by the system. Under these circumstances, the reduction of manual cost calculation processes is able to minimise the potential of human errors and thus, improving the reliability and accuracy of estimated service activity cost. 
Besides, CBR is able to propose solutions in the domains which the user may not fully understand, and this allows the user to make assumptions and predictions based on what has worked in the past without having a complete understanding (Kolodner, 1992). Additionally, CBR is able to provide flexibility in knowledge modelling. The rigidity in problem formulation and modelling of model-based systems sometimes cannot solve a problem that falls on the boundaries of their knowledge or domain, especially when there is missing or incomplete data (Pal \& Shiu, 2004). In contrast, CBR is able to overcome this barrier because it uses past experiences as the domain knowledge and often provides reasonable solutions through appropriate adaptation.

These features allow cost estimators to predict service activities costs without the needs of repetitive, intensive and massive data collections. They are particularly useful during service family design stage where limited service design information is available. By using past service experiences that are stored in the case-base, service designers are able to assess the costs of potential service family designs and assist them to develop a cost effective service family while meeting customers' requirements. This is not achievable with a conventional ABC system. Besides, from the perspectives of service operations, quick assessments to the costs structures of service families are critical for managers to make adjustments on service planning and control, service capacity and operation strategies.

Apart from that, creation of a case-base is usually more rapid than the creation of a knowledge-base for rule-based systems (Ketler, 1993). This is associated with the need of the knowledge engineer to obtain rules behind the expert's reasoning. This process can be labour-intensive and more importantly, this task can further complicates the interrelationships between the rules. Similarly, implementation of an $\mathrm{ABC}$ system requires robust databases to optimise the accuracy of costs estimates. In this sense, large volumes of data are required to be collected, analysed and input into the database. This process is time-consuming and complex. Usually, costing experts are required to analyse the data so that useful data are input into the database.

In comparison to an $\mathrm{ABC}$ database, it is easier to setup and manage a service activity case-base for a CBR system. Many organisations have already documented 
their past cases in the centralised data storage. The users are only required to identify, store and index the key features of service activities. Besides, instead of regular updates and reviews of the database, update and expansion of a CBR case-base is accomplished progressively through each problem solving cycle where adapted and revised solutions are stored automatically into the case-base. Due to the ease of setting up and updating a service activity case-base, technical intensity and time to manage a service activity case-base can be reduced.

An ABC system is sensitive to changes. When changes are made to a service family, new sets of data are required as existing data that are stored in the database are not applicable to new cost estimation problems. However, data collections are difficult and costly. More importantly, a long lead time to process the data and make changes to the ABC system would be expected. This will cause serious problems to a service organisation for keeping up the pace of rapidly change business environment especially quick and accurate business responds to customers' needs and wants are essential ways to retain competitiveness in the market. In contrast, CBR is able to retain the knowledge that are gained from each problem solving into existing casebase and readily applicable to solve future cost estimation problems. Consequently, a CBR system is able to provide instantaneous costing solutions to the users if changes are made to the service families.

\subsubsection{The Case-Based Reasoning (CBR) Cycle for Activity Cost Estimation}

The key working mechanism of CBR reasoning is remembering. It is a process of retrieving a case or a set of cases from the case-base (Kolodner, 1992). Generally, remembering is consists of two major components: 1. integrating past cases or experiences into a case-base; 2 . recalling them in appropriate situations. When broader experiences are store in the case-base, the CBR system is able to reason and solve a wider range of new situations. Besides, the more subtle differences between the cases experienced by the system, it will be more competent in recognising these subtle differences and making more relevant and specific influences. 
Apart from remembering, learning through solving a problem is a critical process in CBR. As one of the subfields of machine learning, learning in CBR occurs naturally as an outcome of problem solving. It is largely a process of accumulating new cases that are dependent on other processes. When a problem is successfully solved, the experience is retained so that similar problems can be solved in future. However, when an attempt to solve a problem fails, the reason for the failure is identified in order to avoid the same mistake in the future. The extent of CBR learning capabilities depends on the range of experiences, ability to explain failures and successes, and ability to generate good indexes (Kolodner, 1993; Aamodt \& Plaza, 1994).

In this research, the concepts and elements of a CBR system are adopted and integrated into the $\mathrm{ABC}$ framework for developing a robust activity cost estimation mechanism to improve the accuracy of service activity cost estimation and to simplify the implementation of ABC (Figure 3.3). Specifically, instead of relying on manual calculations and measurements to estimate activity costs, CBR replaces these processes by using past service activities that are stored in a case-base to estimate service activities costs. The users are only required to define key features of the query case and adopt solutions that are proposed by the system. Apart from that, CBR avoid the requirements of intensive and massive data collections such as cost surveys and extensive data extractions from financial reports through the self-learning capabilities of a CBR system. In this case, progressive learning is achieved through each problem solving and experiences that are gained from the problem solving are retained in the case-base for future usage. 


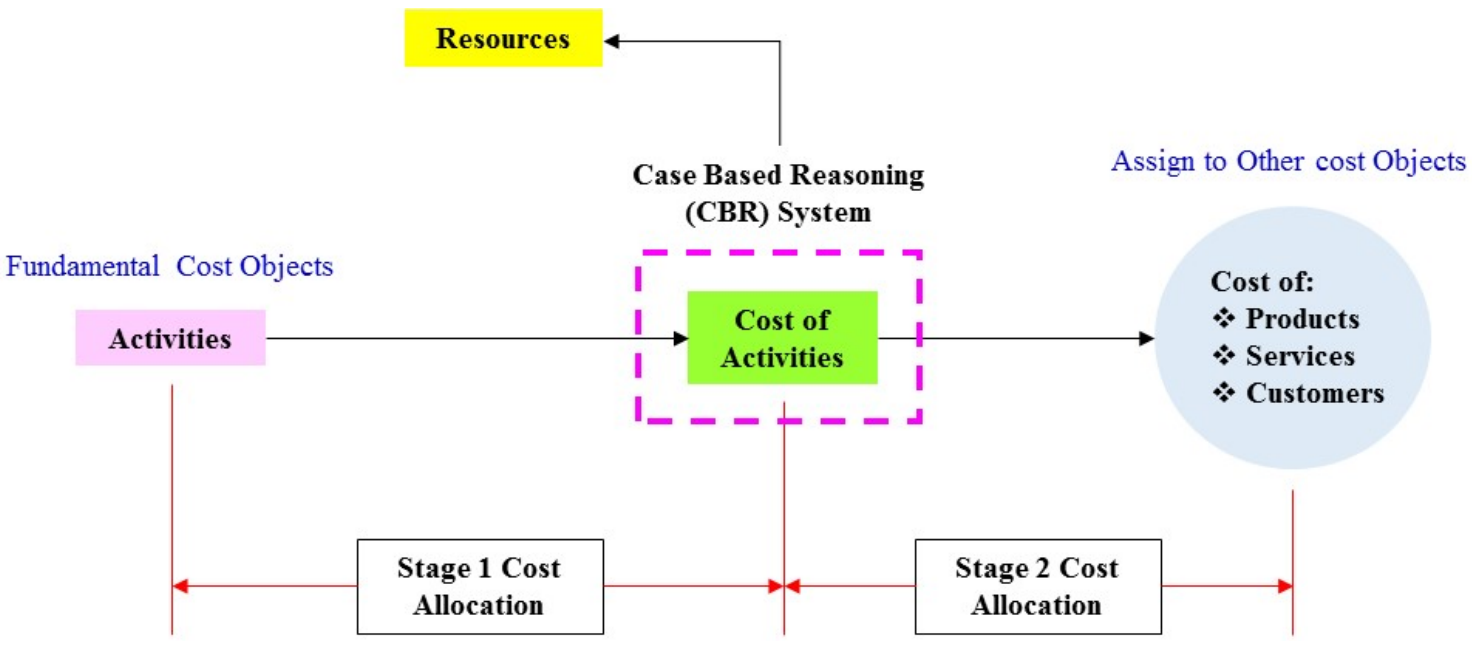

Figure 3.3 Activity cost estimation mechanism of CBR under ABC framework

The CBR reasoning consists of repetitive processes of problem solving, understanding and recalling, which these processes are represented by a reasoning model that is composed of stages that include retrieve, reuse, revise and retain:

\section{a. Retrieve (Past service activities retrieval):}

The objective of this stage is to retrieve past service activities from a service activity case-base when a query service activity is presented to the CBR system. The retrieval process starts with the query description where features are assigned to the query service activity. Subsequently, these features which are usually represented by readable means are input into the retrieval mechanism and past service activities which are matching the input features will be retrieved.

\section{b. Reuse (Solutions adaptions) :}

In reuse stage, the most similar past service activity is selected to generate the solutions for the query. During the process of adaptation, new generalisations and specialisations may be occurred due to solution transformation. The adaptation of past service experiences for current service activity is focusses on two aspects: 1 . Differences between past and current service activity and 2. Which part of the past service activity can be used for current service activity?

\section{c. Revise (Evaluation):}


The solution adapted by the query case is evaluated. If the solution is within expectation, further analysis is not required. Otherwise, a review is necessary. This step is important in CBR as it allows the user to evaluate the suitability of adapted solution to be applied in real world scenarios.

\section{d. Retain (Memory update):}

A CBR system learned by accumulating past experiences. In last stage of a CBR cycle, new service experience (activity) which contains both the problem and its solution is added to the case-base. To ensure the new case is retrievable for future problem solving, appropriate indexes are assigned. .

\subsection{Service Family Modularisation}

The main operation of proposed two-stage cost estimation mechanism is to measure service activities costs and subsequently, assign these costs to services that consumed these activities. However, increasing complexity of a service family due to service variations will increase the difficulties in assigning the activities costs to services. As a result, inaccurate cost estimates may be obtained. Besides, a service family can be a formation of similar services that are developed from different service platforms. Without a proper organisation of the service activities, it is highly complex to analyse the cost implications of the services to a service family.

For example, a bank is a financial institution that provides different banking services such as personal banking, corporate banking, investment banking, commodity trading, trading in equities and so on to the public. In order to reach out these services to the consumers at different locations, a network of retail branches is established. Each of these retail branches may be offering a set of customised services according to the needs of each location. Under such circumstances, a mechanism to systematically organise similar service activities into an entity is important to facilitate cost analysis and cost comparison so that the operating costs can be reduced or optimised to yield greater productivity.

Besides, the objective of a service family is to achieve service mass customisation by providing a variety of cost-effective services. In this sense, service standardisation 
is one of the effective ways to optimise the economies of scale for a service family. Service standardisation is the process of standardising the service contents so that every customer will essentially receive the same services. For example, an automated teller machine (ATM) will be providing same services to the customers regardless of locations. The main advantage of service standardisation is that it is able to lower service delivery costs and increase the productivity. Furthermore, it is easier and faster to deliver the services to customers as compared to highly customised services. To standardise the services, it is only achievable when the service activities are grouped into a set of logical entities for comparing and optimising the service contents.

According to Pimmler \& Eppinger (1995), a complex problem can be solved by breaking it down into a set of smaller problems so that it is easier to manage and the speed to generate solutions for the problems can be accelerated. Based on this analogy, a service family is assumed as a complex service delivery system that is decomposable into a set of sub-systems or modules to facilitate the process of cost estimation and analysis. In this context, a mechanism which is based on modularity concepts is introduced in this research to systematically modularise a service family into a modular structure.

\subsubsection{A Brief Background of Modularity Concepts}

The concepts of modules and modularity are essential parts in product architectures (Ulrich, 1995). A modular architecture is created based on mappings from functional elements to physical components of the products, and specifies decoupled interfaces between components. In more general terms, modularity is defined as the degree of a system's components or a product's architecture can be decomposed and recombined. It refers to the scheme by which interfaces shared among components in a given product architecture are standardised and specified to allow greater reusability and commonality of components among product families. A key aspect of modularity is that it is based on the notion of functional independence that each function should be independent from others (Schilling, 2000; Geum et al, 2012). A module is physical or conceptual grouping of components that shared some characteristics. Modules are identified in such a way that between-module (inter-module) interactions are minimal 
whereas within-module (infra-module) interactions maybe high (Ulrich, 1995; Newcomb et al, 1996).

Modularity concepts are applied in product design, design problems and production systems (Kamrani \& Salhieh, 2002). In modular product design, modular products fulfil various overall function through the combination of distinct building blocks or modules. An important aspect of modular products is the creation of a basic core unit, which different modules can be fitted so that a variety of versions of the same module can be produced. A modern aircraft turbofan engine is considered a good example of modular products. The turbofan engine is a combination of several components or building blocks which include fan module, compressor module, turbine module, shaft driven accessory module and mixed nozzle module. These modules can be modified or changed with little or no modification to other modules. For example, a turbine module of a turbofan engine can be replaced by a turbine module which is removed from another turbofan engine with similar configurations. By using modular product design, a company can choose from a variety of major components and form a product that can fulfil the needs of customers.

In solving design problems, it is often that the design problems can be broken into a set of simpler sub-problems. However, sometimes when a complex problem is decomposed into easier sub-problems, a small change in the solution of one subproblem can result to changes in other sub-problems' solutions. The interdependency between the sub-problems implies that the decomposition has resulted in functionality dependent sub-problems. In contrast, modularity concept focuses on breaking the overall problem into functionality independent sub-problems which the interdependency between these sub-problems is minimal. In such a context, a change in the solution of one sub-problem may lead to a minor modification in other subproblems or it may have no effect on other sub-problems. Apart from that, high variations of production requirements have led to the introduction of high varieties of production machinery and its building blocks. This indicates that there is no standardise modules for these type of machines. In order to build a modular production system, production machineries can be classified into definite number of functional 
groups where a selection of a modular production system can be made in correspondence to different production requirements. The modularity in production systems is used to build production systems from standardised modular machines.

In service context, service modularity is defined as the modularisation of processes or non-manufactured activities, giving the facts that services by nature are process offerings to others. Generally, service modularity is consists of service modules, process modularity and organisational modularity (Sundbo, 1994; Pekkarinene, 2008; Rahikka \& Pekkarinen, 2011). A service module is the smallest unit that can be offered to a customer itself or as part of a service offering that creates the value perceived by the customers. It consists of a group of elements that are highly inter-dependent, but only marginally dependent on the characteristics of other modules. In specific context, a service module is a set of service components for accomplishing a service, and these service components are activities that contain a set of processes, operations, people, objects and/or features.

Process modularity refers to the modularisation of service production process through the combinations of one or several process modules, which can be related to information processing or physical operations. Lastly, organisational modularity, it refers to a way to use the firm's and other firm's resources in a flexible way. Under this definition, an organisation can be modularised into organisational modules or functional units. The modularity in organisation can be accomplished through various supplier network configurations and internal organisational structures.

\subsubsection{The Mechanism to Modularise a Service Family}

In this research, the mechanism to modularise a service family is consists of two parts: 1. Decomposition of a service family into a set of service modules and 2. Mapping of service activities of each service to service modules. According to Jiao et al (2003), a service delivery system is regarded as a broad-sense product. Therefore, in order to decompose a service family into a modular structure, it should be viewed from a product perspective. 
In this sense, product concept analysis is adopted to decompose a service family into physical and functional elements. Functional elements are individual service operations and transformations that contribute to the overall performance of a service family, whereas physical elements are physical systems that are implemented to support the services or functional locations where the service activities are performed. For example, a hospital has different departments such as emergency, oncology, intensive care, cardiology and so on to provide various types of medical services. The medical services that provided by these departments are further grouped into different specialty groups. For instance, the department of cardiology of a hospital may be subdivided the services into adult congenital heart disease, cardiovascular rehabilitation and preventive cardiology, heart failure programme and interventional cardiology.

While product concept analysis systematically decomposes a service family into a set of service modules, an activity mapping mechanism is required to characterise and map the service activities to relevant service modules. To perform the mapping process, the relationships between service activities and each service module are measured. In this case, major characteristics of service modules and service activities are identified. By comparing the characteristics, degree of relevance between each service activity and service module are measured quantitatively. To assign the service activities, a clustering algorithm is applied to reorganise the service activities according to their relationships with the service modules.

\subsection{Overview of Proposed Cost Estimation Methodology}

Based on activity-based costing (ABC), case-based reasoning (CBR) and modularity concepts as discussed in previous sections, a service family cost estimation methodology is proposed as shown in Figure 3.4. This methodology consists of three major steps: 1. Service family representation and formation, 2. Service family modularisation and 3. Service cost estimation and analysis. In service family representation and formation, a service family is formed by selecting a set of similar services. Subsequently, service activities related to individual services are identified. In service family modularisation, a given service family is modularised into a modular 
structure. Service activities are mapped to individual service module by using an activity mapping mechanism. Finally, a two-stage cost estimation mechanism is used to estimate the costs for a service family. In stage one, service activities costs are estimated by case-based reasoning (CBR). Then, activities costs are allocated to relevant services.

In subsequent chapters, detailed architecture of proposed service family cost estimation methodology will be discussed. Besides, applicability of proposed cost estimation methodology will be demonstrated with a case study.

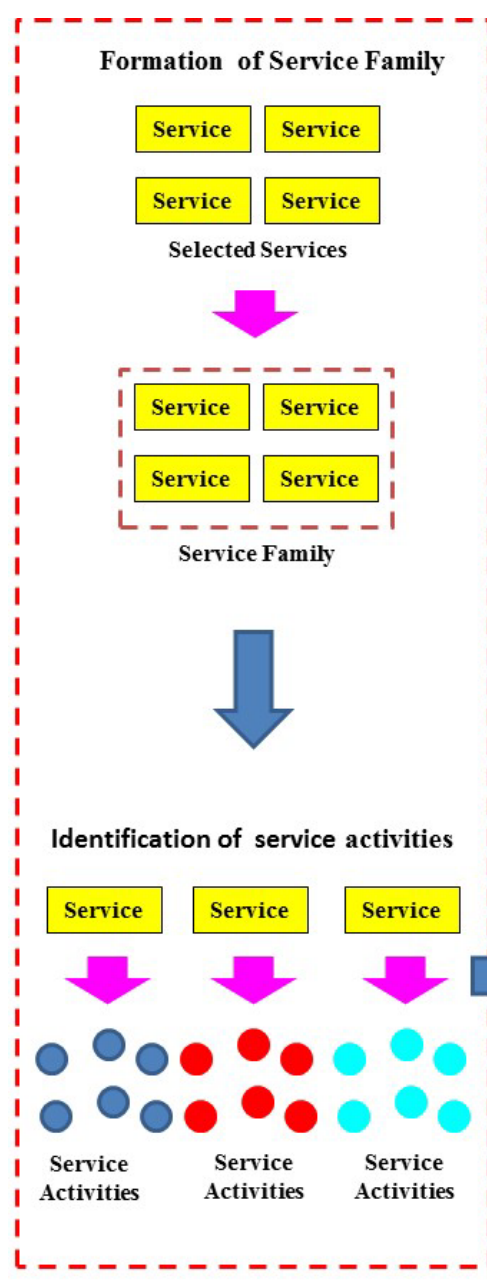

Service Family Identification and Data Collection

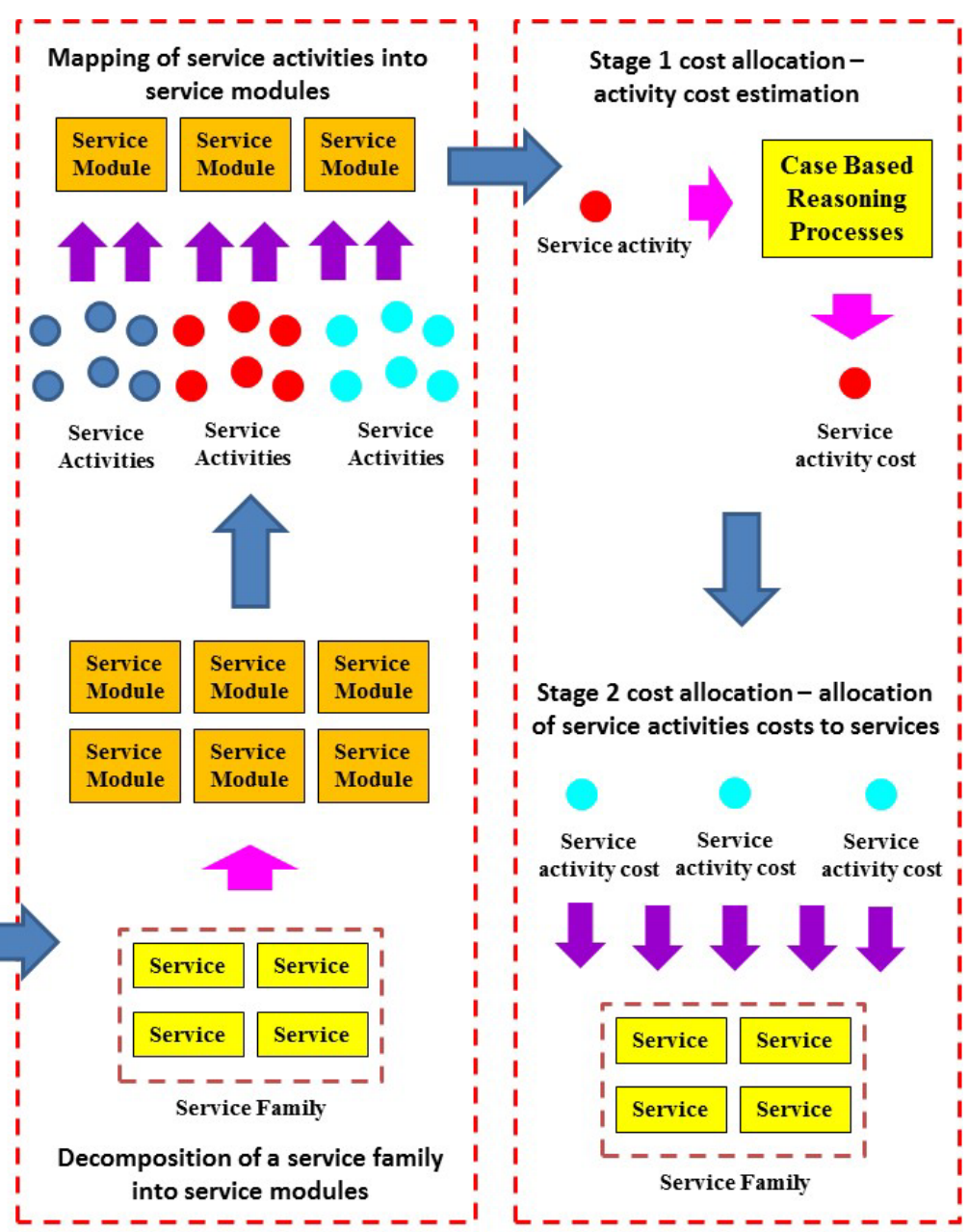

Service Family

Modularisation
Service Family Cost

Estimation and analysis

Figure 3.4 Overview of proposed service family cost estimation methodology 


\section{Chapter 4: Service Family Representation and Formation}

In this chapter, the mechanism to identify a service family based on a set of selected services is presented. Details on how to assess the suitability of selected services forming a service family are discussed. Lastly, classifications of service activities for a service family are also explained.

\subsection{Selection of Services and Formation of a Service Family}

Different from conventional definition that a service family is defined by a set of services that are developed from similar service platform, in this research, a service family is formed by a set of similar services which can be developed from different service platforms. The purpose is to provide flexibility and adaptability to users in selecting appropriate services for cost analysis. It is also practically relevant since service organisations usually offer a wide range of customised services based on the requirements of customers. For instance, an international airline may be using different aircraft types to provide flight services to the public. An Airbus A380 is used to provide long haul services for more than six hours and a Boeing 737 is considered a short haul aircraft which is used to provide short haul services for less than six hours. However, similar inflight services would be provided to the passengers such as inflight catering, inflight entertainment, duty free inflight shopping and different seating configurations.

\subsection{Formation of a Service Family}

\subsubsection{Commonality Analysis of Services}

To examine appropriateness of selected services, a commonality analysis which is based on total constant commonality index (TCCI) is used to measure degree of commonality of the services. This commonality index is a modified version of degree of commonality index (DCI) which is focused on assessing the numbers of common components within a product family (Thevenot \& Simpson, 2006). The main advantage of this commonality index is that it is easy to compute and provides a better indication of part standardisation since it has fixed boundaries. 
In this research, commonality of selected services is evaluated and analysed based on service components of the services. The service components can be referred to features, physical characteristics, functional characteristics and/or contents of the services. Once the service components are identified, total constant commonality index (TCCI) of selected services is calculated. The mathematical function of TCCI is defined as below:

$$
\text { TCCI }=1-\frac{d-1}{\sum_{y=1}^{d} \Phi_{y}-1} \quad 0<\text { TCCI } \leq 1
$$

Where $\Phi_{y}$ the numbers of service component y has over a set of selected services, $d$ is the total number of distinct service components in the set of selected services. Once the TCCI is calculated, a service commonality rating table as shown in Table 4.1 is used to determine whether the set of selected services can be used to form a service family.

Table 4.1 Service Commonality Rating Table

\begin{tabular}{|c|l|c|}
\hline $\begin{array}{c}\text { Calculated } \\
\text { Commonality } \\
\text { Index (CI) }\end{array}$ & \multicolumn{1}{|c|}{ Description } & $\begin{array}{c}\text { Formation of a } \\
\text { Service Family }\end{array}$ \\
\hline TCCI $>0.9$ & $\begin{array}{l}\text { Features, physical characteristics, functional } \\
\text { characteristics and contents of selected services } \\
\text { are almost common. }\end{array}$ & Yes \\
\hline $0.7<$ TCCI $<0.9$ & $\begin{array}{l}\text { Features, physical characteristics, functional } \\
\text { characteristics and contents of selected services } \\
\text { are mostly common. }\end{array}$ & Yes \\
\hline TCCI $<0.7$ & $\begin{array}{l}\text { Features, physical characteristics, functional } \\
\text { characteristics and contents of selected services } \\
\text { are partially common. }\end{array}$ \\
\hline
\end{tabular}

Based on the commonality analysis, a service family $S F$ is assumed to be defined by $k$ number of services $S$ :

$$
S F=S_{1}, S_{2}, S_{3} \ldots . . S_{k} \quad k=1,2,3 \ldots . .
$$

\subsubsection{An Example of Service Family Formation for Hospital Services}

An example to demonstrate the formation of a service family based on a set of hospital services is illustrated in this section. Parkway Pantai Limited is Southeast Asia's 
largest private healthcare service provider which is based in Singapore. It operates a network of 21 private hospitals and more than 60 medical centres, clinics and ancillary healthcare in countries like Singapore, Hong Kong, Malaysia, India and China. In this example, medical services which are offered by cardiovascular department of Gleneagles Hospital and Medical Centre, Mount Elizabeth Hospital (Orchard) and Mount Elizabeth Hospital (Novena) which are based in Singapore have been studied for the feasibility to form a service family.

Based on the information obtained from the websites of the hospitals, treatments that are offered by individual cardiovascular departments have been identified and tabulated in Table 4.2. A total of 51 cardiovascular treatments including heart screening, non-invasive treatments, invasive treatments and interventional treatments have been offered by these hospitals. Assuming each cardiovascular department is considered as a service, treatments offered by the hospitals are regarded as service components $y$ within the selected cardiovascular departments. From the table, numbers of distinctive service components $d$ are equal 6 (T7, T8, T11, T14, T16 and T20) and summation of service components $\Phi_{y}$ of the service family is equal to 51. By applying equation 1, TCCI for the cardiovascular departments of the three hospitals is calculated as shown below:

$$
\begin{aligned}
\text { TCCI } & =1-\frac{(6-1)}{(51-1)} \\
& =1-\frac{5}{50} \\
& =0.9
\end{aligned}
$$

Based on the computation result, it is found that $90 \%$ of the service components of the services are found to be common and referring to Table 4.1, these services can be used to form a service. Besides, to validate the result obtained by TCCI, percent commonality index is applied. In this case, common components of the potential service family is equal to 45 and unique components of the potential service family is equal to 6 . The computation of percent commonality index is shown below: 


$$
\begin{aligned}
& C_{c}=\frac{100 * \text { common }}{\text { common }+ \text { unique }} \\
& C_{c}=\frac{100 * 45}{45+6} \\
& C_{c}=88 \%
\end{aligned}
$$

The result obtains based on percent commonality index is found to be almost identical to result obtain by using TCCI. Hence, it can be concluded that the selected services

\begin{tabular}{|c|c|c|c|c|c|}
\hline $\begin{array}{l}\text { Treatment } \\
\text { Branch }\end{array}$ & $\begin{array}{l}\text { Treatment } \\
\text { Code }\end{array}$ & Treatments & $\begin{array}{l}\text { Gleneagles } \\
\text { Hospital } \\
\text { and Medical } \\
\text { Center } \\
\left(\mathrm{y}_{1}\right)\end{array}$ & $\begin{array}{c}\text { Mount } \\
\text { Elizabeth } \\
\text { Hospital } \\
(\text { Orchard) } \\
\left(\mathbf{y}_{2}\right)\end{array}$ & $\begin{array}{c}\text { Mount } \\
\text { Elizabeth } \\
\text { Hospital } \\
\text { (Novena) } \\
\left(\mathbf{y}_{3}\right)\end{array}$ \\
\hline \multirow{4}{*}{$\begin{array}{c}\text { Heart } \\
\text { Screening } \\
\text { Procedures }\end{array}$} & $\mathrm{T} 1$ & Chest X-ray & $\sqrt{ }$ & $\sqrt{ }$ & $\sqrt{ }$ \\
\hline & $\mathrm{T} 2$ & Electrocardiogram (ECG) & $\sqrt{ }$ & $\sqrt{ }$ & $\sqrt{ }$ \\
\hline & $\mathrm{T} 3$ & Stress Test & $\sqrt{ }$ & $\sqrt{ }$ & $\sqrt{ }$ \\
\hline & $\mathrm{T} 4$ & $\begin{array}{l}\text { Trans-Thoracic Echocardiogram } \\
\text { (TTE) }\end{array}$ & $\sqrt{ }$ & $\sqrt{ }$ & $\sqrt{ }$ \\
\hline \multirow{7}{*}{$\begin{array}{l}\text { Non-Invasive } \\
\text { Procedures }\end{array}$} & T5 & $\begin{array}{l}\text { Ambulatory Blood Pressure } \\
\text { Monitoring }\end{array}$ & $\sqrt{ }$ & $\sqrt{ }$ & $\sqrt{ }$ \\
\hline & T6 & Cardiac Calcium Scoring & $\sqrt{ }$ & $\sqrt{ }$ & $\sqrt{ }$ \\
\hline & $\mathrm{T} 7$ & $\begin{array}{l}\text { Cardiac Magnetic Resonance } \\
\text { Imaging (MRI) }\end{array}$ & $\sqrt{ }$ & & \\
\hline & T8 & $\begin{array}{l}\text { CT Angiography (320-Slice CT } \\
\text { Scanner) }\end{array}$ & $\sqrt{ }$ & & \\
\hline & T9 & Holter Monitoring & $\sqrt{ }$ & $\sqrt{ }$ & $\sqrt{ }$ \\
\hline & $\mathrm{T} 10$ & $\begin{array}{l}\begin{array}{l}\text { Nuclear Perfusion Scan } \\
\text { (SPECT/PET) }\end{array} \\
\end{array}$ & $\sqrt{ }$ & $\sqrt{ }$ & $\sqrt{ }$ \\
\hline & T11 & Nuclear Viability & $\sqrt{ }$ & & \\
\hline \multirow{4}{*}{$\begin{array}{l}\text { Invasive } \\
\text { Procedures }\end{array}$} & $\mathrm{T} 12$ & Coronary Angiogram & $\sqrt{ }$ & $\sqrt{ }$ & $\sqrt{ }$ \\
\hline & $\mathrm{T} 13$ & Electrophysiological Study & $\sqrt{ }$ & $\sqrt{ }$ & $\sqrt{ }$ \\
\hline & T14 & Left \& Right Heart Studies & $\sqrt{ }$ & & \\
\hline & $\mathrm{T} 15$ & $\begin{array}{l}\text { Trans-Oesophageal Echocardiogram } \\
\text { (TEE) }\end{array}$ & $\sqrt{ }$ & $\sqrt{ }$ & $\sqrt{ }$ \\
\hline \multirow{6}{*}{$\begin{array}{l}\text { Interventional } \\
\text { Procedures }\end{array}$} & T16 & $\begin{array}{l}\text { Bi-Ventricular Pacing for Heart } \\
\text { Failure }\end{array}$ & $\sqrt{ }$ & & \\
\hline & $\mathrm{T} 17$ & Defibrillator (AICD) Implantation & $\sqrt{ }$ & $\sqrt{ }$ & $\sqrt{ }$ \\
\hline & T18 & Pacemaker Implantation & $\sqrt{ }$ & $\sqrt{ }$ & $\sqrt{ }$ \\
\hline & T19 & Percutaneous Coronary Intervention & $\sqrt{ }$ & $\sqrt{ }$ & $\sqrt{ }$ \\
\hline & $\mathrm{T} 20$ & $\begin{array}{l}\text { Radiofrequency Catheter Ablation of } \\
\text { Arrhythmias }\end{array}$ & $\sqrt{ }$ & & \\
\hline & $\mathrm{T} 21$ & $\begin{array}{l}\text { Thoracic Aortic Valvular Surgery \& } \\
\text { Endovascular Aneurysm Repair }\end{array}$ & $\sqrt{ }$ & $\sqrt{ }$ & $\sqrt{ }$ \\
\hline
\end{tabular}
are suitable to form a service family.

Table 4.2 Cardiovascular treatments provided by Parkway Pantai Limited in Singapore 


\subsection{Identification of Service Activities}

\subsubsection{Identification of Service Activities Based on Activity Diagram}

Service activities are building blocks of services, they are also the cost factors that consume different organisational resources during service delivery. In activity-based costing $(\mathrm{ABC})$, comprehensiveness in identifying service activities is vital to the accuracy and consistency of cost estimation analysis. Once a service family is identified, activities related to the services are identified. However, different from the productions of physical products, a service is immaterial in nature and traditionally regarded as a highly complex operation (Jiao et al, 2003). To identify service activities, an activity identification mechanism based on activity diagram is introduced.

Activity diagram is one of the behaviour diagrams of unified modelling language (UML) which is often applied in the field of object-oriented software engineering (Dennis et al, 2005). It includes a set of graphical notation techniques that are used to create visual models for object-oriented software intensive systems. As part of UML family, activity diagram is capable of modelling the processes of an information system such as work flow modelling, individual use cases and decision logic contain with an individual method. The modelling and mapping of activities using an activity diagram are carried out by using a group of graphical syntaxes which are in the forms of graphical nodes and representations as shown in Figure 4.1. 


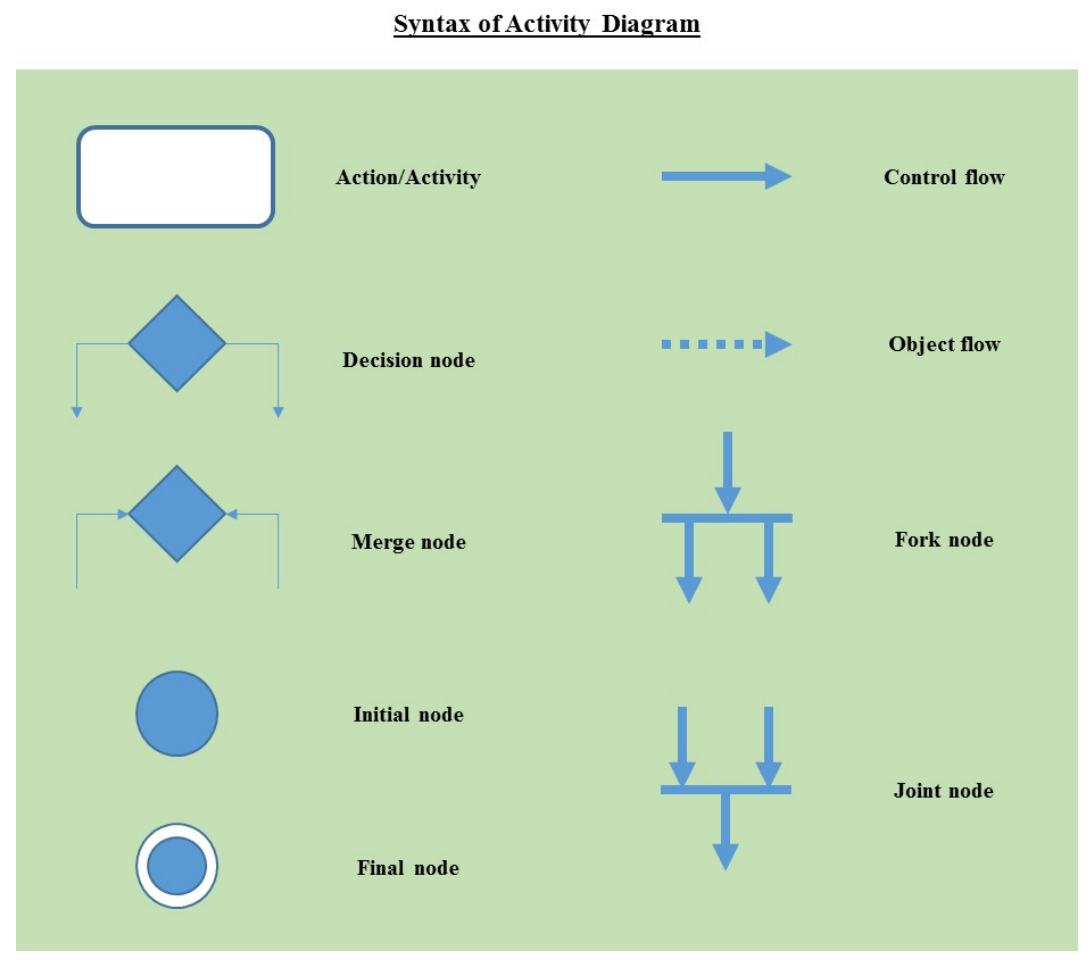

Figure 4.1 Examples of activity diagram syntaxes and nodes

\subsubsection{An Illustration of Service Activities Identifications}

The aircraft engine has two ignition systems that function independently to supply electrical sparks in the combustion chamber to initiate combustion or make sure the combustion continues. The ignition system consists of components such as ignition exciter, ignition igniters, ignition leads, start/ignition sector, fuel control switch, airfoil and cowl ice protection system (ACIPS) and flap slat electronic unit (FSEU). Igniter plugs are important parts of ignition system that supply continuous high voltage sparks to combustion chamber to ignite the gases. To ensure its functionalities, regular maintenance of the igniter plugs is necessary. In this example, maintenance activities to replaced upper and lower igniter plugs of General Electric GE90 engine within every 500 flight cycles are identified by using activity diagram. The maintenance activities related to this maintenance task are mapped into a diagram as shown in Figure 4.2. From the analysis, activity 3, 4, 5, 6 can be incurred due to the requirement of activity 2 where Acheson GP460 is required during the process to replace the igniter plugs. 


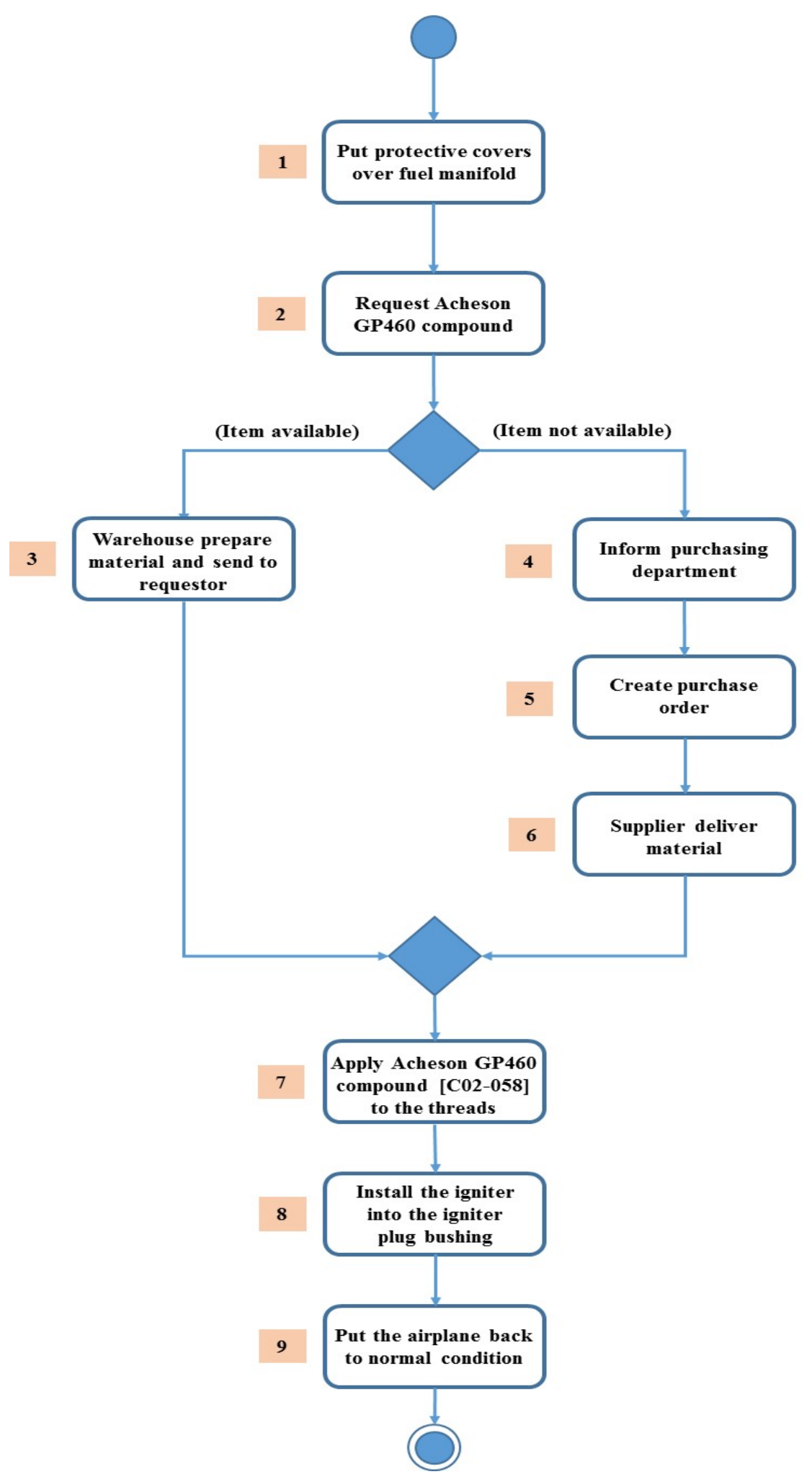

Figure 4.2 Activity diagram for lower and upper igniter plugs replacement of GE90 engine 


\subsection{Classification of Service Activities}

Proper classification of service activities is important to enhance the accuracy of cost estimation and analysis for a service family as it helps to trace the cost behaviours of the service family as well as individual services. In this study, service activities are classified into direct service activities (DSA) and indirect service activities (ISA). DSA refer to the class of service activities that are directly contributing to the delivery of a service. For example, when a doctor is performing a medical diagnosis, he or she is required to detect any physical deviation of a patient from the aspects of anatomy, physiology, pathology, psychology and human homeostasis. Besides, the doctor is also required to analyse the complaints that are expressed by the patient for matching the information with similar medical complications prior to any medical prescription or treatment. These activities are considered as examples of direct service activities that are required to deliver a medical service to a patient.

Meanwhile, an ISA is classified as a supporting activity that is needed to support the completion of a service or service activity. Activities such as human resource management, equipment, facilities, material purchasing, warehouse management and logistics services can be classified as indirect service activities. This category of service activities is further broken down into activity attributed (AISA) and service attributed (SISA) indirect service activities. AISA are indirect service activities incurred by DSA. This class of activities support the completion of a service at activity level. On the other hand, SISA is defined as a class of indirect service activities that are incurred due to a service. Even though indirect service activities are considered supporting activities that are functioned to support the accomplishments of direct service activities or services, but this category of service activities can be consuming significant amount of organisational resources or commonly known as overhead costs. For instance, a logistics service provider would be engaging an airline to deliver a shipment to a designated airport. In this example, the air cargo service provided by the airline is considered as an indirect service activity that is incurred to support the logistics provider in delivering a service. 
Assuming, a service $S_{k}$ consists of $j$ numbers of DSA, $i$ numbers of AISA and $l$ numbers of SISA, a service $S_{k}$ can be written as:

$$
\begin{aligned}
& S_{k}=D S A_{1, k}, D S A_{2, k \ldots D S A_{j, k}} \\
& + \text { AISA }_{1, j, k} \text { AISA } 2, j, k \ldots A I S A_{i, j, k} \\
& +S I S A_{1, k}, S_{S} A_{2, k} \ldots . . S I S A_{l, k} \\
& i=1,2,3 \ldots . \quad j=1,2,3 \ldots . \quad k=1,2,3 \ldots . \quad l=1,2,3 \ldots .
\end{aligned}
$$

\subsection{Chapter Summary}

This chapter has presented a systematic mechanism to identify a service family and service activities related to the services. Unlike prevailing definition of a service family, this research defines a service family from a set of selected services that can be developed from different service platforms. This feature provides flexibility and adaptability to in selecting appropriate services for cost estimation and analysis. Besides, a commonality assessment is used to assess the appropriateness of the services by examining and comparing the general characteristics of the services. Lastly, comprehensiveness in identifying service activities for a service family is vital for obtaining accurate cost estimates. Hence, in this research, activity diagram is employed to identify direct service activities (DSA) and indirect service activities (ISA) for a service family. 


\section{Chapter 5: Service Family Modularisation}

Chapter 5 introduces the mechanism to modularise a service family. It describes the decomposition of a service into its basic service elements and combination of these elements into a set of service modules. Besides, steps and procedures to map service activities to relevant service modules is illustrated.

\subsection{Creating a Modular Service Family}

\subsubsection{Decomposition of a Service Family}

A modular system can be created by decomposing a system into its basic elements and combining these elements into a set of basic components that capable of achieving the intended functions. Based on the assumption that a service family is a complex service system, it is decomposable into smaller service units. To systematically decompose a service family, product concept analysis is adopted. The objective of this concept is to decompose a service family into its basic service elements of functional and/or physical elements. As explained in section 3.3.2, functional elements are individual service operations and transformations that contribute to the overall performance of a service family. Meanwhile, physical elements are physical systems that are implemented to support the services or functional locations where service activities are performed.

The mechanism to decompose a service family consists of physical decomposition and functional decomposition. Physical decomposition reorganises a service family into a simpler physical structure by decomposing it into a set of sub-systems or components. For example, a hospital is typically consists of different medical departments to provide different types of medical and healthcare services. By assuming a hospital as a service delivery system, it can be decomposed into a set of physical sub-systems or components such as emergency department, diagnostic department, hospital business centre, admission service counters, cardiology department and general surgery. The physical decomposition of a hospital into a set of physical entities is intended to deliver the banking services more efficiently and to different groups of patients and achieve overall medical and healthcare functions. 
Apart from that, functional decomposition aims to describe the overall functions of a service family and identifies functions for service components. In this context, service functions can be performed by a physical element or combinations of elements that are arranged in a specific manner. For example, the overall function of an automobile workshop is to provide various types of vehicle maintenance services to the customers. To optimise operational efficiency and productivity, a vehicle maintenance workshop is usually decomposed into several stations so that specific service functions can be carried out.

Once the physical elements and functional elements are identified, they can be visually represented by a function-structure diagram to analyse the relationships between the elements and identify a set of service modules as shown in Figure 5.1.

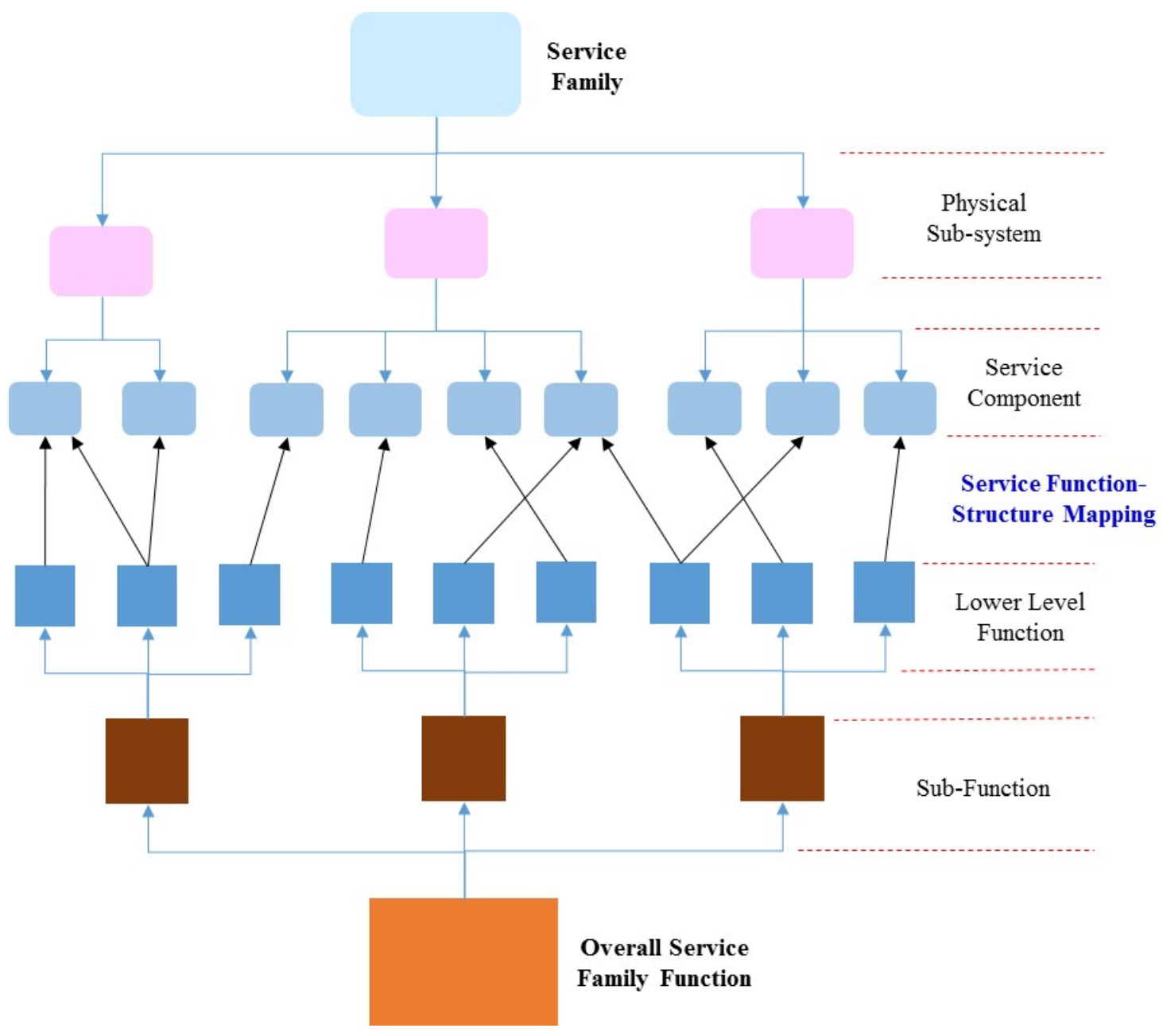

Figure 5.1 Function-structure diagram for a service family 
Based on product concept analysis, a service family is assumed to be decomposable into $n$ numbers of service modules $m$ and the modular structure of a service family can be expressed as:

$$
S F=m_{1}, m_{2}, m_{3} \ldots . . m_{n} \quad n=1,2,3 \ldots .
$$

\subsubsection{Creating a Modular Service Family for Branch Banking Services}

A branch or banking centre is a place that enables banks to provide their banking services to various groups of customers at different retail locations. Banking services related to savings and investments accounts, lending facilities, money transmission, payments services, share dealing and investment, safe custody services and so on are usually offered to the public. Typically, large banking companies tend to setup a sizeable network of banking centres to extend their business coverage. For instance, Bank of America provides banking services to more than 38 million customers and small businesses across 29 states of the U.S.A through 5,800 banking centres and 17,000 ATMs. Besides, Citigroup’s Global Consumer Group serves more than 200 million of banking accounts and provides banking services to its customers through a network of 7,237 branches, 6,920 ATMs, 682 Automated Lending Machines (ALMs), online banking, telephone and mail (Federal Reserve Bank of New York, 2007).

In this section, an example to illustrate the modularisation of branch banking service family for Overseas Chinese Banking Corporation Limited (OCBC) of Singapore is presented. OCBC is second largest banking group in Singapore. It has an estimated total assets of $\$ 100$ billion and owning a business network of more than 610 branches and representative offices in 18 countries and regions (OCBC, 2017). In Singapore, OCBC provides banking services to its customers through 46 branches and 1100 ATM across the island. In this example, banking services offered by the OCBC bank branches are considered as a service family SFOCBC-Branch. Under this service family, a wide range of personal and business banking services are offered by OCBC Bank as tabulated in Table 5.1. 
Table 5.1 Personal and business banking services of OCBC Bank at branch

\begin{tabular}{|l|l|}
\hline \multicolumn{1}{|c|}{ Service } & \multicolumn{1}{c|}{ Service Description } \\
\hline S $_{\text {Pers-ACCT }}$ & Personal accounts \\
\hline S $_{\text {Pers-Cards }}$ & Personal cards application \\
\hline$S_{\text {Pers-Loans }}$ & Personal loans \\
\hline$S_{\text {Pers-INS }}$ & Personal insurance \\
\hline S $_{\text {Pers-IVS }}$ & Personal investments \\
\hline$S_{\text {Biz-ACCT }}$ & Business accounts \\
\hline$S_{\text {Biz-Cashflow }}$ & Business and cash flows \\
\hline$S_{\text {Biz-Loans }}$ & Loans \\
\hline$S_{\text {ATM }}$ & Automated teller machine (ATM) \\
\hline
\end{tabular}

To create a modular branch banking service family, physical layouts of the branches are first analysed. In this case, a branch can be physically decomposed into several physical facilities such as personal banking stations, service counters, business banking stations, customer enquiry pod, cheque deposit box and automated teller machines (ATMs) as shown in Figure 5.2.

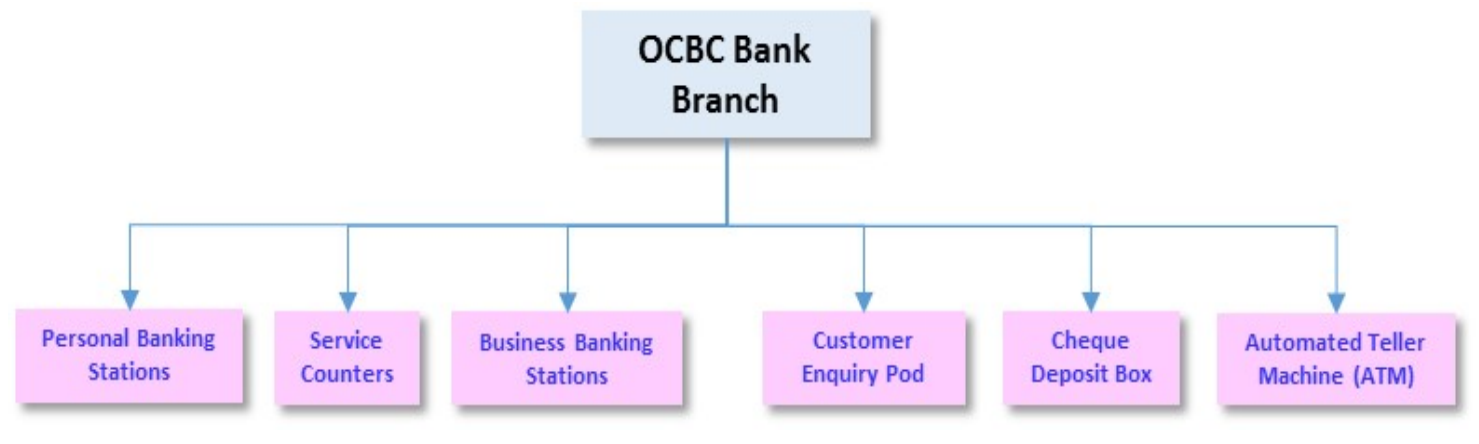

Figure 5.2 Physical decomposition of an OCBC Bank branch

Subsequently, the service family is functionally decomposed into a set of functional elements as shown in Figure 5.2. The overall service function of the service family is to provide banking services to customers at different retail locations within Singapore. Through the branches, sub-service functions which include personal banking, business banking and automated banking can be delivered. Within each entity, specialised services components are provided. 


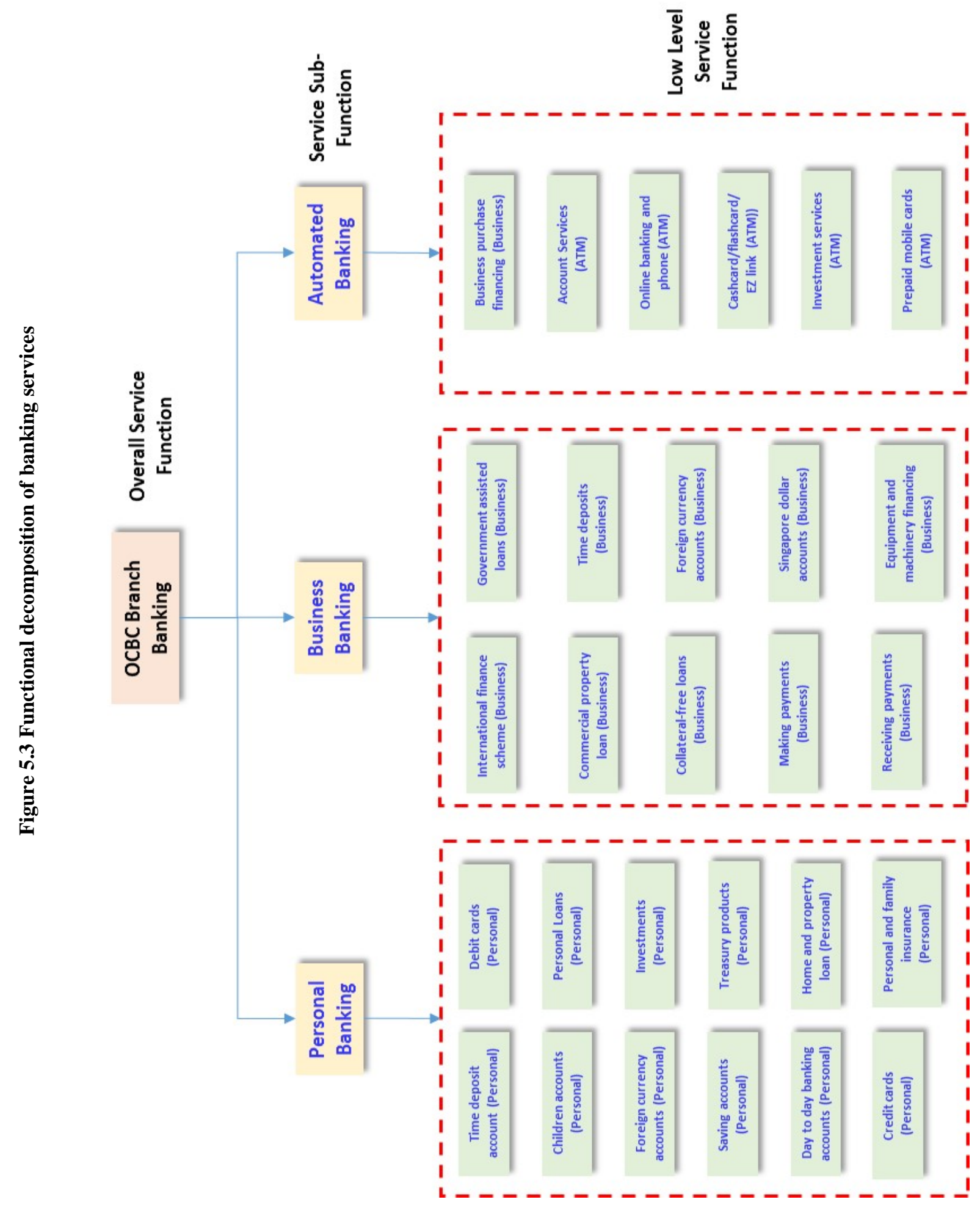

Page | 82 
Lastly, physical and functional elements of the service family is mapped into a function-structure diagram. Figure 5.4 shows the examples of function-structure mapping of branch banking services. Based on the results of functional-structure mapping of the services, a set of service modules are identified which include personal banking module (mPersonal), general banking module ( $\mathrm{m}_{\text {General }}$ ), business banking module ( $\left.m_{\text {Business }}\right)$ and automated service module ( $\left.m_{\text {Automated }}\right)$.

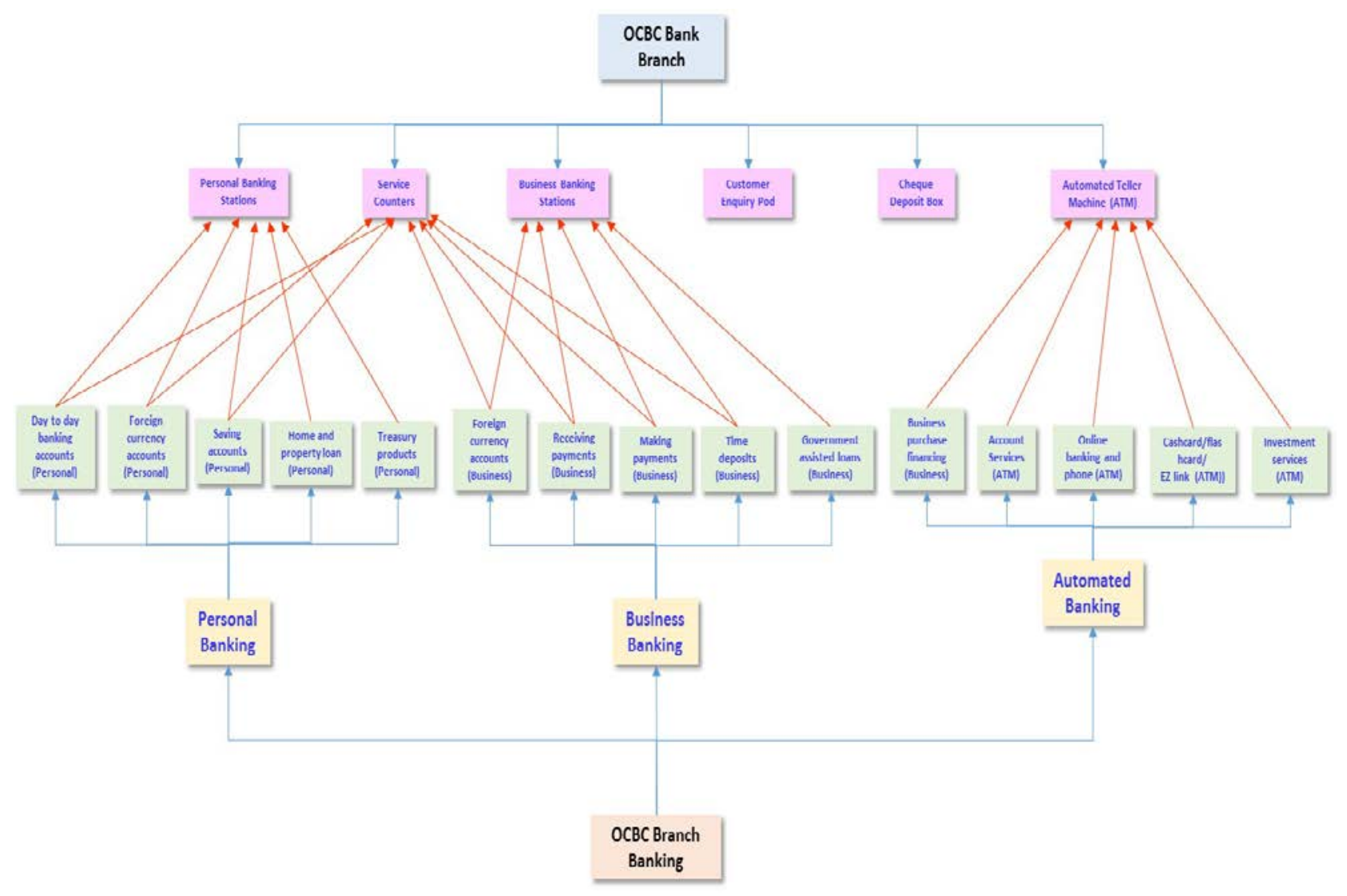

Figure 5.4 Function-structure mapping of branch banking service

\subsection{Mapping of Service Activities to Service Modules}

Following the modularisation of a service family, service activities of each service are required to be mapped to the service modules. The mapping mechanism consists of two parts: 1. Characterisation of relationships between service activities and service modules and 2. Mapping of service activities to service modules. In subsequent sections, detailed illustrations of the mapping process are discussed. 


\subsubsection{Activity-Module Relation Matrix}

In first part of the mapping mechanism, relationships between service activities and service modules are required to be characterised. The function of this step is to assess quantitatively the degree of relevance for the service activities in comparison with the service modules. In this context, functional and physical characteristics for each pair of service activity and service module are analysed and compared. The degree of relevance is subsequently measured with a relation scale (3 - strong relation, 1 - weak relation, 0 - no relation) and the results are recorded in an activity-module relation matrix as shown in Table 5.2. This matrix provides the quantitative relationships between service activities and service modules.

Table 5.2 Example of activity-module relation matrix template

\begin{tabular}{|c|c|c|c|c|c|c|}
\hline \multirow[b]{2}{*}{$\begin{array}{l}\text { Service } \\
\text { Activity }\end{array}$} & \multicolumn{6}{|c|}{ Service Module } \\
\hline & $m_{1}$ & $\boldsymbol{m}_{2}$ & $m_{3}$ & $\cdots \cdots \cdot$ & $\cdots \cdots \cdot$ & $m_{n}$ \\
\hline$D S A_{1, k}$ & $R\left(D S A_{1, k}, m_{1}\right)$ & $R\left(D S A_{1, k}, m_{2}\right)$ & $R\left(D S A_{1, k}, m_{3}\right)$ & ......... & $\ldots \ldots .$. & $R\left(D S A_{1, k}, m_{n}\right)$ \\
\hline$D S A_{2, k}$ & $R\left(D S A_{2, k}, m_{1}\right)$ & $R\left(D S A_{2, k}, m_{2}\right)$ & $R\left(D S A_{2, k}, m_{3}\right)$ & ........ & ....... & $R\left(D S A_{2, k}, m_{n}\right)$ \\
\hline$D S A_{3, k}$ & $R\left(D S A_{3 k j,}, m_{1}\right)$ & $R\left(D S A_{3, k}, m_{2}\right)$ & $R\left(D S A_{3, k}, m_{3}\right)$ & ......... & ........ & $R\left(D S A_{3, k}, m_{n}\right)$ \\
\hline ..... & ........ & ........ & ........ & ......... & ......... & ........ \\
\hline ..... & ........ & ........ & ........ & ........ & $\ldots \ldots$ & ........ \\
\hline$D S A_{j, k}$ & $R\left(D S A_{j, k}, m_{1}\right)$ & $R\left(D S A_{j, k}, m_{2}\right)$ & $R\left(D S A_{j, k}, m_{3}\right)$ & ........ & ....... & $R\left(D S A_{j, k}, m_{n}\right)$ \\
\hline
\end{tabular}

\subsubsection{Mapping of Service Activities to Service Modules}

To map the service activities to relevant service modules, $k$-mean clustering algorithm is applied in this research. This non-hierarchical clustering algorithm technique is first introduced by McQueen in 1967 to describe the process for partitioning an $\mathrm{N}$ dimensional population into $k$ sets on the basis of a sample (Yang \& Shan, 2009). It is considered one of the simplest and widely used unsupervised learning algorithms that is often implemented to resolve well known clustering problems by following a simple way to classify the data set through definite number of clusters. To initiate the algorithm, numbers of clusters $k$ are first determined. Then, initialisation seed points or centroids are randomly selected from the data points. By calculating the Euclidean 
distance between the data points and centroids, each data point is assigned to the nearest centroid. The data points which are assigned to a centroid form a cluster. Due to these assignments, a new set of centroids are identified by calculating the mean point of the clusters. Subsequently, Euclidean distance between the data points and new set of centroids are calculated. Data points nearest to the centroids are assigned to clusters. This process continues until the error function that computes the Euclidean distance between the data points and centroids does not change significantly or the memberships of the clusters are no longer changing (Gan \& Wu, 2007).

Applying similar working principles, mapping of service activities to service modules involves several steps. First, the number of activity clusters $k$ are required to be determined. Each activity cluster is assumed to represent a service module of the service family. Therefore, value of $k$ is eventually equal to number of service modules identified for a service family. To initiate the clustering algorithm, a set of initial centroids are randomly selected from the activity-module relation matrix. These centroids are functioned as the seeding points for each activity cluster. Once this step is completed, Euclidean distance between the service activities and centroids are calculated based on relation scores recorded in the activity-module matrix. Each service activity is assigned to nearest centroid and a collection of service activities forms an activity cluster. Due to the assignments of service activities to activity clusters, coordinates of the initial centroids are required to be updated. This step can be accomplished by averaging the data points of each activity cluster. Following that, Euclidean distance between the service activities and new set of centroids are calculated. This process is repeated until no further assignments or changes are required. The $k$-mean clustering algorithm to map the service activities to service modules can be expressed as:

$$
E=\sum_{n=1}^{S F} \sum_{R \in m b} d\left[R\left(D S A_{j, k}, m_{n}\right), \mu\left(m_{n}\right)\right] \quad n=1,2,3 \ldots
$$

Where $d\left[R\left(S A_{i . j}, m_{b}\right), \mu\left(\mathrm{m}_{\mathrm{b}}\right)\right]$ denotes the Euclidean distance between a random data point $R\left(S A_{i, j}, m_{b}\right)$ in the matrix and centroid $\mu\left(\mathrm{m}_{\mathrm{b}}\right)$ of a service module $m_{b}$. 


\subsubsection{A Numerical Example of Activity Mapping Process}

Based on product concept analysis, service family for branch banking services offered

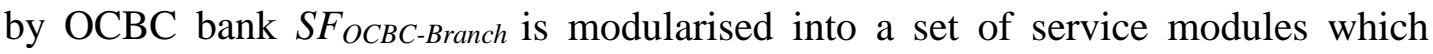
include personal banking module ( $\mathrm{m}_{\text {Personal), }}$ general banking module ( $\mathrm{m}_{\mathrm{General}}$ ), business banking module ( $\left.m_{\text {Business}}\right)$ and automated service module ( $\left.m_{\text {Automated }}\right)$. In this section, an example to demonstrate the activity mapping process for OCBC Bank branch banking service activities to relevant service modules is presented.

Prior to the activity mapping process, relationships between the service activities and service modules are assessed quantitatively. By analysing and comparing the functional and physical characteristics of service activities and service modules, degree of relevance for each pair of service activity and service module is measured and recorded in an activity-module relation matrix as shown in Table 5.3.

Table 5.3 Examples of Activity-Module Relation Matrix

\begin{tabular}{|c|c|c|c|c|c|c|}
\hline \multicolumn{3}{|c|}{ Direct Service Activity (DSA) } & \multicolumn{4}{|c|}{$\begin{array}{c}\text { Degree of Relevance } \\
\text { (3-Strong Relation, 1- Weak Relation, 0 - No Relation) }\end{array}$} \\
\hline $\begin{array}{l}\text { Service } \\
\left(\mathrm{S}_{\mathrm{i}}\right)\end{array}$ & $\begin{array}{c}\text { Service } \\
\text { Activity } \\
\text { (DSA }_{\mathbf{i}, \mathbf{j})}\end{array}$ & Activity Description & $\begin{array}{c}\text { Personal } \\
\text { Banking } \\
\text { Module } \\
\text { (m)ersonal) }\end{array}$ & $\begin{array}{c}\text { General } \\
\text { Banking } \\
\text { Module } \\
\text { (m } \text { meneral } \text {. }\end{array}$ & $\begin{array}{c}\text { Business } \\
\text { Banking } \\
\text { Module } \\
\text { (m) } \\
\text { Business) }\end{array}$ & $\begin{array}{c}\text { Automated } \\
\text { Banking } \\
\text { Module } \\
\text { (m } \text { mutomated } \text { ) }\end{array}$ \\
\hline Sers-ACCT & DSA $_{8 \text {,Pers-ACCT }}$ & OCBC Mighty Savers ${ }^{\circledR}$ Programme & 3 & 3 & 0 & 0 \\
\hline$S_{\text {Pers-Cards }}$ & DSA $_{1, \text { Pers-Cards }}$ & Credit cards application & 3 & 0 & 0 & 0 \\
\hline SPers-INS $_{1}$ & $\mathrm{DSA}_{1, \text { Pers-INS }}$ & MaxFamily Cover & 3 & 0 & 0 & 0 \\
\hline $\mathrm{S}_{\text {Biz-ACCT }}$ & DSA $_{1, \text { Biz-ACCT }}$ & OCBC Business Growth Account & 0 & 3 & 3 & 0 \\
\hline $\mathrm{S}_{\text {Biz-Cashflow }}$ & DSA $_{6, \text { Biz-Cashflow }}$ & Lockbox Service & 0 & 3 & 3 & 0 \\
\hline $\mathrm{S}_{\text {Biz-Loans }}$ & DSA $_{1, \text { Biz-Loans }}$ & Business First Loan & 0 & 0 & 3 & 0 \\
\hline $\mathrm{S}_{\text {Biz-Loans }}$ & DSA $_{10, \text { Biz-Loans }}$ & Banker's guarantee & 0 & 0 & 3 & 0 \\
\hline $\mathrm{S}_{\text {Biz-Loans }}$ & DSA $_{11, \text { Biz-Loans }}$ & Business Purchase Financing & 0 & 0 & 3 & 0 \\
\hline $\mathrm{S}_{\mathrm{ATM}}$ & $\mathrm{DSA}_{1, \mathrm{ATM}}$ & Account balance enquiry & 0 & 0 & 0 & 3 \\
\hline $\mathrm{S}_{\mathrm{ATM}}$ & $\mathrm{DSA}_{4, \mathrm{ATM}}$ & $\begin{array}{l}\text { Fund transfer to any OCBC Bank } \\
\text { account }\end{array}$ & 0 & 0 & 0 & 3 \\
\hline $\mathrm{S}_{\mathrm{ATM}}$ & $\mathrm{DSA}_{5, \mathrm{ATM}}$ & Fund transfer to other bank account & 0 & 0 & 0 & 3 \\
\hline
\end{tabular}

Subsequently, a set of initial centroids are randomly selected from the data points recorded in the matrix to initiate the mapping process. These centroids are functioned 
as seeding points to form activity clusters. In this example, the value of $k$ is equal to 4 since there are only four service modules are identified. Hence, a total of four centroids are required be identified. From Table 5.3, DSA ,Pers-ACCT, DSA $_{1 \text {,Pers-INS, DSA }}$,Biz-Loans and DSA4,ATM are selected as the initial centroids for the initialisation of activity mapping process. Based on these centroids, Euclidean distance between the service activities and centroids are calculated, an example of the calculation is illustrated below:

a. Given the centroids and their data points:

$$
\begin{aligned}
& \mu\left(m_{\text {Personal }}\right)=D S A_{1, \text { Pers-INS }}=(3,0,0,0) \\
& \mu\left(m_{\text {General }}\right)=D S A_{8, \text { Pers-ACCT }}=(3,3,0,0) \\
& \mu\left(m_{\text {Business }}\right)=D S A_{1, \text { Biz-Loans }}=(0,0,3,0) \\
& \mu\left(m_{\text {ATM }}\right)=D S A_{4, \text { ATM }}=(0,0,0,3)
\end{aligned}
$$

b. Calculating the Euclidean distance between DSA 1 ,Pers-Cards and service modules, given the data points for $\mathrm{DSA}_{1, \text { Pers-Cards }}=(3,0,0,0)$ :

i. Euclidean distance between $\mathrm{DSA}_{1, \text { Pers-Cards }}$ and $\mu\left(\mathrm{m}_{\text {Personal }}\right)$ :

$$
\begin{aligned}
d\left(\text { DSA }_{1, \text { Pers-Cards, }} \mu\left(m_{\text {Personal }}\right)\right)^{2} & =(3-3)^{2}+(0-0)^{2}+(0-0)^{2}+(0-0)^{2} \\
& =0+0+0+0 \\
d\left(D_{1, \text { Pers-Cards, }} \mu\left(m_{\text {Personal }}\right)\right) & =\sqrt{ } 0 \\
& =0
\end{aligned}
$$

ii. Euclidean distance between $\mathrm{DSA}_{1, \text { Pers-Cards }}$ and $\mu$ (m General $_{\text {): }}$

$$
\begin{aligned}
d\left(\text { DSA }_{1, \text { Pers-Cards, }} \mu\left(m_{\text {General }}\right)\right)^{2} & =(3-3)^{2}+(0-3)^{2}+(0-0)^{2}+(0-0)^{2} \\
& =0+9+0+0 \\
d\left(\text { DSA }_{\left.1, \text { Pers-Cards, } \mu\left(m_{\text {General }}\right)\right)}\right) & \sqrt{ } 9 \\
& =3
\end{aligned}
$$


iii. Euclidean distance between $\mathrm{DSA}_{1, \text { Pers-Cards }}$ and $\mu$ (m Business $_{\text {): }}$

$$
\begin{aligned}
& d\left(\text { DSA }_{1, \text { Pers-Cards, }} \mu\left(m_{\text {Business }}\right)\right)^{2}=(3-0)^{2}+(0-0)^{2}+(0-3)^{2}+(0-0)^{2} \\
& =9+0+9+0 \\
& =18 \\
& d\left(D A_{1, \text { Pers-Cards, }} \mu\left(m_{\text {Business }}\right)\right)=\sqrt{ } 18 \\
& =4.24
\end{aligned}
$$

iv. Euclidean distance between $\mathrm{DSA}_{1, \text { Pers-Cards }}$ and $\mu\left(\mathrm{m}_{\mathrm{ATM}}\right)$ :

$$
\begin{aligned}
d\left(D_{1, \text { Pers-Cards, }} \mu\left(m_{A T M}\right)\right)^{2} & =(3-0)^{2}+(0-0)^{2}+(0-0)^{2}+(0-3)^{2} \\
& =9+0+0+9 \\
d\left(D_{\text {DSA }} \text { Pers-Cards, } \mu\left(m_{A T M}\right)\right) & =\sqrt{ } 18 \\
& =4.24
\end{aligned}
$$

Based on the calculation results, DSA 1 ,Pers-Cards is assigned to personal banking module (mPersonnal) as it is nearest to the activity cluster. By repeating similar calculation procedures, service activities are assigned to nearest centroids based on calculated Euclidean distance. Once the service activities are fully assigned to nearest activity clusters, the steps are repeated by recalculating the centroids of the activity clusters. The new set of centroids are identified by averaging the data points of assigned service activities. By using business banking module (mBusiness) as the example, the calculation is illustrated below:

a. From first iteration, a total of 11 service activities are assigned to the activity cluster:

$$
\begin{aligned}
\mu\left(m_{\text {Business }}\right)= & \left(D S A_{1, \text { Biz-Loans }}, D S A_{2, \text { Biz-Loans }}, D S A_{3, \text { Biz-Loans }}, D S A_{4, \text { Biz-Loans }},\right. \\
& D S A_{5, \text { Biz-Loans, }}, D S A_{6, \text { Biz-Loans }}, D S A_{7, \text { Biz-Loans }}, D S A_{8, \text { Biz-Loans },} \\
& \left.D S A_{9, \text { Biz-Loans }}, D S A_{10, \text { Biz-Loans }}, D S A_{11, \text { Biz-Loans }}\right)
\end{aligned}
$$


b. Averaging the data point:

$$
\begin{aligned}
\mu\left(m_{\text {Business }}\right)= & ((0,0,0,0,0,0,0,0,0,0,0) / 11)+((0,0,0,0,0,0,0,0,0,0,0) / 11) \\
& ((3,3,3,3,3,3,3,3,3,3,3) / 11)+((0,0,0,0,0,0,0,0,0,0,0) / 11) \\
= & (0,0,3,0)
\end{aligned}
$$

By repeating the steps as shown in the example, a new set of centroids are identified. The Euclidean distance between the service activities and new set of centroids are recalculated. As there is no further changes or reassignments of service activities, reassignments of activities are not required. Besides, the calculations of error function as defined in equation 5 show that $E=108$ for initial and subsequent iterations. This indicates that the assignments of service activities are accurate.

\subsection{Chapter Summary}

In this chapter, mechanism to modularise a service family is presented. To modularise a service family, product concept analysis is adopted. Based on the assumption that a service family is considered as a service delivery system, it is decomposable into smaller units. Through physical and functional decomposition, a service family can be decomposed into its functional and/or physical elements. By mapping these elements into a function-structure diagram, a set of service modules can be identified. Subsequently, a mapping mechanism is employed to map the service activities to relevant service activities. This mechanism consists of two parts. Part one characterises the relationships between the service activities and service modules. Degree of relation between each pair of service activity and service module is recorded in activity-module relation matrix. Based on the relation scores, $k$-mean clustering algorithm is used to map the service activities to service modules. This clustering algorithm is considered one of the simplest and widely used non-hierarchical clustering techniques. To illustrate the service family modularisation process, several examples are provided. 


\section{Chapter 6: Service Family Cost estimation and Analysis}

Cost estimation is the central part of proposed cost estimation methodology. Based on activity-based costing ( $\mathrm{ABC}$ ) and case-based reasoning (CBR), a two-stage service family cost estimation mechanism is presented in this chapter (Figure 6.1). In stage one cost estimation, instead of relying on highly manual activity cost estimation processes of $\mathrm{ABC}$, the introduction of $\mathrm{CBR}$ within an $\mathrm{ABC}$ framework aims to minimise the needs of manual cost calculations and improve accuracy of cost estimation with lesser human interventions. In stage two cost estimation, estimated service activities costs are subsequently assigned to the services. In subsequent sections, details of the cost estimation mechanism will be discussed.

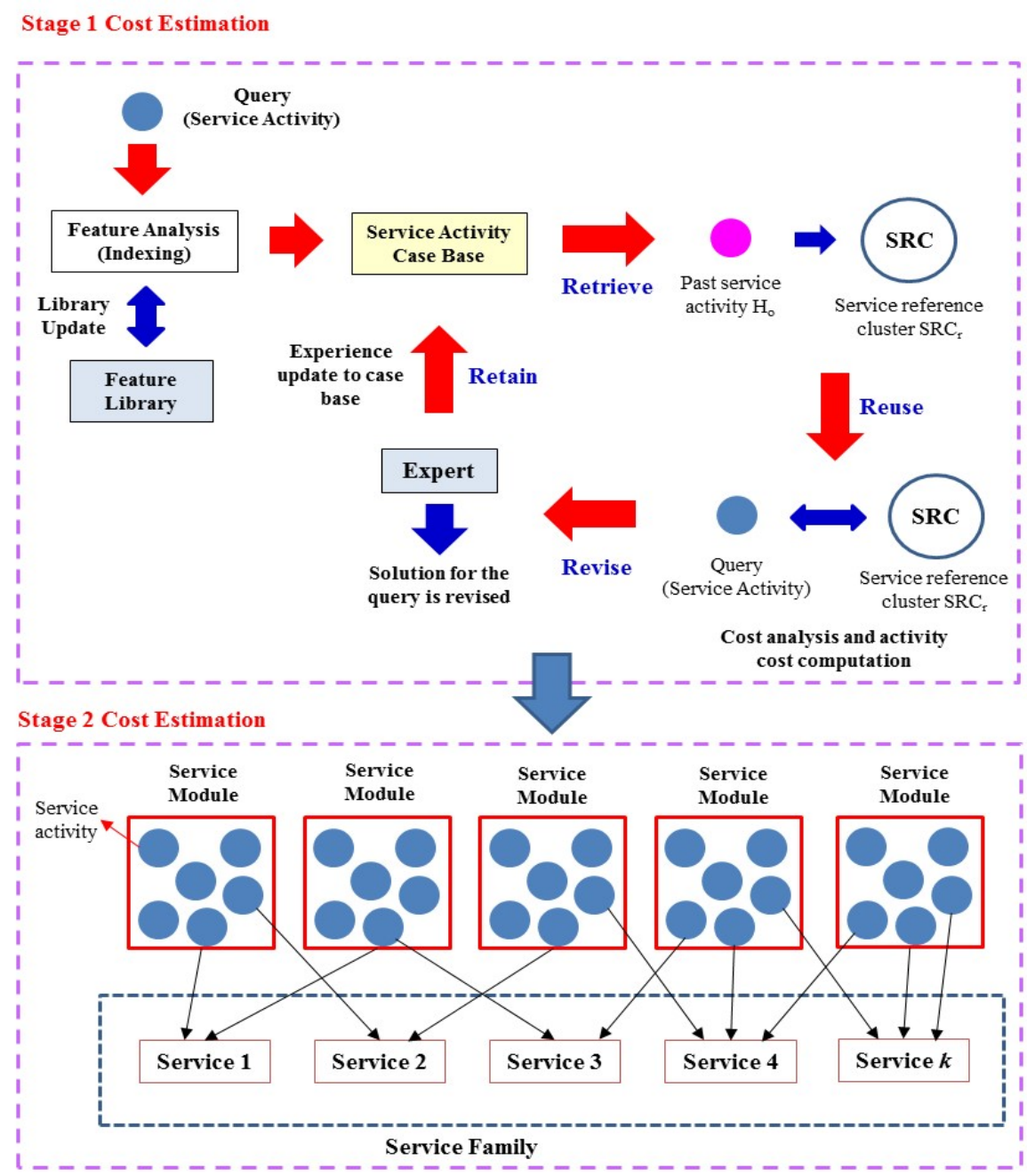

Figure 6.1 Overview of two-stage cost estimation mechanism 


\subsection{Stage One Cost Estimation: Service Activity Cost Estimation}

The key function case-based reasoning (CBR) in stage one cost estimation is to recall past service activities that are stored in a service activity case-base to estimate activities costs. In this context, robustness of a service activity case-base impacts the accuracy, speed and ease of past service activities retrievals and storage. This section discusses the representation, organisation, structure and storage of a service activity case-base. Besides, detailed steps and procedures to estimate service activities based on a CBR cycle that made up of retrieve, reuse, revise and retain stage are illustrated.

\subsubsection{Service Activity Representation and indexing in a CBR System}

CBR is a process of remembering a case or past experience, where it can be used to solve a problem or situation. Typically, a case is defined as an instance of problem solving process or a contextualised piece of knowledge that represents an experience (Watson \& Marir, 1994; Lopez, 2013). In this research, a case refers to a service activity $H_{0}$ which is previously performed for others (customers) during the process of service delivery. It contains critical service information that can be used to provide a solution to solve a service activity cost estimation problem. Therefore, a concise representation of a service activity is considered a critical task in CBR.

The simplest and most frequently used technique to represent a case is by using feature-value pairs where a case is described by a sequence of features (Richter \& Weber, 2013). In this case, a past service activity $H_{o}$ is describable by $t$ numbers of features $f$, where:

$$
H_{o}=f_{1}, f_{2}, f_{3 \ldots \ldots . . .} f_{t} \quad t=1,2,3 \ldots \ldots
$$

And, the features $f$ are attribute-value assignments as defined below:

$$
f_{t}=\left(a_{t}, v_{t}\right) \quad t=1,2,3 \ldots \ldots
$$

Where attributes $a_{t}$ are defined as the vocabulary to describe the feature and values $v_{t}$ are related to the attributes which can be in the forms of numerical values or vocabulary at a different refinement than the attributes. For example, Table 6.1 (a) and

(b) shows the medical treatments related to cataract surgery which can be described 
by a series of features. These features are represented by the attributes and values assigned to each service activity.

Table 6.1 (a) Assisted cataract surgery (b) Non-assisted cataract surgery

(a) Medical Activity ID:MA001

\begin{tabular}{|c|c|}
\hline Attributes $\left(a_{t}\right)$ & Value $\left(v_{t}\right)$ \\
\hline Department & Ophthalmology \\
\hline Clinical branch & $\begin{array}{l}\text { General cataract \& } \\
\text { comprehensive } \\
\text { Ophthalmology }\end{array}$ \\
\hline Clinical sub-branch & Cataract \\
\hline Type of treatment & Cataract eye surgery \\
\hline Assisted Surgery & Yes \\
\hline Equipment & $\begin{array}{l}\text { Victus }^{\mathrm{TM}} \\
\text { Femtosecond laser } \\
\text { machine }\end{array}$ \\
\hline Surgery duration per eye (hrs) & 0.25 \\
\hline No. of doctor & 1 \\
\hline No. of nurse & 1 \\
\hline No. of Technologist & 1 \\
\hline Equipment Cost (per use) & $\$ 1,000$ \\
\hline Medical material cost (per surgery) & $\$ 200$ \\
\hline
\end{tabular}

(b) Medical Activity ID:MA002

\begin{tabular}{|l|l|}
\hline \multicolumn{1}{|c|}{ Attributes $\mathbf{( a}_{\mathbf{t}}$ ) } & \multicolumn{1}{c|}{ Value $\mathbf{( v}_{\mathbf{t}} \mathbf{)}$} \\
\hline Clinical branch & $\begin{array}{l}\text { Ophthalmology } \\
\text { General Cataract \& } \\
\text { Comprehensive } \\
\text { Ophthalmology }\end{array}$ \\
Clinical sub-branch & Cataract \\
Type of treatment & Cataract eye surgery \\
Assisted Surgery & No \\
Equipment & Nil \\
Surgery duration per eye (hrs) & 0.75 \\
No. of doctor & 1 \\
No. of nurse & $\$ 300$ \\
No. of Technologist & 1 \\
\hline
\end{tabular}

Service activity retrieval from a case-base relies heavily on the structure and content of its collection of cases. Therefore, deciding how the service activities should be indexed is one of the key considerations for effective service activity retrieval. To derive a fast retrieval mechanism for massive libraries of service activities, indexes that are assigned to the service activities should be predictive, discriminative or explicative. Predictive means generality of the indexes in recovering a cluster of service activities, which are appropriate for a query (service activity). Besides, assigned indexes should be discriminative, so that they are specific enough to avoid of 
erroneous service activities. Finally, explicative means assigned indexes should be capable of contextualising retrieval with other features of the case or among all of the retrieved service activities. For example, features such as department, clinical branch, clinical sub-branch, type of treatment, and assisted surgery can be used as the indexes for the service activity.

\subsubsection{Organisation of Service Activity Case-Base}

Once the indexes are assigned to the past service activities, a case organisation structure is required to organise the cases so that the cases can be easily retrieved. In this case, case organisation structures which include flat, structured and semistructured are some of the most popular case organisation methods (Lopez, 2013; Richter \& Weber, 2013). Among them, flat organisation is considered the simplest to design and implement. In flat organisation, cases are organised in a single table, with row being cases and columns represent features. Besides, each cell of the table contains the value of the feature for a given case. This kind of organisation is linked to the use of sequential search method to access cases. Flat organisation has been widely used due to its simplicity in implementation and management by non-experts users with spreadsheet tools.

Meanwhile, structured organisations are related to the relational representation. The cases are stored according to the relations of features and can be retrieved in accordance with sub-assumption methods, showing a robust behaviour regarding missing-values management. The structured organisation can be beneficial when the number of cases is very large. Lastly, in semi-structured organisation, there is no framework to represent cases in a uniform way throughout the case-base. Features are represented by tags whose name and place inside the case may vary from one case to another case. The tags enable the identification of semantic interpretation of the features between different cases. The challenge to apply this type of case organisation is to handle different vocabularies for representing cases to identify and match the same semantic entities. The semi-structured organisation is typically used in internetbased approaches and applications that handle XML documents. 


\subsubsection{The Concept of Service Reference Cluster (SRC)}

Instead of estimating the cost for a query (service activity) by adapting the solution from a specific retrieved service activity, referencing the data from a set of similar past experiences in the service activity case-base are able to produce more rational and sensible cost analysis during the process of activity cost estimation. For example, repair costs for B777's power control unit (PCU) of similar part number may be different from one repair order to another repair order (Table 6.2). The variations of cost data can lead to inconsistent activity cost estimation especially in conventional CBR system, since only one or a few of retrieved cases are used to provide solutions for a problem.

Table 6.2 Examples of power control unit repair costs of an international airline

\begin{tabular}{|c|c|c|c|}
\hline $\begin{array}{c}\text { Historical } \\
\text { Service } \\
\text { Activity Case } \\
\text { ID }\end{array}$ & Historical Service Activity Description & Vendor & $\begin{array}{c}\text { Repair Cost } \\
\text { (US\$) }\end{array}$ \\
\hline RO-001 & REPAIR OF POWER CONTROL UNIT ASSEMBLY & MOOG CONTROLS CORP & $\$ 5,146.47$ \\
\hline RO-002 & REPAIR OF POWER CONTROL UNIT ASSEMBLY & MOOG CONTROLS CORP & $\$ 13,927.92$ \\
\hline RO-003 & REPAIR OF POWER CONTROL UNIT ASSEMBLY & MOOG CONTROLS CORP & $\$ 14,688.00$ \\
\hline RO-004 & REPAIR OF POWER CONTROL UNIT ASSEMBLY & MOOG CONTROLS CORP & $\$ 12,253.76$ \\
\hline RO-005 & REPAIR OF POWER CONTROL UNIT ASSEMBLY & MOOG CONTROLS CORP & $\$ 14,688.00$ \\
\hline RO-006 & REPAIR OF POWER CONTROL UNIT ASSEMBLY & MOOG CONTROLS CORP & $\$ 14,688.00$ \\
\hline RO-007 & REPAIR OF POWER CONTROL UNIT ASSEMBLY & MOOG CONTROLS CORP & $\$ 14,688.00$ \\
\hline RO-008 & REPAIR OF POWER CONTROL UNIT ASSEMBLY & MOOG CONTROLS CORP & $\$ 7,878.10$ \\
\hline RO-009 & REPAIR OF POWER CONTROL UNIT ASSEMBLY & MOOG CONTROLS CORP & $\$ 4,215.69$ \\
\hline RO-010 & REPAIR OF POWER CONTROL UNIT ASSEMBLY & MOOG CONTROLS CORP & $\$ 6,913.22$ \\
\hline RO-011 & REPAIR OF POWER CONTROL UNIT ASSEMBLY & MOOG CONTROLS CORP & $\$ 11,768.81$ \\
\hline RO-012 & REPAIR OF POWER CONTROL UNIT ASSEMBLY & MOOG CONTROLS CORP & $\$ 7,200.00$ \\
\hline
\end{tabular}

In such a context, data contain in other similar past cases would be neglected. In this research, service reference cluster (SRC) concept is proposed to optimise the accuracy and consistency of activity cost estimation. Instead of providing solutions to a query (service activity), the selected past service activity is used as the triggering factor to retrieve a relevant SRC to generate cost estimation for the query by applying appropriate data analysis techniques or methodologies. For example, common statistical analysis methods can be used to analyse the repair costs of power control 
unit assembly as shown Table 6.2. In this example the average repair costs for a power control unit assembly is $\$ 10,671$ and the standard deviation of the repair costs is $\$ 3927$.

To identify a SRC, similarity between past service activities within a given service activity case-base is compared. Based on the features $f$ assigned to each service activity, similarity between each pair of service activities is measured by Jaccard similarity coefficient. This methodology identifies the changes of resemblance between activities by using binary codes of "1" and "0", where " 1 " indicates the presence of a feature whereas a " 0 " indicates its absence (Romesberg, 1984). In this study, mathematical function to measure the Jaccard similarity coefficient is defined as:

$$
C\left(R, H_{o}\right)=\frac{a}{a+b+c} \quad 0 \leq C\left(R, H_{o}\right) \leq 1.0
$$

Where reference activity $R$ is a randomly selected past service activity which functioned as the reference point of a SRC. It is used to compare and identify identical past service activities within the case-base. Meanwhile, $a$ denotes the total numbers of features where both reference activity $R$ and activity $H_{0}$ both have a value of $1 . b$ denotes the total numbers of features where feature of reference activity $R$ is 1 and feature of activity $H_{o}$ is 0 . Lastly, $c$ denotes the total number of features where feature of reference activity $R$ is 0 and feature of activity $H_{o}$ is 1 . The Jaccard similarity coefficient indicates maximum similarity when $C\left(R, H_{o}\right)$ is equal to 1 , whereas a past service activity is not identical to the reference activity $R$ when $C\left(R, H_{o}\right)$ is equal to 0 . Based on Jaccard similarity coefficient, a case-base can be subdivided into $r$ numbers of SRCs:

$$
C B=S R C_{1}, S R C_{2}, S R C_{3} \ldots . . . S R C_{r} \quad r=1,2,3 \ldots \ldots .
$$

In this section, an example to illustrate the identification of a SRC is presented. Assuming three past medical treatments are randomly selected from a service activity case-base, MA001 is selected as reference activity R. It is compared with service activity MA002 and MA003 by using Jaccard similarity coefficient and Table 6.3 records the features of the service activities: 
Table 6.3 Examples of medical treatments of a service activity case-base

\begin{tabular}{|c|c|c|c|c|c|}
\hline \multirow{2}{*}{ Activity ID } & Attribute 1 & Attribute 2 & Attribute 3 & Attribute 4 & Attribute 5 \\
\hline & Department & Clinical branch & $\begin{array}{l}\text { Clinical sub- } \\
\text { branch }\end{array}$ & $\begin{array}{l}\text { Type of } \\
\text { treatment }\end{array}$ & $\begin{array}{l}\text { Assisted } \\
\text { Surgery }\end{array}$ \\
\hline MA001 & Ophthalmology & $\begin{array}{c}\text { General cataract \& } \\
\text { comprehensive } \\
\text { Ophthalmology } \\
\end{array}$ & Cataract & $\begin{array}{l}\text { Cataract eye } \\
\text { surgery }\end{array}$ & Yes \\
\hline MA002 & Ophthalmology & $\begin{array}{c}\text { General cataract \& } \\
\text { comprehensive } \\
\text { Ophthalmology } \\
\end{array}$ & Cataract & $\begin{array}{c}\text { Cataract eye } \\
\text { surgery }\end{array}$ & No \\
\hline MA003 & Ophthalmology & $\begin{array}{c}\text { General cataract \& } \\
\text { comprehensive } \\
\text { Ophthalmology }\end{array}$ & Cataract & $\begin{array}{l}\text { Cataract eye } \\
\text { surgery }\end{array}$ & Yes \\
\hline
\end{tabular}

a. Jaccard similarity coefficient between MA001 (R) and MA002:

$$
\begin{aligned}
& C\left(R, H_{o}\right)=\frac{a}{a+b+c} \\
& C(M A 001, M A 002)=\frac{4}{4+1+0} \\
& C(M A 001, M A 003)=0.8
\end{aligned}
$$

b. Jaccard similarity coefficient between MA001 (R) and MA003:

$$
\begin{aligned}
& C\left(R, H_{o}\right)=\frac{a}{a+b+c} \\
& C(M A 001, M A 003)=\frac{5}{5+0+0} \\
& C(M A 001, M A 003)=1
\end{aligned}
$$

Based on the computation result, similarity between MA001 and MA003 is equal to 1. This shows that both activities are found to be identical and shared similar features. Therefore, MA003 can be considered as one of this SRC. On the other hand, the Jaccard coefficient between MA001 and MA002 is equal to 0.8. This indicates that MA002 is dissimilar to MA001 and should not be considered as one of the members for the SRC.

By using similar calculation procedures, MA001 is compared with a set of medical treatments that are recorded in the service activity case-base as shown in Table 6.4. From the computations results, a total of six past medical treatments are found to 
be similar with the reference activity $\mathrm{R}$ while remaining service activities are found to be dissimilar with due to their Jaccard coefficients as compared to reference activity $\mathrm{R}$ are found to be less than 1 . For example, MA006 is only resemble $20 \%$ of the reference activity $\mathrm{R}$. These activities are rejected from the considerations to form a SRC with MA001.

Table 6.4 Jaccard coefficients of past medical treatments in Ophtalmology department of a hospital.

\begin{tabular}{|c|c|c|c|c|c|c|}
\hline \multirow{2}{*}{$\begin{array}{l}\text { Activity } \\
\text { ID }\end{array}$} & Attribute 1 & Attribute 2 & Attribute 3 & Attribute 4 & Attribute 5 & \multirow{2}{*}{$\begin{array}{l}\text { Jaccard } \\
\text { similarity } \\
\text { coeffieicnt }\end{array}$} \\
\hline & Department & Clinical branch & $\begin{array}{c}\text { Clinical sub- } \\
\text { branch }\end{array}$ & $\begin{array}{c}\text { Type of } \\
\text { treatment }\end{array}$ & $\begin{array}{l}\text { Assisted } \\
\text { Surgery }\end{array}$ & \\
\hline MA001 & Ophthalmology & $\begin{array}{c}\text { General cataract } \\
\text { \& comprehensive } \\
\text { Ophthalmology }\end{array}$ & Cataract & $\begin{array}{l}\text { Cataract eye } \\
\text { surgery }\end{array}$ & Yes & 1 \\
\hline MA002 & Ophthalmology & $\begin{array}{l}\text { General cataract } \\
\text { \& comprehensive } \\
\text { Ophthalmology }\end{array}$ & Cataract & $\begin{array}{l}\text { Cataract eye } \\
\text { surgery }\end{array}$ & No & 0.8 \\
\hline MA003 & Ophthalmology & $\begin{array}{l}\text { General cataract } \\
\text { \& comprehensive } \\
\text { Ophthalmology }\end{array}$ & Cataract & $\begin{array}{l}\text { Cataract eye } \\
\text { surgery }\end{array}$ & Yes & 1 \\
\hline MA004 & Ophthalmology & $\begin{array}{l}\text { General cataract } \\
\text { \& comprehensive } \\
\text { Ophthalmology }\end{array}$ & Cataract & $\begin{array}{l}\text { Cataract eye } \\
\text { surgery }\end{array}$ & Yes & 1 \\
\hline MA005 & Ophthalmology & $\begin{array}{c}\text { General cataract } \\
\text { \& comprehensive } \\
\text { Ophthalmology }\end{array}$ & Cataract & $\begin{array}{l}\text { Cataract eye } \\
\text { surgery }\end{array}$ & No & 0.8 \\
\hline MA006 & Ophthalmology & Retina Centre & $\begin{array}{c}\text { Myopic macular } \\
\text { disorders }\end{array}$ & Myopic CNV & No & 0.2 \\
\hline MA007 & Ophthalmology & Retina Centre & $\begin{array}{c}\text { Diabetic } \\
\text { retinopathy and } \\
\text { maculopathy }\end{array}$ & $\begin{array}{l}\text { Diabetic } \\
\text { retinopathy }\end{array}$ & No & 0.2 \\
\hline MA008 & Ophthalmology & $\begin{array}{l}\text { General cataract } \\
\text { \& comprehensive } \\
\text { Ophthalmology }\end{array}$ & Cataract & $\begin{array}{l}\text { Cataract eye } \\
\text { surgery }\end{array}$ & Yes & 1 \\
\hline MA009 & Ophthalmology & $\begin{array}{l}\text { General cataract } \\
\text { \& comprehensive } \\
\text { Ophthalmology }\end{array}$ & Cataract & $\begin{array}{l}\text { Cataract eye } \\
\text { surgery }\end{array}$ & Yes & 1 \\
\hline MA010 & Ophthalmology & $\begin{array}{l}\text { General cataract } \\
\text { \& comprehensive } \\
\text { Ophthalmology }\end{array}$ & Cataract & $\begin{array}{l}\text { Cataract eye } \\
\text { surgery }\end{array}$ & Yes & 1 \\
\hline
\end{tabular}

\subsubsection{Activity Retrieval Mechanism}

In CBR, the objective of retrieve stage is to retrieve similar cases from a case-base that is so close to a given problem (query) where the solutions provided by these cases can be adapted or used to solve the existing problem (Richter \& Weber, 2013). Therefore, case retrieval is a process of searching within a given case-base for cases that are closest to the problem based on the given descriptions of the problem (Pal \& Shiu, 
2004). However, unlike database searches that only target specific value in the records, case retrieval in CBR requires heuristics methodologies which are able to perform partial matches. To carry out effective case retrieval, the key factor is to measure how close the problem as compared to cases that are stored in a given case-base. In this case, similarity measure is used to quantify the degree of resemblance between a pair of cases and it is the determining factor that decides whether a stored case will be retrieved. The similarity concept within the CBR methodology is not considered as a general concept, but a polymorphic concept that varies for each case base.

Case retrieval is a major research area in CBR, a sizeable research has been carried out in both supervised and unsupervised frameworks by many researchers and practitioners, and hundreds of different algorithms and various approaches have been developed to retrieve similar cases from the case-base (Pal \& Shiu, 2004; Lopez, 2013). By far, the most commonly investigated retrieval techniques are $k$-nearest neighbours, decision trees and their variants. These techniques require the development of a similarity metric that allows the measurements of similarity between a problem and cases within a given case-base:

\section{a. Nearest neighbour retrieval}

Nearest neighbour methods are the most widely adopted and exploited retrieval techniques in majority of the case-based reasoning systems (Watson \& Marir, 1994; Watson, 1997; Janssen et al, 2015). It is also one of the two retrieval techniques that is adopted in commercial CBR tools (Watson, 1997; Cunningham, 1998). In this retrieval technique, a case is retrieved when the weighted sum of the features that match the current problem (query) is greater than other cases in the case-base. If all features are measured equally, a case that matches the features of present problem (query) on $n$ features will be retrieved instead of a case that matches only $k$ features,

where $k>n$. Features which are considered more important in a problem-solving situation can be denoted by weighing them more heavily in the case retrieving process.

Besides, nearest neighbour method is an exhaustive search technique that compares a query case with all cases that are stored in a given case-base and retrieve a definite number of similar cases. Hence, it is a powerful case retrieval technique if a 
good similar metric can be setup as compared to other retrieval techniques (Cunningham, 1998). Nearest neighbour methods have been applied commonly in CBR systems due to its simplicity in implementation and less sensitive to missing, or noisy data (Watson, 1997). However, it has a disadvantage that case retrieval speed will be reduced if the number of cases within a case-base increase significantly.

\section{b. Inductive approaches}

Inductive approaches are alternatives retrieval techniques that are applied in many CBR systems. There are developed by machine learning researchers to obtain rules or construct decision trees from past data. Like nearest neighbour retrieval techniques, induction retrieval techniques are also adopted CBR tools (Watson, 1997). In this type of retrieval techniques, a set of features are determined to discriminate cases and generate a decision tree type structure to organise cases within a case-base. They are useful when of the case features is required as a solution and where that particular case feature is dependent on other features (Watson \& Marir, 1994). The most widely used induction retrieval algorithm in CBR systems is called ID3 (Watson, 1997). This retrieval algorithm constructs a decision tree from the database of cases by using a heuristic called information gain to identify a set of features to divide the case-base.

Induction retrieval techniques are relatively straightforward and extremely quick to retrieve cases from a case-base. However, this type of retrieval techniques can become very complex when a case-base consists of several hundred or several thousand cases. Besides, it may be time consuming to implement this retrieval technique since offline pre-indexing is required to build decision tree before case retrieval can start. Furthermore, new decision trees are required to construct from scratch when there are new cases added to the case-base. The main disadvantage of an induction retrieval algorithm is that it may not possible to retrieve a case when the case data is missing or unknown (Watson, 1997).

\section{c. Knowledge guided induction}

Knowledge guided induction approaches apply knowledge to the induction process by manually identifying case features that are known or thought to affect the primary case feature. These type of retrieval techniques are usually combined with other techniques 
since explanatory knowledge is not always readily available for large case bases (Watson, 1997).

\section{d. Template retrieval}

Template retrieval is similar to SQL-like queries, it returns the cases that fit within specific parameters. This retrieval technique is usually used before other techniques such as nearest neighbour to limit the search space to a relevant section of the casebase.

According to Pal \& Shiu (2004), there are several factors to be considered for determining an appropriate retrieval method, which include number of cases to be searched, amount of domain knowledge available, ease of determining weightings for individual features, whether the cases should be indexed by same features or whether each case may have features that are different importance.

To retrieve past service activities in a service activity case-base, the query (new activity cost estimation problem) is required to be indexed by assigning appropriate features so that it is recognisable by the retrieval mechanism. The accuracy in assigning appropriate indexes to the query is particularly important to increase the likelihood of past service activity retrieval. To facilitate the process of indexing, indexes that are stored in the feature library can be used for assigning features to the query. A query (service activity) Q can be described by $t$ numbers of features, where:

$$
Q=f_{1}, f_{2}, f_{3} \ldots \ldots \ldots f_{t} \quad t=1,2,3 \ldots \ldots
$$

Once a query Q is described with a set of indexes (selected features for retrieval), it is input into a retrieval mechanism and compare with past service activities that are stored within a given case-base. In present research, a nearest neighbour based retrieval algorithm is applied to retrieve past service activities that are stored in a casebase due to its simplicity, practicability and ease of implementation. Furthermore, this retrieval technique is able to process large volumes of past service activities without the need to start scratch when there are additions of past service activities. Furthermore, functionality of case retrieval is not affected by missing or noisy data. 
To retrieve past service activities from a given service activity case-base, a weighted Euclidean distance based nearest neighbour is defined. In this algorithm, the number of service activities to be retrieved is first determined. Subsequently, a similarity assessment is carried out to measure similarity between the query case and a randomly selected past service activity. In this assessment, degree of resemblance between the activities is measured by calculating the similarity of the features. The similarity assessment is repeated for all service activities within the case-base. For a pair of query and a randomly selected past service activity, a weighted Euclidean distance is mathematically expressed as below:

$$
d\left(Q, H_{o}\right)=\left[\sum_{f=1}^{t} W_{f_{t}}{ }^{2}\left(v\left(f_{t}, Q\right)-v\left(f_{t}, H_{o}\right)\right)^{2}\right]^{1 / 2}
$$

Where $d\left(Q, H_{o}\right)$ denotes the weighted Euclidean a query $\mathrm{Q}$ and past service activity $\mathrm{H}_{\mathrm{o}}$. Besides, $V\left(f t, H_{o}\right)$ refers to the value of $t^{\text {th }}$ feature of $o^{\text {th }}$ past service activity and $V\left(f_{t}, Q\right)$ refers to the value of $t^{\text {th }}$ feature of a query Q. Finally, $W_{f_{t}}$ denotes the weight of $t^{\text {th }}$ feature or index. Using the weighted Euclidean distance, a similarity measure between the query and a randomly selected past service activity $\operatorname{SIM}\left(\mathrm{Q}, \mathrm{H}_{0}\right)$ is defined as below:

$$
\operatorname{SIM}\left(Q, H_{o}\right)=\frac{1}{1+\alpha d\left(Q, H_{o}\right)} \quad 0 \leq \operatorname{SIM}\left(Q, H_{o}\right) \leq 1
$$

Where $\alpha$ is a positive constant which usually set at 1 and the similarity measure between the activities is range from 0 to 1 where a value of 0 indicates the query is dissimilar to a past service activity and a value of 1 implies that the query is identical to a past service activity.

To demonstrate the retrieval mechanism, an example to illustrate how the past service activities are retrieved from a service activity case-base for a hospital eye treatment service NA001 is presented. Prior to activity retrieval, the query is first indexed. By referring to a list of indexes for Ophthalmology Department (Table 6.4), appropriate indexes are assigned to query as shown in Table 6.5. In subsequent steps, 
the assigned indexes would be used to perform feature to feature comparisons with past service activities that are stored in the case-base so that the degree of resemblance for between the query and each past service activity can be measured.

Table 6.5 Examples of Indexes for Indexing of Query

\begin{tabular}{|c|c|c|}
\hline Attributes (at) & Value (vt) & Value Description \\
\hline Department & 1 & Ophthalmology \\
\hline Clinical branch & $\begin{array}{l}1 \\
2 \\
3 \\
4\end{array}$ & $\begin{array}{l}\text { General Cataract \& Comprehensive Ophthalmology } \\
\text { Corneal \& External Eye Disease } \\
\text { Retina Centre } \\
\text { Glaucoma }\end{array}$ \\
\hline Clinical sub-branch & $\begin{array}{c}1 \\
2 \\
3 \\
4 \\
5 \\
6 \\
7 \\
8 \\
9 \\
10\end{array}$ & $\begin{array}{l}\text { Cataract } \\
\text { Corneal } \\
\text { External eye disease } \\
\text { Anterior segment eye disorders. } \\
\text { Surgical Retina Department } \\
\text { Medical Retina Department } \\
\text { Glaucoma Diagnostics } \\
\text { Glaucoma Therapeutics } \\
\text { Laser Glaucoma Management } \\
\text { Surgical Glaucoma Management }\end{array}$ \\
\hline Type of treatment & $\begin{array}{l}1 \\
2 \\
3 \\
4 \\
5 \\
6 \\
7 \\
8 \\
9 \\
10 \\
11 \\
12 \\
13 \\
14 \\
15 \\
16 \\
17 \\
18 \\
19 \\
20 \\
21 \\
22 \\
\end{array}$ & $\begin{array}{l}\text { Cataract surgery } \\
\text { Contact lens related eye problems (Medical Contact Lens Clinic) } \\
\text { Ocular surface disorders requiring reconstruction } \\
\text { Further treatment for dry eye (Dry Eye Clinic) } \\
\text { Artificial Corneal Transplant } \\
\text { Retinovascular eye diseases } \\
\text { Diabetic retinopathy and maculopathy } \\
\text { Polypoidal choroidal vasculopathy } \\
\text { Miscellaneous eye conditions, e.g. central serous retinopathy and floaters } \\
\text { Stereoscopic Optic Disc Photography } \\
\text { Anterior Segment Imaging Technology } \\
\text { Optic Nerve Head and Retinal Nerve Fibre Layer Imaging Technology } \\
\text { Automated Visual Field Analysis } \\
\text { Glaucoma medications } \\
\text { Laser Peripheral Iridotomy } \\
\text { Selective Laser Trabeculoplasty } \\
\text { Laser Suturelysis post-trabeculectomy } \\
\text { Goniotomy } \\
\text { Trabeculectomy with anti-metabolites } \\
\text { Bleb Needling with anti-metabolites } \\
\text { Bleb Revisions } \\
\text { Goniosynechiolysis }\end{array}$ \\
\hline $\begin{array}{c}\text { Machine Assisted } \\
\text { Surgery }\end{array}$ & $\begin{array}{l}1 \\
2\end{array}$ & $\begin{array}{l}\text { Yes } \\
\text { No }\end{array}$ \\
\hline Level of Complexity & $\begin{array}{l}1 \\
2 \\
3\end{array}$ & $\begin{array}{l}\text { Simple } \\
\text { Medium } \\
\text { Complex } \\
\end{array}$ \\
\hline Required Implant & $\begin{array}{l}1 \\
2\end{array}$ & $\begin{array}{l}\text { Yes } \\
\text { No }\end{array}$ \\
\hline
\end{tabular}


Table 6.6 Indexes assigned to query NA001

Medical Activity ID: NA001

\begin{tabular}{|c|l|c|l|}
\cline { 2 - 4 } \multicolumn{1}{c|}{} & \multicolumn{3}{|c|}{ Feature (f) } \\
\hline No. & \multicolumn{1}{|c|}{ Attributes (A) } & $\begin{array}{c}\text { Value } \\
\left(\boldsymbol{v}_{\boldsymbol{t}}\right)\end{array}$ & \multicolumn{1}{|c|}{ Value Description } \\
\hline $\mathbf{1}$ & Department & 1 & Ophthalmology \\
$\mathbf{2}$ & Clinical branch & 1 & General Cataract \& \\
$\mathbf{3}$ & Clinical sub-branch & 1 & Comprehensive Ophthalmology \\
$\mathbf{4}$ & Type of treatment & 1 & Cataract \\
$\mathbf{5}$ & Machine Assisted Surgery & 1 & Yes \\
$\mathbf{6}$ & Level of Complexity & 1 & Simple \\
$\mathbf{7}$ & Required Implant & 2 & No \\
$\mathbf{8}$ & Type of Machine & & \\
$\mathbf{9}$ & Surgery Duration (hrs) & & hours \\
$\mathbf{1 0}$ & Surgeon Rate (\$) & & Per hour rate \\
$\mathbf{1 1}$ & Nursing Costs (\$) & & Per Surgery \\
$\mathbf{1 2}$ & Equipment Costs (\$) & & Per Surgery \\
$\mathbf{1 3}$ & Facility Costs (\$) & & Per Surgery \\
\hline
\end{tabular}

For example, to assess the similarity between query NA001 and past service activity MA001 and MA002, Euclidean distance between the service activities are calculated:

a. Given the indexes and attribute values of NA001, MA001 and MA002:

\begin{tabular}{|c|c|c|c|c|}
\hline & \multicolumn{3}{|c|}{ Activity ID } \\
\hline & & NA001 & MA001 & MA002 \\
\hline $\begin{array}{c}\text { feature } \\
1\end{array}$ & $\begin{array}{l}\text { Attribute } \\
\text { Value } \\
\text { Description } \\
\end{array}$ & $\begin{array}{c}\text { Department } \\
1 \\
\text { Ophthalmology } \\
\end{array}$ & $\begin{array}{c}\text { Department } \\
1 \\
\text { Ophthalmology } \\
\end{array}$ & $\begin{array}{c}\text { Department } \\
1 \\
\text { Ophthalmology } \\
\end{array}$ \\
\hline $\begin{array}{c}\text { feature } \\
2\end{array}$ & $\begin{array}{l}\text { Attribute } \\
\text { Value } \\
\text { Description }\end{array}$ & $\begin{array}{c}\text { Clinical branch } \\
1 \\
\text { General Cataract \& } \\
\text { Comprehensive Ophthalmology }\end{array}$ & $\begin{array}{c}\text { Clinical branch } \\
1 \\
\text { General Cataract \& } \\
\text { Comprehensive Ophthalmology }\end{array}$ & $\begin{array}{c}\text { Clinical branch } \\
1 \\
\text { General Cataract \& } \\
\text { Comprehensive Ophthalmology }\end{array}$ \\
\hline $\begin{array}{c}\text { feature } \\
3\end{array}$ & $\begin{array}{l}\text { Attribute } \\
\text { Value } \\
\text { Description }\end{array}$ & $\begin{array}{c}\text { Clinical sub-branch } \\
1 \\
\text { Cataract }\end{array}$ & $\begin{array}{c}\text { Clinical sub-branch } \\
1 \\
\text { Cataract }\end{array}$ & $\begin{array}{c}\text { Clinical sub-branch } \\
1 \\
\text { Cataract }\end{array}$ \\
\hline $\begin{array}{c}\text { feature } \\
4\end{array}$ & $\begin{array}{l}\text { Attribute } \\
\text { Value } \\
\text { Description }\end{array}$ & $\begin{array}{c}\text { Type of treatment } \\
1 \\
\text { Cataract Surgery }\end{array}$ & $\begin{array}{c}\text { Type of treatment } \\
1 \\
\text { Cataract Surgery }\end{array}$ & $\begin{array}{c}\text { Type of treatment } \\
1 \\
\text { Cataract Surgery }\end{array}$ \\
\hline $\begin{array}{c}\text { feature } \\
5\end{array}$ & $\begin{array}{l}\text { Attribute } \\
\text { Value } \\
\text { Description }\end{array}$ & $\begin{array}{c}\text { Machine Assisted Surgery } \\
1 \\
\text { Yes }\end{array}$ & $\begin{array}{c}\text { Machine Assisted Surgery } \\
1 \\
\text { Yes }\end{array}$ & $\begin{array}{c}\text { Machine Assisted Surgery } \\
2 \\
\text { No }\end{array}$ \\
\hline $\begin{array}{c}\text { feature } \\
6\end{array}$ & $\begin{array}{l}\text { Attribute } \\
\text { Value } \\
\text { Description }\end{array}$ & $\begin{array}{c}\text { Level of Complexity } \\
1 \\
\text { Simple }\end{array}$ & $\begin{array}{c}\text { Level of Complexity } \\
1 \\
\text { Simple }\end{array}$ & $\begin{array}{c}\text { Level of Complexity } \\
3 \\
\text { Complex }\end{array}$ \\
\hline $\begin{array}{c}\text { feature } \\
7\end{array}$ & $\begin{array}{l}\text { Attribute } \\
\text { Value } \\
\text { Description }\end{array}$ & $\begin{array}{c}\text { Required Implant } \\
2 \\
\text { No }\end{array}$ & $\begin{array}{c}\text { Required Implant } \\
2 \\
\text { No }\end{array}$ & $\begin{array}{c}\text { Required Implant } \\
1 \\
\text { Yes }\end{array}$ \\
\hline
\end{tabular}


b. Given the weights of indexes:

Weight scale: 5 (very important) to 1 (least important)

Weight of feature $1, W_{f_{1}}=5 \quad$ Weight of feature $2, W_{f^{2}}=4$

Weight of feature $3, W_{f_{3}}=4 \quad$ Weight of feature $4, W_{f_{4}}=4$

Weight of feature $5, W_{f_{3}}=5 \quad$ Weight of feature $6, W_{f_{6}}=3$

Weight of feature 7, $W_{f_{6}}=2$

c. Similarity assessment between NA001 and MA001:

i. Calculating weighted Euclidean distance between NA001 and MA001:

$$
\begin{aligned}
& d\left(Q, H_{o}\right)=\left[\sum_{f=1}^{t} W_{f_{t}}{ }^{2}\left(v\left(f_{t}, Q\right)-v\left(f_{t}, H_{o}\right)\right)^{2}\right]^{1 / 2} \\
& d\left(\text { NA001, MA001) }=\left[5^{2}(1-1)^{2}+4^{2}(1-1)^{2}+4^{2}(1-1)^{2}+4^{2}(1-1)^{2}+5^{2}(1-2)^{2}+2^{2}(1-3)^{2}+2^{2}(2-1)^{2}\right]^{1 / 2}\right. \\
& d(N A 001, \text { MA001 })=[25(0)+16(0)+16(0)+16(0)+25(0)+4(0)+4(0)]^{1 / 2} \\
& d(N A 001, \text { MA001 })=0
\end{aligned}
$$

ii. Calculating similarity between NA001 and MA001, assuming $\alpha=1$ :

$$
\begin{aligned}
& \operatorname{SIM}\left(Q, H_{0}\right)=\frac{1}{1+\alpha d\left(Q, H_{0}\right)} \\
& \operatorname{SIM}\left(Q, H_{0}\right)=\frac{1}{1+(1)(0)} \\
& \operatorname{SIM}\left(Q, H_{o}\right)=1
\end{aligned}
$$

d. Calculation of degree of similarity between NA001 and MA002

i. Calculating weighted Euclidean distance between NA001 and MA001: 


$$
\begin{aligned}
& d\left(Q, H_{o}\right)=\left[\sum_{f=1}^{t} W_{f_{t}}{ }^{2}\left(v\left(f_{t}, Q\right)-v\left(f_{t}, H_{o}\right)\right)^{2}\right]^{1 / 2} \\
& d(N A 001, M A 001)=\left[5^{2}(1-1)^{2}+4^{2}(1-1)^{2}+4^{2}(1-1)^{2}+4^{2}(1-1)^{2}+5^{2}(1-2)^{2}+2^{2}(1-3)^{2}+2^{2}(2-1)^{2}\right]^{1 / 2} \\
& d(N A 001, M A 001)=[25(0)+16(0)+16(0)+16(0)+25(1)+4(4)+4(1)]^{1 / 2} \\
& d(N A 001, M A 001)=6.71
\end{aligned}
$$

ii. Calculating similarity between NA001 and MA001, assuming $\alpha=1$ :

$$
\begin{aligned}
& \operatorname{SIM}\left(Q, H_{o}\right)=\frac{1}{1+\alpha d\left(Q, H_{o}\right)} \\
& \operatorname{SIM}\left(Q, H_{o}\right)=\frac{1}{1+(1)(6.71)} \\
& \operatorname{SIM}(Q, H o)=0.13
\end{aligned}
$$

The calculation result in c. shows that the similarity index between NA001 and MA001 is equal to 1. This implies that the key features of NA001 is identical to MA001. Besides, MA001 is perceived as one of the past service activity that can be used to provide solution for NA001. On the other hand, NA001 is only resemble 13\% of MA002. The result shows that only specific features of NA001 are similar to MA002. Likely, MA002 is not part of the retrieved service activities.

\subsubsection{Solution Adaptation and Service Activity Cost Estimation}

In a typical CBR system, past cases are retrieved from a case-base to solve new problems. Usually, when a best case is selected, its solution would be adapted for solving the problem. In this case, prominent differences between the best case and query are identified and then apply formulae or rules that make those differences into account when suggesting a solution. Typically, structural and derivational adaptation can be used in adaptation stage (Watson \& Narir, 1994). For structural adaptation, rules are applied directly to the solutions stored in the cases, whereas derivational 
adaptation requires the application of algorithms, methods or rules to generate original solution to produce a new solution to the current problem. Additionally, this adaptation method also requires planning sequence that original solution must be stored in memory along with the solution.

In this research, conventional adaptation approach is modified by introducing service reference cluster concept (SRC) as discussed in section 6.1.2. Under this concept, a SRC is identified and used to generate cost analyses for solving an activity cost estimation problem. Therefore, instead of adapting the solution contained within the best case, it is used as the triggering factor to retrieve a set similar past service activities for providing a more comprehensive solution to the problem. Based on the information of a SRC, appropriate cost analysis methods and techniques can be applied. In this case, the cost of a direct service activity $A C\left(D C A_{j, k}\right)$ can be calculated by:

$$
A C\left(D S A_{j, k}\right)=D A D R\left(D S A_{j, k}\right) \times A S\left(D S A_{j, k}\right)
$$

Where $\operatorname{DADR}\left(D S A_{j, k}\right)$ refers direct activity cost driver rate for $D S A_{j, k}$ and $A S\left(D S A_{j, k}\right)$ is activity spent (AS) for $D S A_{j, k}$. Besides, the mathematical function of activity-attributed indirect service activity $A C\left(A I S A_{i, j, k}\right)$ is defined as:

$$
A C\left(\operatorname{AISA}_{i, j, k}\right)=\operatorname{IDADR}\left(\operatorname{AISA}_{i, j, k}\right) \times \operatorname{AS}\left(\operatorname{AISA}_{i, j, k}\right)
$$

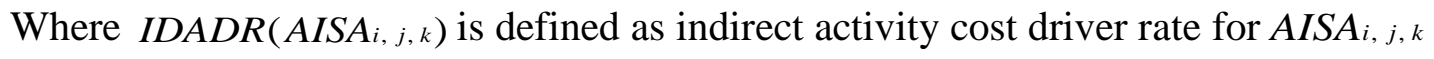
and $A S\left(A I S A_{i, j, k}\right)$ is activity spent (AS) for $A I S A_{i, j, k}$. Lastly, the cost of a serviceattributed indirect service activity $A C\left(S I S A_{l, k}\right)$ can be calculated by:

$$
A C\left(\operatorname{SISA}_{l, k}\right)=\operatorname{IDADR}\left(\operatorname{SISA}_{l, k}\right) \times A S\left(\operatorname{SISA}_{l, k}\right)
$$

Where $\operatorname{IDADR}\left(S I S A_{l, k}\right)$ defined as indirect activity cost driver rate for $S I S A_{l, k}$ and $A S\left(S I S A_{l, k}\right)$ is activity spent (AS) for $S I S A_{l, k}$.

\subsubsection{Revise and Retain of Solution}

Following the adaptation stage, solution evaluation and solution repair are carried out, if required. The evaluation stage is a process to determine the goodness of a proposed 
solution. It is done in the context of previous cases, feedback from the real world or simply based on a mental or real simulation. The evaluation of a solution includes explaining differences, justifying differences, projecting outcomes and ranking alternative possibilities. Information or results obtained from the evaluation can be used as additional information to improve future problem solving. In last step of a CBR cycle, the query is retained in the service activity case-base for future use.

\subsection{Stage Two Cost Estimation: Service Cost Estimation}

In this stage, calculated service activity costs are allocated to relevant services. The total costs of a service the total costs of a service $S C\left(S_{j}\right)$ is equal to the summation of total modular costs $M C\left(m_{n}\right)$ relevant to the service and total service-attributed indirect service activity costs $A C\left(S I S A_{l, k}\right)$ incurred by a service $S_{k}$, where:

$$
S C\left(S_{k}\right)=\sum_{m_{n} \in S_{k}} M C\left(m_{n}\right)+\sum_{S I S A l \in S k} A C\left(S I S A_{l, k}\right)
$$

As the cost of a service module is resulted by the accumulations of direct service activities costs and activity attributed indirect service activities costs, the computation of the service cost can be written as:

$$
S C\left(S_{k}\right)=\sum_{m n \in S k}\left[\sum_{D S A_{j} \in S k} A C\left(D S A_{j, k}\right)+\sum_{A I S A_{i} \in D S A_{j} \in S k} A C\left(A I S A_{i, j, k}\right)\right]+\sum_{S I S A l \in S k} A C\left(S I S A_{l, k}\right)
$$

\subsection{Chapter Summary}

In this chapter, a two-stage cost estimation mechanism based on activity-based costing (ABC) and case-based reasoning (CBR) has been presented. Different from conventional $\mathrm{ABC}$, the cost of a service activity is estimated by using past experiences stored in a service activity case-base without the need of identifying activity cost drivers and cost driver rates which required time consuming and expensive cost calculations and measurements. Apart from that, service reference cluster (SRC) is introduced to improve the accuracy and consistency of activity cost estimations. Instead of adapting the solutions based on a retrieved case, a SRC which consists of a set of similar past service activities is used to generate a more rational and accurate 
activity cost estimates. In this case, the data consists in a SRC can be analysed statistically. Once the service activities costs are calculated, the activities costs are allocated individual services in stage two cost estimation. 


\section{Chapter 7: A Case Study of Aircraft Maintenance Cost Estimation}

This chapter demonstrates the feasibility of proposed cost estimation methodology with a case study related to the maintenance service cost estimation for a family of long range aircraft. In this case study, detailed steps and procedures to estimate the costs for a service family are described. Apart from that, cost analyses are also carried out to show the effectiveness of proposed cost estimation methodology.

\subsection{Introduction of Case Study}

\subsubsection{Background}

In aviation industry, ensuring high level of aircraft reliability and safety are top priorities for airlines. Each year, airlines spend significant amount of financial resources to carry out aircraft maintenance activities. For example, Delta airlines Corporation spent US\$1.8 billion in year 2011 to maintain its 722 aircraft. Besides, Lufthansa AG has spent $€ 1.9$ billion in year 2012 on aircraft maintenance, repair and overhaul activities. Similarly, Singapore Airlines spent SGD\$655 million in year 2015 to maintain its 109 aircraft which consists of various types of aircraft.

According to the forecast reported by International Air Transport Association (IATA)'s 2013 Airline Maintenance Cost Executive Commentary, total aircraft maintenance expenditures will increase from US $\$ 60.7$ billion in year 2013 to US\$89 billion in year 2023. The increasing trend is highly associated with the strong demands that resulted in increasing numbers of aircraft volumes. Based on Airbus's Global Market Forecast 2015-2035, total numbers of aircraft manufactured and delivered to the aircraft operators will be increased from 15,118 in year 2015 to 32,585 by year 2035. Boeing also predicted that, the number of aircraft entering into service will grow from 21,400 in year 2014 to 43,560 by year 2034. The massive increase in aircraft fleet size and aircraft fleet compositions create challenges to airlines in managing aircraft maintenance resources effectively while providing optimal aircraft maintenance to the aircraft. 
For airlines, reducing and eliminating financial wastage due to aircraft maintenance are important factors to achieve effective aircraft maintenance operations in terms of short and long term aircraft maintenance strategies, planning and cost control. For aircraft maintenance service providers, ability to identify cost driving provide factors enable them to optimise productivity and determine competitive priorities. However, this is only achievable with the availability of in-depth understanding on how aircraft maintenance resources are distributed and consumed by the aircraft fleet.

Assuming an airline is reviewing its aircraft maintenance services in one of the aircraft hangars, the objective of this case study is to estimate and analyse costs that are required to carry out periodic maintenance for a fleet of long range aircraft which includes Boeing B777-200ER (12 aircraft), B777-300ER (26 aircraft), B747 (11 aircraft) and Airbus A380 (19 aircraft) by using proposed cost estimation methodology. Historical maintenance cost data of the aircraft have been used in this case study. Results that are obtained from this case study would be used to identify cost driving factors of the maintenance programmes and based on these cost driving factors to improve maintenance productivity and production capacity.

\subsubsection{A Brief Introduction of B777-200ER, B777-300ER, B747 and A380}

Despite the uncertainties in aviation industry and global economy, air travel has grown on an average of five percent annually since 1980s. As the air traffic continues to grow, airlines accommodate the growth of their businesses by increasing airplane capacities and adding more frequencies and nonstop markets to their service networks (Boeing, 2015). In the past 10 years, the number of long-haul city pairs (more than 4,000 miles) has increased by more than 450 routes and the number of long-haul flights has grown by 50 percent. The growth is contributed by strong long-haul travel demands across the world, especially from six largest long-haul travel source markets which include USA, UK, China, Canada, Japan and Germany (ITB Berlin, 2014).

Besides, additions of new and more efficient wide-body aircraft enable airlines to develop new long-haul routes more efficiently. For example, in the 1980s, Boeing 
B747 was the only airplane type that dominates the air travel market between North America to Northeast Asia. Majority of the flights had to make a connection through the West Coast of North America, primarily through Anchorage and very few nonstop from the East Coast. Then, in the 1990s and 2000s, introduction of B777 and B787 families help the airlines to develop new long-haul routes through smaller markets. Many of these new routes connect the major aviation hubs with secondary markets (Boeing, 2015).

According to IATA, long-haul travel can be defined as flights of more than five hours or more. Hence, a long-haul aircraft shall have the capability to cover a flight of more than 5 hours. Typically, long-haul aircraft are wide-body aircraft which are capable of increasing passenger traffic and strengthening the load factors. Over the last few decades, various types of long range aircraft have been developed by aircraft manufacturers. For example, Boeing has developed and manufactured B747, B767, B777 and B787 whereas Airbus has produced long aircraft families that include A330, A340, A350 and A380. These aircraft families provide choices for airlines in developing and customising their long-haul service networks. Among them, B747-400, B777-200ER, B777-300ER and A380 are the most popular long range aircraft that are operated by many airlines due to their superior characteristics over other types of long range aircraft in terms of operating efficiency, passenger capacity and technologies.

Boeing B747-400 is the most popular variant of B747 family. It is developed based on 747-300 with development objectives that include additions of new technologies, increase of range, more efficient engines and a 10 percent decrease in operating costs (Norris \& Wagner, 1999). Since its introduction in the 1980s, a total of 442 aircraft have been manufactured and delivered to airlines around the world (Boeing, 2015). The aircraft is powered by four turbo fan engines and it has the capability to cover a travelling range up to $12,900 \mathrm{~km}$. In terms of cabin capacity, it can accommodate up to 400 passengers with two-class configurations.

Boeing B777 family was designed and developed to compete with McDonnell Douglas MD-11 and airbus A340 in the 1980s. Instead of extending the B767 fuselage 
for more passenger capacity, Boeing decided to design and develop a completely new aircraft model which is wider in fuselage cross-section, fully flexible interior configurations, short to intercontinental range capability and low in operating cost. Since its launch in the 1990s, B777 has provided the capabilities and features for airlines in developing more nonstop routes. The versatility, efficiency and reliability of B777 have made this aircraft family the backbone of many international airlines such as Singapore Airlines, Emirates, Cathay Pacific, British Airways and so on. Today, 35 to 45 percent of long-haul capabilities are serviced by B777.

The B777 aircraft family includes B777-200, B777-300, B777-200ER, B777200LR, B777-300ER and B777 freighter. B777-200ER and B777-300ER are the most popular variants that are used by many international airlines for long-haul flight services. They have contributed about $76 \%$ of total B777 manufactured and delivered by Boeing. In terms of performance and capacities, B777-200ER has a travelling range of up to $13,100 \mathrm{~km}$ and it has a seating capacity of 300 passengers. Meanwhile, a B777$300 \mathrm{ER}$ can travel up to a range of $13,600 \mathrm{~km}$ and it is capable of lifting close to 400 passengers.

The airbus A380 was designed to challenge the dominance of Boeing B747 aircraft family back in the 1990s. The design of A380 targets a 15-20 percent reduction in operating costs over the existing Boeing 747-400. The A380 design converged on a double-decker layout that enables more passenger volume than a traditional singledeck design. The design is in line with hub and spoke theory as opposed to the point to point theory with Boeing B777 (Flight Global, 1995). A380 is the world's largest passenger airliner that required specialised airport equipment for its operations. It has a maximum travelling range of $15,200 \mathrm{~km}$ and a seating capacity that can accommodate 544 to 853 passengers.

Apart from superior travelling and seating capacities, A380 design also uses some of the most advanced material technologies that make it a highly efficient aircraft. For instance, the A380 uses glass laminate reinforced epoxy (Glare ${ }^{\mathrm{TM}}$ ) in making the pressurised fuselage's upper and lateral shells. It is a type of laminate that incorporates 
alternate layers of aluminium alloy and glass fibre reinforced adhesive. The use of this material in making the fuselage of the aircraft is able to reduce the weight of the aircraft significantly and provide very good fatigue and damage resistance characteristics (Airbus, 2015). Based on the advanced material technologies, the reduction of weights by 25 percent makes A380 a more efficient and greener aircraft. Apart from that, Airbus also introduces brake to vacate technology on A380 which allows the flight crew to manage the approach and landing and to pre-select the optimum runway exit more effectively. The introduction of this technology reduces the occupancy time by up to 30 percent and significantly increase the number of aircraft that can be handled by the airports (Airbus, 2015).

\subsection{Formation of Long Range Aircraft Maintenance Service Family}

\subsubsection{Commonality Analysis of Services}

To find out the suitability of B777-200ER, B777-300ER, B747-400 and A380 maintenance services to form a maintenance service family, general characteristics of the aircraft are identified as shown in Table 7.1. For instance, the selected aircraft families are designed and developed to provide long-haul flight of more than $12,000 \mathrm{~km}$ or 6 hours of continuous flight. Another important feature is that, these aircraft are fitted with modern turbofan engines to provide the thrust. Even though these aircraft are different in terms of aircraft manufacturers and design, these jetliners are only required two flight crews to pilot the aircraft.

Table 7.1 General characteristics of B777-200ER, B777-300ER, B747-400 and A380

\begin{tabular}{|l|c|c|c|c|}
\hline \multicolumn{1}{|c|}{ Characteristics } & B777-200ER & B777-300ER & B747-400 & A380 \\
\hline Long-haul flight service & $\sqrt{ }$ & $\sqrt{ }$ & $\sqrt{ }$ & $\sqrt{ }$ \\
\hline Fixed wing aircraft & $\sqrt{ }$ & $\sqrt{ }$ & $\sqrt{ }$ & $\sqrt{ }$ \\
\hline Turbofan engine & $\sqrt{ }$ & $\sqrt{ }$ & $\sqrt{ }$ & $\sqrt{ }$ \\
\hline Service range $>12,000 \mathrm{~km}$ & $\sqrt{ }$ & $\sqrt{ }$ & $\sqrt{ }$ \\
\hline Three class configurations & $\sqrt{ }$ & $\sqrt{ }$ & & $\sqrt{ }$ \\
\hline Two flight crews & $\sqrt{ }$ & $\sqrt{ }$ & $\sqrt{ }$ \\
\hline Single deck cabin & $\sqrt{ }$ & & & $\sqrt{ }$ \\
\hline Double deck cabin & & &
\end{tabular}


Subsequently, the similarity of the aircraft is assessed by calculating total constant commonality index (TCCI) as defined in equation 1. From Table 7.1, there are four distinctive characteristics of the aircraft, where $d=4$. Besides, total summation of aircraft characteristics $\Phi_{y}$ is equal to 28 . The calculation of TCCI for the aircraft services is shown below:

$$
\begin{aligned}
\text { TCCI } & =1-\frac{d-1}{\sum_{y=1}^{d} \Phi_{y}-1} \\
\text { TCCI } & =1-\frac{(4-1)}{(28-1)} \\
& =1-\frac{3}{27} \\
& =0.89
\end{aligned}
$$

Based on the computation result, it is found that $89 \%$ of the characteristics of the aircraft are found to be common. Therefore, it is concluded that B777-200ER, B777300ER, B747-400 and A380 maintenance services are able to form a maintenance service family. In this case, $S F_{\text {Long_Range }}$ is consisted of A380 maintenance service $S_{A 380 \text {, }}$ 747-400 maintenance service $S_{747-400,}$ 777-300ER maintenance service $S_{773 E R}$ and 777200ER maintenance service $S_{772 E R}$

\subsubsection{Identification of Service Activities for $\boldsymbol{S F}_{\text {Long_Range }}$}

Aircraft maintenance is highly regularised by aviation authorities such as Federal Aviation Administration (FAA), European Aviation Safety (EASA), International Civil Aviation Organisation (ICAO) and International Air Transport Association (IATA) to ensure high level of aviation safety. In order to sustain civil aviation services, an aircraft must obtain its airworthiness from the aviation authorities. According to the definition defined by Civil Aviation Authority of Singapore (CAAS), an aircraft shall not be flown unless there is a valid Certificate of Airworthiness, issued or rendered valid under the law of the country in which the aircraft was registered. The issuance of Certificate of Airworthiness is dependent on evidence being provided that the 
aircraft complies with the appropriate airworthiness requirements and is airworthy. And, optimal and approved maintenance works performed on an aircraft are primary requirements.

According to FAA's FAR 25.1529 Appendix H. Periodic (scheduled) and EASA's certification specification CS25.1529, aircraft and engine manufacturers are required to develop a set of maintenance procedures (activities) for airlines and aircraft operators to sustain its airworthiness. The maintenance planning document (MPD) provides maintenance planning information necessary for the aircraft operator to develop scheduled maintenance programmes. This document lists out all aircraft manufacturer recommended schedule maintenance tasks that enable the aircraft to be continued airworthy for civil aviation services. Apart from MPD, aircraft maintenance manual (AMM) is used extensively during aircraft maintenance as this document provides detail steps and procedures to carry out maintenance activities that are listed in the MPD. Besides, this document also provides information such as equipment, tools and materials to maintain the aircraft.

Thus, instead of using activity diagrams, service activities of the maintenance services are identified based on maintenance planning document (MPD) and aircraft maintenance manual (AMM) of the aircraft. In this case, a total of 1327 maintenance activities are identified. About $87.7 \%$ of total service activities are classified as direct service activities and 155 indirect service activities are incurred due to direct service activities. At service level, a total of eight indirect service activities are identified to support the accomplishments of the services. 
Table 7.2 Classification of identified service activities

\begin{tabular}{|c|c|c|c|}
\cline { 2 - 4 } \multicolumn{1}{c|}{} & \multicolumn{3}{|c|}{ No. of activities } \\
\hline \multirow{2}{*}{ Service } & $\begin{array}{c}\text { Indirect Service Activities (ISA) } \\
\text { Direct Service } \\
\text { Activity (DSA) }\end{array}$ & $\begin{array}{c}\text { Activity- } \\
\text { Attributed } \\
\text { Service Activities } \\
\text { (AISA) }\end{array}$ & $\begin{array}{c}\text { Service- } \\
\text { Attributed } \\
\text { Service Activities } \\
\text { (SISA) }\end{array}$ \\
\hline S $_{\text {A380 }}$ & 151 & 38 & 2 \\
S $_{747}$ & 389 & 61 & 2 \\
S772ER $_{773 E R}$ & 293 & 20 & 2 \\
S $_{773 E}$ & 331 & 36 & 2 \\
\hline
\end{tabular}

\subsection{Modularisation of $S_{F_{\text {Long_Range }}}$}

\subsubsection{Decomposition of $S F_{\text {Long_Range }}$ and Identification of Service Modules}

An aircraft is the combination of a set of interacting systems that enable the aircraft to perform a particular role or a set of roles (Moir \& Seabridge, 2012). These systems are designed to meet stringent design specifications such as low mass, lower power consumption, high performance, high accuracy, high integrity and availability and low cost. More importantly, these systems must meet stringent safety requirements. Typically, the major components of an aircraft include wings, horizontal tail, vertical tail, fuselage, propulsion system, landing gear, navigation and communication system, and control surfaces (Sadraey, 2013).

For example, the fuselage is the main structure or body of a fixed-wing aircraft. Its main function is to accommodate the payloads which include passengers, cargo, luggage, and other useful loads. Apart from that, it is also to provide space for the pilot, crew members, fuel tanks and engines. Structurally, the fuselage provides a moment arm to the horizontal and vertical tail where it plays an influential role in longitudinal and directional stability and control of the aircraft. The wings are airfoils that create lift when moved rapidly through the air. They are built in many shapes and sizes so that certain desirable flight characteristics can be achieved. Control at various operating speeds, the amount of lift generated, balance, and the stability all changes as 
the shape of the wing is altered. The wing is an essential component in providing the aircraft lateral stability, which is fundamentally significant for flight safety.

From the perspective of aviation safety, an aircraft must achieve continued airworthiness in order to continually provide flight services, and implementing aircraft maintenance in accordance to aircraft maintenance planning data and maintenance manual developed by aircraft manufacturer is one of the pre-requisite requirements to be fulfilled. In these maintenance documents, maintenance service activities are outlined to perform maintenance for all the functional system and physical structures of the aircraft (Figure 7.1).

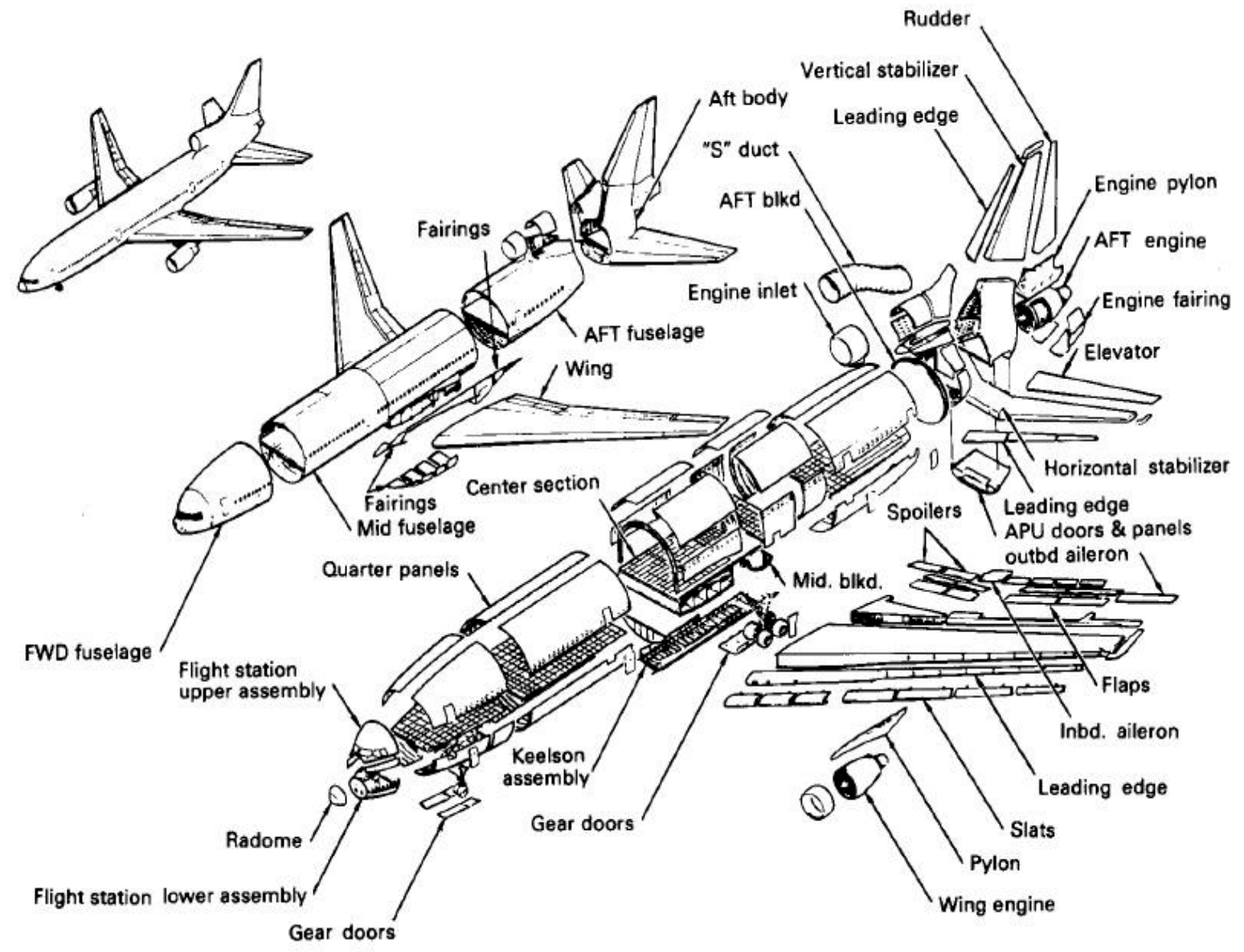

Figure 7.1 Structural components of commercial airliners (Niu, 1999) 
By assuming the long range aircraft maintenance service family $S F_{\text {Long_Range }}$ as a service delivery system, it is decomposable into a set of functional and physical elements as shown in Table 7.3. For example, the landing gear system of A380 can be physically decomposed into a set of sub-systems such as wing landing gears, body landing gears and nose landing gear. In term of service function, the maintenance of landing system can be separated into wing landing gears maintenance, body landing gears maintenance, nose landing gear maintenance and main body landing gears maintenance (B777-200ERand B777-300ER only). These functional and physical elements are subsequently mapped into a function-structure diagram for identification of service modules. By combining some of the elements, a total of 10 maintenance zones or service modules are identified. These modules include landing gear module $\left(\mathrm{m}_{\mathrm{LG}}\right)$, engine module ( $\left.\mathrm{m}_{\text {Engine}}\right)$, wing module ( $\left.\mathrm{m}_{\text {Wing }}\right)$, fuselage module (mFuselage), cockpit module (mCockpit), cabin module (m Cabin), cargo module (mCargo), auxiliary power unit (APU) module (m $\left.\mathrm{m}_{\mathrm{APU}}\right)$, empennage module (mEmpennage) and main equipment compartment (MEC) module (mMEC). 
Table 7.3 Major physical and functional elements of A380, 747-400, 777-200ER and 777-300ER

\begin{tabular}{|c|c|c|c|c|c|c|}
\hline $\begin{array}{l}\text { Major Physical } \\
\text { Elements }\end{array}$ & Low Level Service Function & Sub-Service Function & A380 & $\begin{array}{l}747- \\
400\end{array}$ & $\begin{array}{c}\text { 777- } \\
\text { 200ER }\end{array}$ & $\begin{array}{l}\text { 777- } \\
\text { 200ER }\end{array}$ \\
\hline $\begin{array}{l}\text { Forward cargo } \\
\text { compartment }\end{array}$ & $\begin{array}{l}\text { Forward cargo compartment } \\
\text { maintenance }\end{array}$ & $\begin{array}{l}\text { Cargo compartment } \\
\text { maintenance }\end{array}$ & $\sqrt{ }$ & $\sqrt{ }$ & $\sqrt{ }$ & $\sqrt{ }$ \\
\hline $\begin{array}{l}\text { AFT cargo } \\
\text { compartment }\end{array}$ & $\begin{array}{l}\text { AFT cargo compartment } \\
\text { maintenance }\end{array}$ & $\begin{array}{l}\text { Cargo compartment } \\
\text { maintenance }\end{array}$ & $\sqrt{ }$ & $\sqrt{ }$ & $\sqrt{ }$ & $\sqrt{ }$ \\
\hline $\begin{array}{l}\text { Passenger } \\
\text { compartment } \\
\text { doors }\end{array}$ & $\begin{array}{l}\text { Passenger compartment door } \\
\text { maintenance }\end{array}$ & Aircraft door maintenance & $\sqrt{ }$ & $\sqrt{ }$ & $\sqrt{ }$ & $\sqrt{ }$ \\
\hline $\begin{array}{l}\text { Cargo } \\
\text { compartment } \\
\text { doors }\end{array}$ & $\begin{array}{l}\text { Cargo compartment door } \\
\text { maintenance }\end{array}$ & Aircraft door maintenance & $\sqrt{ }$ & $\sqrt{ }$ & $\sqrt{ }$ & $\sqrt{ }$ \\
\hline $\begin{array}{l}\text { Wing landing } \\
\text { gears }\end{array}$ & Wing landing gears maintenance & Landing gear maintenance & $\sqrt{ }$ & $\sqrt{ }$ & & \\
\hline $\begin{array}{l}\text { Body landing } \\
\text { gears }\end{array}$ & Body landing gears maintenance & Landing gear maintenance & $\sqrt{ }$ & $\sqrt{ }$ & & \\
\hline $\begin{array}{l}\text { Nose landing } \\
\text { gear }\end{array}$ & Nose landing gear maintenance & Landing gear maintenance & $\sqrt{ }$ & $\sqrt{ }$ & $\sqrt{ }$ & $\sqrt{ }$ \\
\hline $\begin{array}{l}\text { Main Landing } \\
\text { gears }\end{array}$ & Main landing gears maintenance & Landing gear maintenance & & & $\sqrt{ }$ & $\sqrt{ }$ \\
\hline $\begin{array}{l}\text { Auxiliary power } \\
\text { unit (APU) }\end{array}$ & APU maintenance & APU maintenance & $\sqrt{ }$ & $\sqrt{ }$ & $\sqrt{ }$ & $\sqrt{ }$ \\
\hline APU doors & APU door maintenance & Aircraft door maintenance & $\sqrt{ }$ & $\sqrt{ }$ & $\sqrt{ }$ & $\sqrt{ }$ \\
\hline Engine & Power plant maintenance & Power plant maintenance & $\sqrt{ }$ & $\sqrt{ }$ & $\sqrt{ }$ & $\sqrt{ }$ \\
\hline Nacelle & Nacelle assembly maintenance & $\begin{array}{l}\text { Nacelle assembly } \\
\text { maintenance }\end{array}$ & $\sqrt{ }$ & $\sqrt{ }$ & $\sqrt{ }$ & $\sqrt{ }$ \\
\hline $\begin{array}{l}\text { Air inlet cowl } \\
\text { assembly }\end{array}$ & $\begin{array}{l}\text { Air inlet cowl assembly } \\
\text { maintenance }\end{array}$ & Exhaust system maintenance & $\sqrt{ }$ & $\sqrt{ }$ & $\sqrt{ }$ & $\sqrt{ }$ \\
\hline $\begin{array}{l}\text { Fan cowl } \\
\text { assembly }\end{array}$ & Fan cowl assembly maintenance & Exhaust system maintenance & $\sqrt{ }$ & $\sqrt{ }$ & $\sqrt{ }$ & $\sqrt{ }$ \\
\hline Thrust reverser & $\begin{array}{l}\text { Thrust reverser system } \\
\text { maintenance }\end{array}$ & Exhaust system maintenance & $\sqrt{ }$ & $\sqrt{ }$ & $\sqrt{ }$ & $\sqrt{ }$ \\
\hline Exhaust system & Exhaust system maintenance & Exhaust system maintenance & $\sqrt{ }$ & $\sqrt{ }$ & $\sqrt{ }$ & $\sqrt{ }$ \\
\hline Fan exhaust cowl & $\begin{array}{l}\text { Fan exhaust cowl assembly } \\
\text { maintenance }\end{array}$ & Exhaust system maintenance & $\sqrt{ }$ & $\sqrt{ }$ & $\sqrt{ }$ & $\sqrt{ }$ \\
\hline Passenger cabin & $\begin{array}{l}\text { Passenger compartment } \\
\text { maintenance }\end{array}$ & Fuselage maintenance & $\sqrt{ }$ & $\sqrt{ }$ & $\sqrt{ }$ & $\sqrt{ }$ \\
\hline Rudder & Rudder system maintenance & Flight controls maintenance & $\sqrt{ }$ & $\sqrt{ }$ & $\sqrt{ }$ & $\sqrt{ }$ \\
\hline Elevators & Elevators system maintenance & Flight controls maintenance & $\sqrt{ }$ & $\sqrt{ }$ & $\sqrt{ }$ & $\sqrt{ }$ \\
\hline Wings & $\begin{array}{l}\text { Wing structure assembly } \\
\text { maintenance }\end{array}$ & $\begin{array}{l}\text { Wings structural } \\
\text { maintenance }\end{array}$ & $\sqrt{ }$ & $\sqrt{ }$ & $\sqrt{ }$ & $\sqrt{ }$ \\
\hline $\begin{array}{l}\text { Cabin crew rest } \\
\text { compartments }\end{array}$ & $\begin{array}{l}\text { Passenger compartment } \\
\text { maintenance }\end{array}$ & Fuselage maintenance & $\sqrt{ }$ & $\sqrt{ }$ & $\sqrt{ }$ & $\sqrt{ }$ \\
\hline Ailerons & Ailerons system maintenance & Flight controls maintenance & $\sqrt{ }$ & $\sqrt{ }$ & $\sqrt{ }$ & $\sqrt{ }$ \\
\hline Flaps & Flaps system maintenance & Flight controls maintenance & $\sqrt{ }$ & $\sqrt{ }$ & $\sqrt{ }$ & $\sqrt{ }$ \\
\hline Spoilers & Spoilers system maintenance & Flight controls maintenance & $\sqrt{ }$ & $\sqrt{ }$ & $\sqrt{ }$ & $\sqrt{ }$ \\
\hline Slats & Slats system maintenance & Flight controls maintenance & $\sqrt{ }$ & $\sqrt{ }$ & $\sqrt{ }$ & $\sqrt{ }$ \\
\hline $\begin{array}{l}\text { Horizontal } \\
\text { stabiliser }\end{array}$ & $\begin{array}{l}\text { Horizontal stabilizer structural } \\
\text { and system maintenance }\end{array}$ & Stabilisers maintenance & $\sqrt{ }$ & $\sqrt{ }$ & $\sqrt{ }$ & $\sqrt{ }$ \\
\hline Vertical stabiliser & $\begin{array}{l}\text { Vertical stabilizer structural and } \\
\text { system maintenance }\end{array}$ & Stabilisers maintenance & $\sqrt{ }$ & $\sqrt{ }$ & $\sqrt{ }$ & $\sqrt{ }$ \\
\hline $\begin{array}{l}\text { Leading edge } \\
\text { flaps }\end{array}$ & $\begin{array}{l}\text { Leading edge flaps system } \\
\text { maintenance }\end{array}$ & Flight controls maintenance & $\sqrt{ }$ & $\sqrt{ }$ & $\sqrt{ }$ & $\sqrt{ }$ \\
\hline $\begin{array}{l}\text { Main equipment } \\
\text { centre }\end{array}$ & $\begin{array}{l}\text { Main equipment centre } \\
\text { maintenance }\end{array}$ & Fuselage maintenance & $\sqrt{ }$ & $\sqrt{ }$ & $\sqrt{ }$ & $\sqrt{ }$ \\
\hline Cockpit & Flight compartment maintenance & Fuselage maintenance & $\sqrt{ }$ & $\sqrt{ }$ & $\sqrt{ }$ & $\sqrt{ }$ \\
\hline
\end{tabular}




\subsubsection{Characterisations of Activity-Module Relationships}

Once the service modules are defined, identified service activities of each service are mapped to relevant service modules by using an activity mapping mechanism which is composed of two parts. First, in order to map the service activities to relevant service modules, the relationships between service activities and service modules are first characterised. This is accomplished by identifying both functional and physical characteristics of a pair of service activity and service module. Using $D S A_{32,772 E R}$ (lubrication of inboard no.4 flap support mechanism) and $m_{\text {Wing }}$ (wing module) in the case study as example, functional and physical characteristics for this pair of service activity and service module are identified as shown in Figure 7.2a and 7.2b.
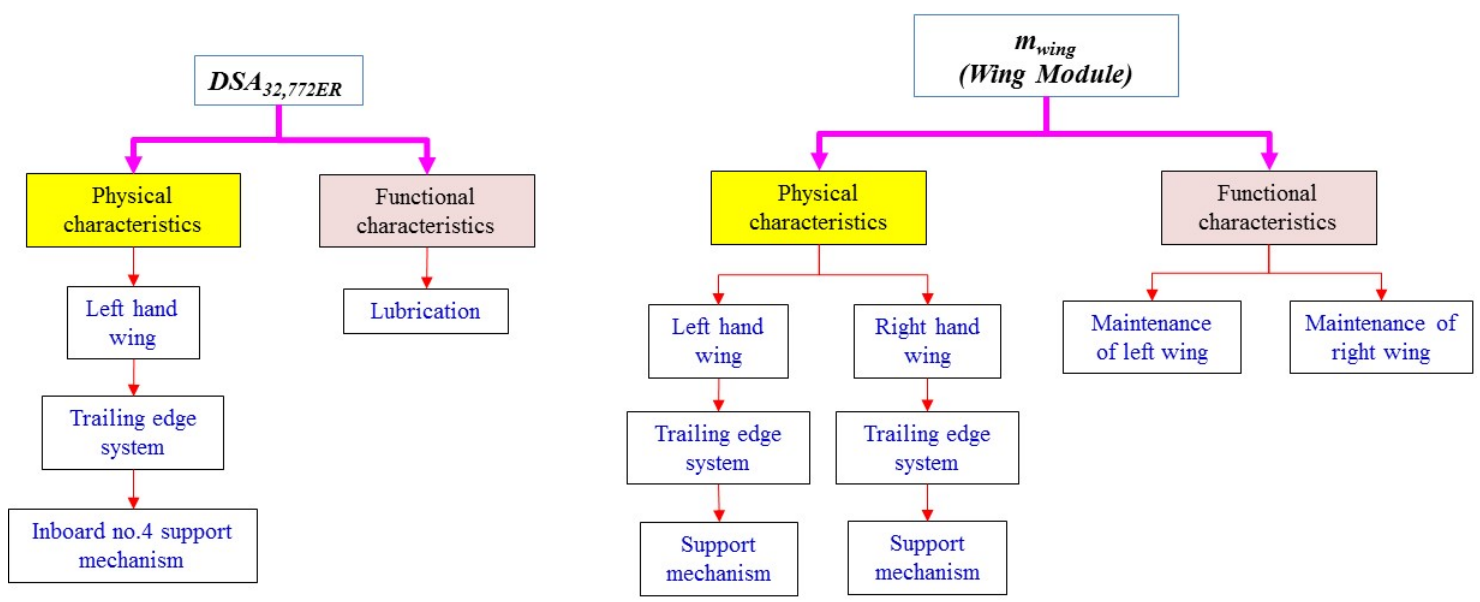

Figure 7.2a Characteristics of $D S A_{32,772 E R}$

Figure 7.2b Characteristics of $\boldsymbol{m}_{\text {Wing }}$

Subsequently, by comparing these characteristics, degree of relevance for each pair of service activity and service module is measured quantitatively with a relation scale (3 - strong relation, 1 - weak relation, 0 - no relation) that translate the comparison results into numerical values. The results of comparisons are retained in an activity-module relation module. Table 7.4 shows the examples of relations scores obtained for the case study which are recorded in an activity-module relation matrix. Taking $D S A_{4, A 380}$ and $D S A_{5, A 380}$ as examples, both activities show strong relation with cockpit module (mCockpit), while these activities have no relation with other service modules. 
Table 7.4 Examples of relation scores for $\boldsymbol{S F}_{\text {Long_Range }}$

\begin{tabular}{|c|c|c|c|c|c|c|c|c|c|c|}
\hline \multirow{2}{*}{ Service Activity } & \multicolumn{10}{|c|}{$\begin{array}{c}\text { Degree of Relevance } \\
\text { (3-Strong Relation, 1- Weak Relation, } 0 \text { - No Relation) }\end{array}$} \\
\hline & $\mathbf{m}_{\text {Engine }}$ & $\mathbf{m}_{\mathrm{LG}}$ & $\mathbf{m}_{\text {Cockpit }}$ & $\mathbf{m}_{\text {Wing }}$ & $\mathbf{m}_{\text {empennage }}$ & $\mathbf{m}_{\text {Cabin }}$ & $\mathbf{m}_{\mathrm{APU}}$ & $\mathbf{m}_{\text {Fuselage }}$ & $\mathbf{m}_{\text {Cargo }}$ & $\mathbf{m}_{\mathrm{MEC}}$ \\
\hline $\mathrm{DSA}_{4, \mathrm{~A} 380}$ & 0 & 0 & 3 & 0 & 0 & 0 & 0 & 0 & 0 & 0 \\
\hline $\mathrm{DSA}_{5, \mathrm{~A} 380}$ & 0 & 0 & 3 & 0 & 0 & 0 & 0 & 0 & 0 & 0 \\
\hline $\mathrm{DSA}_{50, \mathrm{~A} 380}$ & 0 & 0 & 0 & 0 & 0 & 0 & 0 & 3 & 0 & 0 \\
\hline $\mathrm{DSA}_{12,773 \mathrm{ER}}$ & 3 & 0 & 0 & 0 & 0 & 0 & 0 & 0 & 0 & 0 \\
\hline DSA $_{56,773 E R}$ & 3 & 0 & 0 & 0 & 0 & 0 & 0 & 0 & 0 & 0 \\
\hline $\mathrm{DSA}_{132,773 \mathrm{ER}}$ & 0 & 0 & 3 & 0 & 0 & 0 & 0 & 0 & 0 & 0 \\
\hline $\mathrm{DSA}_{296,773 \mathrm{ER}}$ & 0 & 3 & 0 & 0 & 0 & 0 & 0 & 0 & 0 & 0 \\
\hline DSA $_{297,773 E R}$ & 0 & 0 & 3 & 0 & 0 & 0 & 0 & 0 & 0 & 0 \\
\hline DSA $_{51,772 \mathrm{ER}}$ & 0 & 0 & 0 & 0 & 0 & 3 & 0 & 0 & 0 & 0 \\
\hline $\mathrm{DSA}_{52,772 \mathrm{ER}}$ & 0 & 0 & 0 & 0 & 0 & 3 & 0 & 0 & 0 & 0 \\
\hline $\mathrm{DSA}_{88,772 \mathrm{ER}}$ & 0 & 0 & 3 & 0 & 0 & 0 & 0 & 0 & 0 & 0 \\
\hline $\mathrm{DSA}_{89,772 \mathrm{ER}}$ & 0 & 0 & 3 & 0 & 0 & 0 & 0 & 0 & 0 & 0 \\
\hline DSA $_{152,772 E R}$ & 0 & 0 & 0 & 3 & 0 & 0 & 0 & 0 & 0 & 0 \\
\hline $\mathrm{DSA}_{153,772 \mathrm{ER}}$ & 0 & 0 & 0 & 3 & 0 & 0 & 0 & 0 & 0 & 0 \\
\hline DSA $_{269,772 E R}$ & 0 & 0 & 0 & 0 & 0 & 3 & 0 & 0 & 0 & 0 \\
\hline $\mathrm{DSA}_{270,772 \mathrm{ER}}$ & 0 & 0 & 0 & 0 & 0 & 3 & 0 & 0 & 0 & 0 \\
\hline $\mathrm{DSA}_{39,747}$ & 0 & 0 & 0 & 0 & 0 & 0 & 0 & 3 & 0 & 0 \\
\hline DSA $_{146,747}$ & 3 & 0 & 0 & 0 & 0 & 0 & 0 & 0 & 0 & 0 \\
\hline $\mathrm{DSA}_{264,747}$ & 3 & 0 & 0 & 0 & 0 & 0 & 0 & 0 & 0 & 0 \\
\hline
\end{tabular}

\subsubsection{Activity Mapping}

A numerical illustration is discussed in this section to demonstrate the process of activity mapping by employing $k$-mean clustering algorithm as defined in Equation 5. From activity-module relation matrix, $D S A_{52,773 E R}, D S A_{52,772 E R}, D S A_{6, A 380}, D S A_{32,747}$, $D S A_{77,747}, D S A_{237,772 E R}, D S A_{60, A 380}, D S A_{73,773 E R}, D S A_{156,773 E R}$ and $D S A_{64,747}$ are selected as initial centroids of the service modules. Following that, Euclidean distances 
between the service activities and centroids are calculated. An example to demonstrate the calculation of the Euclidean distance between $D S A_{1, A 380}$ and $\mu\left(m_{L G}\right)$ is shown below:

a. Given the initial centroids and its data points:

$$
\begin{aligned}
& \mu\left(m_{\text {Engine }}\right)=D S A_{52,773 E R}=(3,0,0,0,0,0,0,0,0,0) \\
& \mu\left(m_{L G}\right)=D S A_{52,772 E R}=(0,3,0,0,0,0,0,0,0,0) \\
& \mu\left(m_{\text {Cockpit }}\right)=D S A_{6, A 380}=(0,0,3,0,0,0,0,0,0,0) \\
& \mu\left(m_{\text {Wing }}\right)=D S A_{32,747}=(0,0,0,3,0,0,0,0,0,0) \\
& \mu\left(m_{\text {Empennage }}\right)=D S A_{77,747}=(0,0,0,0,3,0,0,0,0,0) \\
& \mu\left(m_{\text {Cabin }}\right)=\operatorname{DSA}_{237,772 E R}=(0,0,0,0,0,3,0,0,0,0) \\
& \mu\left(m_{\text {APU }}\right)=D S A_{60, A 380}=(0,0,0,0,0,0,3,0,0,0) \\
& \mu\left(m_{\text {Fuselage }}\right)=\operatorname{DSA}_{73,773 E R}=(0,0,0,0,0,0,0,3,0,0) \\
& \mu\left(m_{\text {Cargo }}\right)=\operatorname{DSA}_{156,773 \mathrm{ER}}=(0,0,0,0,0,0,0,3,0) \\
& \mu\left(m_{M E C}\right)=\operatorname{DSA}_{64,747}=(0,0,0,0,0,0,0,0,0,3)
\end{aligned}
$$

b. And, given $D S A_{1, A 380}=(0,0,0,3,0,0,0,0,0,0)$, Euclidean distance between $D S A_{1, A 380}$ and $\mu\left(m_{L G}\right)$ is calculated:

$$
\begin{aligned}
d\left(D_{\left.S A_{1, A 380}, \mu\left(m_{L G}\right)\right)^{2}=}\right. & (0-0)^{2}+(0-3)^{2}+(0-0)^{2}+(3-0)^{2}+(0-0)^{2}+(0-0)^{2}+(0-0)^{2} \\
& +(0-0)^{2}+(0-0)^{2}+(0-0)^{2} \\
= & 0+9+0+9+0+0+0+0+0+0 \\
= & 18 \\
d\left(D_{S A}, A 380, \mu\left(m_{L G}\right)\right)= & \sqrt{ } 18 \\
= & 4.243
\end{aligned}
$$

The computation procedures are repeated between $D S A_{1, A 380}$ and other centroids, where $d\left(D S A_{1, A 380}, \mu\left(m_{\text {Engine }}\right)=4.243, d\left(D S A_{1, A 380}, \mu\left(m_{\text {Cockpit }}\right)=4.243, d\left(D S A_{1, A 380}\right.\right.\right.$, $\mu\left(m_{\text {Wing }}\right)=0, \quad d\left(D S A_{1, A 380}, \quad \mu\left(m_{\text {Empennage }}\right)=4.243, \quad d\left(D S A_{1, A 380}, \quad \mu\left(m_{\text {Cabin }}\right)=4.243\right.\right.$, $d\left(D S A_{1, A 380,}\right.$

$\mu\left(m_{A P U}\right)=4.243, d\left(D S A_{1, A 380}, \mu\left(m_{\text {Fuselage }}\right)=4.243, d\left(D S A_{1, A 380}, \mu\left(m_{\text {Cargo }}\right)=4.243 \quad\right.\right.$ and 
$d\left(D S A_{1, A 380}, \mu\left(m_{M E C}\right)=4.243\right.$. Since the distance between $D S A_{1, A 380}$ and $\mu\left(m_{\text {Wing }}\right)$ is the shortest, this activity is assigned to wing module $\left(m_{\text {Wing }}\right)$. By repeating similar calculation procedures, Euclidean distances for other service activities are calculated.

When the service activities are fully assigned to the service modules, a validation of these assignments is required, and the validation is accomplished by calculating the Euclidean distances between the assigned activities and centroids of the activity clusters. The centroids of the activity clusters are identified by averaging the data points of assigned service activities. Using main equipment center module (mMEC) as an example, the process to calculate the coordinates of the centroid is presented:

Based on initial activity clustering iteration, a total of 11 service activities are assigned to main equipment center module (mMEC) where:

$$
\begin{aligned}
\mu\left(m_{M E C}\right)= & \left(D S A_{23, A 380}, D S A_{31,773 E R}, D S A_{179,773 E R}, D S A_{257,773 E R}, D S A_{71,772 E R}\right. \\
& \left.D S A_{105,772 E R}, D S A_{60,747}, D S A_{64,747}, D S A_{116,747}, D S A_{253,747}, D S A_{257,747}\right)
\end{aligned}
$$

The data points of assigned service activities are averaged:

$$
\mu\left(m_{M E C}\right)=((0+0+0+0+0+0+0+0+0+0+0) / 11),(0+0+0+0+0+0+0+0+0+0+0) /
$$

11),

$$
\begin{gathered}
(0+0+0+0+0+0+0+0+0+0+0) / 11), \\
(0+0+0+0+0+0+0+0+0+0+0) / 11), \\
(0+0+0+0+0+0+0+0+0+0+0) / 11), \\
(0+0+0+0+0+0+0+0+0+0+0) / 11), \\
(0+0+0+0+0+0+0+0+0+0+0) / 11), \\
(3+3+3+3+3+3+3+3+3+3+3) / 11)) \\
=(0,0,0,0,0,0,0,0,0,3)
\end{gathered}
$$

Based on the new set of centroids, Euclidean distances between the centroids and the service activities are recalculated. As there is no further changes or reassignments 
of service activities, further iteration of activity clustering process is not required. Besides, using the equation defined in equation 5 , the value of error function $E=0$. This indicates that the assignments of service activities are accurate.

\subsection{Activity Cost Estimation of Long Range Aircraft Maintenance Service Family}

\subsubsection{Creation of Long Range Aircraft Maintenance Service Activity Case-Base}

In this case study, two years of past experiences are collected from 134 periodic maintenance services related to B747-400, B777-200ER, B777-300ER and A380, and a total of 23,669 past service activities have been identified from these maintenance services. Subsequently, indexing is carried out to assign features to these past service activities. For ease of indexing, each activity is assigned with a maximum of six features $(f)$ to represent the maintenance and physical functions of the activity. Each feature is then assigned with appropriate attributes and service codes.

For example, Table 7.5 shows an indexed past service activity (Activity ID - HA00001) which is represented by five activity features. In this particular example, the objective of this activity is to perform functional check on the torque limits of engine number one integrated driver generator (IDG)'s QAD coupling. By assigning indexes to this activity, maintenance information is retained in a simplified way and it is readable by the retrieval mechanism. Apart from readable information, this past case also retain some critical information such as activity applicability, details of activity and cost information. When the indexes are assigned to all the past cases, they are organised into a flat structure as shown in Table 7.6. 
Table 7.5 Example of indexed past service activity

\begin{tabular}{|c|c|c|}
\hline \multicolumn{3}{|l|}{ Activity Case ID: HA-00001 } \\
\hline \multicolumn{3}{|l|}{ SRC ID: SRC-001 } \\
\hline \multicolumn{3}{|c|}{ Activity Description: CAD-(ETOPS) IDG QAD COUPLING-ENGINE \#1 } \\
\hline \multicolumn{3}{|l|}{ Activity Applicability: B777-300ER } \\
\hline \multicolumn{3}{|l|}{ Direct Maintenance Cost } \\
\hline 1. Maintenance Labour & $\$ 132.22$ & \\
\hline 2. Maintenance Material & $\$ 0.00$ & \\
\hline Features $(f)$ & Attribute (a) & Value (v) \\
\hline 1. Main Function & Function Check & 6 \\
\hline 2. Sub-function 1 & Torque limits & 70 \\
\hline 3. Sub-function 2 & & \\
\hline 4. Physical Function - Main System & Engine 1 & 13 \\
\hline 5. Physical Function - Sub-system & Generator drive system & 105 \\
\hline 6. Physical Function - Component & IDG QAD coupling & 256 \\
\hline
\end{tabular}

Besides, to facilitate the process of case indexing and case retrieving, attributes and service codes that are assigned to the past cases are stored in a feature library. The main function of this feature library is to serve as references for the user in assigning appropriate features and service codes to a past service activity or a new query. Table 7.7 shows the examples of activity features and service codes. 


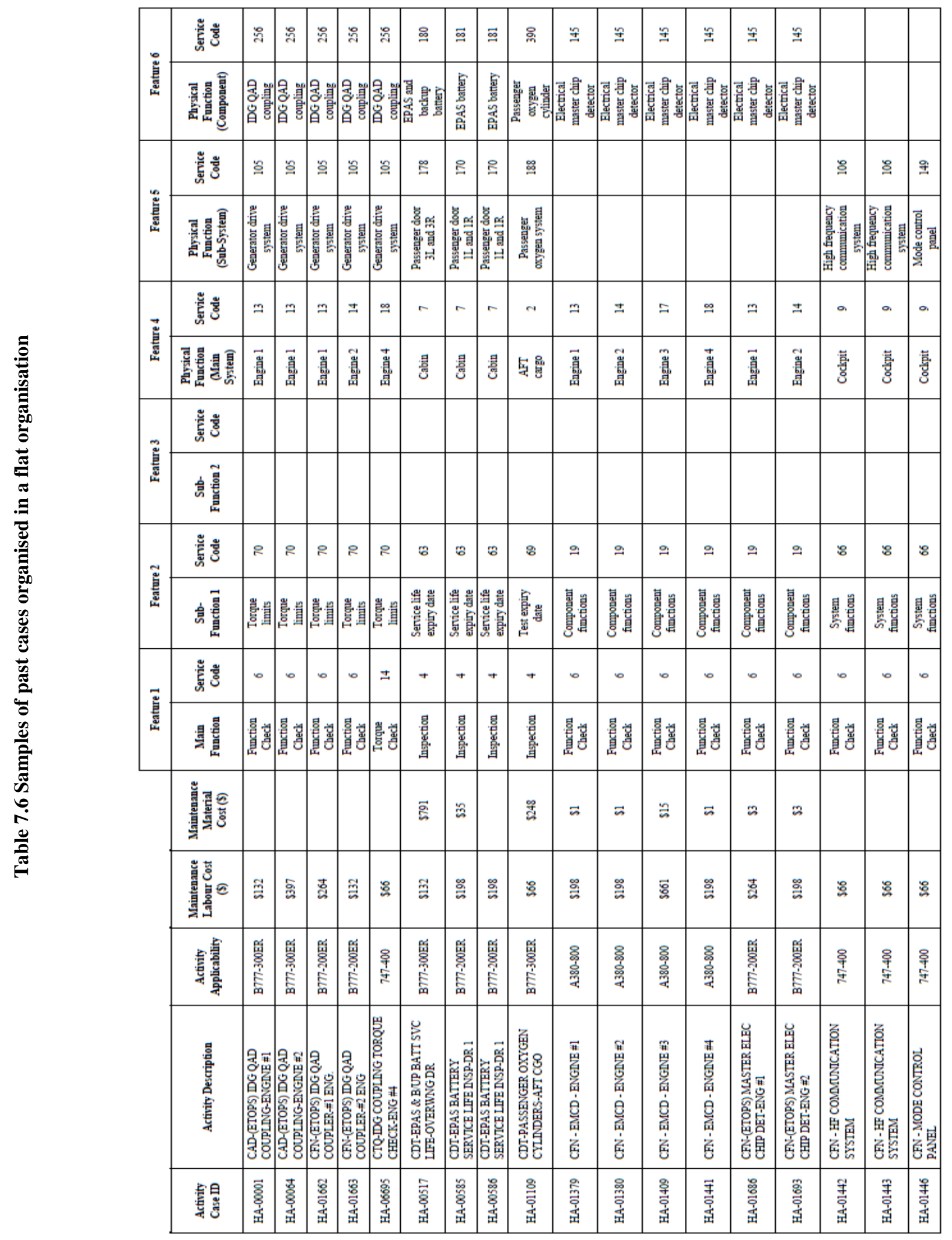

Page | 126 


\begin{tabular}{|c|c|c|c|c|c|c|c|c|c|c|c|c|c|c|c|}
\hline \multirow{6}{*}{ 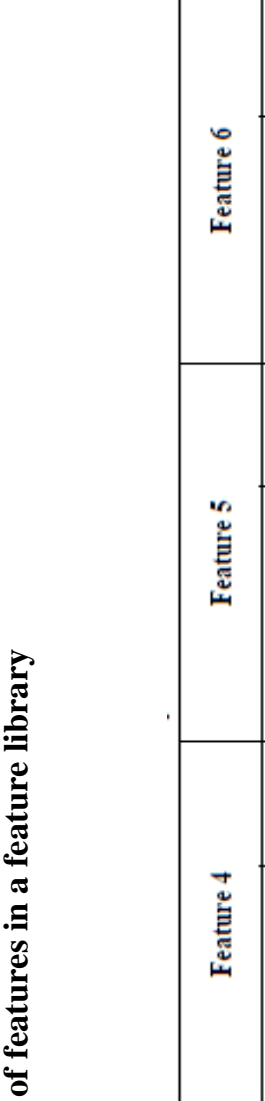 } & 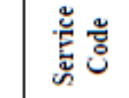 & $\cong$ & $\stackrel{\circ}{\circ}$ & ন & $\approx$ & $\stackrel{\infty}{\infty}$ & 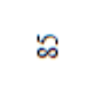 & ஃ & 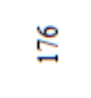 & $E$ & 气 & ‡ั & ริ & $\stackrel{\circ}{\circ}$ & $\stackrel{\text { }}{\sigma}$ \\
\hline & $\begin{array}{l}\text { 总 } \\
\text { 息 } \\
\text { 总 } \\
\text { 兽 } \\
\text { 点 }\end{array}$ & 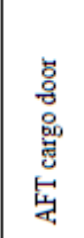 & 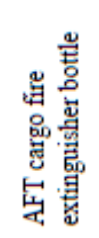 & 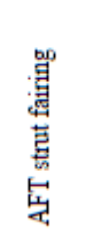 & 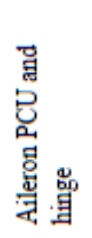 & $\begin{array}{l}\text { 葛 } \\
\text { 镸 } \\
\text { 言 } \\
\text { 号 } \\
\text { 完 }\end{array}$ & 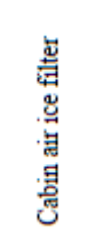 & 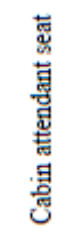 & 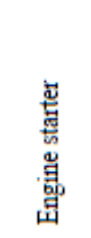 & 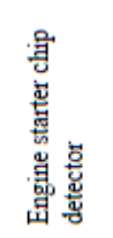 & 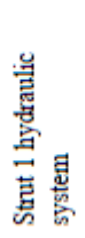 & 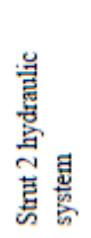 & 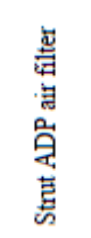 & 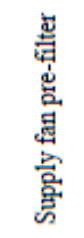 & 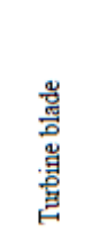 \\
\hline & 苛 : & + & $n$ & $b$ & a & 으 & 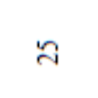 & $\stackrel{2}{\circ}$ & $E$ & $\stackrel{\infty}{\leftarrow}$ & $\infty$ & ஃ & $\stackrel{\varrho}{\varrho}$ & $\stackrel{ \pm}{ \pm}$ & సి \\
\hline & 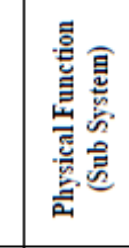 & 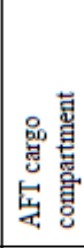 & 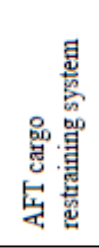 & 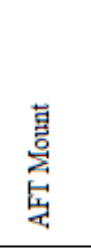 & 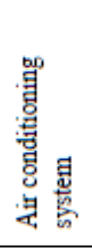 & 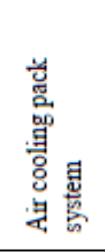 & 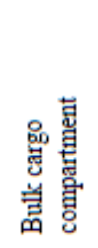 & 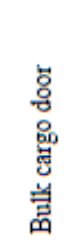 & 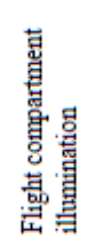 & 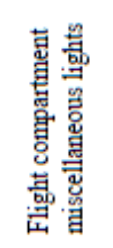 & 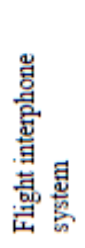 & 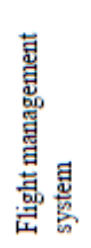 & 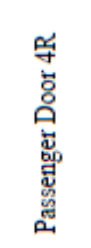 & 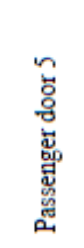 & 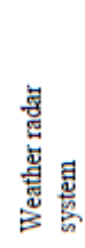 \\
\hline & 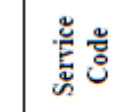 & $m$ & $\Xi$ & $=$ & $\stackrel{\infty}{\sim}$ & ন & $\stackrel{\sim}{\sim}$ & $\vec{m}$ & लี & क̊ & $g$ & $\approx$ & $\therefore$ & $\approx$ & 8 \\
\hline & 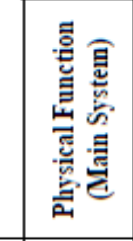 & $\begin{array}{l}\overrightarrow{\mathrm{g}} \\
\text { 惫 }\end{array}$ & 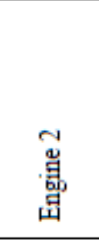 & $\begin{array}{l}\text { 悬 } \\
\text { 昜 }\end{array}$ & $\begin{array}{l}\stackrel{+}{ \pm} \\
\text { 昜 } \\
\text { 㞻 }\end{array}$ & 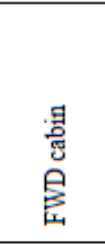 & 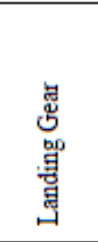 & 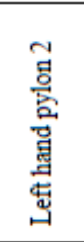 & 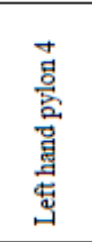 & 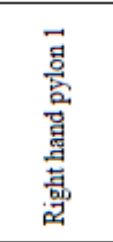 & 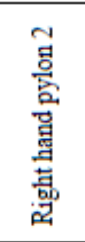 & 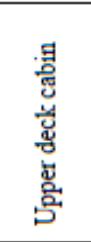 & 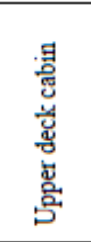 & 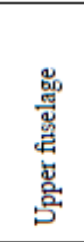 & 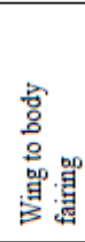 \\
\hline & 总 : & - & $\sim$ & $m$ & + & 9 & $\cong$ & $\stackrel{\circ}{\circ}$ & 기 & $\vec{\lambda}$ & ন & ๗ิ & $\stackrel{\sim}{\circ}$ & $\approx$ & $\stackrel{\sim}{~}$ \\
\hline 莺 & 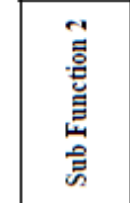 & 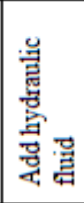 & 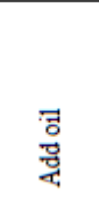 & 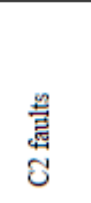 & 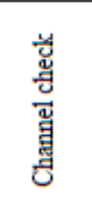 & 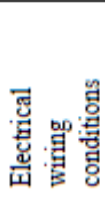 & 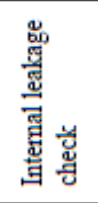 & 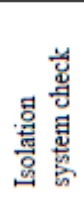 & 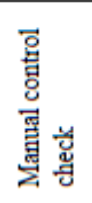 & 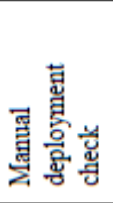 & 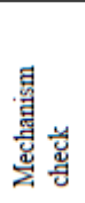 & 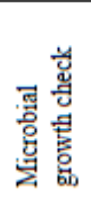 & 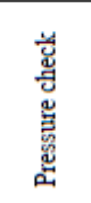 & 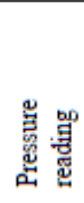 & 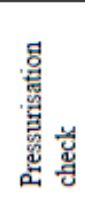 \\
\hline & 苞 & $\rightarrow$ & $\sim$ & $m$ & + & $n$ & r & $\infty$ & ₹ & q & 寸 & ร & 웅 & 于 & $\stackrel{\infty}{+}$ \\
\hline 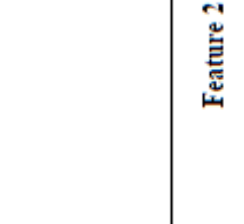 & 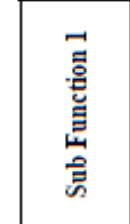 & 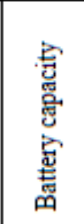 & 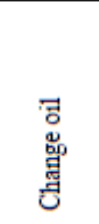 & 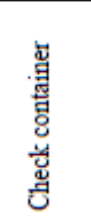 & 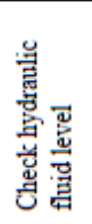 & 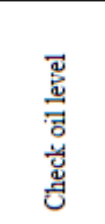 & 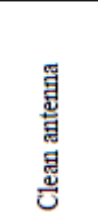 & 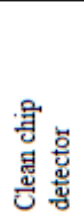 & 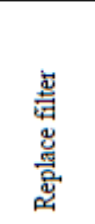 & 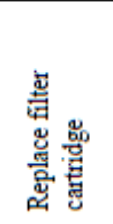 & 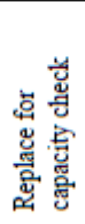 & 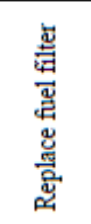 & 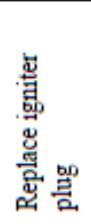 & 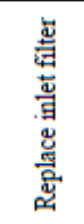 & 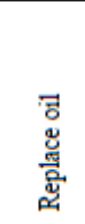 \\
\hline & 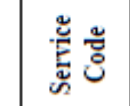 & - & $\sim$ & $m$ & 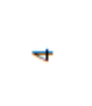 & $n$ & $r$ & $\infty$ & $a$ & 으 & $\Rightarrow$ & $\simeq$ & $\cong$ & $\Xi$ & $\cong$ \\
\hline $\begin{array}{l}\text { 总 } \\
\text { Еँّ }\end{array}$ & 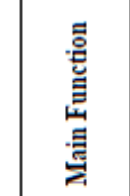 & 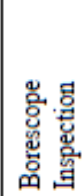 & 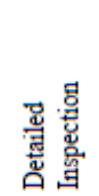 & $\begin{array}{l}\text { 蛋 } \\
\text { 总 } \\
\text { 营 }\end{array}$ & 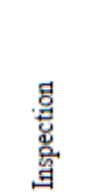 & $\begin{array}{l}\text { 骂 } \\
\text { 赏 }\end{array}$ & 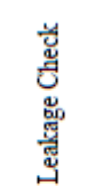 & 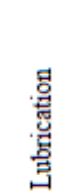 & 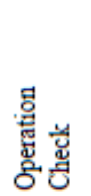 & 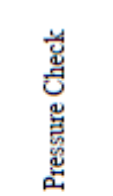 & 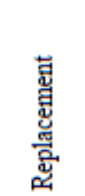 & 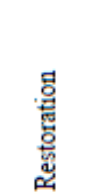 & 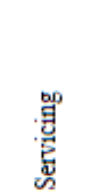 & 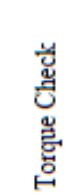 & 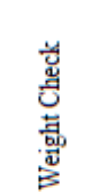 \\
\hline
\end{tabular}

Page | 127 


\subsubsection{Identification of Service Reference Clusters (SRC)}

In this section, an example to illustrate the identification of a SRC is presented. Assuming past service activity HA-00234 ( $\left.\mathrm{H}_{00234}\right)$ is randomly selected from the service activity case-base as reference activity $R$. It is compared with another past

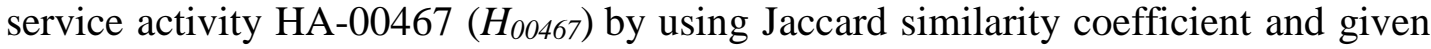
the features of both activities as below:

\begin{tabular}{|c|c|c|c|c|c|c|}
\cline { 2 - 7 } \multicolumn{1}{c|}{} & \multicolumn{6}{c|}{ Service Code } \\
\hline Activity ID & $\begin{array}{c}\text { Feature } \\
\mathbf{1}\end{array}$ & $\begin{array}{c}\text { Feature } \\
\mathbf{2}\end{array}$ & $\begin{array}{c}\text { Feature } \\
\mathbf{3}\end{array}$ & $\begin{array}{c}\text { Feature } \\
\mathbf{4}\end{array}$ & $\begin{array}{c}\text { Feature } \\
\mathbf{5}\end{array}$ & $\begin{array}{c}\text { Feature } \\
\mathbf{6}\end{array}$ \\
\hline $\begin{array}{c}\text { HA-00234 } \\
\left(\boldsymbol{H}_{\mathbf{0 0 2 3 4}}\right)\end{array}$ & 4 & 63 & & 9 & 63 & 174 \\
\hline $\begin{array}{c}\text { HA-00467 } \\
\left(\mathbf{H}_{\mathbf{0 0 4 6 7}}\right.\end{array}$ & 4 & 63 & & 9 & 63 & 174 \\
\hline
\end{tabular}

Jaccard similarity coefficient between HA-00234 and HA-00467 is calculated by applying Equation 8:

$$
\begin{aligned}
& C\left(R, H_{o}\right)=\frac{a}{a+b+c} \\
& C\left(H_{00234}, H_{00467}\right)=\frac{5}{5+0+0} \\
& C\left(H_{00234}, H_{00467}\right)=1
\end{aligned}
$$

Based on the computation result, similarity between HA-00234 and HA-00467 is equal to 1 . The result shows that both activities are found to be identical as the shared similar features. Therefore, HA-00467 can be considered as one of the members of this SRC. By using similar calculation procedures, HA-00234 is compared with remaining service activities. As shown in Table 7.8, a total of eight past service activities are found to be identical with the reference activity while other activities are found to be dissimilar with the reference activity since the similarity coefficient for these activities are less than 1. For example, past service activity HA-00237 (H00237), HA-00240 $\left(H_{00240}\right)$ and $H A-00245\left(H_{00245}\right)$ are only resemble $25 \%$ of the reference activity. These 
activities are rejected from the considerations to form a SRC with HA-00234. Subsequently, by repeating the process as discussed in this section, a total of 633 SRCs are identified.

Table 7.8 Examples of Jaccard similarity coefficients

\begin{tabular}{|c|c|c|c|c|c|c|c|c|c|c|c|}
\hline \multirow[b]{2}{*}{ No. } & \multirow[b]{2}{*}{ Activity ID } & \multicolumn{6}{|c|}{ Service Code } & \multicolumn{4}{|c|}{ Jaccard Coefficient } \\
\hline & & $\begin{array}{c}\text { Feature } \\
1\end{array}$ & $\begin{array}{c}\text { Feature } \\
2\end{array}$ & $\begin{array}{c}\text { Feature } \\
3\end{array}$ & $\begin{array}{c}\text { Feature } \\
4\end{array}$ & $\begin{array}{c}\text { Feature } \\
5\end{array}$ & $\begin{array}{c}\text { Feature } \\
6\end{array}$ & $\mathbf{a}$ & b & c & $\begin{array}{c}C= \\
\mathbf{a} /(\mathbf{a}+\mathbf{b}+\mathbf{c})\end{array}$ \\
\hline $\mathbf{R}$ & HA-00234 $\left(\mathrm{H}_{00234}\right)$ & 4 & 63 & & 9 & 63 & 174 & & & & \\
\hline 1 & HA-00467 $\left(\mathrm{H}_{00467}\right)$ & 4 & 63 & & 9 & 63 & 174 & 5 & 0 & 0 & 1.00 \\
\hline 2 & HA-00467 $\left(\mathrm{H}_{00470}\right)$ & 4 & 63 & & 9 & 63 & 174 & 5 & 0 & 0 & 1.00 \\
\hline 3 & HA-00473 $\left(\mathrm{H}_{00473}\right)$ & 4 & 63 & & 9 & 63 & 174 & 5 & 0 & 0 & 1.00 \\
\hline 4 & HA-00226 $\left(\mathrm{H}_{00226}\right)$ & 4 & 63 & & 9 & 63 & 174 & 5 & 0 & 0 & 1.00 \\
\hline 5 & HA-00464 $\left(\mathrm{H}_{00464}\right)$ & 4 & 63 & & 9 & 63 & 174 & 5 & 0 & 0 & 1.00 \\
\hline 6 & HA-00465 $\left(\mathrm{H}_{00465}\right)$ & 4 & 63 & & 9 & 63 & 174 & 5 & 0 & 0 & 1.00 \\
\hline 7 & HA-00468 $\left(\mathrm{H}_{00468}\right)$ & 4 & 63 & & 9 & 63 & 174 & 5 & 0 & 0 & 1.00 \\
\hline 8 & HA-00469 $\left(\mathrm{H}_{00469}\right)$ & 4 & 63 & & 9 & 63 & 174 & 5 & 0 & 0 & 1.00 \\
\hline 9 & HA-00237 $\left(\mathrm{H}_{00237}\right)$ & 4 & 63 & & 8 & 135 & 96 & 2 & 3 & 3 & 0.25 \\
\hline 10 & HA-00240 $\left(\mathrm{H}_{00240}\right)$ & 4 & 63 & & 8 & 135 & 96 & 2 & 3 & 3 & 0.25 \\
\hline 11 & HA-00245 $\left(\mathrm{H}_{00245}\right)$ & 4 & 63 & & 8 & 135 & 96 & 2 & 3 & 3 & 0.25 \\
\hline
\end{tabular}

\subsubsection{An Illustration of Activity Cost Estimation for $\boldsymbol{S F}_{\text {Long_Range }}$}

Prior to the initialisation of activity estimation, a query or service activity cost estimation problem must be indexed so that it is identifiable and readable by the retrieval mechanism. For example, to estimate the cost for a query $Q$ ( $\left.D S A_{45,773 E R}\right)$ involving the lubrication of left hand elevator power control unit (PCU) and hinge assembly, appropriate features and service codes are assigned to the activity by referring to feature library (Table 7.7). 
Table 7.9 An Example of indexed a query case $Q$ (DSA45,773ER)

\begin{tabular}{|c|c|c|}
\hline \multicolumn{3}{|l|}{ Query Case ID: DSA45,773ER } \\
\hline \multicolumn{3}{|c|}{ Activity Description: LUB-LFT ELEV PWR CTRL ACTR \& HGE-EMPNNGE } \\
\hline \multicolumn{3}{|l|}{ Activity Applicability: 777-300ER } \\
\hline Features $(f)$ & Attribute (a) & Value $(v)$ \\
\hline 1. Main Function & Lubrication & 8 \\
\hline 2. Sub-function 1 & Component lubrication & 20 \\
\hline \multicolumn{3}{|l|}{ 3. Sub-function 2} \\
\hline 4. Physical Function - Main System & Empennage & 11 \\
\hline 5. Physical Function - Sub-system & Elevator control system & 54 \\
\hline 6. Physical Function - Component & $\begin{array}{l}\text { Left elevator PCU and } \\
\text { hinge }\end{array}$ & 293 \\
\hline
\end{tabular}

Once the service activity is indexed, case retrieval mechanism as defined in Equation 10 is employed to retrieve past service activities that similar to the query. To illustrate the process of past service activity retrieval, an example to calculate the Euclidean distance between query Q (DSA45,773ER) and past service activity HA-19013 $\left(H_{19013}\right)$ is shown below:

a. Given the attribute values of the query $Q\left(D S A_{45,773 E R}\right)$ and past service activity HA-19013 (H19013):

\begin{tabular}{|c|c|c|c|c|c|c|}
\hline Activity & $\begin{array}{c}\text { Feature } 1 \\
\left(f_{1}\right)\end{array}$ & $\begin{array}{c}\text { Feature } 2 \\
\left(f_{2}\right)\end{array}$ & $\begin{array}{c}\text { Feature } 3 \\
\left(f_{3}\right)\end{array}$ & $\begin{array}{c}\text { Feature } 4 \\
\left(f_{4}\right)\end{array}$ & $\begin{array}{c}\text { Feature } 5 \\
\left(f_{5}\right)\end{array}$ & $\begin{array}{c}\text { Feature } 6 \\
\left(f_{6}\right)\end{array}$ \\
\hline$Q\left(D S A_{45,773 E R}\right)$ & 8 & 20 & & 11 & 54 & 293 \\
\hline$H_{19013}$ & 8 & 20 & & 11 & 54 & 293 \\
\hline
\end{tabular}

b. And, given the weights of features:

Weight of feature $1, \quad W_{f_{1}}=3$

Weight of feature $3, W_{f_{3}}=2$

Weight of feature $5, \quad W_{f_{3}}=5$
Weight of feature 2, $W_{f_{2}}=3$

Weight of feature $4, \quad W_{f_{4}}=5$

Weight of feature $6, W_{f_{6}}=5$ 
c. Similarity assessment between $Q=D S A_{45,773 E R}$ and $H A-19013\left(H_{19013}\right)$ is calculated:

i. Weighted Euclidean distance between $Q=D S A_{45,773 E R}$ and HA-19013 ( $H_{19013):}$

$$
\begin{aligned}
& d\left(Q, H_{o}\right)=\left[\sum_{f=1}^{t} W_{f_{t}}{ }^{2}\left(v\left(f_{t}, Q\right)-v\left(f_{t}, H_{o}\right)\right)^{2}\right]^{1 / 2} \\
& d\left(H_{19013, D S A_{45}, 733 E R}\right)=\left[3^{2}(8-8)^{2}+3^{2}(20-20)^{2}+2^{2}(0-0)^{2}+5^{2}(11-11)^{2}+5^{2}(54-54)^{2}+5^{2}(293-293)^{2}\right]^{1 / 2} \\
& d\left(H_{19013,}, D S A_{45,733 E R}\right)=[9(0)+9(0)+4(0)+25(0)+25(0)+25(0)]^{1 / 2} \\
& d\left(H_{19013}, D S A_{45,}, 773 E R\right)=0
\end{aligned}
$$

ii. Calculating similarity between $Q=D S A_{45,773 E R}$ and $H A-19013\left(H_{19013}\right)$, assuming $\alpha=1$ :

$$
\begin{aligned}
& \operatorname{SIM}\left(Q, H_{0}\right)=\frac{1}{1+\alpha d\left(Q, H_{o}\right)} \\
& \operatorname{SIM}\left(Q, H_{o}\right)=\frac{1}{1+(1)(0)} \\
& \operatorname{SIM}\left(Q, H_{o}\right)=1
\end{aligned}
$$

The computation result shows that Euclidean distance between query $Q$ (DSA $45,773 E R)$ and past service activity HA-19013 $\left(H_{19013}\right)$ is equal to 1 . This implies that the features for both activities are identical and this particular past service activity can be considered as a candidate for best matching case. The calculation process is repeated to calculate Euclidean distance between query $Q\left(D S A_{45,773 E R}\right)$ and other past service activities in the case-base. To reduce the candidates of best matching case, 10 past service activities which have the shortest Euclidean distances are selected as shown in 
Table 7.10. From these past service activities, HA-19013 is selected as the best matching case for query $Q\left(D S A_{45,773 E R}\right)$.

Table 7.10 Euclidean distances between query $Q\left({ } S_{45,773 E R}\right)$ and past service activities

\begin{tabular}{|c|l|c|}
\hline $\begin{array}{c}\text { Past Service } \\
\text { Activity ID }\end{array}$ & \multicolumn{1}{|c|}{ Activity Description } & $\begin{array}{c}\text { Similarity Index } \\
\mathbf{( 0 ~ t o ~ 1 ) ~}\end{array}$ \\
\hline HA-02930 & COP-(ETOPS)FUEL BST PUMP GFI CTL RLY-RHW & 0.00 \\
HA-03886 & COP-E/E COOLING SYS INSTRUMENT DETECTOR & 0.02 \\
HA-04725 & COP-GFI OF CENTER TANK JETTISON PUMPS & 0.00 \\
HA-04968 & COP-JETTISON PUMP PRESS SW \& CIRCUIT & 0.02 \\
HA-09821 & IDV-INLET CONE EXTERNAL SURFACE-ENG \#1 & 0.00 \\
HA-12814 & IGE-INLET COWL -RIGHT ENGINE & 0.00 \\
HA-21425 & RPL-(ETOPS)LP FUEL FILTER-\#1 ENG & 0.00 \\
HA-19013 & LUB-LFT ELEV PWR CTRL ACTR \& HGE-EMPNNGE & 1.00 \\
HA-04887 & COP-INTEGRAL PANEL LIGHTS-CKPT & 0.00 \\
HA-22037 & RPL-LP FUEL FILTER ELEMENT-ENG \#4 & 0.00 \\
\hline
\end{tabular}

Based on the best case, SRC-601 is triggered to generate activity cost estimation for query $Q\left(D S A_{45,773 E R}\right)$ (Table 7.11). The cost data contain in this SRC is input into a statistical analysis software to generate a statistical analysis as shown in Figure 7.3. The mean value of maintenance labour cost is adapted by the query where $A C$ $\left(D S A_{45,773 E R}\right)=\$ 279.27$. Subsequently, the solution for query $Q\left(D S A_{45,773 E R}\right)$ is revised for additional information. Lastly, it is retained in the case-base as a new addition of past service activity for future usage.

Table 7.11 List of service activities contain in SRC-601

\begin{tabular}{|c|c|c|c|c|}
\hline Activity Case ID & Activity Description & $\begin{array}{c}\text { Activity } \\
\text { Applicability }\end{array}$ & $\begin{array}{c}\text { Maintenance } \\
\text { Labour Cost (\$) }\end{array}$ & $\begin{array}{c}\text { Maintenance } \\
\text { Material Cost (\$) }\end{array}$ \\
\hline HA-19004 & LUB-LFT ELEV PWR CTRL ACTR \& HGE-EMPNNGE & B777-200ER & $\$ 99$ & \\
HA-19005 & LUB-LFT ELEV PWR CTRL ACTR \& HGE-EMPNNGE & B777-200ER & $\$ 198$ \\
HA-19006 & LUB-LFT ELEV PWR CTRL ACTR \& HGE-EMPNNGE & B777-200ER & $\$ 198$ \\
HA-19007 & LUB-LFT ELEV PWR CTRL ACTR \& HGE-EMPNNGE & B777-300ER & $\$ 331$ \\
HA-19008 & LUB-LFT ELEV PWR CTRL ACTR \& HGE-EMPNNGE & B777-300ER & $\$ 1,190$ \\
HA-19009 & LUB-LFT ELEV PWR CTRL ACTR \& HGE-EMPNNGE & B777-300ER & $\$ 132$ \\
HA-19010 & LUB-LFT ELEV PWR CTRL ACTR \& HGE-EMPNNGE & B777-300ER & $\$ 264$ & \\
HA-19011 & LUB-LFT ELEV PWR CTRL ACTR \& HGE-EMPNNGE & B777-300ER & $\$ 99$ & \\
HA-19012 & LUB-LFT ELEV PWR CTRL ACTR \& HGE-EMPNNGE & B777-300ER & $\$ 99$ & \\
HA-19013 & LUB-LFT ELEV PWR CTRL ACTR \& HGE-EMPNNGE & B777-300ER & $\$ 264$ \\
HA-19014 & LUB-LFT ELEV PWR CTRL ACTR \& HGE-EMPNNGE & B777-300ER & $\$ 198$ & \\
\hline
\end{tabular}




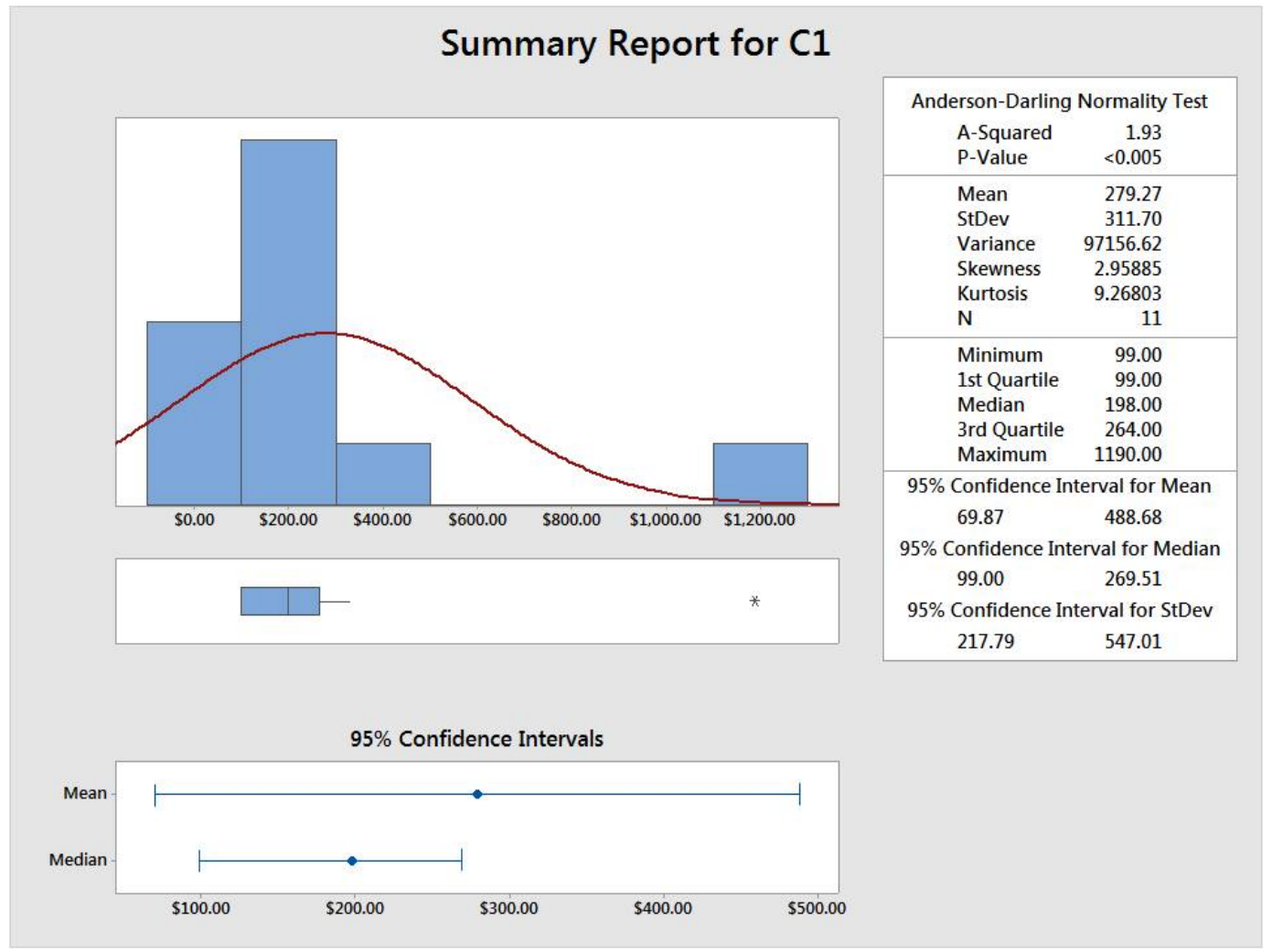

Figure 7.3 Statistical summary of SRC-601 cost data

The activity cost estimation processes as described above are repeated to estimate direct service activity costs for the service activities of $S F_{\text {Long_Range. Table } 7.12}$ shows the examples of estimated direct service activity costs for the services. Apart from calculating the costs for direct service activities, based on indirect service activity rates obtained from aircraft maintenance contracts and other sources of cost information, indirect service activities for various indirect service activities are calculated. An example to calculate the cost for $S I S A_{1,773 E R}$ is shown below:

Given indirect activity rate of $\mathrm{B} 777$ hangarage, $I D A D R_{\text {Hangarage_B777 }}=\$ 4,800$ per day and $A S\left(S I S A_{1,773 E R}\right)=1$ day:

$$
\begin{aligned}
A C\left(S_{S A} A_{1,773 E R}\right) & =I D A D R_{\text {Hangarage_B777 }} \times A S\left(S I S A_{1,773 E R}\right) \\
& =\$ 4,800 \times 1 \\
& =\$ 4,800
\end{aligned}
$$

Table 7.13 shows the examples of indirect service activities costs calculated based on indirect service activity rates. 


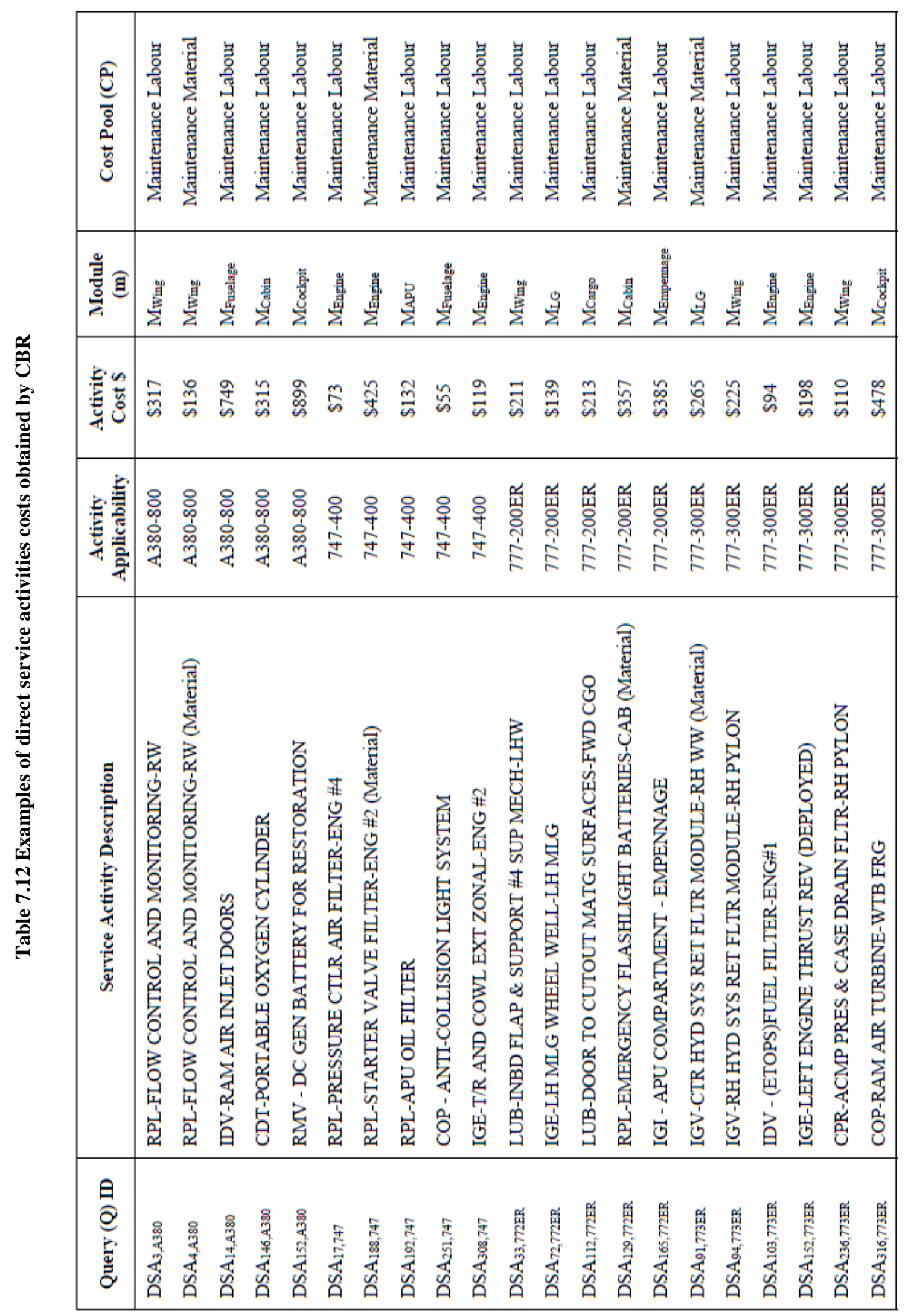

Page | 134 


\begin{tabular}{|c|c|c|c|c|c|c|c|c|c|c|c|c|c|c|c|c|c|}
\hline 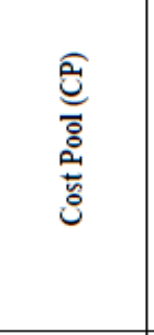 & 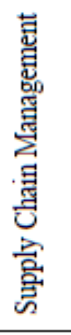 & 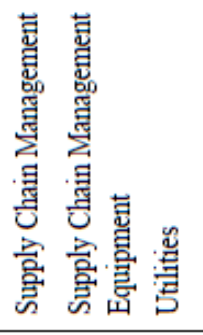 & 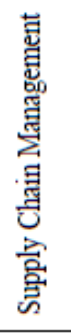 & 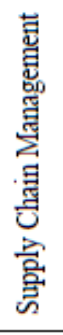 & 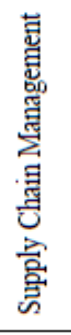 & 鸪 & 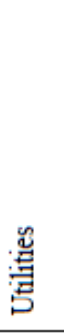 & 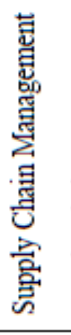 & 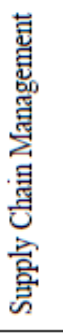 & 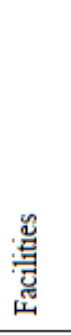 & 营 & 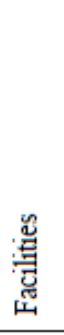 & 鸪 & 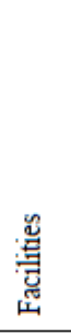 & 嗬 & 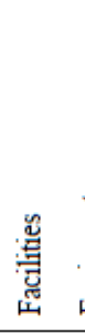 & 蓄 \\
\hline 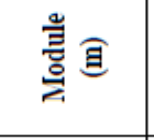 & 量 & 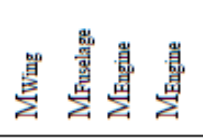 & 貝 & 昜 & 量 & 惫 & 兽 & 鄫 & 昜 & $\begin{array}{l}\text { 免 } \\
\text { 点 }\end{array}$ & $\begin{array}{l}\text { 畄 } \\
\text { 点 }\end{array}$ & 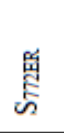 & 总 & $\frac{F}{2}$ & $\frac{F}{n}$ & 总 & 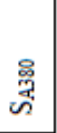 \\
\hline 总育 & 管 & 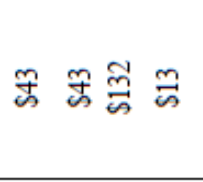 & 急 & 管 & 恙 & $\stackrel{\text { लै }}{\infty}$ & $\bar{m}$ & 站 & 管 & $\begin{array}{l}\text { \&े } \\
\text { स゙ }\end{array}$ & సิ & $\begin{array}{l}8 \\
\text { 今 } \\
\text { 犬 }\end{array}$ & $\begin{array}{l}\text { สิ } \\
\text { สิ }\end{array}$ & 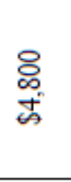 & 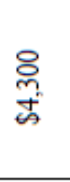 & $\begin{array}{l}\text { 官 } \\
0 \\
8\end{array}$ & 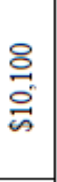 \\
\hline 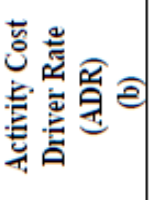 & 管 & 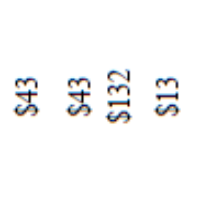 & 急 & 恚 & 恙 & 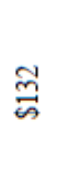 & $\ddot{m}$ & 䍂 & 管 & $\begin{array}{l}\text { ठ̊口 } \\
\text { ボ }\end{array}$ & $\begin{array}{l}\text { సิ } \\
\text { ऊิ }\end{array}$ & $\begin{array}{l}\text { ठ্口 } \\
\text { ボ }\end{array}$ & तิ & $\begin{array}{l}\text { \& } \\
\text { ホ̇ }\end{array}$ & 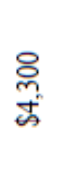 & 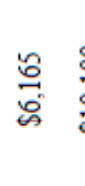 & $\begin{array}{l}8 \\
\stackrel{0}{0} \\
\stackrel{-1}{s}\end{array}$ \\
\hline 㝕尊 & $\rightarrow$ & $\neg$ & $\neg$ & - & $\neg$ & - & $\rightarrow$ & $\rightarrow$ & - & $\rightarrow$ & $\neg$ & - & $\neg$ & - & $\neg$ & $\rightarrow$ & $\rightarrow$ \\
\hline 点薏 & 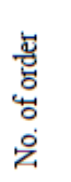 & 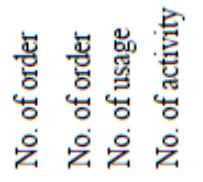 & 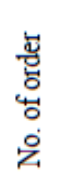 & $\begin{array}{l}\text { 总 } \\
\text { 岁 } \\
\dot{0} \\
\dot{2}\end{array}$ & 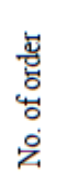 & 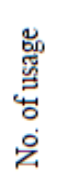 & 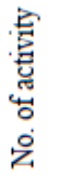 & 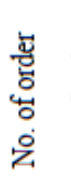 & 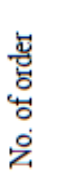 & 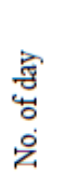 & 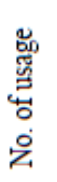 & 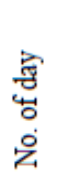 & 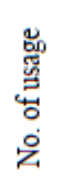 & 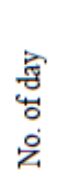 & 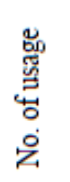 & 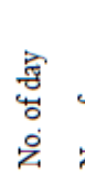 & \\
\hline 点害 & 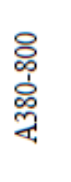 & 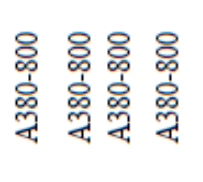 & 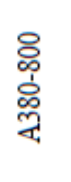 & 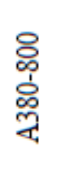 & $\begin{array}{l}\text { 古 } \\
\text { 守 }\end{array}$ & $\begin{array}{l}\stackrel{8}{+} \\
\stackrel{+}{ \pm}\end{array}$ & 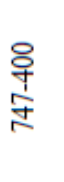 & 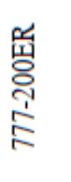 & $\begin{array}{l}\text { 岁 } \\
\text { 혼 } \\
\stackrel{1}{\Sigma}\end{array}$ & 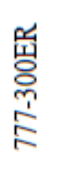 & 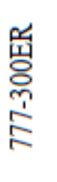 & $\begin{array}{l}\text { 獣 } \\
\text { I } \\
\stackrel{5}{\Sigma}\end{array}$ & $\begin{array}{l}\text { 岁 } \\
\text { 今̊ } \\
\stackrel{1}{ミ}\end{array}$ & $\begin{array}{l}\text { 古 } \\
\text { 守 }\end{array}$ & 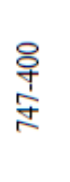 & 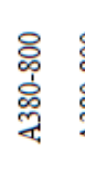 & \\
\hline 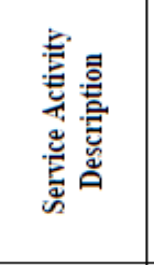 & 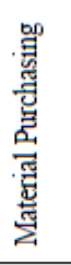 & 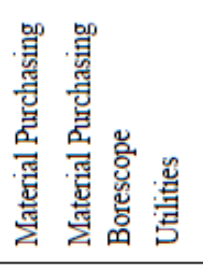 & 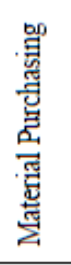 & 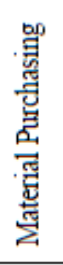 & 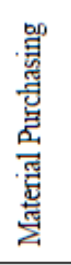 & 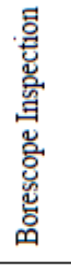 & 鸹 & 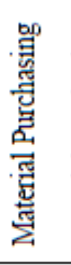 & 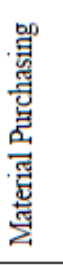 & 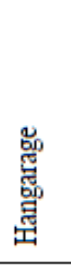 & 点 & $\begin{array}{l}\text { 品 } \\
\text { 营 } \\
\text { 胥 } \\
\text { 焉 }\end{array}$ & 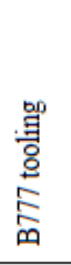 & 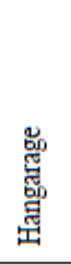 & 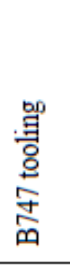 & & 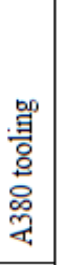 \\
\hline 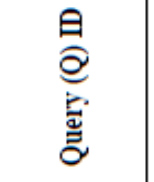 & 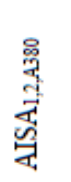 & 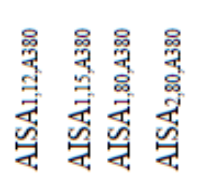 & 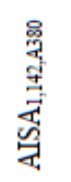 & 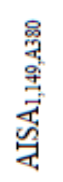 & 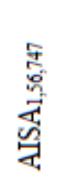 & 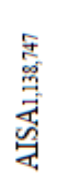 & 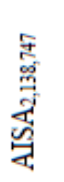 & $\begin{array}{l}\text { 总 } \\
\text { 至 } \\
\text { 离 } \\
\text { 学 }\end{array}$ & $\begin{array}{l}\text { 总 } \\
\text { है } \\
\text { 孛 } \\
\text { 岁 } \\
\text { 学 }\end{array}$ & $\begin{array}{l}\text { 总 } \\
\text { 窝 } \\
\text { 岕 }\end{array}$ & $\begin{array}{l}\text { 畄 } \\
\text { 交 } \\
\text { 岁 }\end{array}$ & 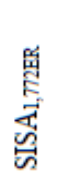 & $\begin{array}{l}\text { 总 } \\
\text { E } \\
\text { 荇 } \\
\text { 岁 }\end{array}$ & 㕿 & 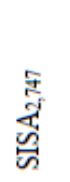 & 桑 & 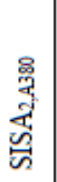 \\
\hline
\end{tabular}




\subsection{Stage Two Cost Estimation - Service Cost Estimation}

In this stage, estimated service activity costs are allocated to individual services by using mathematical functions as defined in Equation 16 and 17. Taking the example of estimating maintenance service costs for $747-400$ maintenance service $\left(S_{747}\right)$, modular costs related to the service are calculated by adding direct service activity costs and indirect service activity costs allocated to the modules. An example to calculate maintenance costs of auxiliary power unit (APU) module $M C\left(m_{A P U}\right)$ of $S_{747}$ is shown below:

a. Given calculated activities costs of auxiliary power unit (APU) module of $S_{747}$ :

\begin{tabular}{|l|l|c|c|}
\hline $\begin{array}{c}\text { Query (Q) } \\
\text { ID }\end{array}$ & \multicolumn{1}{|c|}{ Service Activity Description } & $\begin{array}{c}\text { Activity } \\
\text { Cost } \$\end{array}$ & Module (m) \\
\hline$D S A_{42,747}$ & CLK-APU FUEL FEED LINE SHROUD & $\$ 90$ & $m_{A P U}$ \\
$D S A_{94,747}$ & LEAKAGE & $\$ 112$ & $m_{A P U}$ \\
$D S A_{192,747}$ & RVC-APU STARTER MOTOR OIL & $\$ 132$ & $m_{A P U}$ \\
$D S A_{193,747}$ & RPL-APU OIL FILTER & $\$ 118$ & $m_{A P U}$ \\
$A I S A_{1,193,747}$ & Material Purchasing & $\$ 43$ & $m_{A P U}$ \\
$D S A_{195,747}$ & IDV-APU STARTER MOTOR BRUSH. & $\$ 101$ & $m_{A P U}$ \\
\hline
\end{tabular}

b. Total costs of auxiliary power unit (APU) module $M C\left(m_{A P U}\right)$,

$$
\begin{aligned}
M C\left(m_{A P U}\right)= & A C\left(D S A_{42,747}\right)+A C\left(D S A_{94,747}\right)+A C\left(D S A_{192,747}\right)+A C\left(D S A_{193,747}\right)+ \\
& +A C\left(D S A_{195,747}\right)+\operatorname{AISA}(1,193,747) \\
= & \$ 90+\$ 112+\$ 132+\$ 118+\$ 101+\$ 43 \\
= & \$ 596
\end{aligned}
$$

When the modular costs of each service module is calculated, maintenance service costs of 747-400 $S C\left(S_{747}\right)$ are simply calculated by summing the modular costs. The service cost calculation is illustrated below:

$$
\begin{aligned}
S C\left(S_{747}\right)= & M C\left(m_{\text {Cabin }}\right)+M C\left(m_{\text {Empennage }}\right)+M C\left(m_{\text {Cockpit }}\right)+M C\left(m_{\text {Engine }}\right)+M C\left(m_{L G}\right) \\
& +M C\left(m_{M E C}\right)+M C\left(m_{\text {Fuselage }}\right)+M C\left(m_{\text {Wing }}\right)+M C\left(m_{A P U}\right)+M C\left(m_{\text {Cargo }}\right) \\
& +A C\left(S I S A_{1,747}\right)+A C\left(S I S A_{2,747}\right)
\end{aligned}
$$




$$
\begin{aligned}
= & \$ 10,851+\$ 1,202+\$ 5,908+\$ 33,501+\$ 5,487+\$ 531+\$ 5,640+\$ 5,611 \\
& +\$ 5,611+\$ 596+\$ 9,128+\$ 4,800+\$ 4,300 \\
& =\$ 87,555
\end{aligned}
$$

Using similar service cost calculation procedures, service costs of $S_{A 380}, S_{773 E R}$ and $S_{772 E R}$ are calculated (Table 7.14). The results reveal that unit cost to perform a periodic maintenance service for a B777-300ER aircraft is found to be most expensive as compared to other type of long range aircraft. In this case, the costs to maintain engines and passenger cabin are main cost drivers to maintain the aircraft. In general, it is estimated that a total of $\$ 11.3$ million is required annually to carry out periodic maintenance for a fleet of 19 A380, 11 B747-400, 12 B777-200ER and 26 B777-

\begin{tabular}{|c|c|c|c|c|}
\hline \multirow[b]{2}{*}{ Maintenance Costs } & \multicolumn{4}{|c|}{ Maintenance Service (per aircraft) } \\
\hline & $S C\left(S_{A 380}\right)$ & $S C\left(S_{747}\right)$ & $S C\left(S_{772 E R}\right)$ & $S C\left(S_{773 E R}\right)$ \\
\hline$M C\left(m_{A P U}\right)$ & $\$ 728$ & $\$ 596$ & $\$ 0$ & $\$ 0$ \\
\hline$M C\left(m_{\text {Engine }}\right)$ & $\$ 11,926$ & $\$ 33,501$ & $\$ 4,856$ & $\$ 23,232$ \\
\hline$M C\left(m_{\text {Cargo }}\right)$ & $\$ 3,631$ & $\$ 9,128$ & $\$ 7,162$ & $\$ 6,427$ \\
\hline$M C\left(m_{\text {Fuselage }}\right)$ & $\$ 8,540$ & $\$ 5,640$ & $\$ 1,241$ & $\$ 1,883$ \\
\hline$M C\left(m_{\text {Empennage }}\right)$ & $\$ 712$ & $\$ 1,202$ & $\$ 1,665$ & $\$ 2,754$ \\
\hline$M C\left(m_{\text {Cockpit }}\right)$ & $\$ 8,857$ & $\$ 5,908$ & $\$ 7,329$ & $\$ 9,115$ \\
\hline$M C\left(m_{M E C}\right)$ & $\$ 2,496$ & $\$ 531$ & $\$ 398$ & $\$ 583$ \\
\hline$M C\left(m_{\text {Cabin }}\right)$ & $\$ 10,557$ & $\$ 10,851$ & $\$ 19,945$ & $\$ 23,745$ \\
\hline$M C\left(m_{L G}\right)$ & $\$ 8,155$ & $\$ 5,487$ & $\$ 5,480$ & $\$ 7,780$ \\
\hline$M C\left(m_{\text {Wing }}\right)$ & $\$ 3,630$ & $\$ 5,611$ & $\$ 12,789$ & $\$ 12,135$ \\
\hline$A C(S I S A)$ & $\$ 16,265$ & $\$ 9,100$ & $\$ 7,027$ & $\$ 7,027$ \\
\hline (a) Unit cost per service & $\$ 75,497$ & $\$ 87,555$ & $\$ 67,892$ & $\$ 94,681$ \\
\hline (b) Total number of aircraft & 19 & 11 & 12 & 26 \\
\hline (c) No. of service per year & 2 & 2 & 2 & 2 \\
\hline $\begin{array}{l}\text { Total service costs per year } \\
\text { (a) } \times \text { (b) } \times \text { (c) }\end{array}$ & $\$ 2,868,878$ & $\$ 1,926,221$ & $\$ 1,629,419$ & $\$ 4,923,406$ \\
\hline
\end{tabular}
300ER. Out of these total expenditures, 44\% are spent on B777-300ER aircraft.

Table 7.14 Service costs for long range aircraft maintenance service family (SF Long_Range) 
Apart from calculating the costs consumed by the services, it is also important to understand the types of service resources that are consumed by the maintenance service family. As shown in Table 7.15, approximately $86.22 \%$ of total maintenance resources are distributed to maintenance labour and material while remaining maintenance resources are distributed to equipment, utilities, supply chain management and facilities which are consumed by indirect service activities. Besides, the analysis also implies that aircraft maintenance for $S F_{\text {Long_Range }}$ is laboured intensive ad $63 \%$ of total maintenance resources are attributed to maintenance labour. This finding is associated with the needs of large number of maintenance activities to maintain highly complex mechanical and structural systems of an aircraft. Even though the requirements to utilise human resources in aircraft maintenance are unavoidable, improvements on methodologies and processes to perform these maintenance activities can be effective in reducing human efforts. For example, The Boeing Company has introduced the use of radio frequency identification device (RFID) and contact memory button (CMB) in maintaining aircraft emergency equipment management. These technologies are able to reduce the inspection of B777 oxygen generator from 6.5 hours to 15 minutes.

Table 7.15 Annual resources consumed by the long range aircraft

\begin{tabular}{|l|l|r|c|}
\hline \multicolumn{1}{|c|}{ Resources } & \multicolumn{1}{|c|}{ Type of resources } & $\begin{array}{c}\text { Total } \\
\text { Accumulated } \\
\text { Resources }\end{array}$ & $\begin{array}{c}\text { Percentage } \\
\text { (\%) }\end{array}$ \\
\hline Maintenance Labour & Direct Service Resources & $\$ 7,204,417$ & $63.06 \%$ \\
Maintenance Material & Direct Service Resources & $\$ 2,646,137$ & $23.16 \%$ \\
Equipment & Indirect Service Resources & $\$ 706,918$ & $6.19 \%$ \\
Utilities & Indirect Service Resources & $\$ 5,613$ & $0.05 \%$ \\
Supply Chain Management & Indirect Service Resources & $\$ 156,788$ & $1.37 \%$ \\
Facilities & Indirect Service Resources & $\$ 704,670$ & $6.17 \%$ \\
\hline
\end{tabular}

\subsection{Effectiveness of Proposed Cost Estimation Methodology}

\subsubsection{Validation of Proposed Cost Estimation Methodology}

\section{a. Comparison of estimated unit maintenance costs with actual average unit costs}

To validate the accuracy of proposed cost estimation methodology, unit maintenance costs (excluding overhead costs) to perform maintenance services for the long range 
aircraft family have been carried out. In this comparison, estimated unit maintenance costs obtained by proposed cost estimation methodology have been compared with unit maintenance costs for each aircraft type based on past maintenance services cost over a period of two years. Besides, both sets of unit maintenance costs are benchmarked against unit maintenance cost estimated based on aircraft manufacturer data (Boeing and Airbus). The aircraft manufacturer data consists of labour and material information that are estimated by aircraft designers for each maintenance task under the assumptions of ideal aircraft maintenance operations. Usually, the aircraft manufacturer data are used as a guide for aircraft maintenance planning.

The comparison results as recorded in Figure 7.4 shown that unit maintenance costs estimated by proposed cost estimation methodology are much closer to the benchmarking unit costs as compared to the actual average unit costs. For instance, average unit cost of $\mathrm{S}_{\mathrm{A} 380}$ is $297 \%$ higher than unit cost estimated by aircraft manufacturer data. Meanwhile, unit cost estimated by proposed cost estimation methodology is $213 \%$ higher than unit cost estimated by aircraft manufacturer data. In this example, there is an $84 \%$ reduction in estimation error in predicting the unit maintenance cost for A380 maintenance services.

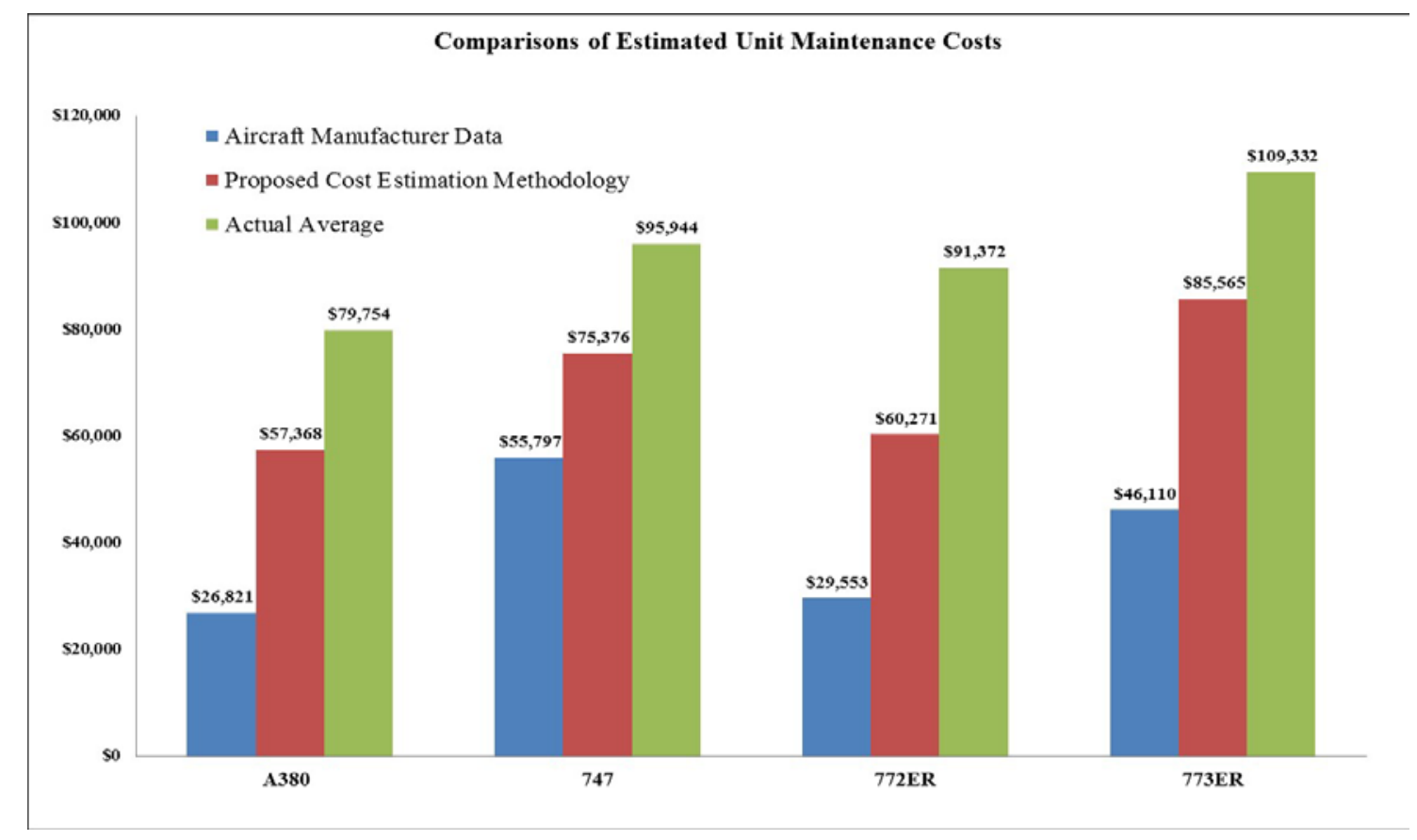

Figure 7.4 Comparisons of unit maintenance costs (estimated vs actual average) 
Apart from assessing overall unit cost for each aircraft fleet, actual unit costs of randomly selected samples with similar maintenance work scopes of each aircraft fleet are compared with unit costs estimated by proposed cost estimation methodology. The results of comparisons (Figure 7.5a, 7.5b, 7.5c and 7.5d) shown that actual unit costs of the samples are inconsistent. Besides, they are consistently higher than unit costs estimated by proposed cost estimation methodology.

The comparison results imply that, in real life aircraft maintenance operations, inconsistent resources consumptions occur regularly and this may results in maintenance resources wastage in terms of human resources and materials. Unnoticeably, a service organisation may lost its competitiveness in long term. More importantly, the comparison has proven that proposed cost estimation methodology is able to produce consistent cost estimation results under similar cost estimation conditions since similar past experiences are used during the process of cost estimation. This is particular important to assist users in estimating resources that are consumed for the services.

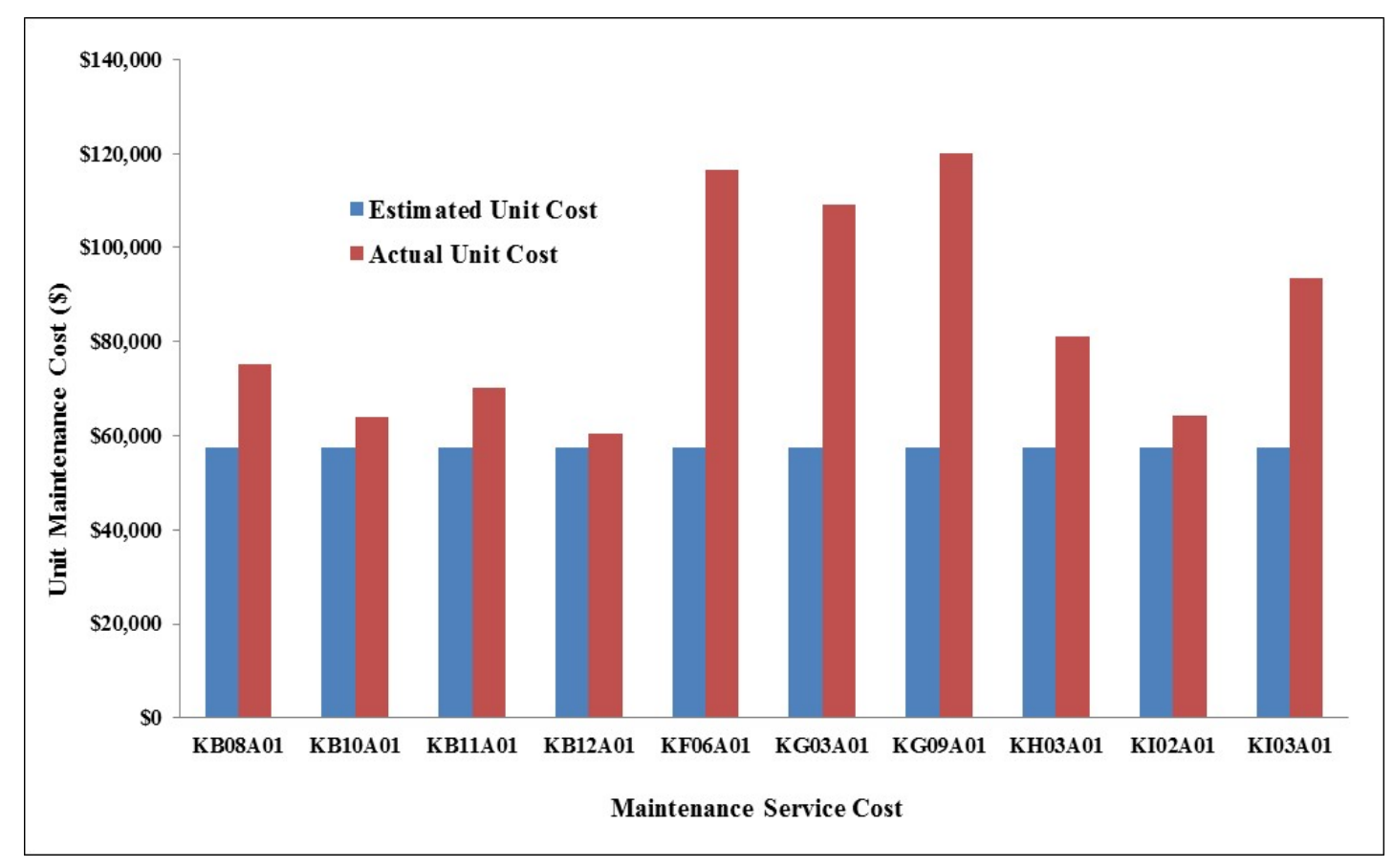

Figure 7.5a A380 unit cost (Estimated Vs Actual) 


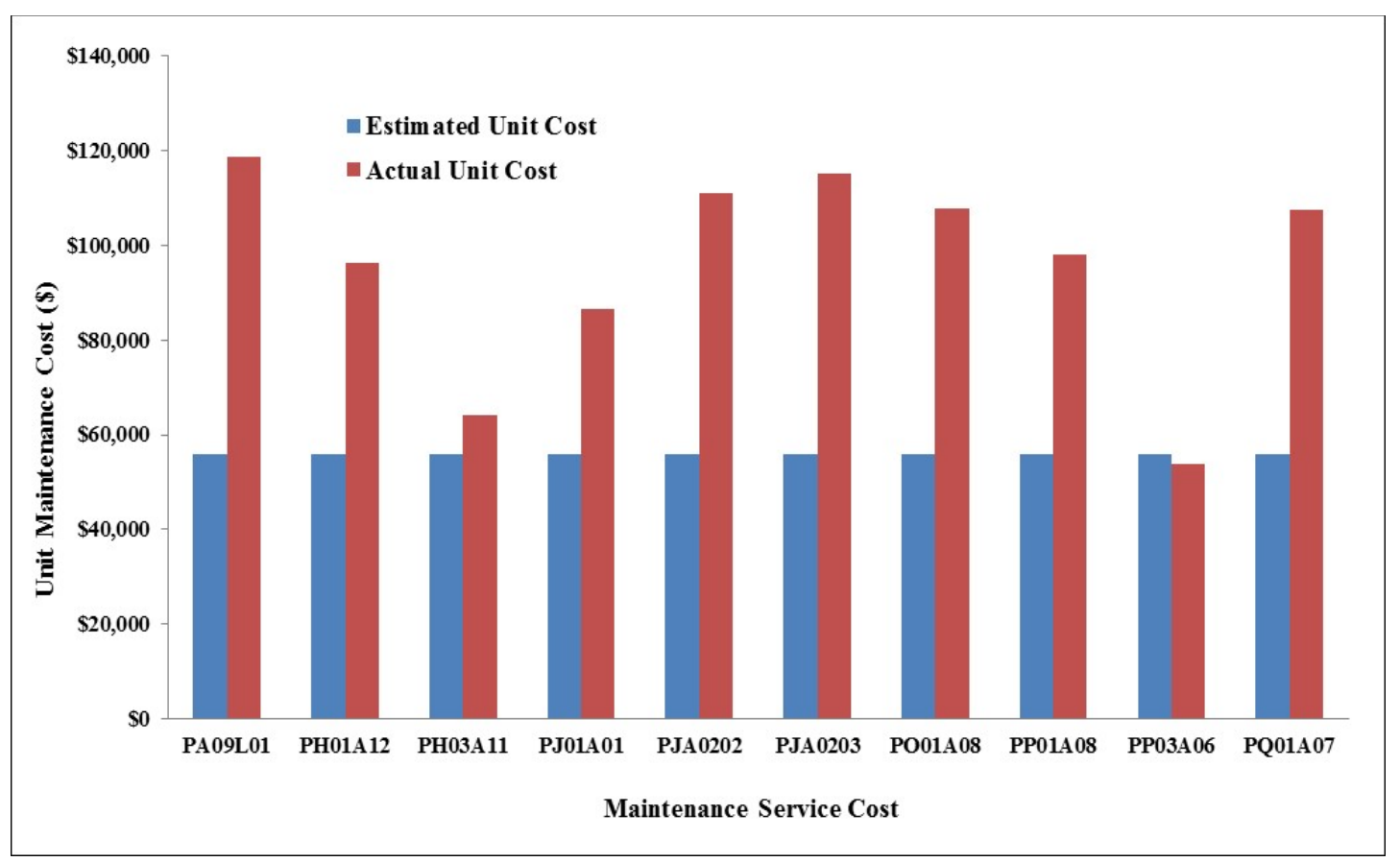

Figure 7.5b 747 unit cost (Estimated Vs Actual)

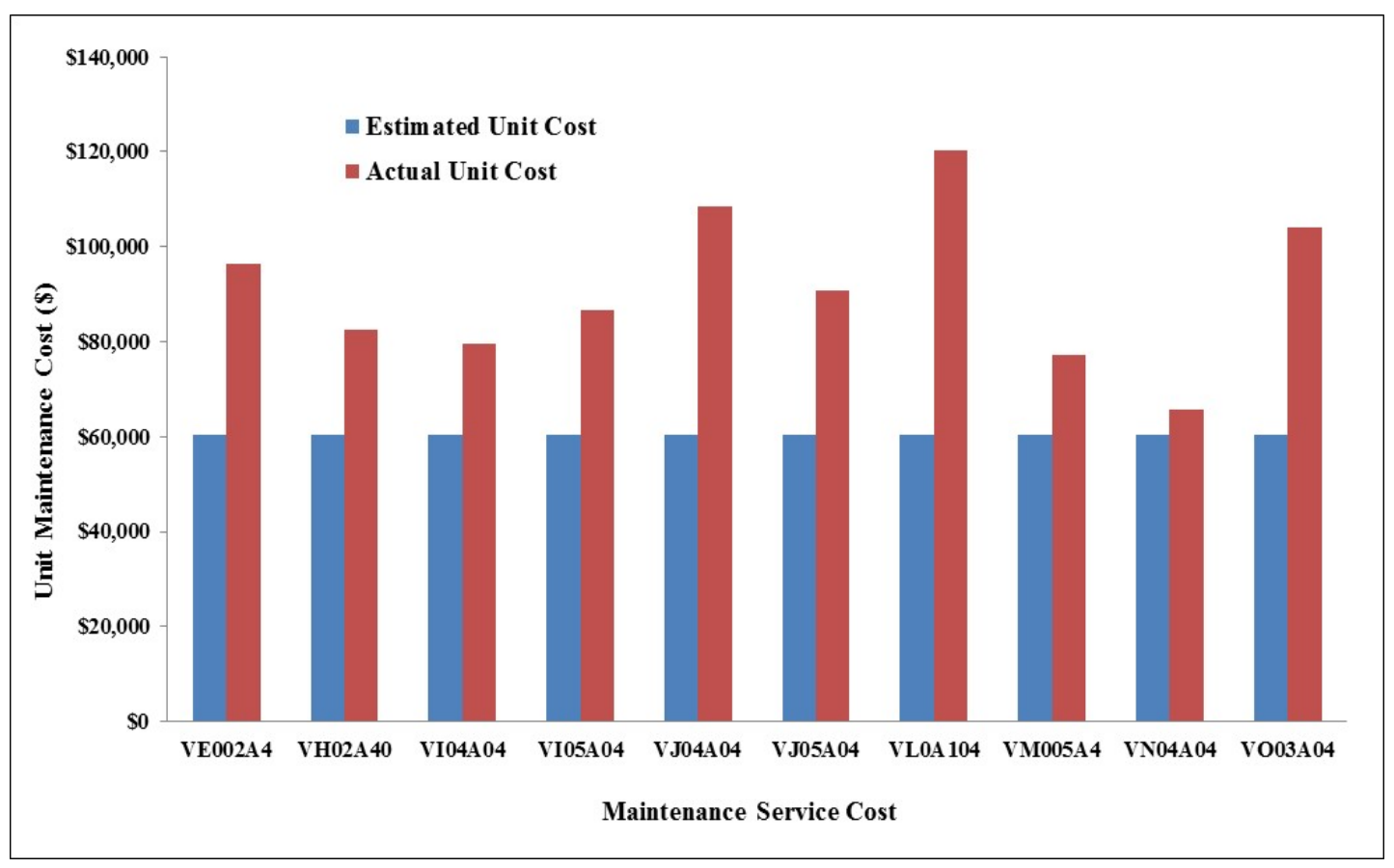

Figure 7.5c 777-200ER unit cost (Estimated Vs Actual) 


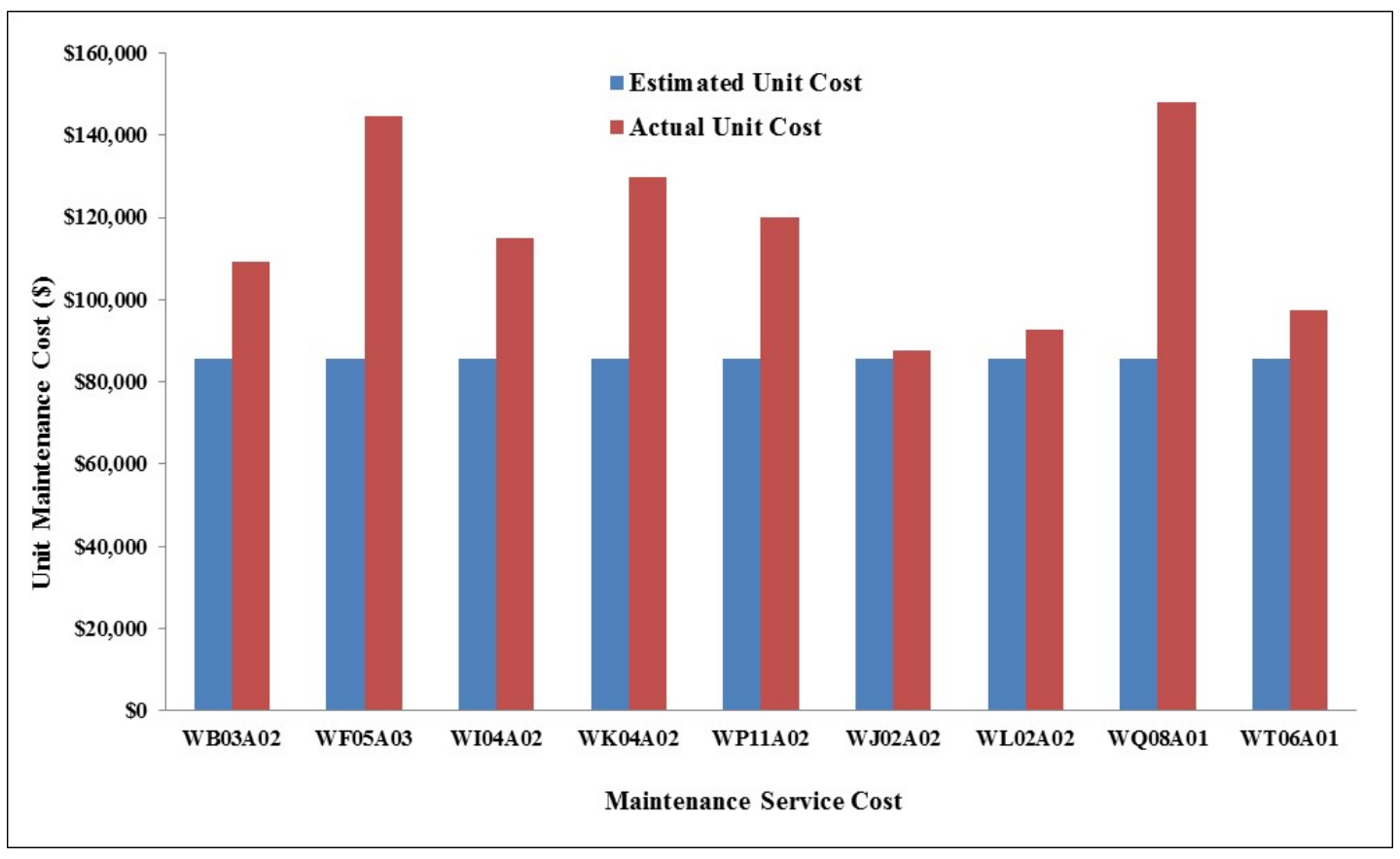

Figure 7.5d 777-300ER unit cost (Estimated Vs Actual)

b. Comparison of estimated unit maintenance cost by with conventional activitybased costing (ABC)

In this analysis, unit maintenance costs estimated by proposed cost estimation methodology are compared with unit maintenance costs estimated by conventional activity-based costing method under the assumptions that similar maintenance work scopes are studied. Based on actual average unit costs computed based on maintenance services cost data over a period of two years, a total of \$14.8 million maintenance costs have been forecasted to perform a total of 136 maintenance services within a year. By referring to the fleet size, the maintenance costs have been allocated to three main cost pools which include maintenance labour, maintenance materials and hangarage as shown in Table 7.16 
Table 7.16 Stage one cost allocation of ABC

\begin{tabular}{|c|c|c|c|c|c|c|}
\hline $\begin{array}{c}\text { Aircraft } \\
\text { Type }\end{array}$ & $\begin{array}{c}\text { No. of } \\
\text { Aircraft }\end{array}$ & $\begin{array}{c}\text { Total } \\
\text { Services Per } \\
\text { Year }\end{array}$ & $\begin{array}{c}\text { Total } \\
\text { Services Per } \\
\text { Year }\end{array}$ & $\begin{array}{c}\text { Allocated } \\
\text { Maintenance } \\
\text { Labour Costs }\end{array}$ & $\begin{array}{c}\text { Allocated } \\
\text { Maintenance } \\
\text { Material Costs }\end{array}$ & $\begin{array}{c}\text { Allocated } \\
\text { Hangarage Costs }\end{array}$ \\
\hline $\mathbf{A 3 8 0}$ & 19 & 2 & 38 & $\$ 2,531,304.20$ & $\$ 499,355.65$ & $\$ 701,784$ \\
\hline $\mathbf{7 4 7}$ & 11 & 2 & 22 & $\$ 1,476,386.18$ & $\$ 428,810.42$ & $\$ 316,800$ \\
\hline $\mathbf{7 7 2 E R}$ & 12 & 2 & 24 & $\$ 1,716,483.21$ & $\$ 497,778.07$ & $\$ 345,600$ \\
\hline 773ER & 26 & 2 & 52 & $\$ 4,473,262.94$ & $\$ 1,089,260.17$ & $\$ 748,800$ \\
\hline Total & & $\mathbf{6 8}$ & $\mathbf{1 3 6}$ & $\mathbf{\$ 1 0 , 1 9 7 , 4 3 7}$ & $\mathbf{\$ 2 , 5 1 5 , 2 0 4}$ & $\mathbf{\$ 2 , 1 1 2 , 9 8 4}$ \\
\hline
\end{tabular}

Subsequently, allocated maintenance costs are assigned to each maintenance service activity by using appropriate activity drivers. Lastly, maintenance costs for each service are computed. In Figure 7.6, unit maintenance costs estimated by proposed cost estimation methodology and conventional ABC are compared. The comparison shows that unit maintenance costs estimated for individual aircraft type are higher than unit costs predicted by proposed cost estimation methodology. Conventional ABC is considered a top down approach cost estimation methodology that distributes the costs in multi-stage cost allocations. Even though it is capable of modelling how the costs are consumed by activities and services, but it is a passive cost estimation methodology that unable to assist the users to moderate and regulate the costs that are allocated to each service activity. In this analysis, a total of approximate \$3 million has been overestimated by conventional ABC as compared to proposed cost estimation methodology.

In contrast, proposed cost estimation methodology predicts activity costs based on past experiences that are stored in the case-base. By retrieving service activities that are similar to the query (service activity), rational activity cost is proposed. Besides, the introduction of service reference cluster (SRC) in this research regulates the activity costs of a given case-base. By employing statistical techniques, consistent, rational and reasonable activity costs can be predicted. 


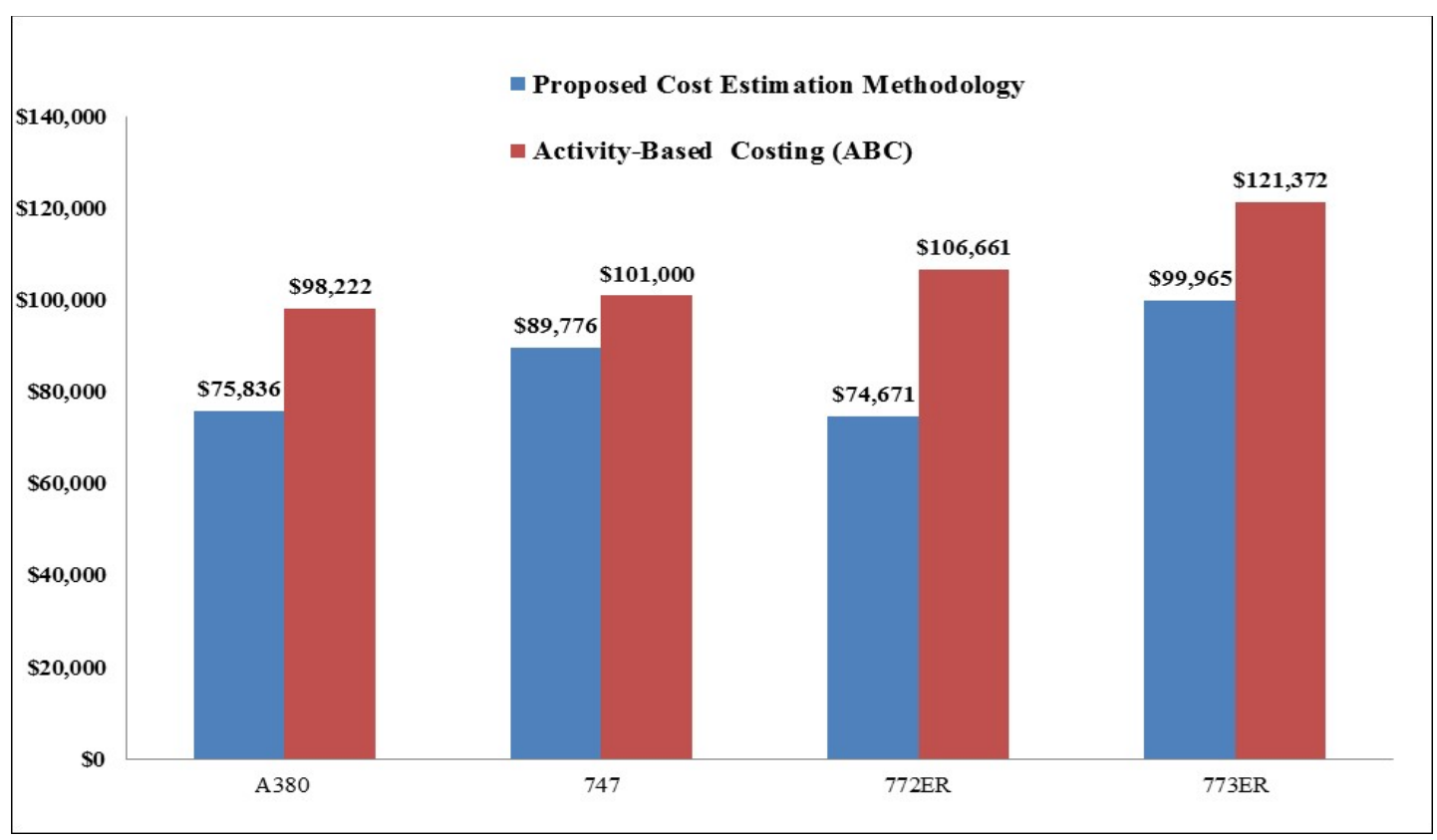

Figure 7.6 Unit maintenance cost (Estimated Vs Activity-Based Costing)

\section{c. Comparison of unit maintenance costs with cost estimating relationships (CER)}

From Table 7.15, it shown that maintenance labour and material costs are the main contributors of aircraft maintenance activities. In this case, it is assumed that maintenance service costs are dependent on number of days an aircraft is stayed in a hangar for performing maintenance. This analysis compares unit maintenance costs forecasted by proposed cost estimation methodology with unit maintenance costs predicted by cost estimating relationships (CER). To identify CERs, simple linear regression analysis is carried out by using Microsoft ${ }^{\circledR}$ Excel. For example, regression analysis for A380 is shown below: 
Table 7.17 Regression analysis generated by Microsoft ${ }^{\circledR}$ Excel spreadsheet

\begin{tabular}{|c|c|c|c|c|c|c|c|c|}
\hline SUMMARY OUTPUT & & & & & & & & \\
\hline \multicolumn{9}{|c|}{ Regression Statistics } \\
\hline R Square & 0.861779591 & & & & & & & \\
\hline Adjusted R Square & 0.857940135 & & & & & & & \\
\hline Standard Error & 7971.987412 & & & & & & & \\
\hline \multicolumn{9}{|l|}{ ANOVA } \\
\hline & $d f$ & SS & $M S$ & $F$ & Significance $F$ & & & \\
\hline Regression & 1 & 14264604617 & 14264604617 & 224.4535765 & $4.80351 \mathrm{E}-17$ & & & \\
\hline Residual & 36 & 2287892999 & 63552583.29 & & & & & \\
\hline Intercept & 10159.35871 & 4821.955442 & 2.106896017 & 0.042159983 & 379.9798076 & 19938.73762 & 379.9798076 & 19938.73762 \\
\hline X Variable 1 & 27627.62135 & 1844.082006 & 14.98177481 & $4.80351 \mathrm{E}-17$ & 23887.6497 & 31367.59301 & 23887.6497 & 31367.59301 \\
\hline
\end{tabular}

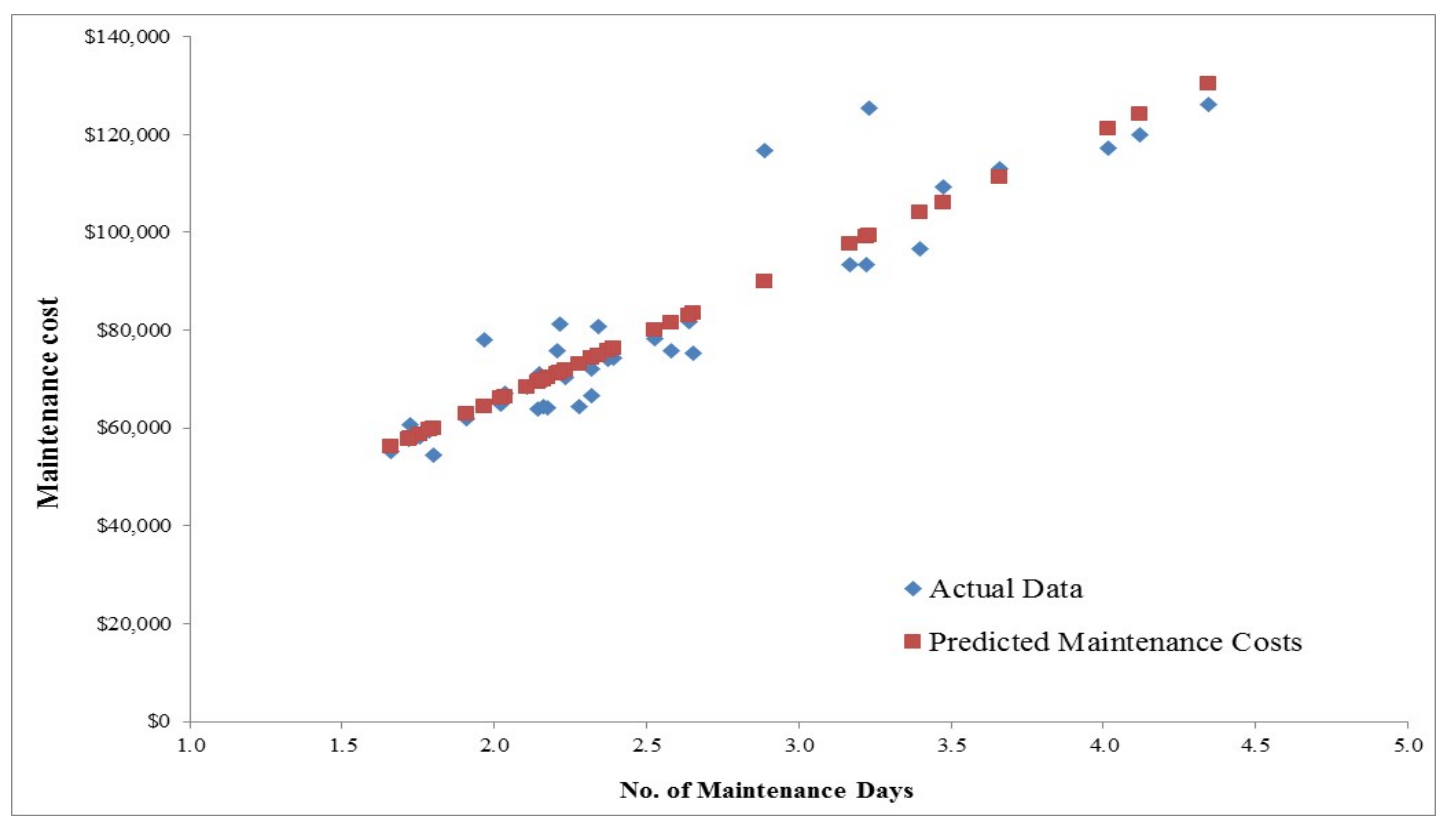

Figure 7.7 Simple regression analysis graph (actual Vs predicted costs)

Based on the regression analysis, cost estimating CERs of relationships (CER) to predict the maintenance labour costs are identified as shown in Table 7.18. 
Table 7.18 CERs for predicting unit maintenance cost

\begin{tabular}{|cc|}
\hline $\begin{array}{c}\text { Aircraft } \\
\text { Type }\end{array}$ & CER for predicting maintenance service costs \\
\hline A380 & SC(A380) $=$ \$27627 (Maintenance Days) $+\$ 10159$ \\
\hline 747 & SC(747) $=\$ 27076$ (Maintenance Days) $+\$ 31860$ \\
\hline $777-200 \mathrm{ER}$ & $\mathrm{SC}(772 \mathrm{ER})=\$ 27092$ (Maintenance Days) $+\$ 13286$ \\
\hline $777-300 \mathrm{ER}$ & $\mathrm{SC}(773 \mathrm{ER})=\$ 25864$ (Maintenance Days) $+\$ 22602$ \\
\hline
\end{tabular}

Assuming an aircraft is typically stayed in the hangar for three days, unit maintenance cost for each aircraft can be calculated. Figure 7.8 shows the comparison of unit maintenance costs estimated by proposed cost estimation methodology and CER. The results show that unit maintenance costs estimated by proposed cost estimation methodology are lower than unit maintenance costs estimated CERs. For instance, unit cost of A380 which is estimated by CER is $62 \%$ higher than unit cost estimated by proposed cost estimation methodology. Besides, unit cost of 747 is $50 \%$ higher when predicted by CER. Meanwhile, unit cost of 777-200ER is 57\% lower if estimated by proposed cost estimation methodology. Lastly, unit cost of 777-300ER is $17 \%$ higher as predicted by CER.

Even though CER is able to generate cost estimation within a short period of time, but accuracy and consistency provided by this methodology are questionable. Furthermore, it is not able to generate a detailed cost analysis as compared to proposed cost estimation methodology. 


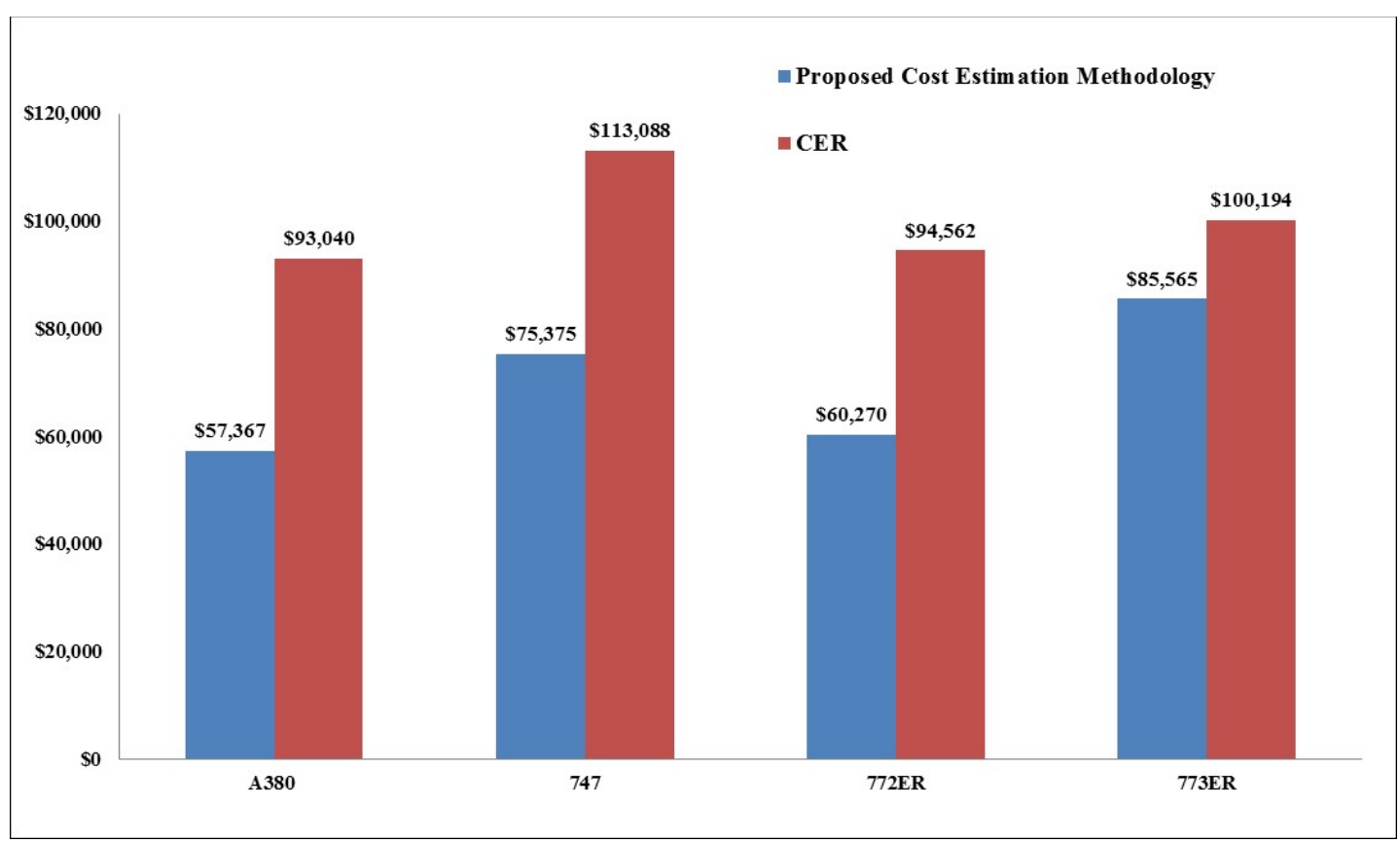

Figure 7.8 Unit maintenance cost comparison (Estimated Vs CER)

\subsubsection{Service Cost Standardisation and Its Implications to Maintenance Operations}

Production planning and control (PPC) is one of the key components of an aircraft maintenance organisation (Kinnison, 2004). Its primary functions include forecasting, planning and control of aircraft maintenance activities. In this case, the objective of forecasting is to estimate long term and short term maintenance workload based on existing aircraft fleet and business plans. Besides that, planning determines the scheduling of upcoming maintenance activities which also include the planning and scheduling of manpower, parts, facilities and time frame requirements. Lastly, control makes adjustments to maintenance plans and keep track on maintenance schedule. In this section, a study is carried out to assess the impacts of service activity cost standardisation to production planning and control of hangar maintenance operations.

From Table 7.15, 63\% of total maintenance costs are attributed to maintenance labours and $23 \%$ of total maintenance costs are attributed to maintenance materials. The results imply that aircraft maintenance activities are mainly driven by human resources and effectiveness in managing the human resources would improve the 
maintenance capacity and productivity of hangar maintenance operations. In this analysis, maintenance labours (hours) that are required to carry out maintenance activities are reviewed and standardised by comparing activities within each service module. For example, duration to perform lubrication of wing landing gear and landing gear doors DSA 8,747 is 2.9 hours, while other similar maintenance activities take longer duration to complete the maintenance tasks. In this case, DSA45,A380 and DSA46,A380 take 16.4 hours and 17 hours respectively to accomplish the maintenance activities. Since maintenance contents of these activities are found to be similar to DSA 8,747 , the maintenance labour hours are standardised to 2.9 hours. The reduction for DSA45,A380 is $434 \%$, DSA $46, \mathrm{~A}_{380}$ is $486 \%$ and $\mathrm{DSA}_{7,747}$ is $20 \%$.

Table 7.19 Examples of standardised maintenance service activities of landing gear module

\begin{tabular}{|c|c|c|c|c|c|}
\hline $\begin{array}{c}\text { Query } \\
\text { (Q) ID }\end{array}$ & Service Activity Description & $\begin{array}{c}\text { Activity } \\
\text { Applicability }\end{array}$ & $\begin{array}{c}\text { Module } \\
(\mathbf{m})\end{array}$ & $\begin{array}{c}\text { Labour } \\
\text { Hours }\end{array}$ & $\begin{array}{c}\text { Standardised } \\
\text { Labour Hours }\end{array}$ \\
\hline $\mathrm{DSA}_{7,747}$ & LUB-WING GEAR AND DOORS-LH & $747-400$ & $\mathrm{M}_{\mathrm{LG}}$ & 3.5 & 2.9 \\
\hline $\mathrm{DSA}_{8,747}$ & LUB-WING GEAR AND DOORS-RH & $747-400$ & $\mathrm{M}_{\mathrm{LG}}$ & 2.9 & 2.9 \\
\hline $\mathrm{DSA}_{45, \mathrm{~A} 380}$ & LUB-WING LANDING GEAR - LH & $\mathrm{A} 380-800$ & $\mathrm{M}_{\mathrm{LG}}$ & 16.4 & 2.9 \\
\hline $\mathrm{DSA}_{46, \mathrm{~A} 380}$ & LUB-WING LANDING GEAR - RH & $\mathrm{A} 380-800$ & $\mathrm{M}_{\mathrm{LG}}$ & 17.0 & 2.9 \\
\hline
\end{tabular}

The service standardisation processes are repeated for each service module. Based on the results shown in Figure 7.9, maintenance labours that are required for each type of maintenance services are reduced and total maintenance labours that are required to deliver a total of 136 maintenance services are reduced from 108,719 to 100,548 hours a year. The reduction of maintenance labour hours creates some impacts to the productivity and capacity of hangar maintenance operations for maintaining a fleet of long range aircraft. 


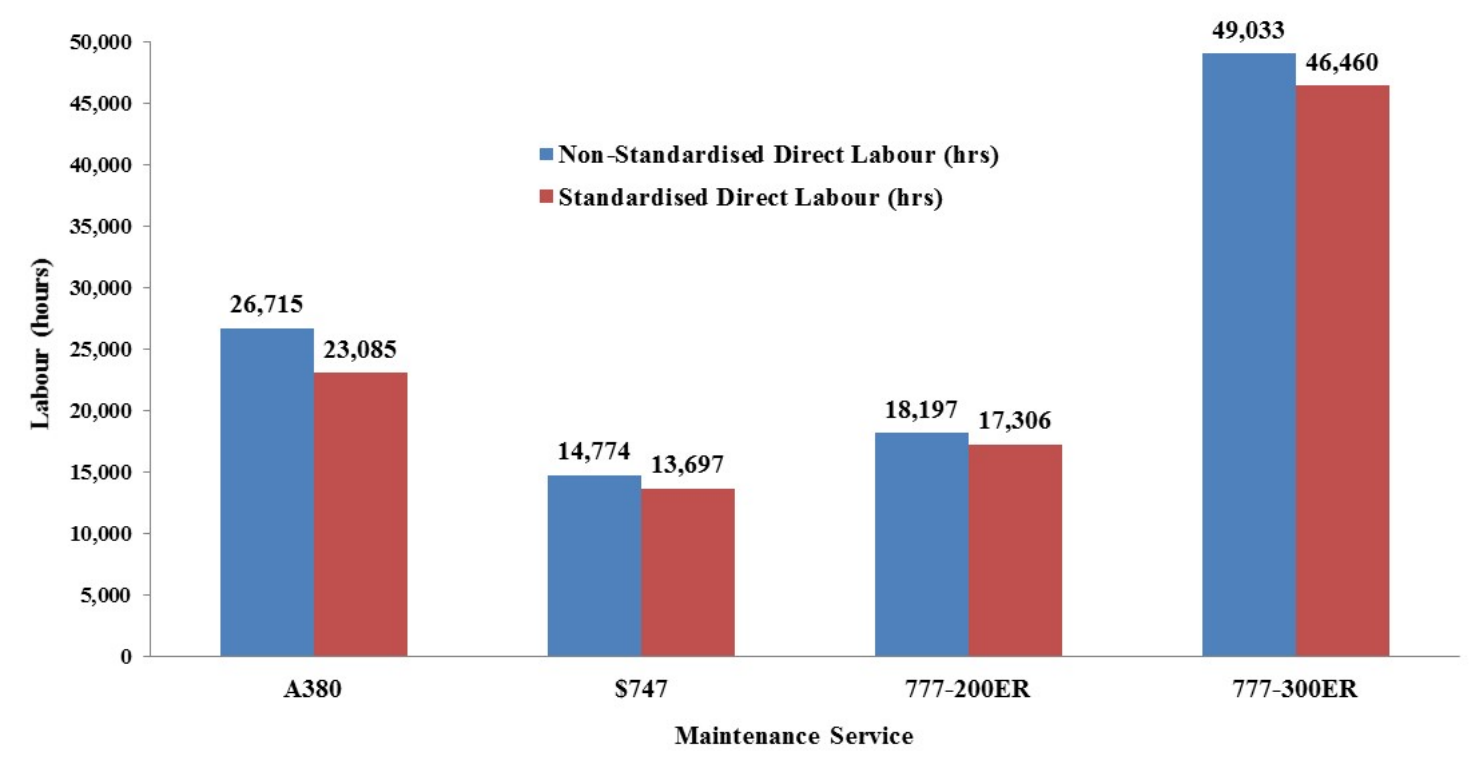

Figure 7.9 Comparisons of annual total labour hours before and after standardisation

To quantify the impacts on hangar maintenance operations' productivity and capacity, the productivity growth is calculated as shown below:

a. Potential labour productivity growth for long range aircraft fleet maintenance services:

$$
\begin{aligned}
\text { Overall Labour Productivity Growth }= & \frac{\text { Current Labour (hrs) }- \text { Future Labour (hrs) }}{\text { Current Labour (hrs) }} \times 100 \% \\
& =\frac{108,719(\mathrm{hrs})-100,548(\mathrm{hrs})}{108,719(\mathrm{hrs})} \times 100 \%
\end{aligned}
$$

Overall Labour Productivity Growth $=7.5 \%$

b. Potential labour productivity growth for individual aircraft fleet:

i. $\quad$ Labour Productivity Growth (A380) $=\frac{\text { Current Labour (hrs) }- \text { Future Labour (hrs) }}{\text { Current Labour (hrs) }} \times 100 \%$

$$
=\frac{26,715 \text { (hrs) }-23,085 \text { (hrs) }}{26,715 \text { (hrs) }} \times 100 \%
$$

Labour Productivity Growth (A380) $=13.6 \%$ 
ii. Labour Productivity Growth (747) $=\frac{\text { Current Labour (hrs) - Future Labour (hrs) }}{\text { Current Labour (hrs) }} \times 100 \%$

$$
=\frac{14,774(\mathrm{hrs})-13,697(\mathrm{hrs})}{14,774(\mathrm{hrs})} \times 100 \%
$$

Labour Productivity Growth (747) $=7.3 \%$

iii. Labour Productivity Growth (777-200ER) $=\frac{\text { Current Labour (hrs) - Future Labour (hrs) }}{\text { Current Labour (hrs) }}$ 100\%

$$
=\frac{18,197(\mathrm{hrs})-17,306(\mathrm{hrs})}{18,197(\mathrm{hrs})} \times 100 \%
$$

Labour Productivity Growth (777-200ER) $=4.9 \%$

iv. Labour Productivity Growth (777-300ER) $=\frac{\text { Current Labour (hrs) }- \text { Future Labour (hrs) }}{\text { Current Labour (hrs) }} x 100 \%$

$$
=\frac{49,033(\mathrm{hrs})-46,460(\mathrm{hrs})}{49,033(\mathrm{hrs})} \times 100 \%
$$

Labour Productivity Growth (777-300ER) = 5.3\%

Based on the calculation results, an overall 7.5\% of potential productivity growth can be achieved through service standardisation. The result implies that lesser human resources are required to perform the maintenance services based on current aircraft fleet size. Individually, the service standardisation produces a large productivity growth for A380 fleet where a 13.6\% productivity growth is calculated. Meanwhile, productivity gains for other aircraft types are range from $4.9 \%$ to $7.3 \%$. The productivity growth is likely related to the maturity of maintenance production lines. Apart from productivity growth, maintenance capacity of the hangar is also increased. 
Assuming average maintenance labour for each aircraft maintenance service is 800 hours, the reduction of total maintenance labour can increase the hangar maintenance capacity from 136 to 146 services. The additional maintenance capacity is able to accommodate an increase of fleet size up to five aircraft. 


\section{Chapter 8: Summary and Future Research Work}

A service family cost estimation methodology primarily based on case-based reasoning (CBR) have been developed in this research to assist the management to estimate and analyse the costs of a service family. This chapter provides the conclusion of this research from the perspective of academic and layouts the limitations, and proposes future research works related to this research.

\subsection{Summary}

\subsubsection{Contribution to Academic Research}

One of the key contributions of this research is the development of a service family cost estimation methodology that filled the research gaps related to service family costing. The recent literature on service family has been focused on the development of methodologies and techniques to develop and design a service family. Furthermore, review on literature related to service costing reveals that none of the cost estimation methodologies and techniques are found to be suitable for estimating the cost of a service family. This research takes a holistic approach and introduces a novel cost estimation methodology based on the theories and concepts of product design, cost accounting and machine learning.

Another key novelty of this research is the application of case-based reasoning (CBR) in performing activity cost estimation. The integration of this methodology within an activity-based costing (ABC) framework is able to overcome implementation and accuracy problems induced by a conventional ABC system. First, the need of identification and measurement of activity cost drivers and activity driver rates which may lead to inaccuracy and inconsistency in activity cost estimation can be eliminated as the functions to estimate the activity costs are taken over by a semiautomatic CBR cycle where the user is only needs to identify the key features for the activity (query) and to make decisions on the solutions proposed by the system. Second, cost estimation of a service family can be carried out without the need of regular updates. Different from conventional ABC system, a CBR system learns through each problem-solving cycle, and solved problems are retained in a case-base. This feature 
greatly reduces the requirements of mass data collections. More importantly, a CBR system can be easily set up with minimal number of knowledge engineer and subject expert. Apart from that, service reference cluster (SRC) is introduced to improve the accuracy and consistency of activity cost estimation. Instead of relying the best matching case to generate activity costs, a set of similar past experiences are pulled out from the case-base in assisting the user to generate rational and unbiased cost analysis.

A third area of contribution is the development of a systematic framework to manage a service family. Unlike traditional definition of a service family, the formation of a service family in this research is based on a set suitable services which may be developed from different service platforms. This allows the user to have greater flexibility, adaptability and practicality in assessing and benchmarking the service costs of similar services. Besides, systematic mechanisms are included to facilitate the process of cost estimation and analysis. One of the most important features is the development of service family modularisation framework that can simplify a complex service family into a simple and manageable modular structure.

\subsubsection{Practicability Insight}

Through the examples presented in the case study involving cost estimation and analysis for a set of long range aircraft which includes Boeing B747-400, B777-300ER, B777-200ER and Airbus A380, practicability of proposed cost estimation methodology is justified. For example, these aircraft are developed and manufactured by different aircraft platforms and aircraft manufacturers, by carrying out a homogeneity assessment, suitability of the aircraft are testified. Once a service family is defined, it is decomposed systematically and service modules are identified from functional and physical elements of the service family. Then, service activities of the services are mapped systematically to the service modules via a clustering algorithm. The service family modularisation mechanism developed in this research creates a systematic and consistent platform for the user to reorganise a complex service family 
into a simpler and manageable structure that can be managed independently through the service modules.

From the perspective of business management, a quick and accurate cost analysis is important for management team to make business decisions and infer future business trends. The results of the case study show that proposed cost estimation methodology can provide a detailed and comprehensive cost analysis without the need of complex and tedious cost calculation procedures. Thus, expensive and complicated cost management systems can be avoided, thus reducing the costs to implement an effective cost management system. Furthermore, proposed methodology able assist user to identify cost driving factors at micro (activity) and macro (modular) level and provide association of these cost driving factors with the cost elements of a service family. This is particularly important for a service organisation to continually improve its cost structure while delivering high quality services to the consumers.

\subsection{Limitations and Future Research Work}

\subsubsection{Limitations of Proposed Cost Estimation Methodology}

The proposed cost estimation methodology contains several limitations. One of the main limitations comes from service family modularisation. In section 5.1.1, a service family decomposition mechanism based on product concept analysis is introduced. Even though it can modularise a service family into a set of service modules, but it is highly manual and depends on high level of expertise to decompose a service family into its functional and physical elements. Besides, identification of service modules by mapping functional and physical elements into a functional-structure diagram is found to be less practical as decomposition of a highly complex service family requires a good understanding of the service delivery system. Furthermore, inaccurate identification of service modules can be resulted if inaccurate mapping of functional and physical element is produced.

Apart from that, weighted Euclidean distance based nearest neighbour algorithm has been utilised in this research as the basis to construct the retrieval mechanism, and it has shown good results in achieving the objectives of retrieve stage. However, the major problem of this approach is that users are required to determine the weights of 
service features which can be complex and difficult. Misallocate of features' weights can lead to inaccurate similarity measures. Besides, growing numbers of past service activities in a case-base would reduce retrieval speed since more calculations are required. By creating a modular service family, standardising the contents of service activities can improve the productivity and capacity of the service family. However, there is a lack of effective method or technique that can be used to group similar service activities within a service module.

\subsubsection{Future Research Works}

Despite encouraging results achieved in current research, further research works are required to overcome the limitations of proposed cost estimation methodology:

a. Service family modularisation mechanism

The service modularisation mechanism is essential to create an optimised network of service modules for a service family. In present research, the modularisation mechanism is highly manual and require high level of expertise. Therefore, there is need to research a robust and systematic service family modularisation mechanism to decompose a service family. Besides, it is also able to analyse the relationships between functional and physical elements so that formation of a service module can be quantitatively justified.

In this case, modular function deployment (MFD) is selected as the approach for future research initiative to develop a service modularisation mechanism. It is a systematic methodology that consists of five main steps. First, a quality function deployment (QFD) is employed to understand the requirements of service family modularisation. Subsequently, functional and physical requirements of a service family is analysed and modularisation solutions are selected. To identify possible service modules, module indication matrix (MIM) is used to examine interrelationships between module drivers and service modularisation solutions. When this step is completed, an interface chart is utilised to evaluate the modular concepts. Finally, MIM is used again to identify potential areas for improvements.

b. Retrieval mechanism for activity cost estimation 
Current research uses a weighted Euclidean distance based nearest neighbour algorithm to define the retrieval mechanism for a case-based reasoning (CBR) cycle due to its simplicity and ease of implementation. To validate its effectiveness, a further study to examine different types of case retrieval methodologies or techniques are required. In this case, retrieval algorithms such as induction, knowledge guided induction and template retrieval algorithms would be investigated in future research works.

c. Service cost standardisation mechanism

In current research, proposed two-stage cost estimation methodology has been found to be feasible and effective in estimating the costs for a service family. Apart from providing accurate cost estimations, it can generate detailed cost analysis by correlating service costs with basic cost elements of a service family. This feature allows users to identify cost driving factors at both activity and modular level. More importantly, it helps the users to understand how the service resources are consumed by the services. Based on the cost driving factors, regular cost reviews and adjustments are necessary to reduce and control service delivery costs.

One of the most effective ways is to standardise the services that are delivered to the customers. The key benefit of service standardisation is that it is able to reduce the costs and improve operational effectiveness. In current research, service standardisation is carried out to standardise some of the service activities within each service module. However, there is a lack of an activity segregation mechanism to group service activities into a set of activity clusters for facilitating the process of service standardisation. In this sense, a future approach which is based on unweighted pair-group method with arithmetic mean (UPGMA) is used to develop a robust activity clustering mechanism. UPGMA is the simplest method to construct a dendrogram (tree diagram) for identifying data clusters. 


\section{Reference}

Aibinu, A.A., Dassanayake, D., Chan, T.-K. \& Thangaraj, R. (2015) 'Cost estimation for electric light and power elements during building design', Engineering, Construction and Architectural Management, 22(2), pp. 190-213

Agard, B, \& Kusiak, A 2004, 'Data-mining-based methodology for the design of product families', International Journal of Production Research, 42, 15, pp. 2955-2969. Aamodt, A \& Plaza, E, 1994, 'Case-Based Reasoning: Foundational Issues, Methodological Variations, and System Approaches. ' AI Communications, IOS Press, Vol. 7: 1, pp. 39-59.

Abbas, R, Mohammad Hossein, A, \& Shamsolla, A, 2011, 'Prediction of tractor repair and maintenance costs using Artificial Neural Network', Expert Systems with Applications, 38, pp. 8999-9007.

Anani, S, \& Madanat, S, 2010, 'Estimation of Highway Maintenance Marginal Cost under Multiple Maintenance Activities', Journal of Transportation Engineering, 136, 10, pp. 863-870.

Batarce, M. (2016) 'Estimation of urban bus transit marginal cost without cost data', Transportation Research Part B: Methodological, 90, pp. 241-262

Ben-Arieh, D, \& Qian, L, 2003, 'Activity-Based Cost Management for Design and Development Stage', International Journal of Production Economics, 83, 2, pp. 169183

Bowman, R, \& Schmee, J, 2001, 'Pricing and managing a maintenance contract for a fleet of aircraft engines', Simulation, San Diego, 2, pp. 69.

Cirilovic, J., Vajdic, N., Mladenovic, G. and Queiroz, C. (2014) 'Developing cost estimation models for road rehabilitation and reconstruction: Case study of projects in Europe and central Asia’, Journal of Construction Engineering and Management, 140(3), p. 04013065 
Cook, D, Goh, C, \& Chung, C 1999, 'Service Typologies: A State of the Art Survey'Production \& Operations Management, 8, 3, pp. 318

Cooper, R, \& Kaplan, R, 1988, 'Measure Costs Right: Make the Right Decision', Harvard Business Review, 66, 5, pp. 96-103.

Cooper, R, \& Kaplan, R 1991, 'Profit Priorities from Activity-Based Costing', Harvard Business Review, 69, 3, pp. 130-135

Coombs, H, Hobbs, D, \& Jenkins, D 2005, Management Accounting: Principles And Applications, n.p.: London : SAGE.

Cunningham, P.C.A., 1998. 'CBR: Strengths and weaknesses', Tasks and Methods in Applied Artificial Intelligence Lecture Notes in Computer Science, pp.517-524

Dhillon, BS 2002, Engineering Maintenance: A Modern Approach, n.p.: Boca Raton, Fla.: CRC Press.

Dennis, Alan; Wixom, Barbara Haley; Tegarden, David 2005, Systems Analysis and Design with UML Version 2.0 - An Object Oriented Approach (2nd Edition), John Wiley \& Sons.

De Lit, P., Delchambre, A. and Henrioud, J. (2003) 'An integrated approach for product family and assembly system design', IEEE Transactions on Robotics and Automation, 19(2), pp. 324-334.

Drury, C 1992, Management and Cost Accounting. n.p.: Boston, MA: Springer US: Imprint: Springer.

Elmira, P, Wei, Y, Ernie, K, Alice, S, Drew, R, \& Rick, G, 2006, 'Basic factors to forecast maintenance cost and failure processes for nuclear power plants', Nuclear Engineering And Design, 236, 13th International Conference on Nuclear Energy, pp. 1641-1647.

Edwards, D, Holt, G, \& Harris, F, 2000, 'A model for predicting plant maintenance costs', Construction Management \& Economics, 18, 1, pp. 65-75. 
Flynn, P, Broome, K, Beaston-Blaakman, A, Knight, D, Horgan, C, \& Shepard, D, 2008, 'Treatment Cost Analysis Tool (TCAT) for estimating costs of outpatient treatment services', Drug And Alcohol Dependence, 100, 1-2, pp. 47-53.

Gan, G, Ma, C, \& Wu, J, 2007, Data Clustering: Theory, Algorithms, And Applications n.p.: Philadelphia, Pa.: SIAM, Society for Industrial and Applied Mathematics; Alexandria, Va.: American Statistical Association.

Geum, Y, Kwak, R, \& Park, Y, 2012, 'Modularizing services: A modified HoQ approach', Computers and Industrial Engineering, 62, 2, pp. 579-590

Giovani Da, S, Denis, B, \& Flávio S, F, 2001, 'Mass customization: Literature review and research directions', International Journal of Production Economics, 72, pp. 1-13

Gregório, J., Russo, G. \& Lapão, L.V. (2015) 'Pharmaceutical services cost analysis using time-driven activity-based costing: A contribution to improve community pharmacies' management', Research in Social and Administrative Pharmacy, 12(3), pp. 475-485

Hakimov, R. \& Mueller, J. (2014) 'Marginal costs estimation and market power of German airports’, Research in Transportation Economics, 45, pp. 42-4

Hoult, D, Meador, C, Deyst, J, \& Dennis, M 1996, 'Cost Awareness in Design: The Role of Data Commonality', Cost Engineering -Ann Arbor Then Morgantown-, 38, 10, pp. 13-16

Horngren, C, Datar, S, \& Rajan, M 2012, Cost Accounting: A Managerial Emphasis, n.p.: Boston; Harlow, Essex, England; Amsterdam; Singapore: Pearson Education Limited, (C2012

Hollar, D, Rasdorf, W, Liu, M, Hummer, J, Arocho, I, \& Hsiang, S 2013, 'Preliminary Engineering Cost Estimation Model for Bridge Projects', Journal Of Construction Engineering \& Management, 139, 9, pp. 1259-1267

Huang, XiaoXi, Newnes, Linda B., Parry, Glenn C, 2012, 'The adaptation of product cost estimation techniques to estimate the cost of service', International Journal of Computer Integrated Manufacturing, 25, 4/5, pp. 417-431. 
Hundal, MS 1997, 'Product Costing: A Comparison of Conventional and Activitybased Costing Methods', Journal Of Engineering Design -Abingdon-, 8, 1, pp. 91-103 Hyari, K.H., Al-Daraiseh, A. and El-Mashaleh, M. (2016) 'Conceptual cost estimation model for engineering services in public construction projects', Journal of Management in Engineering, 32(1), p. 04015021.

Janssen, R, Spronck, P, \& Arntz, A 2015, 'Case-based reasoning for predicting the success of therapy', Expert Systems, 32, 2, pp. 165-177

Jiao, J., Ma, Q. and Tseng, M.M., 2003, 'Towards high value-added products and services: mass customization and beyond', Technovation, 23(10), 809-831.

Jiao, J, Simpson, T, \& Siddique, Z, 2007, 'Product family design and platform-based product development: a state-of-the-art review', Journal of Intelligent Manufacturing, 18, 1, pp. 5-29.

Johnson, M, \& Kirchain, R 2011, 'The importance of product development cycle time and cost in the development of product families', Journal Of Engineering Design, 22, 2, pp. 87-112.

Kamrani, A, \& Salhieh, S, 2002, Product Design For Modularity / Ali K. Kamrani, Sa'ed M. Salhieh, n.p.: Boston : Kluwer Academic Publishers.

Kaplan, R, \& Atkinson, A 1989, Advanced Management Accounting, Englewood Cliffs, N.J.Prentice Hall.

Kaplan, R, \& Anderson, S 2007, Time-Driven Activity-Based Costing: A Simpler and More Powerful Path to Higher Profits, Boston: Harvard Business School Press.

Ketler, K 1993, 'Case Based Reasoning: An Introduction', Expert Systems with Applications, Vol. 6, pp. 3-8

Kinney, M, \& Raiborn, C 2009, Cost Accounting: Foundations And Evolutions, n.p.: Mason, Ohio : Thomson/South-Western.

Kinnison, HA 2004, Aviation Maintenance Management, n.p.: New York : McGrawHill, c2004 
Kuo, R.J., Cheng, W.C., Lien, W.C. and Yang, T.J. (2015) 'A medical cost estimation with fuzzy neural network of acute hepatitis patients in emergency room', Computer Methods and Programs in Biomedicine, 122(1), pp. 40-46

Kolodner, JL 1992, 'An introduction to case-based reasoning', Artificial Intelligence Review, 6, 1, p. 3, Supplemental Index

Kolodner, JL 1993, Case-Based Learning. Boston, MA : Springer US

Liang, J, \& Zuo, H 2006, 'The predictive models of maintenance costs for a civil airplane', Proceedings Of The Institution Of Mechanical Engineers, Part G (Journal Of Aerospace Engineering), 5, p. 347

Li, Y.F, Terpeny, J, \& Chang, X.F. 2010. 'A Framework for Activity-based Costing and Product Family Cost Estimation' Proceedings of the 2010 Industrial Engineering Research Conference.

Lesniak, A 2013, 'The application of artificial neural networks in indirect cost estimation', AIP Conference Proceedings, 1558, 1, pp. 1312-1315

Lopez, B 2013, Case-Based Reasoning: A Concise Introduction, San Rafael, Calif.: Morgan \& Claypool, c2013

Mobley, RK 2004, Maintenance Fundamentals n.p.: Amsterdam; Boston: Elsevier/Butterworth Heinemann.

Moir, I, \& Seabridge, A 2012, Design and Development of Aircraft Systems. Chichester : Wiley.

Mok, C, Tummala, V, \& Leung, H, 1997, 'Practices, barriers and benefits of risk management process in building services cost estimation', Construction Management \& Economics, 15, 2, p. 161.

Moon, S, Simpson, T, Shu, J, \& Kumara, S, 2009, 'Service representation for capturing and reusing design knowledge in product and service families using object-oriented concepts and an ontology', Journal of Engineering Design, 20, 4, pp. 413-431. 
Moon, S, Shu, J, Simpson, T, \& Kumara, S, 2011, 'A module-based service model for mass customization: service family design', IIE Transactions, 43, 3, pp. 153-163.

Meyer, M.H. \& Utterback, J.M., 1993, 'The Product Family and the Dynamics of Core Capability' Sloan Management Review pp. 29-47.

Meyer, M, \& Lehnerd, A 1997, The Power of Product Platforms: Building Value and Cost Leadership, New York: Free Press.

Meyer, M, \& DeTore, A, 2001, 'Perspective: Creating a platform-based approach for developing new services', Journal of Product Innovation Management, 3, pp. 188

Nagata, T., Mori, K., Aratake, Y., Ide, H., Ishida, H., Nobori, J., Kojima, R., Odagami, K., Kato, A., Tsutsumi, A. and Matsuda, S. (2014) 'Development of cost estimation tools for total occupational safety and health activities and occupational health services: Cost estimation from a corporate perspective', Journal of Occupational Health, 56(3), pp. 215-224

Niu, C 1999, Airframe Structural Design: Practical Design Information and Data on Aircraft Structures, Hong Kong: Conmilit Press Ltd., 1999.

Newcomb, P, Bras, B, \& Rosen, D, 1996, 'Implications of modularity on product design for the life cycle', Journal of Mechanical Design, 120, 3, pp. 483-490.

O'Sullivan, A, Rubin, J, Nyambose, J, Kuznik, A, Cohen, D, \& Thompson, D, 2011, 'Cost Estimation of Cardiovascular Disease Events in the US', Pharmacoeconomics, 29, 8, pp. 693-704.

Pal, S, \& Shiu, S 2004, Foundations of Soft Case-Based Reasoning, n.p.: Hoboken, N.J. : Wiley-Interscience.

Park, J, \& Simpson, T, 2005, 'Development of a production cost estimation framework to support product family design', International Journal of Production Research, 43, 4, pp. 731-772. 
Park, J, \& Simpson, T, 2008, 'Toward an activity-based costing system for product families and product platforms in the early stages of development', International Journal of Production Research, 46, 1, pp. 99-130.

Pekkarinen, S 2008, 'Modularity in developing business services by platform approach', International Journal of Logistics Management, 19, 1, pp. 84-103

Peter, L, \& Saidin, H, 2000, 'IT and the mass customization of services: the challenge of implementation', International Journal of Information Management, 20, 2, pp. 103119.

Pimmler, U \& Eppinger, S, 1995, 'Integration Analysis of Product Decompositions', ASME Design Theory and Methodology Conference.

Qian, L, \& Ben-Arieh, D 2008, 'Parametric cost estimation based on activity-based costing: A case study for design and development of rotational parts', International Journal of Production Economics, vol. 113, no. Special Section on Advanced Modelling and Innovative Design of Supply Chain, pp. 805-818.

Rahikka, E, Ulkuniemi, P, \& Pekkarinen, S, 2011, 'Developing the value perception of the business customer through service modularity', Journal of Business \& Industrial Marketing, 26, 5, pp. 357-367.

Ramesh, B, Tiwana, A, \& Mohan, K, 2002, 'Supporting Information Product and Service Families with Traceability', Lecture Notes in Computer Science, 2290, pp. 353-363.

Richter, M, \& Weber, R 2013, Case-Based Reasoning: A Textbook, Springer Berlin Heidelberg: Imprint: Springer, 2013

Romesburg, H, 1984, Cluster Analysis for Researchers / H. Charles Romesburg, n.p.: Belmont, Calif.: Lifetime Learning Publications.

Ryu, H, 2009, 'An Estimation of the Cost per Visit of Home Care Nursing Services', Nursing Economics, 27, 2, pp. 111-118. 
Reddy, V, Chattopadhyay, G, Larsson-Kraik, P, \& Hargreaves, D, 2007, 'Modelling and analysis of rail maintenance cost', International Journal of Production Economics, 2, p. 475.

Sadraey, MH 2013, Aircraft Design: A Systems Engineering Approach, Chichester, West Sussex, U.K.: Wiley, 2013

Sanderson, S.W. \& Uzumeri, M., 1997. 'Managing Product Families’. Chicago: Irwin Schilling, MA 2000, 'Toward a General Theory and Its Application to Inter-firm Product Modularity’, Academy Of Management Review, 25, 2, pp. 312-334

Simpson, T.W. (2004) 'Product platform design and customization: Status and promise’, AI EDAM, 18(01).

Subramanian, S, Ekwueme, D, Gardner, J, \& Trogdon, J, 2009, 'Developing and Testing a Cost-Assessment Tool for Cancer Screening Programs', American Journal Of Preventive Medicine, 37, 3, pp. 242-247.

Sun, L., Karwan, M.H., Gemici-Ozkan, B. and Pinto, J.M. (2015) 'Estimating the long-term cost to serve new customers in joint distribution', Computers \& Industrial Engineering, 80, pp. 1-11.

Sundbo, J 1994, 'Modularisation of service production and a thesis of convergence between service and manufacturing organizations', Scandinavian Journal Of Management, 10, pp. 245-266

Sundgren, N 1999, 'Introducing Interface Management in New Product Family Development', Journal of Product Innovation Management, 16, 1, pp. 40-51

Su, B.-G., Chen, S.-F., Yeh, S.-H., Shih, P.-W. \& Lin, C.-C. (2016) 'Cost evaluation of clinical laboratory in Taiwan's national health system by using activity-based costing', Clinical Chemistry and Laboratory Medicine (CCLM), 54(11).

Tan, S, Rutten, F, van Ineveld, B, Redekop, W, \& Hakkaart-van Roijen, L, 2009, 'Comparing Methodologies for the Cost Estimation of Hospital Services', The European Journal Of Health Economics, 1, p. 39. 
Tsai, C. \& Chiu, C., 2007, 'A case-based reasoning system for PCB principal process parameter identification', Expert Systems with Applications, 32(4), pp.1183-1193.

Thevenot, H, \& Simpson, T 2006, 'Commonality indices for product family design: a detailed comparison', Journal of Engineering Design, 17, 2, pp. 99-119

Ulrich, K. \& Tung, K. (1991), 'Fundaments of product modularity', In A. Sharon (Ed.), Issues in mechanical design international (pp. 73-79), New York: ASME, DE-39.

Ulrich, K, 1995, 'The Role of Product Architecture in the Manufacturing ', Research Policy, 24, 3, pp. 419-440.

Watson, I \& Marir, F, 1994, 'Case-Based Reasoning: A Review', The Knowledge Engineering Review, Cambridge University Press, Vol. 9, No. 4: pp355-381

Weygandt, J.J., Kimmel, P.D., Kieso, D.E., Weyg, J.J., t, P.K.D. and Trenholm, B. (2011) Accounting principles. 5th edn. Oxford, United Kingdom: J. Wiley \& Sons Canada

Wei, G.X \& Qin, Y.H, 2011, 'Framework of Rapid Product Cost Estimation Based on the Modular Product Family', International Conference in Electrics, Communication and Automation Control Proceedings, pp 9-14.

Yang, L \& Shan, M, 2009, 'Process Analysis of Service Modularization Based on Cluster Arithmetic', First International Workshop on Database Technology and Applications.

Zarkin, G, Dunlap, L, \& Homsi, G, 2004, 'The substance abuse services cost analysis program (SASCAP): a new method for estimating drug treatment services costs', Evaluation And Program Planning, 27, 1, pp. 35-43.

Zarkin, G, Dunlap, L, Wedehase, B, \& Cowell, A, 2008, 'The effect of alternative staff time data collection methods on drug treatment service cost estimates', Evaluation And Program Planning, 31, 4, pp. 427-435. 